\title{
Cure: Clean Use of Reactor Energy
}

\section{Date Published \\ May 1990}

\section{DISCLAIMER}

This report was prepared as an account of work sponsored by an agency of the United States Government. Neither the United States Government nor any agency thereof, nor any of their employees, makes any warranty, express or implied, or assumes any legal liability or responsibility for the accuracy, completeness, or usefulness of any information, apparatus, product, or process disclosed, or represents that its use would not infringe privately owned rights. Reference herein to any specific commercial product, process, or service by trade name, trademark, manufacturer, or otherwise does not necessarily constitute or imply its endorsement, recommendation, or favoring by the United States Government or any agency thereof. The views and opinions of authors expressed herein do not necessarily state or reflect those of the United States Government or any agency thereof.

\section{Prepared for the U.S. Department of Energy}

\section{(즈} Westinghouse

P.O. Box 1970

Hantord Company Richland, Washington 99352

Hanford Operations and Engineering Contractor for the

U.S. Department of Energy under Contract DE-AC06-87RL10930 


\section{DISCLAIMER}

This report was prepared as an account of work sponsored by an agency of the United States Government. Neither the United States Government nor any agency Thereof, nor any of their employees, makes any warranty, express or implied, or assumes any legal liability or responsibility for the accuracy, completeness, or usefulness of any information, apparatus, product, or process disclosed, or represents that its use would not infringe privately owned rights. Reference herein to any specific commercial product, process, or service by trade name, trademark, manufacturer, or otherwise does not necessarily constitute or imply its endorsement, recommendation, or favoring by the United States Government or any agency thereof. The views and opinions of authors expressed herein do not necessarily state or reflect those of the United States Government or any agency thereof. 


\section{DISCLAIMER}

Portions of this document may be illegible in electronic image products. Images are produced from the best available original document. 
WHC-EP-0268

APPROVAL PAGE

Document Title: CURE: Clean Use of Reactor Energy

Approved by:

Approved by: ohm A, Ravin
John A. Raw ins
Development

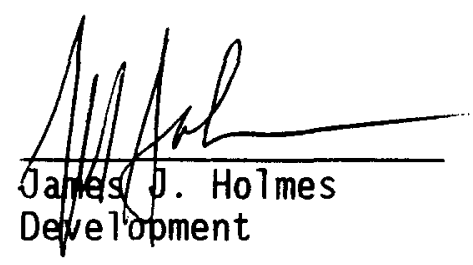

$\frac{6 / 22 / 90}{\text { Date }}$

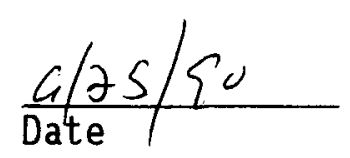


WHC-EP-0268

\section{LIST OF CONTRIBUTORS}

Several dedicated scientists and engineers in the Westinghouse Hanford Company and Battelle's Pacific Northwest Laboratory generously devoted much time and energy to preparation of this report. Principal contributors are:

S. E. Binney*

C. H. Bloomster

H. R. Brager

C. A. Burgess

W. J. Gruber

G. F. Howden

A. J. Naser

L. G. Niccoli

A. W. Prichard

J. A. Rawl ins

G. W. Reddick, Jr.

W. W. Schulz

J. P. Sloughter

J. L. Swanson

J. W. Thorton

C. N. Wilson

D. E. Wood

*Oregon State University Nuclear Engineering Department 


\section{EXECUTIVE SUMMARY}

\section{BACKGROUND}

The current United States strategy for management of spent commercial reactor fuel and high-level nuclear waste has been specified by the Nuclear Waste Policy Act of 1982 (NWPA), as amended. The NWPA charges the U.S. Department of Energy (DOE) with the responsibility to develop a nuclear waste repository; that is, a site for geologic disposal of these waste types. The Nuclear Waste Policy Amendments Act of 1987 directed the DOE to limit characterization efforts to the Yucca Mountain site in the State of Nevada. The regulations that were established to implement the NWPA require that assessments be made to predict how radionuclides may migrate away from the disposal site within 10,000 $\mathrm{yr}$. It is necessary to assess both the quantity that would be released (in this sense) under a given set of conditions, and the probability of occurrence of the release. Acceptability of a site is evaluated considering both magnitude and probability of radionuclide release. Performance is enhanced if the radionuclides can be contained until they decay to stable final products.

The NWPA specifies how provisions of the National Environmental Policy Act of 1969 (NEPA) are to be implemented for the various activities required to develop a disposal repository. An Environmental Impact Statement (EIS) is required as a part of an application for license submitted to the U.S. Nuclear Regulatory Commission (NRC). Alternatives to geologic disposal are not to be considered in the EIS; however, treatment alternatives are not specifically excluded.

This paper presents the results of a joint Westinghouse Hanford Company (Westinghouse Hanford)-Pacific Northwest Laboratory (PNL) study that considered the feasibility of treating radioactive waste before disposal to reduce the inventory of long-lived radionuclides, making the waste more suitable for geologic disposal. 


\section{THE WASTE DISPOSAL PROBLEM}

Spent fuel and high-level radioactive wastes contain several radionuclides whose half-lives are long enough and whose inventories are large enough that they can cause a site to fail the regulatory requirements if a high percentage of the inventory is predicted to be released. Performance of a given site is determined by three factors: (1) geologic characteristics of the site, (2) design of the underground excavations required for waste emplacement, and (3) how the waste is treated prior to disposal. This report considers a type of waste treatment that could enhance the performance of the geologic disposal system.

The treatment for high-level radioactive waste that has received the most consideration is vitrification into a borosilicate glass, encapsulation into a metal container, and emplacement of these receptacles so that they are surrounded by materials that would retard migration of radionuclides if they escape the glass and container. Disposal of spent fuel without reprocessing has also been evaluated. Two options that have been assessed are encapsulation of intact fuel assemblies in metal containers; and removal of the spent fuel pins from the assemblies and consolidating the pins into sealed receptacles (with a higher density than intact assemblies). Both options would allow emplacement in a manner similar to that of the high-level waste containers.

The treatment considered here is one in which waste would be chemically separated so that long-lived radionuclides can be treated using specific processes appropriate for the nuclide. The technical feasibility of enhancing repository performance by this type of treatment is considered in this report.

\section{CONCLUSIONS}

Many of the long-lived radionuclides present in spent fuel and highlevel radioactive waste can be separated from the waste and exposed to neutron radiation to transmute them to stable isotopes using existing technology. 
Such treatment would reduce the source term at the disposal site and should make it easier to assess the performance of the total repository system. The nuclides that produce the most heat have relatively short half-lives (about $30 \mathrm{yr}$ ), so they could be separated and stored to reduce the heat load if that would be beneficial to the performance of the repository. Some radionuclides with long half-lives that cannot be transmuted may simply require disposal in a manner that ensures long-term isolation with a high degree of confidence. The separation provided by the proposed treatment would allow more effort to be directed to safe geologic disposal of these radionuclides because the volume to be handled would be orders of magnitude smaller than the original waste form.

Segregation of waste radionuclides to allow transmutation or special handling of reduced amounts of waste is a powerful treatment process with the potential to reduce the environmental impact of radioactive waste disposa1. As such, it may merit consideration in the EIS that the DOE must prepare as part of its repository license application to the NRC. The treatment methodologies presented in this report could be the basis for an alternatives assessment for the EIS.

\section{THE CURE PROCESS}

A joint Westinghouse Hanford-PNL study group developed a concept called the Clean Use of Reactor Energy (CURE), and evaluated the potential of current technology to reduce the long-lived radionuclide content in waste from the nuclear power industry. Spent oxide fuel from commercial reactors would be chemically processed with proven aqueous technology to separate the transuranic elements, as well as selected fission and activation products from the waste stream. Following chemical separation, most radioisotopes with half-lives greater than $10 \mathrm{yr}$ would be transmuted to stable nuclides by irradiation with neutrons. Fission products strontium and cesium, activated metal hardware, ${ }^{14} \mathrm{C}$, and radiokrypton would not be transmuted. They would be packaged for storage or for special disposal to ensure adequate geologic isolation. Strontium and cesium radioisotopes produce most of 


\section{WHC-EP-0268}

the waste decay heat. If a decrease in heat load would improve repository system performance or delay the need for a second repository, radiostrontium and radiocesium could be temporarily stored (for a few decades, perhaps).

The CURE process consists of three components: (1) chemical separation of elements that have significant quantities of long-lived radioisotopes in the waste, (2) exposure in a neutron flux to transmute the radioisotopes to stable nuclides, and (3) packaging of radionuclides that cannot be transmuted easily for storage or geologic disposal. Figure ES-1 illustrates these components.

\section{Chemical Separation}

The CURE team developed conceptual chemical processing flow sheets that characterize the necessary separation processes. The initial step is to remove the fuel pins from fuel assemblies, and then to section the fuel pins and dissolve the fuel matrix. The cladding is not dissolved. The resulting acid solution would then be processed to separate the elements required to allow treatment. Figure ES-2 is a simplified schematic of these flow sheets. The major processes used are listed below.

- All of the nitric acid solution would be processed using the Plutonium-URanium EXtraction (PUREX) process to extract recyclable plutonium, uranium and neptunium from the spent fuel. Offgas treatment associated with this front-end process would separate and recover tritium, ${ }^{14} \mathrm{C}$, radiokrypton, and radioiodine.

- The high-level waste stream from the PUREX process would be processed using the TRansUranic EXtraction (TRUEX) technology to extract residual transuranic elements (plutonium, uranium, neptunium, americium, and curium) and also technetium. 


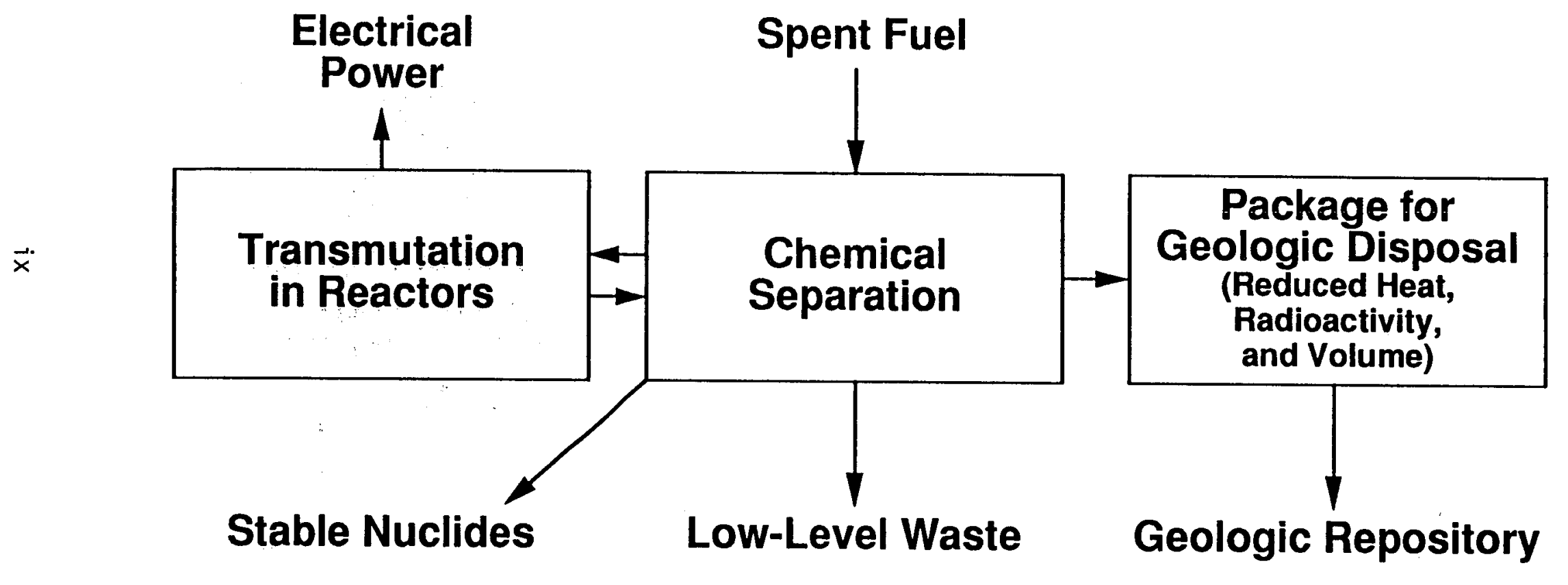




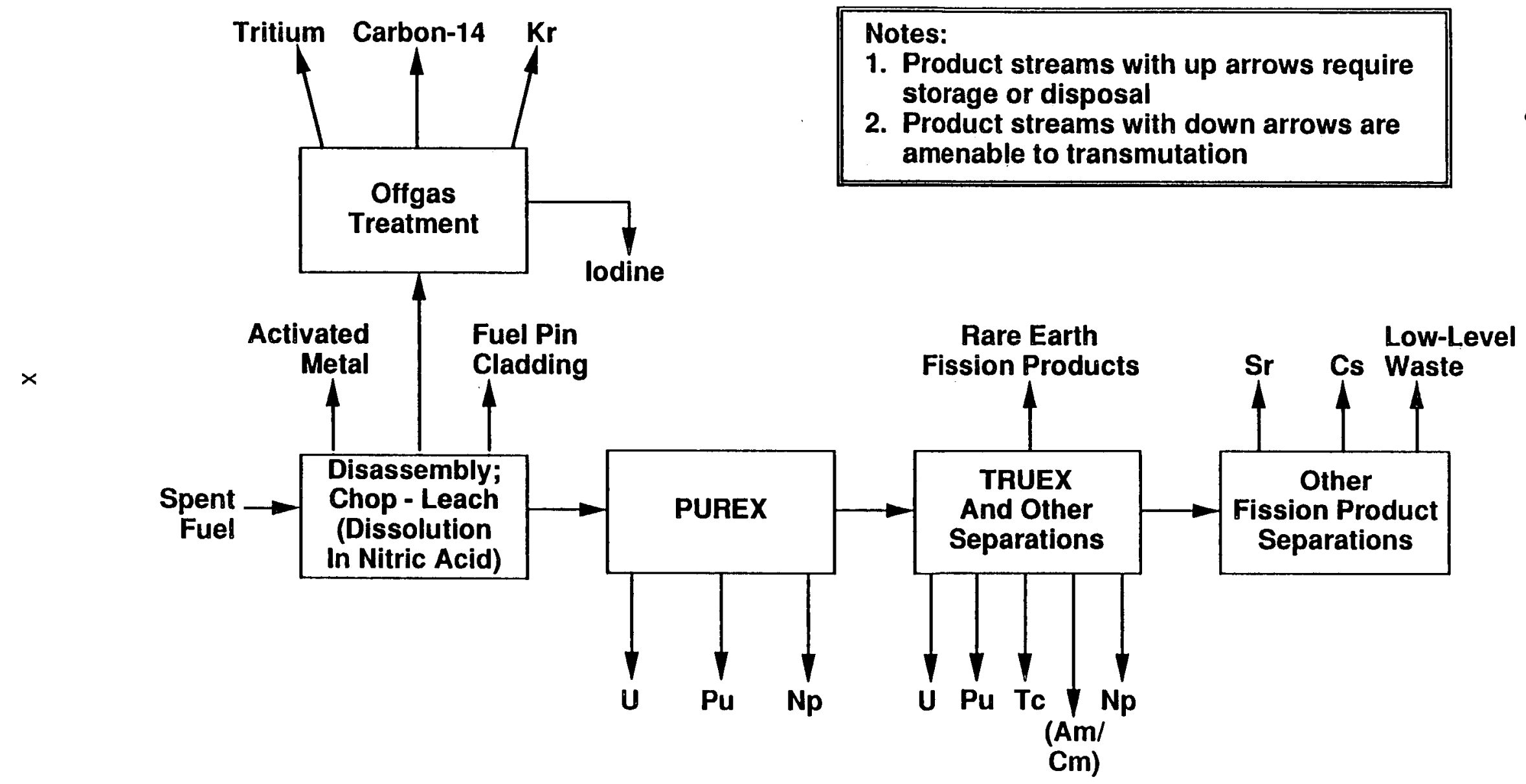


- The high-level waste stream from the TRUEX process would be processed by a variety of extraction methods to separate strontium, cesium, and any other fission product that may be of beneficial use or that may be of regulatory concern.

A technical assessment of this chemical partitioning technology has concluded that the final nitric acid waste stream discharged from the separation processes would contain a low enough radionuclide content to allow treatment and disposal as low-level radioactive waste under 10 CFR 61. The separated streams (actinides, fission products, activation products, ${ }^{14} \mathrm{C}$, etc.) would be subjected to neutron irradiation, storage, or special geologic disposal.

\section{Transmutation}

Many studies of transmutation of long-lived radionuclides exist in the open literature. Additional studies completed by the CURE team focused on using radial leakage neutrons in a hydrogen-moderated environment in a sodiumcooled fast spectrum reactor. These studies, coupled with the rich-actinideburning literature, show that destruction of the actinides, ${ }^{99} \mathrm{Tc}$, and ${ }^{129} \mathrm{I}$ is conceptualiy feasible using fast-spectrum reactors. Studies are currently in progress on the capability of high-powered proton spallation accelerators for waste transmutation. In some circumstances, accelerators may show significant advantages over fast spectrum reactors for waste destruction.

In order to assess the economic impact of implementing the CURE process, a scenario was evaluated in which a specific mix of advanced light-water and liquid-metal cooled reactors was assumed to operate within a CURE fuel cycle. The light-water reactors were assumed to operate on a combination of enriched uranium oxide fuel and mixed (uranium and plutonium) oxide fuel. The liquidmetal reactors were assumed to operate on mixed oxide fuel. All of the reactors were assumed to produce electricity, with 83 percent of the power generated by the light-water reactors. It was assumed that growth in nuclear-generated electrical supply will be one percent per year, and that 
all wastes (that can be) will be transmuted at the same rate at which they are produced. Within this scenario, the liquid-metal reactors would transmute plutonium and other actinides, radioiodine, and most of the ${ }^{99} \mathrm{Tc}$. The 1 ight water reactors would destroy the remainder of the ${ }^{99} \mathrm{Tc}$ and some plutonium. Electricity from this CURE facility complex would cost about 7 percent more than that from the present nuclear reactor power production complex. Most of the increase would come from the high capital cost of liquid-metal reactors relative to light-water reactors.

The CURE team also made an approximate health risk comparison between the same CURE scenario, and the present complex of nuclear power production reactors. The near-term risks were found to be comparable, with increased risk in the CURE scenario as a result of additional chemical processing offset by the reduced risk that would be experienced because less uranium mining and associated processing would be required. The long-term risks from permanent storage of long-lived radionuclides would be almost eliminated with the CURE concept, so the CURE technology shows an advantage in this respect.

Several of the separated radionuclides cannot easily be transmuted to stable forms. They are discussed below.

Carbon-14 - The neutron transmutation cross section for carbon-14 is too small for neutron irradiation to offer a viable means of destruction. Destruction by high-energy protons via spallation reactions may be feasible, but would be very costly. Carbon-14 is a nuclide that presents performance problems at Yucca Mountain; therefore, it is a candidate for specially engineered features to ensure long-term isolation.

Cesium - Three isotopes of cesium are major fission products: ${ }^{133} \mathrm{Cs}$ (stable), ${ }^{135} \mathrm{Cs}$ (long-lived), and ${ }^{137} \mathrm{Cs}$ (30-yr half-life). Irradiation of cesium would transmute ${ }^{135} \mathrm{Cs}$ and ${ }^{137} \mathrm{Cs}$ to stable isotopes, but successive neutron capture by ${ }^{133} \mathrm{Cs}$ and ${ }^{134} \mathrm{Cs}$ would produce more ${ }^{135} \mathrm{Cs}$. Transmutation of $10 \mathrm{ng}-1$ ived ${ }^{135} \mathrm{Cs}$ is, therefore, complicated by the isotopic makeup of fission product 
WHC - EP-0268

cesium. Isotopic separation may be able to solve this problem, but it may be very expensive. The presence of highly radioactive ${ }^{137} \mathrm{Cs}$ would make separation even more challenging. In addition, ${ }^{137} \mathrm{Cs}$ has a very small transmutation cross section. There may be little incentive to transmute ${ }^{137} \mathrm{Cs}$ because it decays rapidly enough that it does not present much of a geologic disposal problem.

Strontium - Although ${ }^{90} \mathrm{Sr}$ has a relatively small cross section, it may be a candidate for transmutation in an advanced, high neutron flux device. Development of such an advanced concept may prove costly and challenging. Strontium-90 has about the same half-live as ${ }^{137} \mathrm{Cs}$, so there may be little incentive to transmute it to facilitate geologic disposal of the waste.

Krypton - Krypton-85 has a relatively small transmutation cross section, making it an unattractive candidate for transmutation, and the half-life is short enough (10.7 yr) that little would be gained by transmutation. Near term decay storage appears to be the most promising disposition.

Activation Products - The CURE process would not dissolve the fuel assembly hardware and fuel pin cladding which contain most of the activation products. In general, the activation products have relatively short half-lives and are contained in a high-integrity metal matrix, making them a candidate for compaction and geologic disposal of the materials that cannot be economically recycled.

\section{Institutional and Technical Issues}

It will be necessary to resolve many institutional and technical issues in order to implement the CURE process. Tables ES-1 and ES-2 give a partial list of the issues. The technical issues will require several years to resolve, and the estimated total cost for a program to attack the nine most 
WHC -EP-0268

Table ES-1. Partial Listing of Significant CURE Institutional Issues*

Issue No.

Issue

1. Public concern for safety of nuclear energy and waste management

2. Proliferation of nuclear weapons

3. Nuclear reactor and separation facility siting and licensing

4. Economics of nuclear power vs. other environmentally benign power production options

5. Public concern that plutonium recycle in commercial nuclear reactors is dangerous or unwise

6. Existing national commitment to deep geologic disposal of spent fuel

7. Completion of GESMO (Generic Environmental Statement for Mixed Oxides)

8. Concentration-based definition of fuel reprocessing high-level waste

9. Licensing of near-surface interim storage of solidified and encapsulated strontium, cesium, and other short-lived radionuclides

10. Resolution of global environmental issues (e.g., acid rain, climate change)

11. Future trends of domestic electrical energy needs

12. Acceptability of CURE concept to electrical utility industry and regulatory agencies [Public Utilities Commission, Nuclear Regulatory Commission (NRC), Federal Energy Regulatory Commission]

13. Transportation of radioactive material

14. Development of national and regional energy strategies and plans

15. Fiscal resource availability

16. Enactment of energy and environmental legislation

17. Institutional structure of the domestic energy industry

18. Compatibility of advanced technology and an open, participatory society

* List is not prioritized 
Table ES-2. Partial Listing of Significant CURE Technical Issues (sheet 1 of 2)

Issue No.

Issue

1.* Applicability of TRUEX process to high-level waste (HLW) solutions

2.* Adequate decontamination of CURE concept solid wastes

3.* Radioiodine target fabrication/irradiation

4.* ${ }^{99}$ Tc target fabrication/irradiation

5.* ${ }^{99} \mathrm{Tc}$ recovery and $\mathrm{Tc} / \mathrm{Ru}$ separation

6.* Separation of actinides and lanthanides

7.* Disposal of CURE system low-level liquid waste

8. * Removal and purification of radiostrontium from acidic HLW

9.* Removal of radiocesium from acidic HLW

10. Actinide target fabrication/irradiation

11. $237 \mathrm{~Np}$ recovery technology

12. Radioiodine recovery technology

13. Head-end treatment of irradiated target assembiies

14. Disposal of radiostrontium and radiocesium

15. Disposal of cladding hulls and fuel assembly hardware

16. Final disposal of ${ }^{135} \mathrm{Cs}$

17. Disposal of ${ }^{14} \mathrm{C}$

18. Encapsulation forms for radiostrontium and radiocesium

19. Dissolver solids target fabrication/irradiation or disposal

20. Key actinide isotope nuclear cross-section data

*Regarded as critical CURE system technology issue. Technical issues 10 through 27 not 1 isted in order of importance. 
Table ES-2. Partial Listing of Significant CURE Technical Issues (sheet 2 of 2)

Issue No. Issue

21. Lanthanide nuclear cross-section data

22. Separation of isotopes of cesium and strontium

23. Strontium nuclear cross-section data

24. Cesium nuclear cross-section data

25. Additional transmutation studies in alternative neutron sources 26. Disposal of other long-1 ived radionuclides including ${ }^{126} \mathrm{Sn},{ }^{79} \mathrm{Se},{ }^{93} \mathrm{Zr}$,

27. Development of low-activation cladding and hardware for fast reactors and accelerators 
critical technology issues would be about $\$ 68$ million [fiscal year (FY) 1990 dollars]. Such a 5- to 10-yr program would allow proper emphasis to be placed on improved chemical partitioning and transmutation technology development, and would provide a firm technical basis for a subsequent decision.

Some of the institutional issues shown in Table ES-1 represent longstanding public concerns about the present and future role of nuclear power generation in the U.S. Implementation of the CURE concept may help provide the public confidence required to resolve the nuclear waste disposal issue, which is one of the barriers to revitalizing the U.S. nuclear power option. Resolution of institutional nuclear power issues will continue to be difficult and time-consuming. It is clear that several institutional issues must be satisfactorily addressed prior to implementing the CURE concept. The major incentive for developing such a futuristic nuclear energy concept may arise from energy supply and global warming concerns driven, in part, by greenhouse gas emissions from fossil fuel energy generation.

\section{International Trends}

The U.S., with its current once-through fuel cycle, comprises about 30 percent of the world's nuclear capacity. Currently, countries representing about 50 percent of the world's capacity plan to reprocess spent fuel; these include Japan, France, the U.K., Germany, and the U.S.S.R. These reprocessing countries are all directing their programs toward separation of uranium and plutonium from commercial reactor spent fuels using the PUREX process and vitrification of the process high-level waste for geologic disposal. This step alone offers a high-level waste volume reduction, while at the same time recovers uranium and plutonium for recycling into reactors. The Japanese are, in addition, funding a long-range program called OMEGA. The OMEGA program is very similar to the CURE concept in that it includes studies of various technologies required to separate and destroy, rather than store, long-lived fission products and actinides. The OMEGA program also emphasizes recovery of beneficial elements of potential strategic importance. 
WHC-EP-0268

\section{SUMMARY}

In conclusion, the technology described in this technical assessment report offers the following potential long-range benefits to the U.S. repository program and the nuclear power generation industry:

- Destruction of the bulk of the long-lived radioactivity rather than geologic disposal would greatly reduce uncertainties in the longterm performance assessment. In effect, the time frame requiring licensing consideration would be less than 1,000 $\mathrm{yr}$, as opposed to $10,000 \mathrm{yr}$ and beyond.

- The CURE concept allows for recovery and use of valuable uranium and plutonium in spent reactor fuel. (Emplacement in the repository is supposed to be "retrievable" for decades.)

- The CURE concept can make various radionuclides and stable elements available for beneficial use.

- Implementation of the CURE concept can add a degree of freedom in controlling the repository heat load (by allowing the storage of heat producing nuclides until they decrease in power). This additional capability could be used to improve the performance of a proposed repository or to delay the need for an additional repository by allowing waste from many more decades of nuclear power generation to be emplaced in the first repository.

In order to realize these benefits, the institutional and technical issues must be resolved. A coordinated, long-range research, development, demonstration, and evaluation program is required to resolve the issues. 
WHC-EP-0268

\section{LIST OF TERMS}

2DB

ALMR

ALWR

BU

CEPOD

CLFR

CMPO

CURE

DF

DOE

$D-T$

EDTA

EIS

EPA

FFTF

FP

FR

FY

GTCC

GWe

HDEHP

HEPA

HLW

IAEA

IFR

LMR

LWR

MCNP

MOX

MRS

$M T$

MTPu

MWd/MTU

MWd/MTHM

NEPA

NIMBY

NNS

NPH

NRC

NWPA

ORNL

PNL

PTA

PUREX

PWR

R\&D

RCRA

SAFR

SIP two-dimensional diffusion theory code

advanced 1iquid-metal reactor

advanced light-water reactor

beneficial use

catalyzed electrolytic plutonium oxide dissolution

cleanup fast reactor

carbamoylmethylphosphine oxide

Clean Use of Reactor Energy

decontamination factor

U.S. Department of Energy

deuterium-tritium

ethylenediaminetetra acetic acid

Environmental Impact Statement

U.S. Environmental Protection Agency

Fast Flux Test Facility

fission product

fast reactors

fiscal year

greater-than-class-C

gigawatts electric

bis(2-ethylhexyl)phosphoric acid

high-efficiency particulate absolute

high-level waste

International Atomic Energy Agency

Integral Fast Reactor

liquid metal reactor

1 ight-water reactor

Monte Carlo neutron photon

mixed oxide

Monitored Retrievable Storage

metric ton

metric ton plutonium

megawatt days per metric ton uranium

megawatt days per metric ton of heavy metals

National Environmental Policy Act of 1969

not-in-my-backyard

dinonylnapthanlene sulfonic acid

normal paraffin hydrocarbons

U.S. Nuclear Regulatory Commission

Nuclear Waste Policy Act of 1982

Oak Ridge National Laboratory

Pacific Northwest Laboratory

phosphotungstic acid

Plutonium-Uranium Extraction

pressurized water reactor

research and development

Resource Conservation and Recovery Act of 1976

Sodium Advanced Fast Reactor

Space Isotope Program 


\section{LIST OF TERMS (CONTINUED)}

SNM

SWU

TBD

TBP

TRU

TRUEX

TUCS
Special Nuclear Material

Separative work unit

to be determined

tributyl phosphate

transuranic

Transuranic Extraction

thermally unstable complexants

Westinghouse Hanford Company 
WHC - EP-0268

\section{CONTENTS}

1.0 Introduction and Background .............. 1-1

1.1 Background Information ............... 1-1

1.2 Scope of this Study ............... 1-23

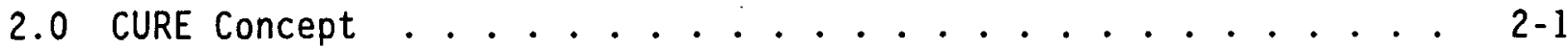

2.1 Description of CURE Concept ........... 2- 2-

2.2 Importance of CURE ............. 2-8

3.0 Partitioning .................. 3- . . . .

3.1 Chemical Processing .............. 3-. 3

3.2 Management/Disposal of CURE Wastes . . . . . . 3-29

4.0 Transmutation ................ . . 4-1

4.1 Nuclear Transmutation of Key Radionuclides . . . . . . 4-1

4.2 Transmutation of Technetium and Iodine . . . . . . . . 4-14

4.3 Fuel and Target Fabrication ............ 4-.30

5.0 Costs, Risks, and Other Issues ............ 5-1

5.1 Comparison of Fuel Cycle Requirements for Two Scenarios ................. 5- . . . .

5.2 Cost Comparisons ............... 5-2

5.3 Risks . . . . . . . . . . . . . . . 5-10

5.4 Transportation Issues ............. 5-15

5.5 Institutional Issues ............ 5-20

6.0 Key CURE Technology Development Issues .......... 6-1

6.1 Introduction . . . . . . . . . . . . . . . . . 6-1

6.2 Chemical Processing Issues ............ 6-1

6.3 Management/Disposal of CURE System Wastes . . . . . . . 6-11

6.4 Fuel and Target Fabrication .............. 6- 6-20

6.5 CURE System Transmutation Processes . . . . . . . . 6-22

7.0 CURE Concept--Technology Development Plan ......... 7-1

7.1 Introduction ................ 7-1

8.0 References ................... 8-1

Appendix:

A. Bibliography of Literature References to Partitioning and Transmutation 
WHC-EP- 0268

\section{LIST OF FIGURES}

1-1 Heavy Metal Isotope Buildup/Decay Chain ........ 1-2

1-2 Relative Ingested Toxicity of CURE Concept Residual Waste ............... 1-22

2-1 Facilities Involved in the CURE Concept ...... 2-2

3-1 The CURE Concept: Integrated Chemical Partitioning Processes .............. 3-2

3-2 CURE Concept Process Schematic .......... 3-7

3-3 Basel ine CURE Concept Fuel Reprocessing Flowsheet ... 3-11

3-4 Elowsheet for Amine Separation of Uranium and 99Tc-Purex Process Uranium Product ... . . . . . . 3-13

3-5 Baseline CURE Program Waste Separations Concept . . . 3-17

3-6 Transuranic Extraction (TRUEX) Process Flowsheet

for Operation with High-Level Waste ....... 3-18

3-7 Flowsheet for Amine Separation of Uranium and 99 TC-Truex Process U-TC Stream .......... 3-. . 30

4-1 Iodine Isotope Transmutation Chain ........ 4-4

4-2 ${ }^{99} T c$ Transmutation Chain .............. 4-4

4-3 Strontium Isotope Transmutation Chain ....... 4-5

4-4 Cesium Isotope Transmutation Chain ........ 4-5

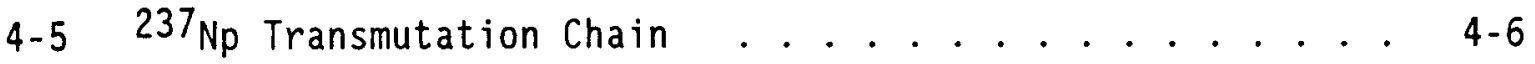

4-6 Approximate Equilibrium Cleanup Fast Reactor $4-15$

Approximate Equilibrium Cleanup Fast Reactor
Iodine Mass Balance . . . . . . . . . . 4-16

4-8 U.S. Nuclear Electricity Production Over Time . . . . 4-18

4-9 Inventory of ${ }^{99} \mathrm{Tc}$ and ${ }^{129} \mathrm{I}$ in Light-Water

Reactor Fuel as a Function of Time (Scenario 1) .... 4-19

4-10 Number of Breeder and Burner Modules as a Function of Time (Scenario 2) 


\section{LIST OF FIGURES (continued)}

4-11 Number of Burner Reactor Modules as a Function of Time (Scenario 3) ............ 4-23

4-12 Inventory of ${ }^{99} \mathrm{Tc}$ as a Function of Time

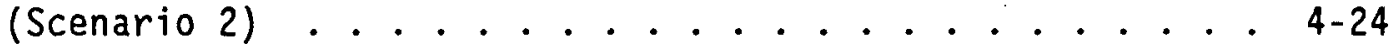

4-13 Inventory of ${ }^{129}$ I as a Function of Time (Scenario 2) ................ 4-26

4-14 Inventory of ${ }^{99} \mathrm{Tc}$ During Phaseout of Fission Reactors ........... 4-. 4-28

4-15 Inventory of ${ }^{129}$ I During Phaseout of Fission Reactors ............ 4-. 429

4-16 Comparison of ${ }^{99} \mathrm{TC}$ Inventory for Three Scenarios ... . 4-31

4-17 Approximate Mass Flow for Potential CURE Complex . . . . 4-32

4-18 Mixed 0xide Fuel Fabrication Process ......... 4-36

4-19 Neptunium Target Pin Fabrication Process . . . . . . . . 4-39

5-1 Light-Water Reactor Once-Through Scenario: Annual Material Flows and Resource Requirements ....... 5-3

5-2 CURE Light-Water Reactor Scenario: Material Flows and Resource Requirements ......... 5-4

5-3 Transportation Streams ............ 5-16 
WHC-EP-0268

\section{LIST OF TABLES}

1-1 Composition of Pressurized Water Reactor Spent Fuel

33,000 MWd/MTU, 10-year Decay .............. 1-4

1-2 Major Constituents of Liquid-Metal Reactor

Spent Driver Fuel .................. 1-10

1-3 World-Wide Spent Fuel Management Summary

(January 1988)

1-4 Pressurized Water Reactor Spent Fuel Radionuclide

Inventories at 1,000 Years .............. 1-19

2-1 Disposition of Key Radionuclides in the CURE Concept . . 2-4

2-2 Other Long-1ived Radionuclides in Light-Water Reactor

Spent Fuel and Fast Reactor Spent Fuel .. . . . . . 2-5

3-1 Required Removal of Key Radionuclides

From Light-Water Reactor Fuel . . . . . . . . . . . 3-3

3-2 Required Removal of Key Radionuclides from Fast

Reactor Fuel ................. 3-4

4-1 Approximate Remaining Inventory of Key Radionuclides

in U.S. Light-Water Reactor Spent Fuel by Year 2030 . . . 4-2

4-2 LWR Nuclide Destruction Rates ............. 4-9

4-3 Cleanup Fast Reactor Fission Product and

Actinide Destruction Rates ............ 4-12

4-4 Approximate Cleanup Fast Reactor

Waste Isotope Annual Generation Rates . . . . . . . 4-13

4-5 Equilibrium ${ }^{99} \mathrm{Tc}$ and ${ }^{129}$ I Inventory

versus Breeder/Burner Ratio .. . . . . . . . . . . 4-27

4-6 Burnup of ${ }^{99}$ Tc During Reactor Phaseout . . . . . . . 4-30

4-7 Approximate Core Material Requirements for CURE System

Fast Reactor ..................... 4-34

5-1 Annual Resource Requirements for Light-Water Reactor Only and CURE Light-Water Reactor Scenarios . . . . . 5-5 


\section{LIST OF TABLES (continued)}

5-2 Net Annual Cost Impacts of CURE Light-Water Reactor Scenario versus Once-Through Light-Water Reactor Only Scenario ........... 5-7

5-3 Short-Term Risk Comparisons (Health Effects/GWe-Year) . . 5-12

5-4 Long-Term Risk Comparisons (Health Effects/GWe-Year) . . 5-14

7-1 CURE System-Critical Technology Items ....... 7-3

7-2 CURE Program Chemical Processing Technology Needs . . . 7-4

7-3 CURE Program Waste Management/Disposal Technology Needs . . . . . . . . . . . . . . . 7-5

7-4 CURE Program Target Fabrication/Irradiation Technology Needs ............ . 7-6

7-5 CURE Program Transmutation Technology Needs . . . . . 7-7

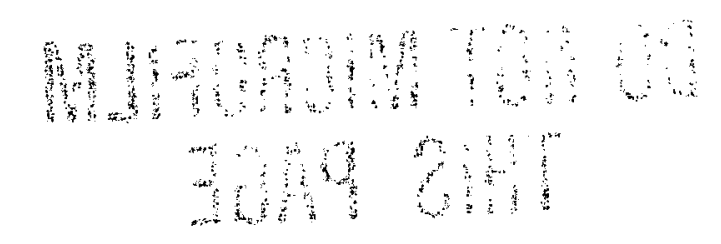


WHC-EP-0268

This page intentionally left blank. 
WHC-EP-0268

\section{CURE: CLEAN USE OF REACTOR ENERGY}

\subsection{INTRODUCTION AND BACKGROUND}

\subsection{BACKGROUND INFORMATION}

Spent fuel from commercial nuclear reactors is accumulating rapidly because many of the world's more advanced countries have increased their reliance on nuclear energy to supply electricity. Although all countries with a nuclear option have some kind of final waste disposal policy, none has completed implementation. Technical and political issues could delay action in many cases. The current U.S. policy is to dispose of spent fuel in a deep geologic repository. This report discusses fuel treatment technologies that could contribute positively to public acceptability and licensing of a geologic repository.

In uranium-fueled thermal neutron spectrum reactors, the fresh fuel consists of $\mathrm{UO}_{2}$ pellets $\mathrm{clad}$ in Zircaloy tubes. The uranium isotopic composition is 3 to $4 \% 235 \mathrm{U}$ and 97 to $96 \% 238 \mathrm{U}$. During reactor operation, $235 \mathrm{U}$ either fissions (highest probability) or captures a neutron to form $236 U$. The $238 U$ either captures a neutron (highest probability) or fissions. Neutron capture by $238 \mathrm{U}$ leads to formation of $239 \mathrm{Pu}$, which has a high fission probability similar to that of $235 \mathrm{U}$. Figure 1-1 shows the heavy metal isotope chain involved in the uranium fuel cycle and also shows how higher mass plutonium isotopes are formed, which lead in turn to the even higher mass elements americium and curium. Another transuranic (TRU) element formed in the uranium fuel cycle is neptunium, which is formed as the single isotope ${ }^{237} \mathrm{~Np}$ (see Figure 1-1).

In addition to TRU elements, fission reactors produce many different radioactive and stable fission products in the fuel. These are formed in different amounts, depending mostly on their mass. Complex radioactive decay chains result in a constantly changing mixture in the spent fuel during and following irradiation. The decay heat associated with both fission 
Figure 1-1. Heavy Metal Isotope Buildup/Decay Chain.

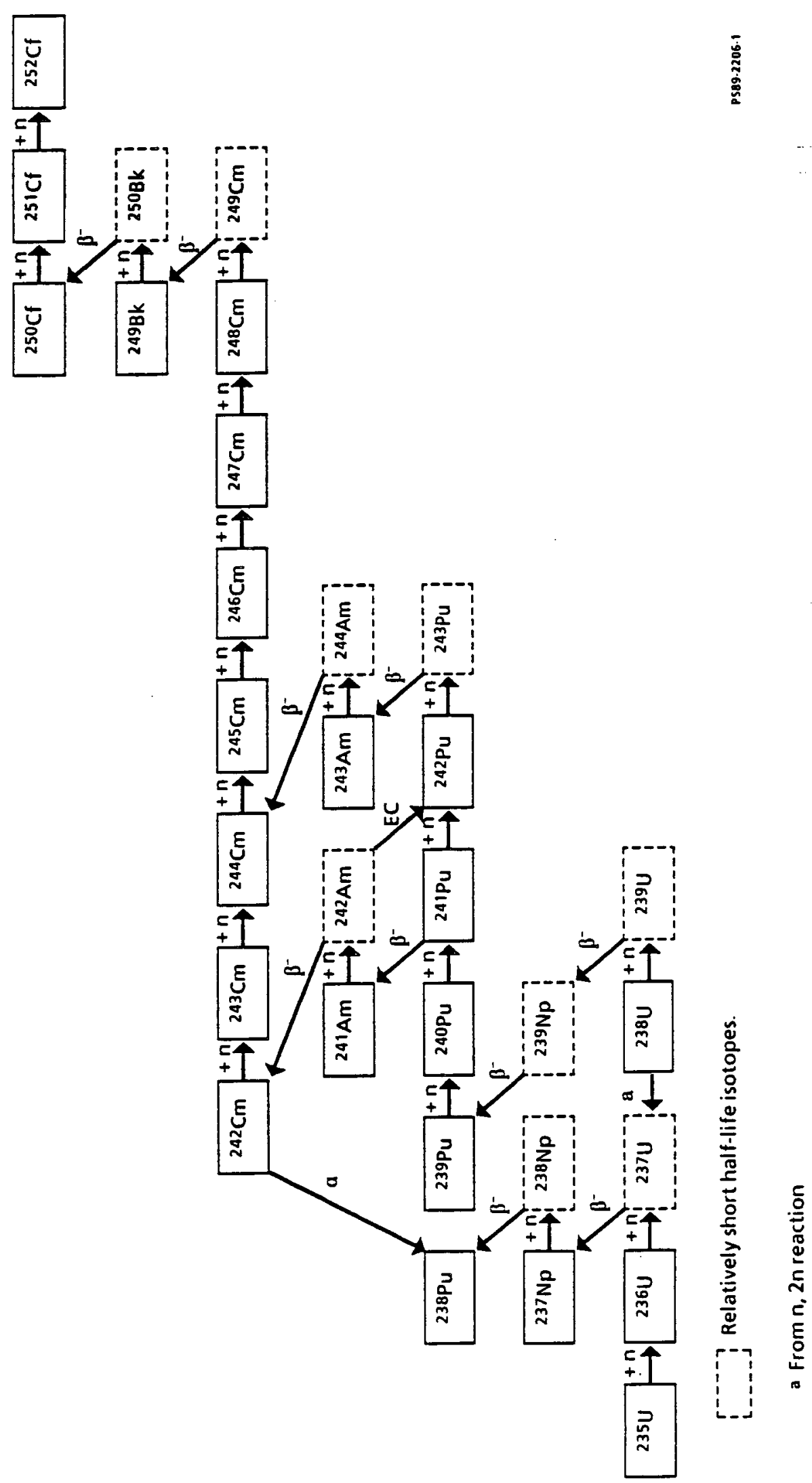


products and actinides (heavy elements) decreases monotonically with time, as does the total radioactivity. The final disposition of spent fuel, therefore, depends to some extent on the age of the fuel.

Table 1-1 1ists the major elements and isotopes in pressurized water reactor (PWR) spent fuel after a decay time of $10 \mathrm{yr}$. The nominal PWR fuel burnup at discharge is currently about 33,000 megawatt days per metric ton uranium (MWd/MTU), the burnup assumed in Table 1-1. Mass values listed in Table 1-1 are calculated using the ORIGEN2 computer code (Croff 1980), the U.S. industry standard for computing isotopic concentrations in a reactor as a function of burnup, neutron spectrum, and decay time. The ORIGEN2 code was also used to calculate a number of other quantities, such as the decay heat in watts, the radioactivity in curies, and the ingestion toxicity (see Table 1-1). Ingestion toxicity is the volume of pure water required to dilute the isotope/element to drinking water standards.

Table 1-2 lists the major constituents of liquid metal reactor (LMR) spent driver fuel after a decay time of $3 \mathrm{yr}$ from reactor discharge. The average driver fuel burnup is assumed to be 150,000 megawatt days per metric ton of heavy metal (MWd/MTHM). The tabulated values are calculated using the ORIGEN2 code.

In the remainder of this report, a distinction will be made between radioactive isotope fission products and elemental fission products. For example, fission product strontium consists of ${ }^{88} \mathrm{Sr}$ and ${ }^{90} \mathrm{Sr}$. The ${ }^{88} \mathrm{Sr}$ is stable, and the ${ }^{90} \mathrm{Sr}$ has a 29 -yr half-life. Chemical separations extract both isotopes, and the designation "radiostontium" will refer to elemental fission product strontium, as opposed to the radioactive ${ }^{90} \mathrm{Sr}$ isotope. Other fission products of relevance in this context include:

- ${ }^{99} \mathrm{Tc}$ - only technetium fission product

- Radiocesium - a mixture of ${ }^{133} \mathrm{Cs},{ }^{135} \mathrm{Cs},{ }^{137} \mathrm{Cs}$

- Radioiodine - a mixture of ${ }^{127} \mathrm{I},{ }^{129} \mathrm{I}$. 


\begin{tabular}{|l|l|c|c|c|c|}
\hline Element/isotope & \multicolumn{1}{|c|}{ g/MTU } & Half-life $(\mathrm{yr})$ & Watts/MTU & Curies/MTU & $\begin{array}{c}\text { Ingestion } \\
\text { toxicity/MTU, } \\
\mathrm{m}^{3} \mathrm{H}_{2} \mathrm{O}\end{array}$ \\
\hline Uranium & $(956,300)^{\mathrm{a}}$ & -- & $(0.022)^{\mathrm{a}}$ & $(2.63)^{\mathrm{a}}$ & $\left(3.96 \times 10^{4}\right)^{\mathrm{a}}$ \\
\hline $234 \mathrm{U}$ & 12.6 & $2.45 \times 10^{5}$ & $2.26 \times 10^{-3}$ & 0.079 & $2.62 \times 10^{3}$ \\
\hline $235 \mathrm{U}$ & 7,373 & $7.04 \times 10^{8}$ & $4.18 \times 10^{-4}$ & 0.016 & $5.32 \times 10^{2}$ \\
\hline $236 \mathrm{U}$ & 3,803 & $2.34 \times 10^{7}$ & $6.67 \times 10^{-3}$ & 0.246 & $8.21 \times 10^{3}$ \\
\hline $238 \mathrm{U}$ & 945,100 & $4.47 \times 10^{9}$ & $8.06 \times 10^{-3}$ & 0.318 & $7.95 \times 10^{3}$ \\
\hline Neptunium & $(440)$ & -- & $(0.053)^{\mathrm{b}}$ & $(18.4)^{\mathrm{b}}$ & $\left(2.85 \times 10^{5}\right)^{\mathrm{b}}$ \\
\hline $237 \mathrm{~Np}$ & 440 & $2.14 \times 10^{6}$ & $9.49 \times 10^{-3}$ & 0.310 & $1.04 \times 10^{5}$ \\
\hline Plutonium & $(8,745)$ & -- & $(107)$ & $(82.420)$ & $\left(1.04 \times 10^{9}\right)$ \\
\hline $238 \mathrm{Pu}$ & 137 & 87.7 & 78.0 & $2.35 \times 10^{3}$ & $4.71 \times 10^{8}$ \\
\hline $239 \mathrm{Pu}$ & 5,044 & $2.41 \times 10^{4}$ & 9.67 & 314 & $6.27 \times 10^{7}$ \\
\hline $240 \mathrm{Pu}$ & 2,324 & $6.56 \times 10^{3}$ & 16.5 & 530 & $1.06 \times 10^{8}$ \\
\hline $241 \mathrm{Pu}$ & 769 & 14.4 & 2.46 & $7.9 \times 10^{4}$ & $3.96 \times 10^{8}$ \\
\hline $242 \mathrm{Pu}$ & 471 & $3.76 \times 10^{5}$ & 0.0532 & 1.80 & $3.60 \times 10^{5}$ \\
\hline Americium & $(594)$ & -- & $(58.0)$ & $\left(1.76 \times 10^{3}\right)$ & $\left(4.38 \times 10^{8}\right)$ \\
\hline $241 \mathrm{Am}$ & 503 & 141 & 57.3 & $1.73 \times 10^{3}$ & $4.32 \times 10^{8}$ \\
\hline $242 \mathrm{mAm}$ & 0.660 & $-37 \times 10^{3}$ & 0.581 & 18.1 & $4.73 \times 10^{6}$ \\
\hline $243 \mathrm{Amb}$ & 90.6 & & & 6.92 & $10^{6}$ \\
\hline
\end{tabular}




\begin{tabular}{|c|c|c|c|c|c|}
\hline Element/isotope & g/MTU & Half-life (yr) & Watts/MTU & Curies/MTU & $\begin{array}{c}\text { Ingestion } \\
\text { toxicity/MTU, } \\
\mathrm{m}^{3} \mathrm{H}_{2} \mathrm{O}\end{array}$ \\
\hline Curium & (18.87) & -- & (50.9) & $(1,453)$ & $\left(2.08 \times 10^{8}\right)$ \\
\hline $243 \mathrm{Cm}$ & 0.337 & 28.5 & 0.637 & 17.4 & $3.47 \times 10^{6}$ \\
\hline $244 \mathrm{Cm}$ & 17.6 & 18.1 & 50.0 & $1.43 \times 10^{3}$ & $2.04 \times 10^{8}$ \\
\hline $245 \mathrm{Cm}$ & 0.932 & $8.5 \times 10^{3}$ & $5.33 \times 10^{-3}$ & 0.160 & $4.01 \times 10^{4}$ \\
\hline Total actinides & $9.66 \times 10^{5}$ & - & 216 & $8.57 \times 10^{4}$ & $1.68 \times 10^{9}$ \\
\hline Selenium & (55.4) & -- & -- & $\left(1.0 \times 10^{-4}\right)$ & $\left(1.35 \times 10^{5}\right)$ \\
\hline $795 e$ & 5.8 & $6.5 \times 10^{4}$ & $1.0 \times 10^{-4}$ & 0.40 & $1.35 \times 10^{5}$ \\
\hline Bromine & (21.3) & Stable & -- & -- & -- \\
\hline Krypton & $(350)$ & -- & (7.1) & $(4,763)$ & $\mathrm{NAe}$ \\
\hline $85 \mathrm{Kr}$ & 12.1 & 10.72 & 7.1 & $4.76 \times 10^{3}$ & NA \\
\hline Rubidium & 345 & -- & -- & $2.1 \times 10^{-5}$ & - \\
\hline Strontium & $(751)$ & -. & $(64.8)$ & - & $\left(1.86 \times 10^{11}\right)$ \\
\hline $88 \mathrm{Sr}$ & 341 & Stable & -- & - & -- \\
\hline $905 r$ & 409 & 29 & 64.8 & $5.59 \times 10^{4}$ & $1.86 \times 1011$ \\
\hline Yttrium & $(445)$ & -- & $(310)$ & $(55,880)$ & $\left(2.79 \times 10^{9}\right)$ \\
\hline $89 Y$ & 445 & Stable & - & - & - \\
\hline $90 Y d$ & Negligible & Short & 310 & $5.59 \times 10^{4}$ & $2.79 \times 10^{9}$ \\
\hline
\end{tabular}




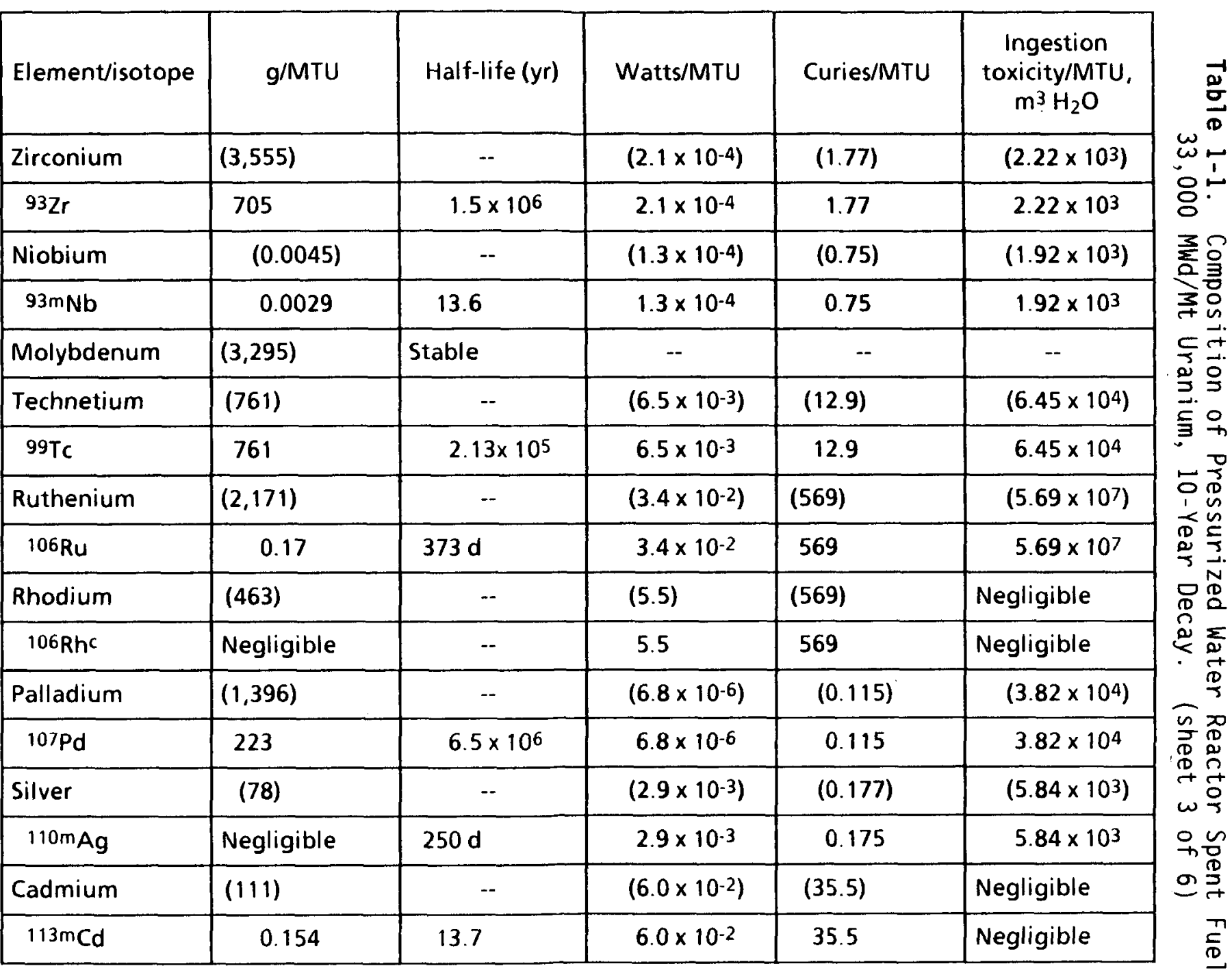




\begin{tabular}{|c|c|c|c|c|c|}
\hline Element/isotope & g/MTU & Half-life (yr) & Watts/MTU & Curies/MTU & $\begin{array}{c}\text { Ingestion } \\
\text { toxicity/MTU, } \\
m^{3} \mathrm{H}_{2} \mathrm{O}\end{array}$ \\
\hline Tin & $(90.7)$ & -- & $\left(1.3 \times 10^{-3}\right)$ & $(0.971)$ & $(3.24 \times 105)$ \\
\hline $1265 n$ & 27.6 & $\sim 10^{5}$ & $9.8 \times 10^{-4}$ & 0.782 & $2.61 \times 10^{5}$ \\
\hline Antimony & (19.7) & -- & (3.7) & $(1,185)$ & $\left(1.19 \times 10^{7}\right)$ \\
\hline $125 \mathrm{Sb}$ & 1.15 & 2.76 & 3.7 & $1.18 \times 10^{3}$ & $1.18 \times 10^{7}$ \\
\hline $126 \mathrm{Sb}$ & - & $12.4 \mathrm{~d}$ & $2.0 \times 10^{-3}$ & 0.11 & $2.61 \times 10^{5}$ \\
\hline $126 \mathrm{mSb}$ & - & $19 m$ & $1.0 \times 10^{-2}$ & 0.78 & $3.65 \times 10^{4}$ \\
\hline Tellurium & $(482)$ & -- & $\left(2.4 \times 10^{-1}\right)$ & $(289)$ & $\left(2.89 \times 10^{6}\right)$ \\
\hline $125 \mathrm{mTe}$ & Negligible & $58 d$ & $2.4 \times 10^{-1}$ & 289 & $2.89 \times 10^{6}$ \\
\hline lodine & $(234)$ & -- & $\left(1.5 \times 10^{-5}\right)$ & $(0.0315)$ & $(5.25 \times 105)$ \\
\hline 1291 & 178 & $1.6 \times 10^{7}$ & $1.5 \times 10^{-5}$ & 0.0315 & $5.25 \times 10^{5}$ \\
\hline Xenon & $(5,293)$ & Stable & -- & -- & NA \\
\hline Cesium & $(2,339)$ & -- & $\left(1.44 \times 10^{2}\right)$ & $(86,680)$ & $\left(4.67 \times 10^{9}\right)$ \\
\hline${ }^{134} \mathrm{Cs}$ & 4.06 & 2.07 & 54 & 5,260 & $5.84 \times 10^{8}$ \\
\hline $135 \mathrm{Cs}$ & 287 & $3 \times 10^{6}$ & $1.1 \times 10^{-4}$ & 0.33 & $3.30 \times 10^{3}$ \\
\hline $137 \mathrm{Cs}$ & 936 & 30.17 & 90 & 81,420 & $4.07 \times 10^{9}$ \\
\hline Barium & $(1,710)$ & -- & $\left(3.02 \times 10^{2}\right)$ & $(77,020)$ & $\left(7.70 \times 10^{4}\right)$ \\
\hline $137 \mathrm{mBa}$ & Negligible & $2.5 \mathrm{~m}$ & $3.02 \times 10^{2}$ & $7.7 \times 10^{4}$ & -- \\
\hline
\end{tabular}




\begin{tabular}{|l|l|l|l|l|c|}
\hline Elementisotope & \multicolumn{1}{|c|}{$\mathrm{g} / \mathrm{MTU}$} & Half-life (yr) & Watts/MTU & Curies/MTU & $\begin{array}{c}\text { Ingestion } \\
\text { toxicity/MTU, } \\
\mathrm{m}^{3} \mathrm{H}_{2} \mathrm{O}\end{array}$ \\
\hline Lanthanum & $(1,200)$ & Stable & -- & -- & -- \\
\hline Cerium & $(2324)$ & -- & $\left(9.9 \times 10^{-2}\right)$ & $(149)$ & $\left(1.49 \times 10^{7}\right)$ \\
\hline $144 \mathrm{Ce}$ & 0.047 & $284.4 \mathrm{~d}$ & $9.9 \times 10^{-2}$ & 149 & $1.49 \times 10^{7}$ \\
\hline Praseodymium & $(1,101)$ & -- & $(1.1)$ & $(151)$ & $\left(1.51 \times 10^{2}\right)$ \\
\hline 144Pr & Negligible & $17.3 \mathrm{~m}$ & 1.1 & 149 & Negligible \\
\hline 144mPr & Negligible & $7.2 \mathrm{~m}$ & $6.1 \times 10^{-4}$ & 1.8 & Negligible \\
\hline Neodymium & $(3,974)$ & Stable & -- & -- & - \\
\hline Promethium & $(10.0)$ & -- & $(3.3)$ & $(9,308)$ & $\left(4.68 \times 10^{7}\right)$ \\
\hline 147Pm & 10.0 & 2.63 & 3.3 & $9.31 \times 10^{3}$ & $4.65 \times 10^{7}$ \\
\hline Samarium & $(785)$ & -- & $\left(3.5 \times 10^{-2}\right)$ & $(299)$ & $\left(7.49 \times 10^{5}\right)$ \\
\hline 151Sm & 11.4 & 90 & $3.5 \times 10^{-2}$ & 299 & $7.49 \times 10^{5}$ \\
\hline Europium & $(128)$ & -- & $(43)$ & $(6,279)$ & $\left(2.42 \times 10^{8}\right)$ \\
\hline 154Eu & 17.3 & 8.5 & 41.8 & $4.67 \times 10^{3}$ & $2.34 \times 10^{8}$ \\
\hline 155Eu & 3.45 & 4.73 & 1.2 & $1.60 \times 10^{3}$ & $8.00 \times 10^{6}$ \\
\hline $\begin{array}{l}\text { Total fission } \\
\text { products }\end{array}$ & $3.36 \times 10^{4}$ & & & $2.99 \times 10^{5}$ & $1.94 \times 10^{11}$ \\
\hline
\end{tabular}




\begin{tabular}{|l|l|l|l|l|l|}
\hline \multirow{5}{*}{ Element/isotope } & g/MTU & Half-life (yr) & Watts/MTU & Curies/MTU & $\begin{array}{c}\text { Ingestion } \\
\text { toxicity/MTU, } \\
\mathrm{m}^{3} \mathrm{H}_{2} \mathrm{O}\end{array}$ \\
\hline \multicolumn{5}{|c|}{ Activation products (AP) } \\
\hline $14 \mathrm{C}$ & 0.126 & 5.730 & $1.7 \times 10^{-4}$ & 0.56 & $7.1 \times 10^{2}$ \\
\hline $54 \mathrm{Mn}$ & $1.1 \times 10^{-4}$ & $312 \mathrm{~d}$ & $4.4 \times 10^{-3}$ & 0.88 & $8.8 \times 10^{3}$ \\
\hline $55 \mathrm{Fe}$ & 0.51 & 2.73 & $4.1 \times 10^{-2}$ & 1.210 & $1.5 \times 10^{6}$ \\
\hline $60 \mathrm{Co}$ & 2.5 & 5.27 & 44 & 2.870 & $9.6 \times 10^{7}$ \\
\hline $59 \mathrm{Ni}$ & 63.0 & $7.5 \times 10^{4}$ & $2.0 \times 10^{-4}$ & 5.09 & $2.5 \times 10^{4}$ \\
\hline $63 \mathrm{Ni}$ & 11.4 & 100 & $2.6 \times 10^{-1}$ & 645 & $2.2 \times 10^{7}$ \\
\hline $93 \mathrm{Zr}$ & 56 & $1.53 \times 10^{6}$ & $1.7 \times 10^{-5}$ & 0.14 & $1.8 \times 10^{2}$ \\
\hline $93 \mathrm{mNb}$ & $2.1 \times 10^{-4}$ & 13.6 & $1.1 \times 10^{-5}$ & 0.059 & $1.5 \times 10^{2}$ \\
\hline $94 \mathrm{Nb}$ & 2.6 & $2.0 \times 10^{4}$ & $5.0 \times 10^{-3}$ & 0.49 & $1.6 \times 10^{5}$ \\
\hline $93 \mathrm{Mo}$ & 0.020 & 3.500 & $2.0 \times 10^{-3}$ & 0.022 & $7.2 \times 10^{3}$ \\
\hline $119 \mathrm{mSn}$ & $5.1 \times 10^{-5}$ & $293 \mathrm{~d}$ & $1.0 \times 10^{-4}$ & 0.19 & $6.5 \times 10^{4}$ \\
\hline $121 \mathrm{mSn}$ & $9.4 \times 10^{-3}$ & 55 & $1.0 \times 10^{-3}$ & 0.51 & $1.7 \times 10^{5}$ \\
\hline $125 \mathrm{Sb}$ & 0.12 & 2.73 & $4.0 \times 10^{-1}$ & 127 & $1.3 \times 10^{6}$ \\
\hline $125 \mathrm{mTe}$ & $1.7 \times 10^{-3}$ & $58 \mathrm{~d}$ & $2.6 \times 10^{-2}$ & 30.9 & $3.1 \times 10^{5}$ \\
\hline Total AP & 136 & $2-$ & 45 & 4.891 & $1.2 \times 10^{8}$ \\
\hline
\end{tabular}

NOTE: Quantities in parentheses are totals for the element.

$\mathrm{MWd} / \mathrm{MTU}=$ megawatt days per initial metric ton of uranium.

${ }^{a}$ Total includes short-lived $237 \mathrm{U}$ (not shown).

6243Am decays to short-lived $239 \mathrm{~Np}$ (not shown).

'106Rh is the short-lived decay daughter of $106 \mathrm{Ru}$.

d90Y is the short-lived decay daughter of $90 \mathrm{Sr}$.

${ }^{\mathrm{e}} \mathrm{NA}=$ not applicable 
Table 1-2. Major Constituents of Liquid-Metal Reactor Spent Driver Fuel. (sheet 1 of 5 )

Assumptions: Decay period $=3 \mathrm{yr}$ from reactor discharge Average burnup $=150,000 \mathrm{MWd}^{\prime} \mathrm{MTHM}^{\mathrm{a}}$

Initial composition: $75 \%$ U, 25\% Pu (light-water reactor discharge)

No Pu decay since reprocessing of $10 \mathrm{yr}$ old light water reactor spent fuel

Ferritic HT-9 structural material

\begin{tabular}{|c|c|c|c|c|c|}
\hline $\begin{array}{l}\text { Element/ } \\
\text { isotope }\end{array}$ & Half-life & $\mathrm{g} / \mathrm{MTHM}$ & $\begin{array}{l}\text { Radioactivity } \\
\text { (Ci/MTHM)b }\end{array}$ & $\begin{array}{l}\text { Watts/ } \\
\text { MTHM }\end{array}$ & Comments \\
\hline Uranium & - & $\left(6.4 \times 10^{5}\right) c$ & (1.2) & $3.5 \times 10^{-2}$ & $75 \%$ of $\mathrm{HMd}$ \\
\hline-234 & $2.5 \times 10^{5} \mathrm{yr}$ & $1.9 \times 10^{2}$ & 1.2 & $3.5 \times 10^{-2}$ & \\
\hline-235 & $7.0 \times 10^{8} \mathrm{yr}$ & $6.2 \times 10^{2}$ & $1.4 \times 10^{-3}$ & $3.5 \times 10^{-5}$ & \\
\hline-236 & $2.3 \times 10^{7} \mathrm{yr}$ & $2.2 \times 10^{2}$ & $1.4 \times 10^{-2}$ & $3.8 \times 10^{-4}$ & \\
\hline-238 & $4.5 \times 10^{9} \mathrm{yr}$ & $6.4 \times 105$ & $2.2 \times 10^{-1}$ & $5.5 \times 10^{-3}$ & \\
\hline Neptunium & - & $\left(6.4 \times 10^{2}\right)$ & $\left(4.5 \times 10^{-1}\right)$ & $\left(1.4 \times 10^{-2}\right)$ & \\
\hline-237 & $2.1 \times 106 \mathrm{yr}$ & $6.4 \times 10^{2}$ & $4.5 \times 10^{-1}$ & $1.4 \times 10^{-2}$ & \\
\hline Plutonium & -- & $\left(2.0 \times 10^{5}\right)$ & $\left(1.3 \times 10^{6}\right)$ & $\left(2.4 \times 10^{3}\right)$ & $\begin{array}{l}24 \% \text { of } H M \\
\text { mass }\end{array}$ \\
\hline-238 & $88 y r$ & $3.0 \times 10^{3}$ & $5.1 \times 10^{4}$ & $1.7 \times 10^{3}$ & \\
\hline-239 & $2.4 \times 10^{4} \mathrm{yr}$ & $1.1 \times 10^{5}$ & $7.0 \times 10^{3}$ & $2.2 \times 10^{2}$ & \\
\hline-240 & $6.6 \times 10^{3} \mathrm{yr}$ & $5.6 \times 10^{4}$ & $1.3 \times 10^{4}$ & $4.0 \times 10^{2}$ & \\
\hline-241 & $14.4 \mathrm{yr}$ & $1.2 \times 10^{4}$ & $1.2 \times 10^{6}$ & $3.7 \times 10^{1}$ & \\
\hline-242 & $3.8 \times 10^{5} \mathrm{yr}$ & $1.4 \times 10^{4}$ & $5.3 \times 10^{1}$ & 1.6 & \\
\hline Americium & - & $\left(7.1 \times 10^{3}\right)$ & $\left(2.1 \times 10^{4}\right)$ & $\left(6.0 \times 10^{2}\right)$ & $\begin{array}{l}1 \% \text { of } \mathrm{HM} \\
\text { mass }\end{array}$ \\
\hline-241 & $432 \mathrm{yr}$ & $5.1 \times 10^{3}$ & $1.8 \times 10^{4}$ & $5.8 \times 10^{2}$ & \\
\hline$-242 m$ & $141 \mathrm{yr} / 16 \mathrm{~h}$ & $1.6 \times 10^{2}$ & $3.2 \times 10^{3}$ & 2.4 & $242 \mathrm{mAm} / 242 \mathrm{Am}$ \\
\hline-243 & $7.4 \times 10^{3} y r$ & $1.9 \times 10^{3}$ & $7.5 \times 10^{2}$ & $1.2 \times 10^{1}$ & $243 \mathrm{Am} / 239 \mathrm{~Np}$ \\
\hline Curium & -- & $\left(2.9 \times 10^{2}\right)$ & $\left(2.8 \times 10^{4}\right)$ & $\left(1.0 \times 10^{3}\right)$ & \\
\hline-242 & $163 d$ & 2.1 & $6.8 \times 10^{3}$ & $2.5 \times 10^{2}$ & \\
\hline-243 & $28.5 y r$ & 6.2 & $3.2 \times 10^{2}$ & $1.2 \times 101$ & \\
\hline-244 & $18.1 \mathrm{yr}$ & $2.6 \times 10^{2}$ & $2.1 \times 10^{4}$ & $7.4 \times 10^{2}$ & \\
\hline-245 & $8.5 \times 10^{3} \mathrm{yr}$ & $2.5 \times 10^{1}$ & 4.2 & $1.4 \times 10^{-1}$ & \\
\hline Total HM & -- & $8.5 \times 105$ & $1.3 \times 10^{6}$ & $3.9 \times 10^{3}$ & \\
\hline
\end{tabular}


Table 1-2. Major Constituents of Liquid-Metal Reactor Spent Oriver Fuel. (sheet 2 of 5 )

\begin{tabular}{|c|c|c|c|c|c|}
\hline $\begin{array}{l}\text { Element } \\
\text { isotope }\end{array}$ & Half-life & g/MTHM & $\begin{array}{l}\text { Radioactivity } \\
\text { (Ci/MTHM)a }\end{array}$ & $\begin{array}{l}\text { Watts/ } \\
\text { MTHMa }\end{array}$ & Comments \\
\hline Selenium & -- & $\left(1.6 \times 10^{2}\right)$ & $(1.6)$ & $\left(4.0 \times 10^{-4}\right)$ & \\
\hline-79 & $6.5 \times 10^{4} y r$ & $2.3 \times 101$ & 1.6 & $4.0 \times 10^{-4}$ & \\
\hline Bromine & Stable & $\left(5.1 \times 10^{1}\right)$ & -- & -- & \\
\hline Krypton & -- & $\left(1.0 \times 10^{3}\right)$ & $\left(2.0 \times 10^{4}\right)$ & $\left(3.0 \times 10^{1}\right)$ & \\
\hline-85 & $10.7 y r$ & $5.1 \times 10^{1}$ & $2.0 \times 10^{4}$ & $3.0 \times 10^{1}$ & \\
\hline Rubidium & -- & $\left(8.9 \times 10^{2}\right)$ & $(5.4 \times 10-5)$ & $\left(4.5 \times 10^{-8}\right)$ & \\
\hline-85 & Stable & $2.7 \times 10^{2}$ & -- & -- & \\
\hline-87 & $5.9 \times 10^{10} \mathrm{yr}$ & $6.1 \times 10^{2}$ & $5.4 \times 10^{-5}$ & $4.5 \times 10^{-8}$ & \\
\hline Strontium & - & $(1.9 \times 103)$ & $(2.9 \times 105)$ & $\left(1.7 \times 10^{2}\right)$ & \\
\hline-88 & Stable & $8.0 \times 10^{2}$ & -- & -- & \\
\hline-89 & $50.5 d$ & $1.3 \times 10^{-5}$ & $3.7 \times 10^{-1}$ & $1.3 \times 10^{-3}$ & \\
\hline-90 & $29 y / 64 h$ & $1.1 \times 10^{3}$ & $2.9 \times 105$ & $1.7 \times 10^{2}$ & $90 \mathrm{Sr} / 90 \mathrm{Y}$ \\
\hline Yttrium & - & $(1.0 \times 103)$ & (3.9) & $\left(1.4 \times 10^{-2}\right)$ & \\
\hline-89 & Stable & $1.0 \times 10^{3}$ & -- & -- & \\
\hline-91 & $59 d$ & $1.6 \times 10^{-4}$ & 3.9 & $1.4 \times 10^{-2}$ & \\
\hline Zirconium & -- & $\left(1.1 \times 10^{4}\right)$ & $(12.6)$ & $\left(3.4 \times 10^{-1}\right)$ & \\
\hline-93 & $\begin{array}{c}1.5 \times 106 \mathrm{yr} / \\
13.6 \mathrm{yr} \\
\end{array}$ & $2.2 \times 10^{3}$ & $5.6 c(93 \mathrm{Zr}$ only) & $6.5 \times 10^{-4}$ & $93 \mathrm{Zr} / 93 \mathrm{~m} \mathrm{Nb}$ \\
\hline-95 & $64 d / 35 d$ & $1.0 \times 10^{-3}$ & $7.0 \times 10^{1}$ & $3.4 \times 10^{-1}$ & $95 \mathrm{Zr} / 95 \mathrm{Nb}$ \\
\hline Niobium & -- & $\left(1.7 \times 10^{-2}\right)$ & $(1.4)$ & $\left(2.4 \times 10^{-4}\right)$ & \\
\hline$-93 m$ & $13.6 \mathrm{yr}$ & $1.2 \times 10^{-3}$ & 1.4 & $2.4 \times 10^{-4}$ & $93 \mathrm{mNb}$ only \\
\hline Molybdenum & Stable & $\left(1.3 \times 10^{4}\right)$ & -- & - & \\
\hline Technetium-99 & $2.1 \times 10^{5} y r$ & $3.4 \times 1.0^{3}$ & $5.8 \times 10^{1}$ & $2.9 \times 10^{-2}$ & \\
\hline Ruthenium & - & $(1: 3 \times 104)$ & $\left(6.5 \times 10^{5}\right)$ & $\left(3.1 \times 10^{3}\right)$ & \\
\hline-103 & $39 d / 56 m$ & $5.9 \times 10^{-7}$ & $3.6 \times 10^{-2}$ & $6.7 \times 10^{-5}$ & $103 \mathrm{Ru} / 103 \mathrm{mRh}$ \\
\hline-106 & $373 d / 30 s$ & $9.7 \times 10^{1}$ & $6.5 \times 105$ & $3.1 \times 10^{3}$ & $106 \mathrm{Ru} / 106 \mathrm{Rh}$ \\
\hline Rhodium & Stable & $\left(3.8 \times 10^{3}\right)$ & -- & -- & \\
\hline Palladium & - & $\left(1.1 \times 10^{4}\right)$ & $(1.0)$ & $\left(6.1 \times 10^{-5}\right)$ & \\
\hline-107 & $6.5 \times 10^{6} y r$ & $2.0 \times 10^{3}$ & 1.0 & $6.1 \times 10^{-5}$ & \\
\hline
\end{tabular}


Table 1-2. Major Constituents of Liquid-Metal Reactor Spent Driver Fue1. (sheet 3 of 5 )

\begin{tabular}{|c|c|c|c|c|c|}
\hline $\begin{array}{l}\text { Element/ } \\
\text { isotope }\end{array}$ & Half-life & g/MTHM & $\begin{array}{l}\text { Radioactivity } \\
\text { (Ci/MTHM)b }\end{array}$ & $\begin{array}{l}\text { Watts/ } \\
\text { MTHMb }\end{array}$ & Comments \\
\hline Silver & -- & $\left(1.1 \times 10^{3}\right)$ & $\left(1.6 \times 10^{3}\right)$ & $\left(2.7 \times 10^{1}\right)$ & \\
\hline$-110 m$ & $250 d$ & $3.4 \times 10^{-1}$ & $1.6 \times 10^{3}$ & $1.6 \times 10^{-1}$ & \\
\hline-110 & $25 \mathrm{~s}$ & negligible & $2.2 \times 10^{1}$ & $2.7 \times 10^{1}$ & \\
\hline Cadmium & -- & $\left(9.6 \times 10^{2}\right)$ & $\left(5.2 \times 10^{2}\right)$ & $\left(8.7 \times 10^{-1}\right)$ & \\
\hline$-113 m$ & $13.7 y r$ & $1.4 \times 10^{2}$ & $5.2 \times 10^{2}$ & $8.7 \times 10^{-1}$ & \\
\hline Indium & -- & $\left(5.2 \times 10^{1}\right)$ & -- & -- & \\
\hline Tin & -- & $\left(8.2 \times 10^{2}\right)$ & $\left(5.9 \times 10^{1}\right)$ & $\left(2.5 \times 10^{-1}\right)$ & \\
\hline-123 & $129 d$ & $5.5 \times 10^{-3}$ & $4.5 \times 10^{1}$ & $1.4 \times 10^{-1}$ & \\
\hline-126 & $\begin{array}{l}105 y / 12 d / \\
19 \mathrm{~m}\end{array}$ & $2.3 \times 10^{2}$ & $1.4 \times 10^{1}$ & $1.1 \times 10^{-1}$ & $\begin{array}{c}126 \mathrm{Sn} / 126 \mathrm{mSb} / \\
126 \mathrm{Sb}\end{array}$ \\
\hline Antimony & -- & $\left(2.1 \times 10^{2}\right)$ & $\left(5.6 \times 10^{4}\right)$ & $\left(1.5 \times 10^{2}\right)$ & \\
\hline-125 & $2.8 \mathrm{y} / 58 \mathrm{~d}$ & $4.4 \times 10^{1}$ & $5.6 \times 10^{4}$ & $1.5 \times 10^{2}$ & $125 \mathrm{Sb} / 125 \mathrm{mTe}$ \\
\hline Tellurium & -- & $\left(2.7 \times 10^{3}\right)$ & $\left(9.3 \times 10^{1}\right)$ & $(6.3 \times 10.2)$ & \\
\hline$-127 m$ & $109 d / 9.5 h$ & $9.9 \times 10^{-3}$ & $9.3 \times 10^{1}$ & $6.3 \times 10^{-2}$ & $127 \mathrm{mTe} / 127 \mathrm{Te}$ \\
\hline$-129 m$ & $33 \mathrm{~d} / 70 \mathrm{~m}$ & $1.1 \times 10^{-9}$ & $3.5 \times 10-5$ & $5.0 \times 10-8$ & $129 \mathrm{~m} \mathrm{Te} / 129 \mathrm{Te}$ \\
\hline lodine & -- & $\left(1.5 \times 10^{3}\right)$ & $\left(1.9 \times 10^{-1}\right)$ & $\left(8.9 \times 10^{-5}\right)$ & \\
\hline-127 & Stable & $4.1 \times 10^{2}$ & - & -- & \\
\hline-129 & $1.6 \times 10^{7} \mathrm{yr}$ & $1.1 \times 10^{3}$ & $\left(1.9 \times 10^{-1}\right)$ & $8.9 \times 10^{-5}$ & \\
\hline Xenon & Stable & $\left(1.9 \times 10^{4}\right)$ & -- & -- & \\
\hline Cesium & -- & $\left(1.6 \times 10^{4}\right)$ & $(9.3 \times 105)$ & $\left(3.3 \times 10^{3}\right)$ & \\
\hline-133 & Stable & $5.1 \times 10^{3}$ & - & -- & \\
\hline-134 & $2.1 \mathrm{yr}$ & $1.1 \times 10^{2}$ & $1.4 \times 10^{5}$ & $1.4 \times 10^{3}$ & \\
\hline-135 & $3 \times 10^{6} y r$ & $6.0 \times 10^{3}$ & 6.9 & $2.3 \times 10^{-3}$ & \\
\hline-137 & $30 y / 2.5 \mathrm{~m}$ & $4.7 \times 10^{3}$ & $7.9 \times 10^{5}$ & $1.9 \times 10^{3}$ & $137 \mathrm{Cs} / 137 \mathrm{mBa}$ \\
\hline Barium & Stable & $\left(6.6 \times 10^{3}\right)$ & - & -- & \\
\hline Lanthanum & Stable & $\left(5.0 \times 10^{3}\right)$ & -- & - & \\
\hline Cerium & -- & $\left(9.0 \times 10^{3}\right)$ & $\left(3.0 \times 10^{5}\right)$ & $\left(1.2 \times 10^{3}\right)$ & \\
\hline-144 & $\begin{array}{c}284 d / 17 m / \\
7 m\end{array}$ & $4.8 \times 10^{1}$ & $3.0 \times 105$ & $1.2 \times 10^{3}$ & $\begin{array}{c}{ }^{144} \mathrm{Ce} / 144 \mathrm{mPr} / \\
144 \mathrm{Pr}\end{array}$ \\
\hline
\end{tabular}


WHC-EP-0268

Table 1-2. Major Constituents of Liquid-Metal Reactor Spent Oriver Fuel. (sheet 4 of 5 )

\begin{tabular}{|c|c|c|c|c|c|}
\hline $\begin{array}{l}\text { Element } \\
\text { isotope }\end{array}$ & Half-life & $\mathrm{g} / \mathrm{MTHM}$ & $\begin{array}{l}\text { Radioactivity } \\
\text { (Ci/MTHM)b }\end{array}$ & $\begin{array}{l}\text { Watts/ } \\
\text { MTHMb }\end{array}$ & Comments \\
\hline Praesodymium & Stable & $\left(4.6 \times 10^{3}\right)$ & -- & - & \\
\hline Neodymium & Stable & $\left(1.5 \times 10^{4}\right)$ & -- & -- & \\
\hline Promethium & -- & $\left(3.4 \times 10^{2}\right)$ & $(3.2 \times 105)$ & $\left(1.1 \times 10^{2}\right)$ & \\
\hline-147 & $2.6 y r$ & $3.4 \times 10^{2}$ & $3.2 \times 10^{5}$ & $1.1 \times 10^{2}$ & \\
\hline Samarium & -- & $\left(4.7 \times 10^{3}\right)$ & $\left(1.5 \times 10^{4}\right)$ & (1.8) & \\
\hline-151 & $90 \mathrm{yr}$ & $5.7 \times 10^{2}$ & $1.5 \times 10^{4}$ & 1.8 & \\
\hline Europium & -- & $\left(5.1 \times 10^{2}\right)$ & $\left(5.9 \times 10^{4}\right)$ & $\left(2.1 \times 10^{2}\right)$ & \\
\hline-152 & $13.4 \mathrm{yr}$ & 2.2 & $3.8 \times 10^{2}$ & 2.9 & \\
\hline-154 & $8.5 y r$ & $7.4 \times 10^{1}$ & $2.0 \times 10^{4}$ & $1.8 \times 10^{2}$ & \\
\hline-155 & $4.7 \mathrm{yr}$ & $8.4 \times 10^{1}$ & $3.9 \times 10^{4}$ & $2.9 \times 10^{1}$ & \\
\hline Gadolinium & -- & $\left(5.3 \times 10^{2}\right)$ & $\left(3.9 \times 10^{1}\right)$ & $\left(3.3 \times 10^{-2}\right)$ & \\
\hline-153 & $242 d$ & $1.1 \times 10^{-2}$ & $3.9 \times 10^{1}$ & $3.3 \times 10^{-2}$ & \\
\hline Terbium & Stable & $\left(3.6 \times 10^{1}\right)$ & -- & -- & \\
\hline Dysprosium & Stable & $\left(3.0 \times 10^{1}\right)$ & -- & -- & \\
\hline Total FPe & -- & $1.5 \times 105$ & $2.7 \times 10^{6}$ & $9.3 \times 10^{3}$ & \\
\hline Carbon-14 & $5.7 \times 10^{3} y r$ & $8.5 \times 10^{-1}$ & 3.8 & $1.1 \times 10^{-3}$ & \\
\hline Oxygen & Stable & $(1.3 \times 105)$ & - & -- & \\
\hline Silicon & Stable & $\left(7.0 \times 10^{2}\right)$ & -- & -- & \\
\hline Vanadium & Stable & $\left(8.6 \times 10^{4}\right)$ & -- & -- & \\
\hline Chromium & Stable & $\left(6.3 \times 10^{4}\right)$ & -- & -- & \\
\hline Manganese & -- & $\left(1.1 \times 10^{3}\right)$ & $\left(2.2 \times 10^{3}\right)$ & $\left(1.1 \times 10^{1}\right)$ & \\
\hline-54 & $312 d$ & $2.8 \times 10^{-1}$ & $2.2 \times 10^{3}$ & $1.1 \times 10^{1}$ & \\
\hline Iron & -- & $\left(4.7 \times 10^{4}\right)$ & $\left(1.2 \times 10^{3}\right)$ & $(3.9 \times 10-2)$ & \\
\hline-55 & $2.7 y r$ & $5.0 \times 10^{-1}$ & $1.2 \times 10^{3}$ & $3.9 \times 10^{-2}$ & \\
\hline-59 & $45 d$ & $2.0 \times 10^{-10}$ & $1.0 \times 10^{-5}$ & $9.7 \times 10.8$ & \\
\hline Cobalt-60 & $5.3 \mathrm{yr}$ & $\ldots$ & $9.8 \times 10^{1}$ & 1.5 & \\
\hline Nickel & - & $\left(2.9 \times 10^{3}\right)$ & $\left(2.5 \times 10^{1}\right)$ & $1.0 \times 10^{-2}$ & \\
\hline-59 & $7.6 \times 10^{4} \mathrm{yr}$ & 2.3 & $1.8 \times 10^{-1}$ & $7.1 \times 10^{-6}$ & \\
\hline-63 & $100 \mathrm{yr}$ & $4.4 \times 10^{-1}$ & $2.5 \times 10^{1}$ & $1.0 \times 10^{-2}$ & \\
\hline
\end{tabular}


Table 1-2. Major Constituents of Liquid-Metal Reactor Spent Oriver Fue1. (sheet 5 of 5 )

\begin{tabular}{|c|c|c|c|c|c|}
\hline $\begin{array}{l}\text { Element/ } \\
\text { isotope }\end{array}$ & Half-life & g/MTHM & $\begin{array}{l}\text { Radioactivity } \\
\text { (Ci/MTHM)b }\end{array}$ & $\begin{array}{l}\text { Watts/ } \\
\text { MTHMb }\end{array}$ & Comments \\
\hline Molybdenum & - & $\left(9.5 \times 10^{3}\right)$ & $\left(4.5 \times 10^{-1}\right)$ & $\left(4.2 \times 10^{-5}\right)$ & \\
\hline-93 & $3.5 \times 10^{3} \mathrm{yr}$ & $4.1 \times 10^{-1}$ & $4.5 \times 10^{-1}$ & $4.2 \times 10.5$ & \\
\hline Technetium-99 & $2.1 \times 105 \mathrm{yr}$ & 9.9 & $1.7 \times 10^{-1}$ & $8.4 \times 10^{-5}$ & \\
\hline Tantalum-182 & $115 d$ & $4.5 \times 10^{-5}$ & $2.8 \times 10^{-1}$ & $2.5 \times 10.3$ & \\
\hline Tungsten & -- & $(8.5 \times 103)$ & $(2.0)$ & $\left(2.0 \times 10^{-3}\right)$ & \\
\hline-181 & $121 d$ & $2.4 \times 10^{-4}$ & 1.4 & $4.0 \times 10^{-4}$ & \\
\hline-185 & $75 d$ & $6.7 \times 10.5$ & $6.3 \times 10^{-1}$ & $1.6 \times 10^{-3}$ & \\
\hline-188 & $69 d$ & $9.5 \times 10^{-7}$ & $9.6 \times 10^{-3}$ & $5.7 \times 10^{-6}$ & \\
\hline Rhenium & -- & $\left(6.2 \times 10^{2}\right)$ & $\left(9.7 \times 10^{-3}\right)$ & $(4.8 \times 10-5)$ & \\
\hline-188 & $17 \mathrm{~h} / 19 \mathrm{~m}$ & Negligible & $9.7 \times 10^{-3}$ & $4.8 \times 10^{-5}$ & $\begin{array}{c}\text { From } 188 W \\
\text { decay }\end{array}$ \\
\hline Osmium & Stable & $\left(6.4 \times 10^{1}\right)$ & -- & -- & \\
\hline $\begin{array}{l}\text { Total APf (no } \\
\mathrm{O}_{2} \text { ) }\end{array}$ & - & $2.2 \times 10^{5}$ & $3.5 \times 10^{3}$ & $1.3 \times 10^{1}$ & \\
\hline $\begin{array}{l}\text { Total } \\
\mathrm{HM}+\mathrm{FP}+\mathrm{APC}+ \\
\mathrm{O}_{2}\end{array}$ & & $1.3 \times 10^{6}$ & $4.0 \times 10^{6}$ & $1.3 \times 10^{4}$ & \\
\hline
\end{tabular}

aMWd/MTHM = Megawatt days per initial metric ton of heavy metals.

bRadioactivity and power for parent and daughter are given if daughter is relatively short half-life. For example, the total radioactivity and power for the decay of 90Sr to $90 Y$ to stable $90 \mathrm{Zr}$ is listed for ${ }^{905} \mathrm{r}$, and the $90 \mathrm{Y}$ contribution to yttrium is not included.

cQuantities in parentheses are totals for the element. Contribution from short-lived daughters produced by longer-lived parent is included in total for parent, except where noted.

$\mathrm{dHM}=$ Heavy metals

EFP $=$ Fission products

$\mathrm{f}_{\mathrm{AP}}=$ Activation products. 
The U.S. nuclear capacity is approaching 100 gigawatts electric (GWe). The projected LWR spent fuel inventory by the year 2030 is about 130,000 MTU. The current U.S. waste management baseline policy is to dispose of LWR spent fuel in a deep geologic repository, which would stay open for possible retrieval of the spent fuel for a limited period. Current policy also allows for spent fuel reprocessing, provided it is cost effective. However, there are no known $\mathrm{plans}$ for reprocessing any U.S. commercial spent fuel at this time. Soon after the December 1987 selection of the State of Nevada as the sole site for repository characterization, there were reports (Nuclear News 1988; Szymanski 1989) of concern that the site lacks the required geological stability. Also, there is concern that the present policy lacks backup positions in case the Nevada site cannot meet the containment criteria. Meanwhile, commercial spent fuel continues to accumulate, and utilities continue to cope with the situation by reracking to consolidate and reduce storage volume, by shipping spent fuel to other sites, by expanding spent fuel storage pools, and by implementing dry storage.

Table 1-3 is a capsule summary of worldwide spent fuel waste management policies. The United Kingdom, France, Germany, Japan, and the U.S.S.R. comprise the bulk of the non-U.S. nuclear capacity, and each of these countries $\mathrm{plans}$ to reprocess its commercial spent fuel. The high-level waste (HLW) from reprocessing, in all cases, will be permanently stored in some kind of geologic repository in the individual countries.

Concern over the future of the U.S. geologic repository program led Westinghouse Hanford Company (Westinghouse Hanford) and Pacific Northwest Laboratory (PNL) personnel to form a study group to determine the feasibility of actinide and fission product partitioning, transmutation ( $P-T)$, and disposal as a realistic waste management alternative to spent fuel disposal. A primary goal of the group was to identify technology required to minimize the amount of long- 7 ived radionuclides requiring disposal, and to manage the high-heat elements separately. These studies led to the evolution of the Clean Use of Reactor Energy (CURE) concept which in its simplest version involves partitioning of actinides, ${ }^{99} \mathrm{Tc}$, and radioiodine from the HLW (or offgas) and subsequent transmutation of these nuclides to short-lived or 
Table 1-3. World-Wide Spent Fuel Management Summary (January 1988).

\begin{tabular}{|c|c|c|c|}
\hline Country & $\underset{M W e}{\text { Capacjty }}\left(\begin{array}{l}\text { ty } \\
\star\end{array}\right.$ & $\begin{array}{l}\text { Percent of } \\
\text { total }\end{array}$ & Approach \\
\hline Argentina & 935 & 0.3 & Reprocess \\
\hline Belgium & 5,488 & 1.9 & Reprocess \\
\hline Brazil & 626 & 0.2 & Reprocess \\
\hline Canada & 12,064 & 4.1 & Not decided \\
\hline Finl and & 2,310 & 0.8 & Not decided \\
\hline France & 49,378 & 16.8 & Reprocess \\
\hline Germany & 18,885 & 6.4 & Reprocess \\
\hline India & 1,154 & 0.4 & Reprocess \\
\hline Italy & 1,273 & 0.4 & Reprocess \\
\hline Japan & 26,877 & 9.1 & Reprocess \\
\hline South Korea & 5,380 & 1.8 & Not decided \\
\hline Nether 1 ands & 507 & 0.2 & Reprocess \\
\hline Spain & 5,599 & 1.9 & Once through \\
\hline Sweden & 9,646 & 3.3 & Once through \\
\hline Switzerl and & 2,932 & 1.0 & Reprocess \\
\hline Taiwan & 4,918 & 1.7 & Not decided \\
\hline United Kingdom & 10,214 & 3.5 & Reprocess \\
\hline United States & 92,982 & 31.5 & Once through \\
\hline $\begin{array}{l}\text { Union of Soviet Socialist } \\
\text { Republics }\end{array}$ & 31,996 & 10.9 & Reprocess \\
\hline Other Soviet block countries & 9,763 & 3.3 & Not stated \\
\hline Pakistan & 125 & 0.04 & Not stated \\
\hline South Africa & 1,842 & 0.6 & Not stated \\
\hline Total & 294,864 & & \\
\hline
\end{tabular}

$(*)_{\text {MWe }}=$ Megawatt electric. 
stable nuclides. The CURE concept also includes partitioning of radiostrontium and radiocesium from the $H L W$ followed by near-surface interim storage. Material requiring geologic disposal would include only activated metal and long-lived radionuclides not easily subject to transmutation.

Previous studies have evaluated proposals to partition various combinations of the actinides and fission products in the HLW and to destroy these combinations by nuclear transmutation (see Appendix A). The $P-T$ process necessarily involved both reprocessing [for example, via the Plutonium-URanium EXtraction (PUREX) process] and follow-on chemical separations treatment of the resulting $H L W$. The general approach was to recover the valuable plutonium and uranium and to reduce the volume and toxicity of HLW that must be permanently stored in a repository. Three recent evaluations (Burkholder et a1. 1976; Logan et al. 1980; IAEA 1982) concluded that, assuming a repository is available for storage of the $H L W$, actinide P-T is not warranted from a cost-risk perspective. Major concerns of the current geologic repository are public acceptance, and the related issue of the very long time that the repository must maintain its integrity to retain the HLW. Use of CURE technology can remove virtually all of the actinides and the mobile, long-lived fission products. This activity could result in substantially reducing the interval that $H$ LW must be environmentally isolated to shorter times (hundreds of years). Such a P-T system would include three major functions:

1. Remove the majority of the near-term radioactivity and heat generation from the waste stream. For decay times between $10 \mathrm{yr}$ and $-200 \mathrm{yr},{ }^{90} \mathrm{Sr},{ }^{137} \mathrm{Cs}$, and the actinides are the major contributors to radioactivity and heat production.

2. Achieve sufficient separation of the long-lived actinides so that their residual activity concentration in the final waste form is below a total of $100 \mathrm{nCi} / \mathrm{g}$. Also separate ${ }^{99} \mathrm{Tc}$ and radioiodine from the waste for transmutation to stable Ru and Xe, respectively.

3. Reduce the long-term risk of groundwater transport of residual radionuclides in the waste packages to an acceptable degree. 
Tabulated data listed in Croff et al. (1980) lead to the conclusion that essentially all of the residual risk of disposal of HLW in a deep geologic repository located in salt strata was from ${ }^{99} \mathrm{Tc}$ and ${ }^{129} \mathrm{I}$. For example, for long-term risk due to water intrusion and leaking into such a salt repository, 92 percent of the residual risk was due to ${ }^{99} \mathrm{TC}$ and 8 percent to ${ }^{129}$ I. Table R.15 of DOE (1987) shows that ${ }^{99} \mathrm{TC}$ and ${ }^{129} \mathrm{I}$ are also the dominant nuclides which determine risks of near-surface disposal of certain Hanford Site wastes. The P-T of ${ }^{99} \mathrm{Tc},{ }^{129} \mathrm{I}$, and actinides, in addition to removal of ${ }^{90} \mathrm{Sr}$ and ${ }^{137} \mathrm{Cs}$, may produce a waste stream that would qualify for near-surface disposal. A comprehensive site-dependent performance assessment may be necessary to confirm the potential of the P-T approach. It is also necessary to ensure that the partitioning processes provide sufficient decontamination (Chapter 3.0) to produce a waste stream that meets established criteria for near-surface disposal.

The U.S. Department of Energy (DOE) is currently studying a candidate repository site at Yucca Mountain, Nevada for the geological disposal of spent fuel and other HLW. The repository horizon under study lies in the unsaturated zone 200 to $400 \mathrm{~m}$ above the water table. With the exception of ${ }^{14} \mathrm{C}$ (and possibly ${ }^{129} \mathrm{I}$ ), which may migrate in a vapor phase, the majority of long-lived radionuclides present in spent nuclear fuel will require dissolution or suspension in water to be transported from a failed waste package in the absence of a major geological event such as volcanism. Water is not expected to contact the waste package during the first several hundred years after disposal while the repository temperature is greater than the $95{ }^{\circ} \mathrm{C}$ boiling temperature of water at the repository elevation. The U.S. Nuclear Regulatory Commission (NRC) requires (NRC 1983) containment for a period of at least $300 \mathrm{yr}$. The release rates for individual radionuclei following the containment period shall not exceed one part in $100,000 / \mathrm{yr}$ of the inventory of each radionuclide calculated to be present at 1,000 $\mathrm{yr}$. The inventories of radionuclei present in PWR spent fuel at 1,000 yr are summarized in Table 1-4. Additional 10,000 yr cumulative release limits have been stated by the U.S. Environmental Protection Agency (EPA 1985). 
Table 1-4. Pressurized Water Reactor Spent Fuel Radionuclide Inventories at 1,000 Years.

\begin{tabular}{|c|c|c|c|c|}
\hline $\begin{array}{l}\text { Radionuclide(a) } \\
\text { activity }(\%)\end{array}$ & $\begin{array}{l}\text { Half-life } \\
\text { (year) }\end{array}$ & $\begin{array}{l}\mathrm{Ci} / 1,000 \\
\text { MTHM(b) }\end{array}$ & $\begin{array}{l}1,000 \text {-year } \\
\text { activity }\end{array}$ & $\begin{array}{l}\text { Cumulative } \\
\text { (\% of total) }\end{array}$ \\
\hline${ }^{241}{ }_{A m}$ & 432 & $8.95 \times 10^{5}$ & 51.33 & 51.33 \\
\hline $243 \mathrm{Am}$ & $7.37 \times 10^{3}$ & $3.11 \times 10^{4(c)}$ & 1.78 & 53.11 \\
\hline $240 \mathrm{pu}$ & $6.56 \times 10^{3}$ & $4.77 \times 10^{5}$ & 27.37 & 80.48 \\
\hline $239 p u$ & $2.41 \times 10^{4}$ & $3.05 \times 10^{5}$ & 17.45 & 97.96 \\
\hline $242 \mathrm{Pu}$ & $3.76 \times 10^{5}$ & $1.76 \times 10^{3}$ & 0.10 & 98.07 \\
\hline $238 \mathrm{pu}$ & 88 & 967 & 0.06 & 98.12 \\
\hline${ }^{99} \mathrm{Tc}$ & $2.13 \times 10^{5}$ & $1.30 \times 10^{4}$ & 0.75 & 98.87 \\
\hline $59_{\mathrm{Ni}}$ & $7.50 \times 10^{4}$ & $5.15 \times 10^{3}$ & 0.295 & \\
\hline${ }^{63} \mathrm{Ni}$ & 100 & 354 & 0.020 & \\
\hline $93 \mathrm{Zr}$ & $1.53 \times 10^{6}$ & $1.93 \times 10^{3}$ & 0.111 & \\
\hline $93 m_{N b}$ & 13.7 & $1.84 \times 10^{3}$ & 0.105 & \\
\hline $94 \mathrm{Nb}$ & $2.03 \times 10^{4}$ & $1.24 \times 10^{3}$ & 0.071 & \\
\hline${ }^{14} \mathrm{C}$ & $5.73 \times 10^{3}$ & $1.37 \times 10^{3}$ & $0.079(d)$ & \\
\hline $234 U$ & $2.45 \times 10^{5}$ & $1.98 \times 10^{3}$ & 0.114 & \\
\hline $238 U$ & $4.47 \times 10^{9}$ & 317 & 0.016 & \\
\hline $236 u$ & $2.34 \times 10^{7}$ & 271 & 0.018 & \\
\hline $237_{\mathrm{Np}}$ & $2.14 \times 10^{6}$ & $1.00 \times 10^{3}$ & 0.057 & \\
\hline $126 \mathrm{Sn}$ & $1.00 \times 10^{5}$ & 772 & 0.044 & \\
\hline${ }^{79} \mathrm{Se}$ & $6.50 \times 10^{4}$ & 405 & 0.023 & \\
\hline${ }^{135} \mathrm{Cs}$ & $3.00 \times 10^{6}$ & 345 & 0.020 & \\
\hline${ }^{15} 1_{\mathrm{Sm}}$ & 90 & 163 & 0.009 & \\
\hline $107 \mathrm{Pd}$ & $6.50 \times 10^{6}$ & 112 & 0.006 & \\
\hline${ }^{129} \mathrm{I}$ & $1.57 \times 10^{7}$ & 32 & 0.0018 & \\
\hline
\end{tabular}

NOTE: Based on ORIGEN2 data for 33,000 MWd/MTHM burnup pressurized water reactgr spent fuel, actinides plus fission products plus activation products. than 1 year omitted.

(b) MTHM = metric ton of heavy metal.

(c) Includes activity of ${ }^{239} \mathrm{~Np}$ daughter product. impurities.

(d) ${ }^{4} \mathrm{C}$ activity may vary considerably depending on as-fabricated nitrogen 
The dissolution behavior of spent fuel and potential mechanisms for radionuclide release during the repository post-containment period are being studied by the Yucca Mountain Project using geochemical models and laboratory tests with actual spent fuel specimens. Current results indicate that releases for all of the actinide nuclides including ${ }^{237} \mathrm{~Np}$ will be 1 imited by their very low solubilities to levels several orders of magnitude below the one part in 100,000/yr annual release 1 imit. The problem nuclei for the repository appear to be the soluble and volatile fission and activation products that account for less than 2 percent of the total activity of spent fuel at 1,000 $\mathrm{yr}$. Continuous release rates greater than one part in $100,000 / \mathrm{yr}$ have been measured for ${ }^{99} \mathrm{Tc},{ }^{14} \mathrm{C},{ }^{135} \mathrm{Cs}$ and ${ }^{129} \mathrm{I}$ in laboratory dissolution tests. In addition, the $\mathrm{UO}_{2}$ fuel matrix phase that contains most of the radionuclide inventory is thermodynamically unstable relative to degradation by oxidation in the repository air atmosphere, suggesting a potential for even more rapid dissolution of soluble nuclides if the fuel is eventually contacted by water. Meeting the NRC requirements for the soluble nuclei will likely require dependence on considerations such as low probability water contact scenarios and time-distributed container/cladding failure rates.

The studies cited by Croff et al. (1980) and by Wachter and Croff (1980) considered transmutation of the ${ }^{99} \mathrm{Tc}$ and ${ }^{129} \mathrm{I}$ in light-water reactors (LWR), with transmutation rates of 11 percent/yr and 3 percent/yr, respectively. In order to establish viability of transmutation of any species, an annual transmutation rate of at least 5 percent/yr is desirable. The LWRs do not meet this criterion for ${ }^{129} \mathrm{I}$. Additional difficulties cited by croff et al. (1980) for ${ }^{129}$ I transmutation are the corrosiveness of iodine on encapsulation materials and the fact that ${ }^{129}$ I transmutes to xenon (a gas) with the potential for pressurizing the target pins.

There have been many studies of actinide transmutation in neutron fields generated by a variety of devices, including fast reactors (FR), thermal reactors, high-power accelerators, and fusion reactors. A hard-spectrum FR is a good neutron source for fissioning most of the actinides recovered from HLW. The LWRs do not induce as much fission in most actinides, but these are transmuted by neutron capture to higher mass actinides. Production 
of higher mass actinides is desirable only to the extent that there exists a beneficial use for them. Recent accelerator development activities in support of the Strategic Defense Initiative program have made high-power accelerators a realistic source of hard spectrum neutrons.

${ }^{90} \mathrm{Sr}$ and ${ }^{137} \mathrm{Cs}$, each with a half-life of about $30 \mathrm{yr}$, constitute most of the intermediate term (10 to $200 \mathrm{yr}$ ) heat load and radioactivity of spent fuel. The thermal neutron transmutation cross-section for both of these isotopes is far too small to consider transmutation in a thermal reactor neutron spectrum. Both ${ }^{90} \mathrm{Sr}$ and ${ }^{137} \mathrm{Cs}$, however, have potential for beneficial use. Consequently, management of ${ }^{137} \mathrm{Cs}$ and ${ }^{90} \mathrm{Sr}$ may include beneficial use as well as monitored interim storage. High-power accelerators and high-flux reactors may be able to transmute ${ }^{90} \mathrm{Sr}$ and ${ }^{137} \mathrm{Cs}$, but this is likely a longrange potential.

Figure 1-2 shows qualitatively the benefits of incrementally removing elements from spent fuel as a function of decay time. The figure plots radiological ingestion toxicity versus time for four cases:

I. Spent fuel with no reprocessing

II. Reprocessing that removes 99 percent of the plutonium and all the uranium

III. Additional processing beyond Case II that removes all actinide elements

IV. Additional processing beyond Case III that removes all radiostrontium, radiocesium, ${ }^{99} \mathrm{Tc}$, and radioiodine.

Information from Figure 1-2 can be used, along with information relating to groundwater flow rate, radionuclide retardation, etc., for calculation of the total societal health risk of reprocessing with $P-T$ and associated waste management activities. Actinide removal also shows benefit in the long range (greater than several hundred years), as does removal of ${ }^{99} \mathrm{Tc}$ and ${ }^{129} \mathrm{I}$. Removal of ${ }^{90} \mathrm{Sr}$ and ${ }^{137} \mathrm{Cs}$ shows short-term (less than $500 \mathrm{yr}$ ) benefit, 
Figure 1-2. Relative Ingested Toxicity of CURE Concept Residual Waste.

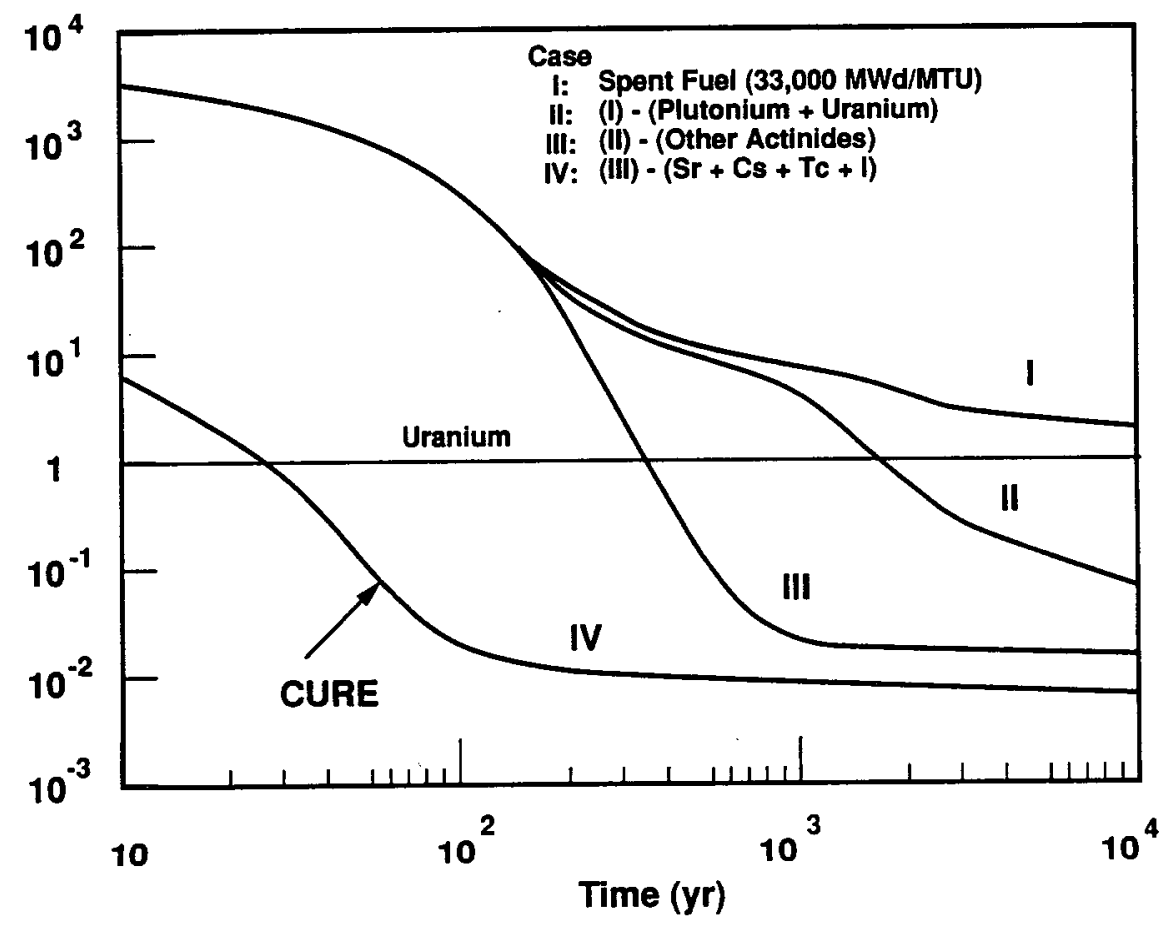

38908053.8 
subject to the caveats already noted concerning their disposition. In the short term, two other major factors must be considered:

1. Negative benefit resulting from reprocessing and transmutation activities

2. Positive benefit resulting from beneficial use of some isotopes and elements, e.g.,

- Use of plutonium for reactor fuel (electricity generation)

- Use of radioisotopes for commercial, research, and medical applications

- Use of stable elements for commercial applications.

Japanese researchers in their newly-announced OMEGA Program (AIJ 1988) for $P-T$ of HLW have also concentrated on removal of actinides, ${ }^{99} \mathrm{TC}$, radioiodine, radiostrontium, and radiocesium, as well as valuable stable fission products.

Finally, it is noted that Argonne National Laboratory personnel are developing technology for pyrochemical partitioning and subsequent transmutation of various actinide elements (Johnson 1986). This process generates chloride salt wastes produced as the result of proposed pyrochemical processing of spent integral fast reactor (IFR) $\mathrm{Zr}$-U-Pu metal alloy fuel. The partitioning of other key radioactive elements, e.g., ${ }^{99} \mathrm{Tc}$, radioiodine, radiocesium, radiostrontium, from salt and other wastes generated in proposed processing of IFR fuel are not being considered, however. The aqueous-based CURE system chemical processing technology described in Chapter 3.0 of this report, suitably modified and developed, also appears capable of partitioning actinides and other key radionuclides from IFR fuel pyrochemical processing wastes. 


\subsection{SCOPE OF THIS STUDY}

Major features of the CURE system are described in Chapter 2.0. Chapter 2.0 also 7 ists reasons why the CURE concept is timely and worthwhile. Chapters 3.0 and 4.0 describe the CURE concept P-T reference technology. Preliminary estimates of CURE concept costs and both short- and long-term risks are presented in Chapter 5.0 as well as a brief discussion of CURE concept transportation and institutional issues. Chapter 6.01 ists additional technology development and demonstration required to make the CURE concept an acceptable geologic repository disposal pretreatment alternative. The concluding Chapter 7.0 presents an abbreviated technology assessment plan (costs and schedules) keyed to demonstrate essential CURE concept technology. 
WHC-EP-0268

\subsection{CURE CONCEPT}

\subsection{DESCRIPTION OF CURE CONCEPT}

\subsubsection{Essential Features}

The CURE concept involves three primary functions:

- Chemical processing of spent LWR fuel to recover and recycle uranium and plutonium

- Partitioning of long-lived actinides and long-lived fission products ( ${ }^{99} \mathrm{Tc}$ and radioiodine), from either the HLW or certain offgases generated in the reprocessing of spent reactor fuels. Radiostrontium and radiocesium will also be partitioned from the HLW.

- Transmutation, in suitable nuclear reactors and accelerators, of the recovered and purified actinide elements, ${ }^{99} \mathrm{Tc}$, and ${ }^{129} \mathrm{I}$ to stable isotopes, short-lived radioactive products, or potentially valuable by-products (e.g., 238pu). Solidified and encapsulated radiostrontium and radiocesium could be stored in near-surface engineered facilities either before or after beneficial use until the decay heat is suitably low for final disposal.

A deployed CURE system can thus serve an important function:

- Enhancement to realization of a deep geologic repository for disposal of spent fuel and/or HLW by contributing toward public acceptance and ease of siting and licensing of such a repository (Figure 2-1). 


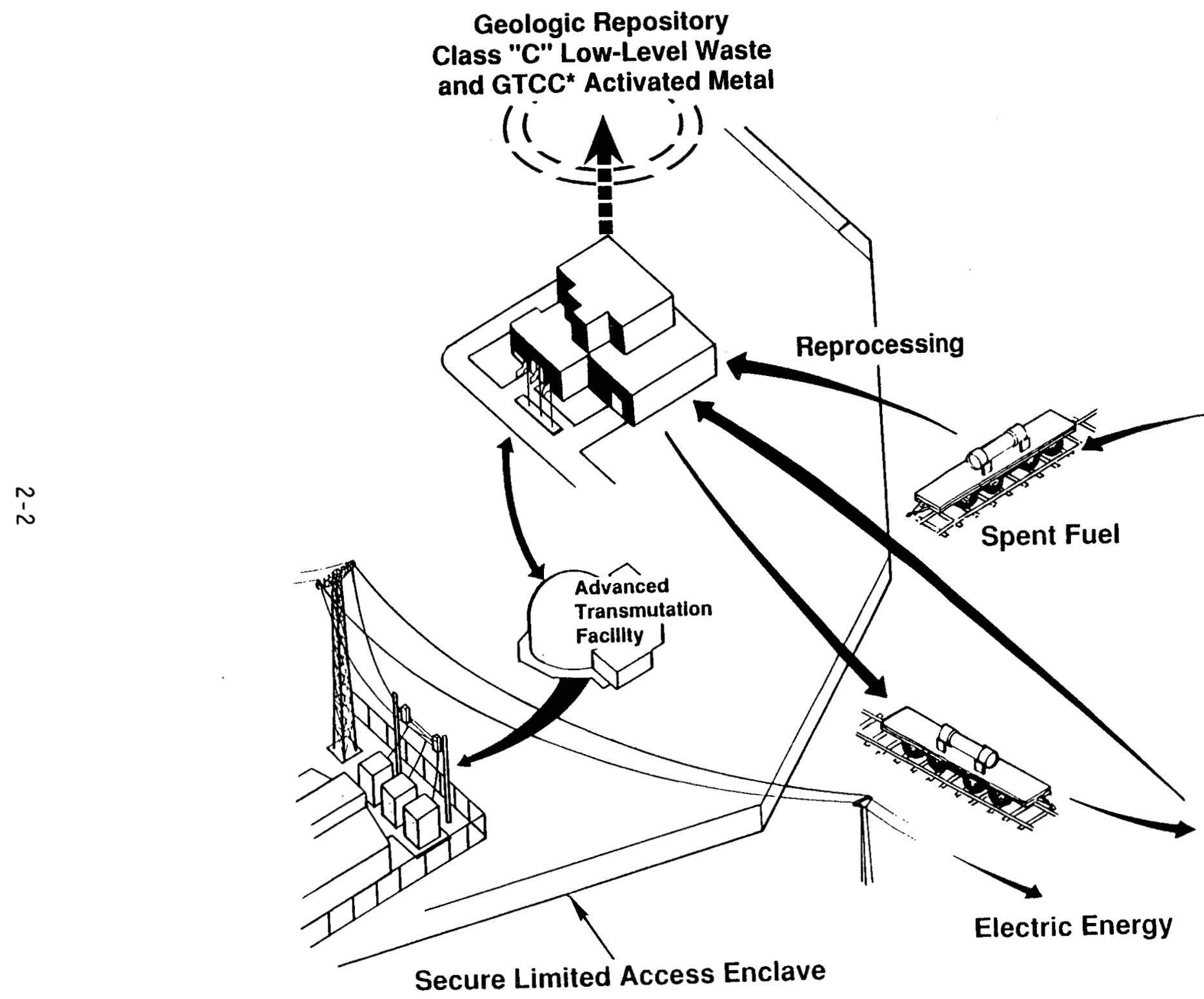

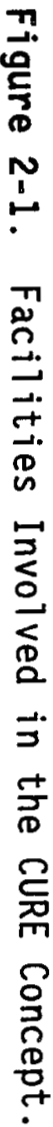

Beneficial

Radioisotopes

(Medical, Industrial)

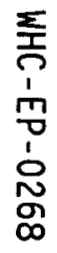

79002114.2

\footnotetext{
- GTCC = Greater-than-Class-C
} 
The CURE concept includes P-T of actinide elements, ${ }^{99} \mathrm{Tc}$, and radioiodine (Table 2-1). Certain other long-lived radionuclides (Table 2-2) will be converted to a stable form (e.g., glass) and, along with other reprocessing solid wastes, will be disposed of in a deep geologic repository. The CURE concept also involves partitioning of radiostrontium and radiocesium, followed by interim decay storage prior to geologic disposal.

As currently envisioned (Figure 2-1), all the various activities (e.g., chemical processing, target fabrication and irradiation, low-level waste (LLW) disposal, etc.) involved in the CURE concept could be located and performed in a few suitably controlled access areas. The only products of a CURE facility will be electric energy, low-level wastes, a small quantity of high-level waste, and, as appropriate, beneficial by-product radioisotopes.

The radionuclides listed in Table 2-1 are the key contributors to the radioactivity and long-term disposal risks for LWR and FR spent fuel. A few additional long-lived radionuclides (Table 2-2) may also need to be considered in performance assessments to confirm the expectation that partitioning of the key radionuclides 1 isted in Table 2-1 is sufficient to reduce the longterm risks of disposal of the residual waste to acceptable levels. Such performance assessments may dictate the need to remove one or more of the fission products listed in Table 2-2 from the TRansUranic EXtraction (TRUEX) process raffinate. Thus, as development of the CURE concept technology proceeds, it may be necessary to devise suitable separations procedures for some of the fission products enumerated in Table 2-2.

\subsubsection{Technologies}

To accomplish the overall CURE concept objective, five principal technologies--chemical processing, target fabrication, target irradiation, waste management/disposal, and transportation--must be successfully operated in a closely-coupled and integrated system. Each of these technologies is described briefly below and more fully in subsequent sections of this report. 
Table 2-1. Disposition of Key Radionuclides in the CURE Concept.

\begin{tabular}{|l|l|l|}
\hline \multicolumn{1}{|c|}{ Element } & \multicolumn{1}{c|}{ Baseline disposition } & \multicolumn{1}{c|}{ Disposition option(s) } \\
\hline $\mathrm{Ua}$ & Recover and store & Transmute to $\mathrm{Pu}$ \\
\hline $\mathrm{Pu}^{\mathrm{a}}$ & Recover, use for reactor fuel & \\
\hline $237 \mathrm{~Np}$ & Fission & Transmute to 238Pu \\
\hline Ama & Fission & Transmute to 238Pu and Cm \\
\hline $\mathrm{Cm}$ a & Fission & Transmute to 252Cf \\
\hline 99TC & Transmute to stable Ru & Immobilized form in repositoryb \\
\hline Radioiodine & Transmute to stable Xe & Immobilized form in repositoryc \\
\hline Radiostrontium & Geologic repository & $\begin{array}{l}\text { Interim storage followed by } \\
\text { repository disposal }\end{array}$ \\
\hline Radiocesium & Geologic repository & $\begin{array}{l}\text { Interim storage followed by } \\
\text { repository disposal }\end{array}$ \\
\hline
\end{tabular}

alncludes all isotopes listed in Table $1-1$.

bAssumes separated and purified $99 \mathrm{Tc}$ fraction can be converted to an alloy (or other form) which releases $99 \mathrm{Tc}$ at an acceptably low rate under repository conditions.

cAssumes separated and purified 1291 fraction can be converted to a compound which releases 1291 at an acceptably low rate under repository conditions. 


\begin{tabular}{|c|c|c|c|c|c|c|}
\hline \multirow{2}{*}{$\begin{array}{l}\text { Radio- } \\
\text { nuclide }\end{array}$} & \multirow{2}{*}{ Half-life (yr) } & \multicolumn{2}{|c|}{ Light-water reactora spent fuel } & \multicolumn{2}{|c|}{ Fast reactor spent fuelb } & \multirow{2}{*}{$\begin{array}{c}\text { Decay modes, radiation, } \\
\text { energiesc }\end{array}$} \\
\hline & & $\mathrm{g} / \mathrm{MTU}$ & $\mathrm{Ci} / \mathrm{MTU}$ & g/MTHM & Ci/MTHM & \\
\hline \multicolumn{7}{|c|}{ Fission products } \\
\hline $795 e$ & $6.5 \times 10^{4}$ & 5.8 & 0.4 & 2.3 & 2.6 & $\beta-(0.16)$ \\
\hline $93 \mathrm{Zr}$ & $1 \times 10^{6}$ & 705 & 1.77 & $2.2 \times 10^{3}$ & 5.6 & $\beta-(0.063,0.034)$ \\
\hline $107 \mathrm{Pd}$ & $7 \times 10^{6}$ & 223 & 0.115 & $2.0 \times 10^{3}$ & 1.0 & $\beta-(0.035)$ \\
\hline $126 \mathrm{Sn}$ & $2 \times 10^{5}$ & 27.6 & 0.782 & 230 & 6.5 & $\beta ; \gamma=0.06,0.067,0.092$ \\
\hline $151 \mathrm{sm}$ & 90 & 11.4 & 299 & 570 & $1.5 \times 10^{4}$ & $\beta-(0.076)$ \\
\hline \multicolumn{7}{|c|}{ Activation productsd } \\
\hline${ }^{14 C} \mathrm{C}$ & $5.7 \times 10^{3}$ & 0.13 & 0.56 & 0.85 & 3.8 & $\beta-(0.155)$ \\
\hline${ }^{59} \mathrm{Ni}$ & $8 \times 10^{4}$ & 6.3 & 5.1 & 2.3 & 1.8 & EC \\
\hline${ }^{63} \mathrm{Ni}$ & 92 & 11.4 & 645 & 0.44 & 25 & $\beta-(0.67)$ \\
\hline 93Mo & $2.5 \times 10^{3}$ & 0.020 & 0.022 & 0.41 & 0.45 & $\mathrm{EC}$ \\
\hline $94 \mathrm{Nb}$ & $2 \times 10^{4}$ & 2.6 & 0.49 & & & $\beta-(0.50) ; \gamma=0.7,0.87$ \\
\hline
\end{tabular}

a 10 yr old spent fuel.

b3 yr old spent. fuel.

$\mathrm{CEC}=$ Electron capture.

dProduced in cladding and other fuel assembly hardware.

MTU = Metric ton uranium.

MTHM = Metric ton heavy metal. 
Chemical processing of irradiated LWR and FR fuels will be accomplished by means of the classic aqueous PUREX process; state-of-the-art PUREX process technology will be employed throughout, including modern shear-leach dissolution procedures and extensive use of chemical reagents (e.g., plutonium reductants, solvent wash solutions, etc.) which minimize the salt content of the HLW. Radioiodine will be recovered from the PUREX process offgas by special sorption methods. The $\mathrm{Am}, \mathrm{Cm}$, and other actinides ( $U, \mathrm{~Np}$, and $\mathrm{PU}$ ), as well as $99 \mathrm{Tc}$ in the acidic PUREX HLW, will be effectively removed by the newly-developed, highly selective and efficient TRUEX process (Schulz and Horwitz 1988). The TRUEX process will be operated to produce three products: Am-Cm-lanthanide fraction; Pu-Np fraction; and U-TC fraction. * Ancillary separations processes (see Chapter 3 ) will be used to prepare purified actinide and technetium products. Precipitation and solvent extraction processes will then be employed to remove radiocesium and radiostrontium, respectively, from the TRUEX process aqueous raffinate.

Appropriate portions of the aqueous methods used to reprocess LWR and FR fuels will also be used to process irradiated target assemblies. In some cases, e.g., irradiated ${ }^{99} \mathrm{Tc}$ and radioiodine targets, pyrochemical procedures may be developed and applied to recover remaining technetium and iodine.

Fabrication and irradiation of purified actinide element targets will involve conversion of purified nitrate solutions to solid oxides, preparation of oxide pellets, and loading of oxide pellets into suitable fuel rod assemblies. Similar operations may be performed with purified ${ }^{99} \mathrm{Tc}$ and radioiodine target materials; the optimal technetium and iodine compounds for preparation of targets remain to be determined.

\footnotetext{
*If desirable or necessary, other product fractions can be produced; for example, $\mathrm{Np}-\mathrm{Pu}-\mathrm{Am}-\mathrm{Cm}-\mathrm{lanthanide}$ fraction.
} 
Waste management/disposal will involve collection, treatment, and disposal of all liquid and solid wastes generated in CURE chemical processing and target fabrication activities. As indicated previously, offgases will be treated to remove radioiodine and, to the extent necessary, $\mathrm{NO}_{\mathrm{X}}$, and any other components needed to meet air quality standards.

The principal liquid waste to be produced in CURE chemical processing operations will be that resulting from removal of actinide elements, ${ }^{99} \mathrm{Tc}$, radiocesium, and radiostrontium. Other liquid wastes, e.g., solvent wash wastes, process condensates, etc., will be treated so that they can be satisfactorily and properly combined with the LLW from the mainline PUREXTRUEX processes. The resulting LLW will be incorporated into a solid-matrix for disposal in a geologic repository, or possibly in engineered near-surface facilities. If desirable for any reason (e.g., destruction of organic materials, decreased water solubility of residual radionuclides, etc.), the LLW can by calcined prior to incorporation into the solid matrix.

Various solid wastes [e.g., high-efficiency particulate absolute (HEPA) filters, dissolution residues, failed equipment, combustible material, etc.] generated during CURE concept chemical processing and target fabrication activities will be adequately treated and decontaminated (i.e., leached, reacted with $\mathrm{H}_{2} \mathrm{SO}_{4}-\mathrm{HNO}_{3}$ solutions, etc.) to permit their disposal as LLW. It is anticipated that fuel assembly hardware and cladding hulls will be consolidated and disposed of as a Greater-Than-Class-C (GTCC) waste (NRC 1982 and 1989).* The FR fuel assembly hardware is currently stainless steel (316, D-9, or HT-9) and is assumed not to be dissolved in the head-end treatment processes. The LWR fuel assembly hardware is currently Zircaloy and is assumed not to be dissolved in the head-end and treatment processes.

The waste management/disposal activity of the CURE concept will also include packaging and safe storage of recovered radiokrypton, radiostrontium, and radiocesium. It is anticipated that purified and concentrated 6.3 .4 .

*See discussion in Chapter 6 , particularly, Technical Issues 6.3 .1 and 
radiostrontium and radiocesium fractions will be converted to appropriate solid forms, which, after double encapsulation, can be used as radiation sources and/or stored for approximately 300 to $500 \mathrm{yr}$ (>10 half-lives). (Future technology developments may allow selective isotopic separation of ${ }^{135} \mathrm{Cs},{ }^{137} \mathrm{Cs}$, and ${ }^{90} \mathrm{Sr}$ and subsequent transmutation.)

Transportation will involve shipments of unprocessed spent fuel to the CURE facility, of beneficial radioisotopes from the CURE facility, and immobilized HLW free of actinides to a geologic repository. Appropriate federal regulations will be met. Within the CURE facility, transportation streams will include reprocessed fuel, target material and assemblies, LLW, and beneficial radioisotopes.

\subsection{IMPORTANCE OF CURE}

There are a number of reasons why serious consideration and further development of the CURE concept are particularly timely and worthwhile, namely:

- The CURE concept provides a positive method for destroying, rather than storing, long-lived radionuclides.

- The CURE concept system may enhance public acceptability of licensing of a geologic repository.

- The CURE concept allows for recovery and utilization of valuable uranium and plutonium in spent LWR fuel, as opposed to disposal of these resources in a geologic repository.

- The CURE concept makes various radioisotopes and stable elements available for beneficial use. 
In the United States, the demand for electrical energy is expected to continue to increase because it closely correlates with the gross national product (Bloomster and Merrill 1987). The expected growth in demand for electrical power, accompanied by a decreasing margin in the excess electrical generating capacity, combine to support the need for significant increases in near-term electrical generating facilities. While predictions of U.S. energy needs are notably changeable, information in DOE publications (DOE/EIA-0173 1981) indicates that fossil fuel and nuclear fission energy are the only two near-term (next $-30 \mathrm{yr}$ ) options available that can significantly increase ( $>1 \% / y r)$ electrical power generation. Given the current regulatory climate and we11-known public concerns about the safety of nuclear reactors, and the long-term risks associated with geologic disposal of HLW and spent fuel, it might be expected that near-term utility commitments to increase electrical energy generation capacity will be mostly fossil fuel burning facilities.

Coal-fired electrical generating facilities have come under increasingly close scrutiny in recent years because of their contribution to acid rain and "greenhouse" concerns. If these issues become important enough to influence overall U.S. energy strategy, an emphasis on continued commercial nuclear power generation in the United States may become necessary. The CURE concept could make a significant contribution to public acceptance of nuclear power by eliminating concerns that deep geologic disposal of commercial spent fuel (or HLW) defers nuclear waste disposal risks to future generations while the present generation receives the benefits of the nuclear power. The CURE concept may also help to reduce the 'not-in-my-backyard' (NIMBY) syndrome that exists in the United States today.

By providing a supply of fissionable material (uranium and plutonium) for use in future commercial LWRs or FRs, the CURE concept can make a further contribution to a revitalized nuclear power industry. In contrast, geologic disposal of the uranium and plutonium in the currently stored inventory of LWR fuel will negate these valuable resources. 
In addition to recovery of uranium and plutonium, the CURE concept will also allow for recovery of valuable by-product radionuclides. The radionuclide ${ }^{137} \mathrm{Cs}$ is currently of interest as a source of gamma radiation to sterilize medical supplies, etc. Furthermore, the CURE concept will allow recovery of radionuclides that can be used as targets for production of such useful isotopes as ${ }^{238} \mathrm{pu}$ and ${ }^{252} \mathrm{Cf}$. 


\subsection{PARTITIONING}

\subsection{CHEMICAL PROCESSING}

\subsubsection{Introduction}

The CURE concept comprises three major activities: (1) reprocessing of spent fuel to recover uranium and plutonium, (2) chemical partitioning of key radionuclides (Table 2-1) from $H L W$, and (3) transmutation of certain partitioned long-lived radionuclides into stable or short-lived products. Partitioning involves chemical separation of selected radionuclides from the $H L W$ and offgas produced in reprocessing of spent reactor fuel and irradiated nuclide target assemblies. The long-term goal of the integrated partitioning activities (Figure $3-1$ ) is to minimize the volume of waste requiring geologic disposal. Gaseous effluents are treated to meet permit requirements for release to the environment.

Tables 3-1 and 3-2 1ist the range of decontamination factors (DF) which CURE system partitioning processes must achieve with typical LWR and FR fuel to obtain different classes of radioactive waste, all suitable for land disposal. In each case, the required decontamination depends not only on the class of radioactive waste, but also on the volume of the waste. A range of final waste volumes from $0.1 \mathrm{~m}^{3} /$ MTU to $5 \mathrm{~m}^{3} /$ MTU is used to calculate the factors 1isted in Tables 3-1 and 3-2; this range is believed to encompass process waste volumes which would be produced from a fully implemented CURE system.

For each of the four different waste volumes, OFs required to produce waste meeting the radionuclide specifications shown in 10 CFR 61 for $C$ lasses $A, B$, and $C$ wastes are listed. The very low radionuclide 
Figure 3-1. The CURE Concept: Integrated Chemical Partitioning Processes.

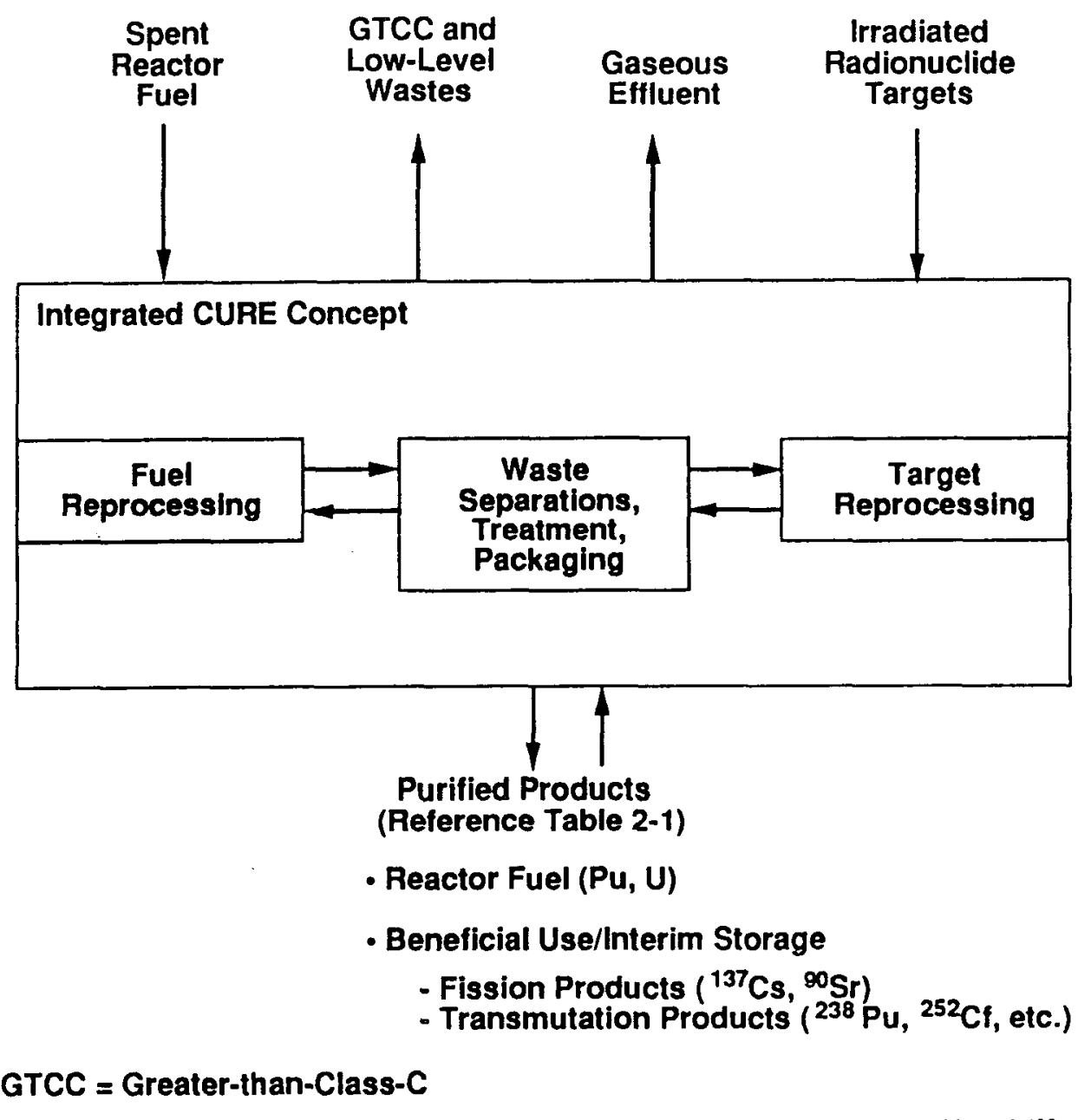

$38809235.1 M$ 


\begin{tabular}{|c|c|c|c|c|c|c|c|c|c|c|c|c|}
\hline \multirow{4}{*}{$\begin{array}{l}\text { Element/ } \\
\text { nuclide }\end{array}$} & \multicolumn{12}{|c|}{ Required decontamination factor to produce } \\
\hline & \multicolumn{4}{|c|}{ Class C wastea } & \multicolumn{4}{|c|}{ Class B waste ${ }^{a}$} & \multicolumn{4}{|c|}{ Class A wastea } \\
\hline & \multicolumn{4}{|c|}{ Waste volume, $\mathrm{m}^{3} / \mathrm{MTU}$} & \multicolumn{4}{|c|}{ Waste volume, $\mathrm{m}^{3} / \mathrm{MTU}$} & \multicolumn{4}{|c|}{ Waste volume, $\mathrm{m}^{3} / \mathrm{MTU}$} \\
\hline & 0.1 & 0.5 & 3 & 5 & 0.1 & 0.5 & 3 & 5 & 0.1 & 0.5 & 3 & 5 \\
\hline $\begin{array}{l}\text { Total } \\
\text { TRUb }\end{array}$ & $3.4 \times 10^{5}$ & $6.8 \times 10^{4}$ & $1.1 \times 10^{4}$ & $6.8 \times 10^{3}$ & $3.4 \times 106$ & $6.8 \times 105$ & $1.1 \times 105$ & $6.8 \times 10^{4}$ & $3.4 \times 10^{6}$ & $6.8 \times 10^{5}$ & $1.1 \times 105$ & $6.8 \times 10^{4}$ \\
\hline $90 \mathrm{Sr}$ & 80. & 16. & 3. & 2. & 3,700 & 750. & 120. & 75. & $1.4 \times 10^{7}$ & $2.8 \times 10^{6}$ & $4.7 \times 10^{5}$ & $2.8 \times 10^{5}$ \\
\hline 99Tc & 43. & 9. & 1. & 1. & 430. & 86. & 14. & 9. & 430. & 86. & 14. & 9. \\
\hline 1291 & 4. & 1. & 1. & 1. & 39. & 8. & 1. & 1. & 39. & 8. & 1. & 1. \\
\hline${ }^{137} \mathrm{Cs}$ & 180 & 35. & 6. & 4. & $1.9 \times 10^{4}$ & 3,700 & 620. & 370. & $8.3 \times 10^{5}$ & $1.7 \times 10^{5}$ & $2.8 \times 10^{4}$ & $1.7 \times 10^{4}$ \\
\hline
\end{tabular}

'Specifications for these waste classes are:

$\begin{array}{lcccc}\text { Class C } & \text { Class B } & & \text { Class A } & \begin{array}{c}\text { Savannah River Saltstone } \\ \text { (Incidental Waste) }\end{array} \\ \text { Total TRU, nCi/g } & 100 & 10 & 10 & 2 \\ 905 \mathrm{r}, \mathrm{Ci} / \mathrm{m}^{3} & 7,000 & 150 & 0.04 & 0.0009 \\ 99 \mathrm{TC}, \mathrm{Ci} / \mathrm{m}^{3} & 3 & 0.3 & 0.3 & 0.07 \\ 1291, \mathrm{Ci} / \mathrm{m}^{3} & 0.08 & 0.008 & 0.008 & 0.00004 \\ 137 \mathrm{Cs}, \mathrm{Ci} / \mathrm{m}^{3} & 4,600 & 44 & 1 & 0.025\end{array}$

${ }^{b}$ Calculated on basis of following assumptions:

- High-level waste from PUREX process contains all neptunium, americium, and curium, including ${ }^{244} \mathrm{Cm}(\mathrm{t}, 1 / 2=18.1 \mathrm{yr})$, and

$0.25 \%$ of the plutonium, including $241 \mathrm{Pu}\left(\mathrm{t} \mathrm{t}^{1 / 2}=14.4 \mathrm{yr}\right)$.

- Solid waste form has a density of $1.0 \mathrm{~g} / \mathrm{cm}^{3}$

- 10 yr decay of spent fuel prior to processing; 33,000 MWd/MTU burnup.

MTU = metric ton uranium

TRU = transuranic. 


\begin{tabular}{|c|c|c|c|c|c|c|c|c|c|c|c|c|}
\hline \multirow{4}{*}{$\begin{array}{l}\text { Element } \\
\text { nuclide }\end{array}$} & \multicolumn{12}{|c|}{ Required decontamination factor to produce } \\
\hline & \multicolumn{4}{|c|}{ Class C wastea } & \multicolumn{4}{|c|}{ Class B wastea } & \multicolumn{4}{|c|}{ Class A wastea } \\
\hline & \multicolumn{4}{|c|}{ Waste volume, $\mathrm{m}^{3 / \mathrm{MTHM}}$} & \multicolumn{4}{|c|}{ Waste volume, m3/MTHM } & \multicolumn{4}{|c|}{ Waste volume, $\mathrm{m}^{3} / \mathrm{MTHM}$} \\
\hline & 0.1 & 0.5 & 3 & 5 & 0.1 & 0.5 & 3 & 5 & 0.1 & 0.5 & 3 & 5 \\
\hline $\begin{array}{l}\text { Total } \\
\text { TRUD }\end{array}$ & $4.6 \times 10^{6}$ & $9.3 \times 10^{5}$ & $1.5 \times 105$ & $9.3 \times 10^{4}$ & $4.6 \times 10^{7}$ & $9.3 \times 10^{6}$ & $1.5 \times 10^{6}$ & $9.3 \times 105$ & $4.6 \times 10^{7}$ & $9.3 \times 106$ & $1.5 \times 10^{6}$ & $9.3 \times 10^{2}$ \\
\hline $905 r$ & 410. & 83. & 14. & 8. & $1.9 \times 10^{4}$ & 3,900 & 640. & 390. & $7.2 \times 10^{7}$ & $1.4 \times 10^{7}$ & $2.4 \times 10^{6}$ & $1.4 \times 106$ \\
\hline 99TC & 190. & 39. & 6. & 4. & 1.900 & 390. & 64. & 39. & 1,900 & 390. & 64. & 39. \\
\hline 1291 & 24. & 5. & 1. & 1. & 240. & 48. & 8. & 5. & 240. & 48. & 8. & 5. \\
\hline $137 \mathrm{Cs}$ & 1,700 & 340. & 58 & 34. & $1.8 \times 10^{5}$ & $3.6 \times 10^{6}$ & 6,000 & 3,600 & $7.8 \times 10^{6}$ & $1.6 \times 10^{6}$ & $2.6 \times 10^{5}$ & $1.6 \times 10^{5}$ \\
\hline
\end{tabular}

-Specifications for these waste classes are listed in Table 3.1.

Calculation basis is listed in Table 3-1, except for burnup and decay assumptions.

Table 1.2 lists the fast reactor fuel assumptions

MTHM = metric ton heavy meta 
concentrations in Incidental Waste correspond to those projected to be present in DOE Savannah River Site "saltstone".* Discussion of the capabilities of present-day, as well as projected future partitioning technology to realize the various DFs stated in Tables $3-1$ and $3-2$ is deferred until Section 3.1.5.

Except for TRU elements, DFs listed in Tables 3-1 and 3-2 are defined and calculated by means of Equation 1:

$\frac{C i \text { of nuclide (in spent fuel) }}{M T U \text { (or MTHM) in spent fuel }} / \frac{C i \text { of nuclide (in solid waste) }}{\mathrm{m}^{3} \text { of solid waste }}$ $\mathrm{DF}=$

$$
\frac{\mathrm{m}^{3} \text { of solid waste }}{\text { MTU (or MTHM) in spent fuel }}
$$

Data for the first term in the numerator of Equation 1 were taken from Tables 1-1 and 1-2 while data for the second term in the numerator ( $\mathrm{Class} C$, $B$, and $A$ waste criteria) are listed in footnote (a) to Table 3-1. The DFs were calculated for four values of the specific volume of solid waste, namely $0.1,0.5,3.0$, and $5.0 \mathrm{~m}^{3} /$ MTU. Equation 1 shows that $\mathrm{DFs}$ are dimensionless quantities. A DF of 1 means that no removal of a particular nuclide is required in the CURE system partitioning process.

Equation 1, suitably modified, was also used to calculate required DFs for the total TRU elements. The DFs for TRU elements listed in Tables 3-1 and 3-2 are conservative in that the sizeable contribution of ${ }^{244} \mathrm{Cm}$ $\left(t_{1 / 2}=18.1 \mathrm{yr}\right)$ to the TRU concentration of the HLW is included; the current NRC definition of TRU elements, for waste disposal purposes, excludes actinide elements with half lives less than 20 years. Conversely, however, only 0.25 percent of the ${ }^{241} \mathrm{Pu}$ in the spent fuel is assumed to be in the HLW; ${ }^{241} \mathrm{Am}$ from beta decay of ${ }^{241} \mathrm{Pu}\left(\mathrm{t}_{1 / 2}=14.4 \mathrm{yr}\right)$ may eventually have to be partitioned and transmuted when the stored PUREX process plutonium product is placed into service.

*Saltstone is the name given by Savannah River Site personnel to the cementitious product formed by combining decontaminated alkaline defense waste solutions containing large amounts of $\mathrm{NaNO}_{3}$ and other sodium salts with portland, or other type, cement (Wilhite et al. 1987). 
Chemical processing entails three principal interrelated steps (see Figures 3-1 and 3-2):

\section{Fuel Reprocessing}

2. Waste Separations, Treatments, Packaging

3. Target Reprocessing.

In the Fuel Reprocessing step, plutonium, uranium, and neptunium are recovered from spent reactor fuels, purified, and converted to oxides. From offgases generated in fuel reprocessing, radioiodine is recovered, purified, and concentrated for subsequent treatment and disposal.

The Waste Separations step involves a carefully selected series of chemical processes to remove residual plutonium and uranium, other actinides (e.g., neptunium, americium, curium), ${ }^{99} \mathrm{Tc}$, fission products cesium and strontium, and rare earths from the HLW separated in the Fuel Reprocessing step. Plutonium, uranium, and neptunium are recycled to the Fuel Reprocessing step. Certain radionuclides removed from fuel reprocessing HLW are purified, converted to solids, and packaged for engineered storage (e.g., ${ }^{137} \mathrm{Cs},{ }^{90} \mathrm{Sr}$ ) and/or transmutation (e.g., ${ }^{99} \mathrm{Tc},{ }^{129} \mathrm{I}$, neptunium, americium, curium). Fission product rare earths (Ln), after separation from americium and curium, are combined with the aqueous solution remaining after removal of actinides, ${ }^{99} \mathrm{Tc}$, and fission products cesium and strontium for eventual solidification and disposal.

The third part of the integrated chemical processing operations is Target Reprocessing. This latter step is designed to recover radionuclides and transmutation products from spent target (e.g., ${ }^{99} \mathrm{Tc}$, radioiodine, Am, etc.) assemblies. Transmutation products are packaged either for beneficial use or disposal. The remaining ${ }^{99} \mathrm{Tc}$, radioiodine, Am, etc., are recycled for additional irradiation. It is anticipated that the bulk of the technology and chemical separations processes used in the Fuels Reprocessing and Waste Separations steps will also apply to recovery of radionuclides and/or transmutation products from spent target assemblies. 


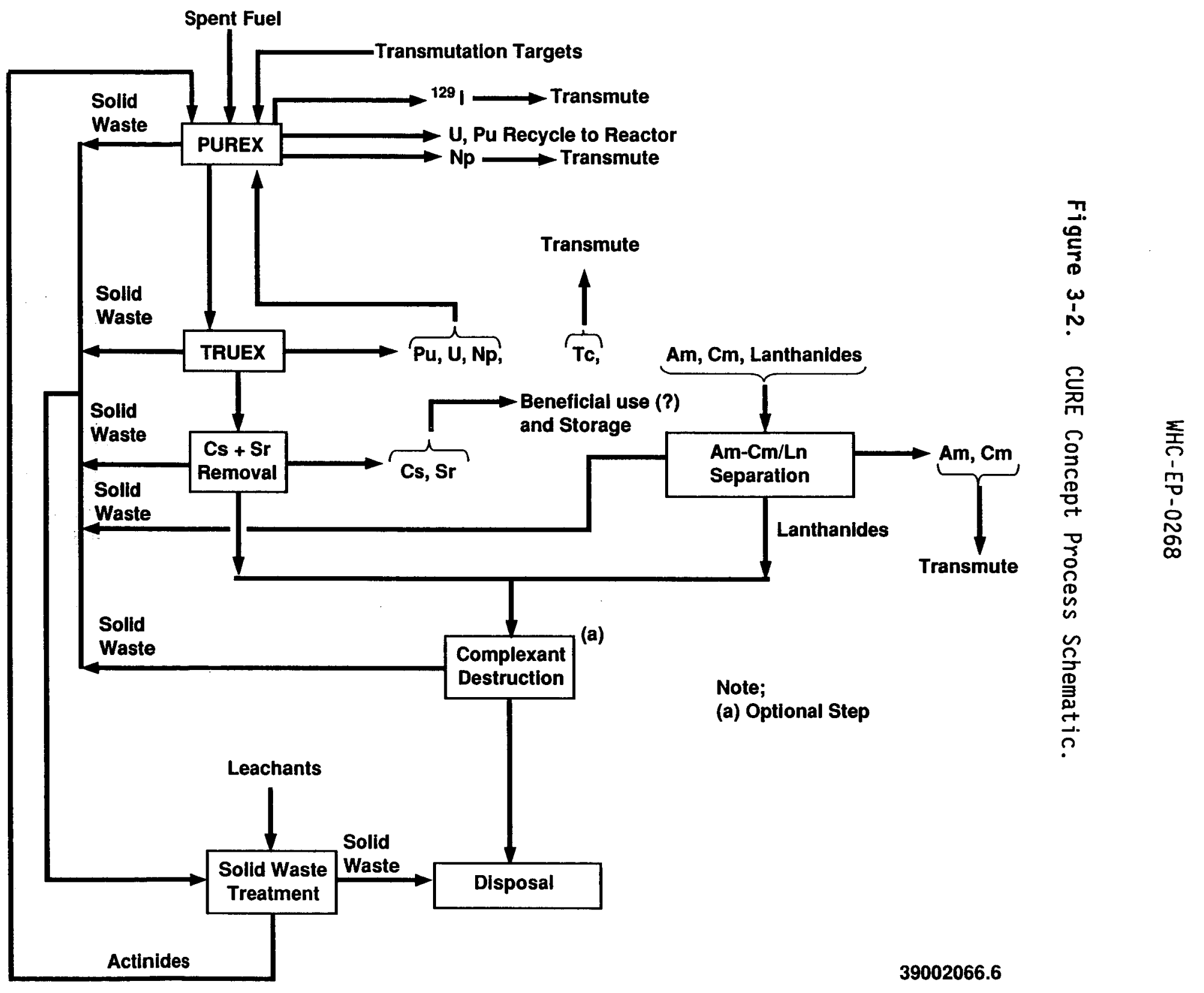


Processes and chemical flowsheets presented and discussed in this section are intended to provide a technical baseline for comparison of alternative processes and to identify (see Section 6.1) chemical separations technology needs for the CURE concept. Baseline separations processes described subsequently in this section are selected on the basis of proven and accepted practices and are considered to be the best available technology. In some instances, e.g., removal of radiostrontium from acidic HLW, it is anticipated that improved separation processes can and will be developed and applied.*

\subsubsection{Fuel Processing}

3.1.2.1 Function. The basic function of the Fuel Processing operations of the overall CURE chemical processing operation is to recover, separate, and purify uranium, plutonium, and neptunium from spent reactor fuels including both LWR and FR fuels. Ancillary functions to be accomplished in Fuel Processing operations include recovery, separation, and concentration of ${ }^{129} \mathrm{I}$ from gaseous waste streams as well as conversion of purified plutonium, uranium, and neptunium nitrate solutions to solid oxides.

*Dr. E. P. Horwitz, Argonne National Laboratory, Argonne, Illinois, has recently developed a highly efficient and highly selective process for solvent extraction of strontium from strongly acidic media which does not involve use of objectionable organic complexants, does not add sodium to the HLW, and does not require difficult-to-control $\mathrm{pH}$ adjustments. Further details of this new solvent extraction process cannot be disclosed in this report because of patentability constraints. However, countercurrent tests of the new process with simulated HLW, and batch tests with actual HLW have been uniformly successful. If further countercurrent tests with actual HLW are also successful, the new ${ }^{90} \mathrm{Sr}$ solvent extraction process of Horwitz will replace the reference process described in this report. 
3.1.2.2 Key Assumptions. The following listed assumptions are used to establish the baseline Fuel Reprocessing process and process flowsheet.

- The aqueous-based PUREX process (McKay et al. 1989) is used to reprocess spent reactor fuel.

- For criticality control, process solutions obtained from the Fast Reactor (FR) fuel head-end dissolver could be appropriately diluted with depleted $U$ to allow subsequent PUREX process operations in the same extraction equipment used to process LWR fuel dissolver solutions. Alternatively, a separate processing line could treat the FR fuel without dilution.

- Light-water reactor spent fuel has the composition shown in Table 1-1, and liquid-metal reactor spent fuel has the composition shown in Table 1-2.

- For convenient scale-up purposes, the baseline processing rate is 1,000 MTU (or MTHM) of spent fue1 per year.

- No special oxidation or reduction treatments will be performed to adjust the valence state of ${ }^{237} \mathrm{~Np}$ in the fuel dissolver solution; accordingly, ${ }^{237} \mathrm{~Np}$ will distribute both to the HLW and to the tributyl phosphate (TBP) phase in the first PUREX process extraction cycle.

- In PUREX process operations, ${ }^{99}$ Tc splits between the HLW ( $\left.-80 \%\right)$ and the uranium nitrate product $(-20 \%) . *$

- The PUREX process is operated to minimize as much as possible the amount of any nonradioactive chemicals other than $\mathrm{HNO}_{3}$ in the HLW stream.

*The possibility of modifying PUREX process flowsheet conditions so as to drive all the 99 Tc to the HLW is recognized and needs to be explored experimentally. 
3.1.2.3 Flow Diagram. Figure 3-3 illustrates the baseline fuel reprocessing (PUREX process) flowsheet.

3.1.2.4 Process Description. The PUREX process for reprocessing spent reactor fuel consists of six separate and distinguishable sections:

1. Head-End

2. Solvent extraction

3. Oxide conversion

4. Organic recycle

5. Liquid waste handling

6. Offgas treatment.

Head-End. In the Head-End of the PUREX facility spent fuel assemblies are mechanically disassembled, and fuel pins are sheared (chopped) into small ( 2 to $8 \mathrm{~cm}$ long) sections to expose core material. Contained in speciallyconstructed baskets, the sheared fuel is treated with boiling $\mathrm{HNO}_{3}$ to dissolve uranium, plutonium, and fission products. Following completion of the fuel dissolution step, undissolved fuel cladding (cladding hulls) are rinsed first with $12 \mathrm{M} \mathrm{HNO}_{3}$ and then with a water spray. Rinsed hulls are subsequently treated (cf. Section 3.2) to remove any remaining actinides prior to packaging for final disposal.

The $\mathrm{HNO}_{3}$ dissolver solution resulting from dissolution of fuel cores will contain a small amount of finely divided solids. These solids consist mainly of noble metals (e.g., ruthenium, palladium, etc.), but various actinide elements (e.g., plutonium, uranium, etc.) may also be present. Thus, the solids will be separated by centrifugation or filtration, dried, and routed to either further aqueous treatment [e.g., leaching with $\mathrm{HNO}_{3}$ or $\mathrm{HNO}_{3}-\mathrm{Ag}$ (II) (CEPOD reagent) solutions (Bray 1982; Bray 1985; Ryan 1987)] or directly to fabrication of actinide targets. 


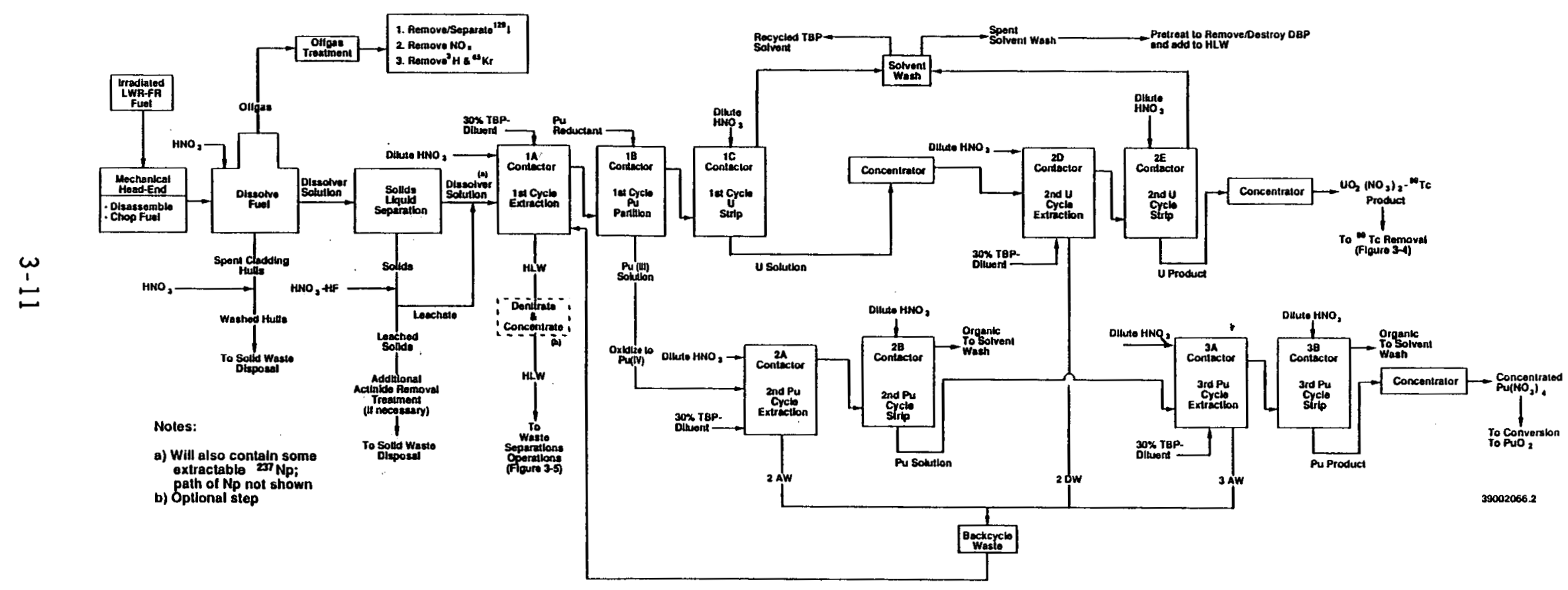

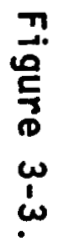

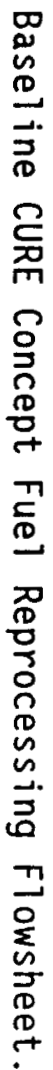

족
1
m.
0
0
0
0
0 
Solvent Extraction. Standard and well-known PUREX process technology will be employed to recover, separate, and purify plutonium and uranium. The chemical flowsheet to be used involves co-decontamination of uranium and plutonium, partitioning of plutonium, and further purification extraction cycles for both uranium and plutonium. Strict attention will be given to the choice of plutonium valence adjustment reagents $\left[\right.$ e.g., $\mathrm{NO}_{X}$, hydroxylamine nitrate, U(IV), etc.] which do not add inorganic salts to the HLW.

Although not indicated in Figure 3-3, any neptunium which co-extracts with uranium and plutonium is expected to follow uranium in the plutonium partitioning step. Neptunium will be separated from uranium in the second uranium purification cycle (Figure 3-3) employing technology used successfully at the DOE Hanford Site PUREX PIant (Isaacson and Judson 1964). Further TBP extraction cycles, not shown in Figure 3-3, will be used to concentrate and purify ${ }^{237} \mathrm{~Np}$ from uranium, plutonium, and fission products (Schulz and Benedict 1972). Final purification of the $237 \mathrm{~Np}$ will be accomplished by standard (Poe et al. 1964) anion exchange procedures.

A new and unique feature of the CURE-type PUREX solvent extraction flowsheet is inclusion of a separate tail-end solvent extraction process (see Figure 3-4) to remove ${ }^{99} \mathrm{Tc}$ from the uranium nitrate product. This tail-end process will use a commercially available primary amine (Primene JM-T)* dissolved in a mixture of normal paraffin hydrocarbons to preferentially extract ${ }^{99} \mathrm{Tc}$ from the aqueous uranium stream. An alkaline [e.g., $\left(\mathrm{NH}_{4}\right)_{2} \mathrm{CO}_{3}$ ] solution will be used to strip ${ }^{99} \mathrm{Tc}$ from the amine extract. The resulting ${ }^{99} \mathrm{Tc}$ stream will be further processed to produce a solid ${ }^{99} \mathrm{Tc}$ material for use in transmutation target assemblies. To permit direct calcination to $\mathrm{UO}_{3}$ it is essential that no impurity metal cations be added during $\mathrm{pH}$ adjustment of the feed to the amine extraction process. Decomposable materials such as formic acid must be used to accomplish any needed pH adjustments.

*Primene JM-T is a trademark of Rohm and Haas Company. 
Figure 3-4. Flowsheet for. Amine Separation of Uranium and ${ }^{99} \mathrm{TC}-$ PUREX Process Uranium Product.

(b)

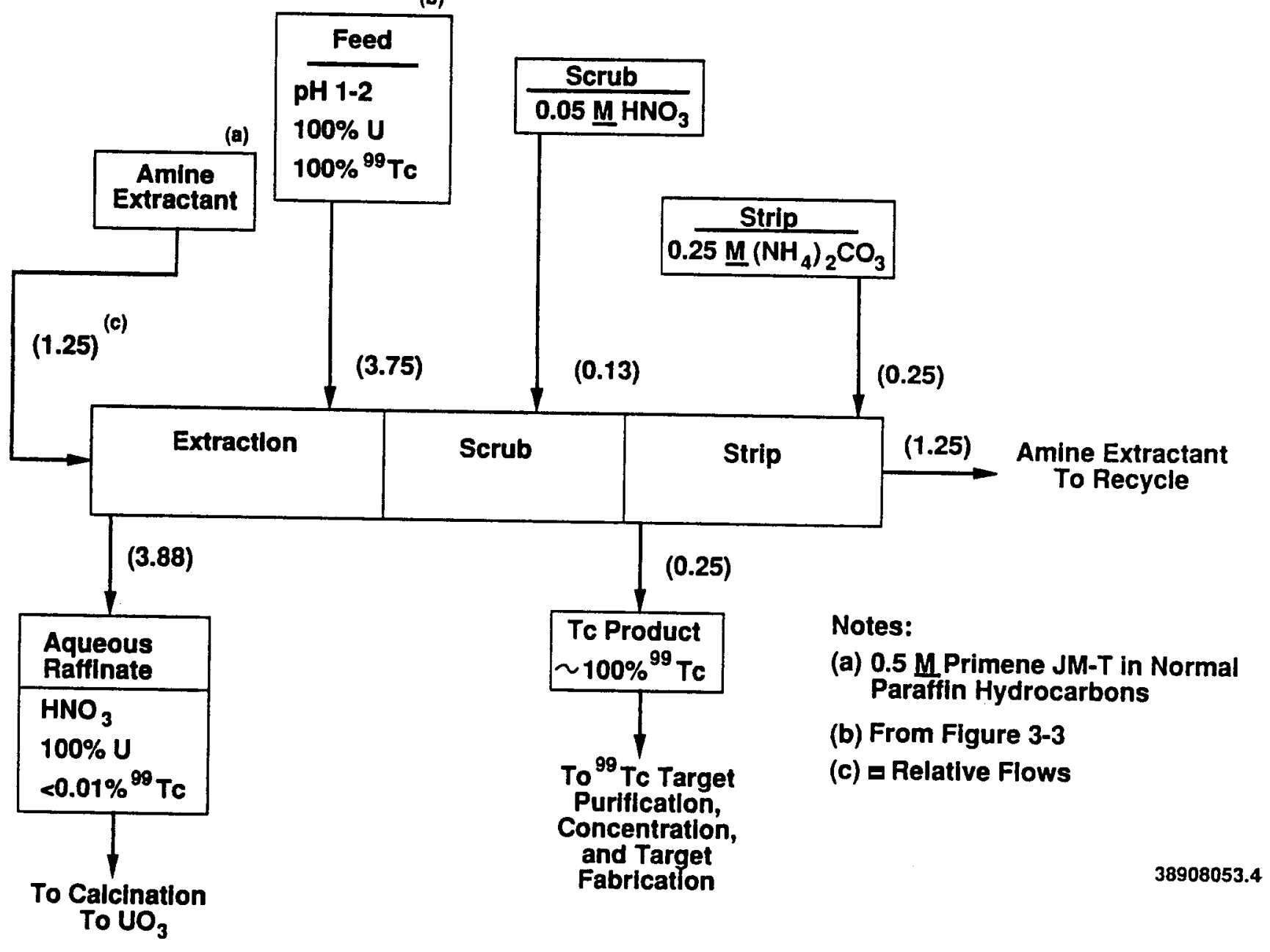


Oxide Conversion. The PUREX process-purified plutonium and uranium nitrate products will be converted to $\mathrm{PuO}_{2}$ and $\mathrm{UO}_{3}$, respectively. Direct calcination of the ${ }^{99} \mathrm{Tc}$-free uranium nitrate to $\mathrm{UO}_{3}$ can be accomplished by standard production-scale methodology. The $\mathrm{PuO}_{2}$ will be produced by calcination of plutonium oxalate previously precipitated from the plutonium nitrate solution. The $\mathrm{PuO}_{2}$ and $\mathrm{UO}_{3}$ products will be stored until needed as fuel.

Purified neptunium nitrate solution will be directly calcined to $\mathrm{NpO}_{2}$. The resulting $\mathrm{NpO}_{2}$ will then be fabricated into targets for irradiation.

Organic Recycle. Standard solvent washing methodology employing alkaline reagents such as hydrazine carbonate or hydrazine oxalate will be used routinely to remove radiolytic and hydrolytic degradation products from the PUREX process tri-n-butyl phosphate (TBP) solvent for recycle to solvent extraction operations. After suitable treatment to remove or destroy dibutyl phosphoric acid (DBP), the spent solvent washes will be incorporated into the PUREX process HLW for subsequent TRUEX process recovery of uranium and TRU elements. A solvent extraction process devised by Horwitz (Horwitz 1978) may be applicable to removal of OBP from the alkaline solvent wash. Alternatively, it may be desirable to convert the DBP to unobjectionable phosphate ions by boiling the acidified $\left(\mathrm{HNO}_{3}\right)$ spent solvent wash solution prior to addition to the PUREX process HLW.

Liquid Waste Handling. This section encompasses all the activities involved in treating and disposing of all liquid wastes generated in the Fuels Reprocessing (Section 3.1.2) of the CURE chemical processing program. The key unit operations are concentration, if necessary, of the PUREX process HLW to prepare feed for Waste Separations operations and treatment (e.g., ion exchange, reverse osmosis, etc.) of any liquid wastes which are not suitable for incorporation into the HLW. Section 3.2 presents further details of waste handling activities. 
Offgas Treatment. This section includes treatment of all offgases generated in Fuels Reprocessing activities. Such treatment involves not only removal and/or destruction of $\mathrm{NO}_{X}$ but also removal and concentration of other gaseous effluents including radioiodine. Radioiodine will be selectively removed from the offgas stream by sorption on beds of silver mordenite from which it can be desorbed by treatment with hydrogen gas.

\subsubsection{Waste Separations}

3.1.3.1 Function. The function of the Waste Separations part of the CURE chemical processing operations is to separate certain radionuclides (Table 2-1) from the HLW from the Fuel Reprocessing PUREX process operation to a level where the residual waste qualifies for 1 and disposal (Tables 3-1 and 3-2). Radionuclides separated from the HLW include isotopes of uranium, neptunium, plutonium, americium, and curium, as well as radiostrontium, ${ }^{99} \mathrm{Tc}$, and radiocesium. The uranium, plutonium, and neptunium product streams are recycled to the PUREX Plant. Other radionuclides are purified and converted to solid materials for beneficial uses, target fabrication, and/or intermediate term ( 300 to $500 \mathrm{yr}$ ) storage.

3.1.3.2 Key Assumptions. The following listed assumptions are used to establish the baseline Waste Separations process and process flowsheets.

- The HLW generated in Fuel Reprocessing activities is fed to the Waste Separations treatment processes.*

- The processing rate in the Waste Separations facility is set to accommodate the rate at which $H L W$ is generated in the PUREX Plant of the Fuel Reprocessing (Section 3.1.2).

*It is assumed that the feed to the Waste Separations processes will also contain equipment flushes, laboratory wastes, etc., and that the feed will be suitably treated (e.g., digested, etc.) to destroy organic compounds. 
3.1.3.3 Flow Diagram. Figure 3-5 illustrates the baseline Waste Separations flow diagram.

3.1.3.4 Process Description. The overall Waste Separations operations consists of seven separate processing activities:

1. Head-End

2. The TRUEX process

3. ${ }^{99}$ TC isolation

4. Separation of radiocesium

5. Separation of radiostrontium

6. Solidification of radionuclides

7. Waste handling.

Head-End. The essential Head-End operation separates, by centrifugation or filtration, any solids in the HLW and suitably treats them by successive exposure to $\mathrm{HNO}_{3}$ and/or $\mathrm{Ag}$ (II) $-\mathrm{HNO}_{3}$ solutions in a CEPOD electrolytic dissolver. Solids in the HLW are typically expected to contain some TRU elements as well as ${ }^{99} \mathrm{Tc}$ and, possibly, radiostrontium. The acidic solution resulting from treatment of the solids will be added to the HLW as feed to the TRUEX process.

TRUEX Process. The TRUEX process is a recently-developed solvent extraction process capable of removing all actinides $(+3,+4,+6)$ from any $\mathrm{HNO}_{3}$ nuclear waste solution (Schulz and Horwitz 1987). The extractant in the TRUEX process is octyl (phenyl) $-\mathrm{N}, \mathrm{N}$-diisobutylcarbamoylmethylphosphine oxide (CMPO) dissolved in a normal paraffin hydrocarbon; TBP is added to prevent "third phase" formation.

Figure 3-6 presents a chemical flowsheet for TRUEX process operation with HLW. Oxalic acid is added to the HLW to minimize extraction of impurities such as iron and zirconium. In the extraction contactor actinides (U, $\mathrm{Np}, \mathrm{Pu}, \mathrm{Am}$, and $\mathrm{Cm}$ ), lanthanides (both radioactive and nonradioactive), and ${ }^{99} \mathrm{Tc}$ are adequately and satisfactorily extracted. The aqueous raffinate 
Figure 3-5. Baseline CURE Program Waste Separations Concept.

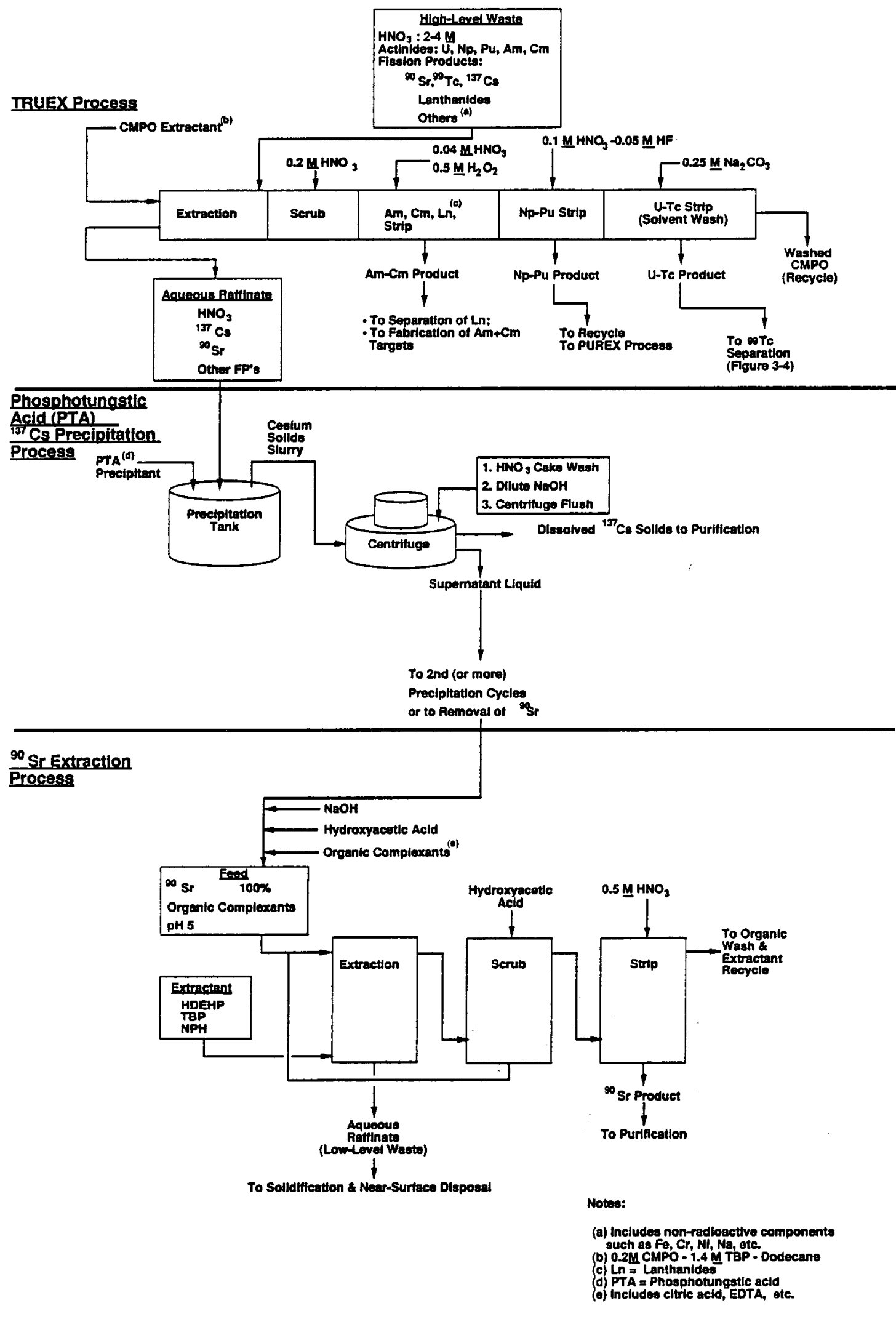




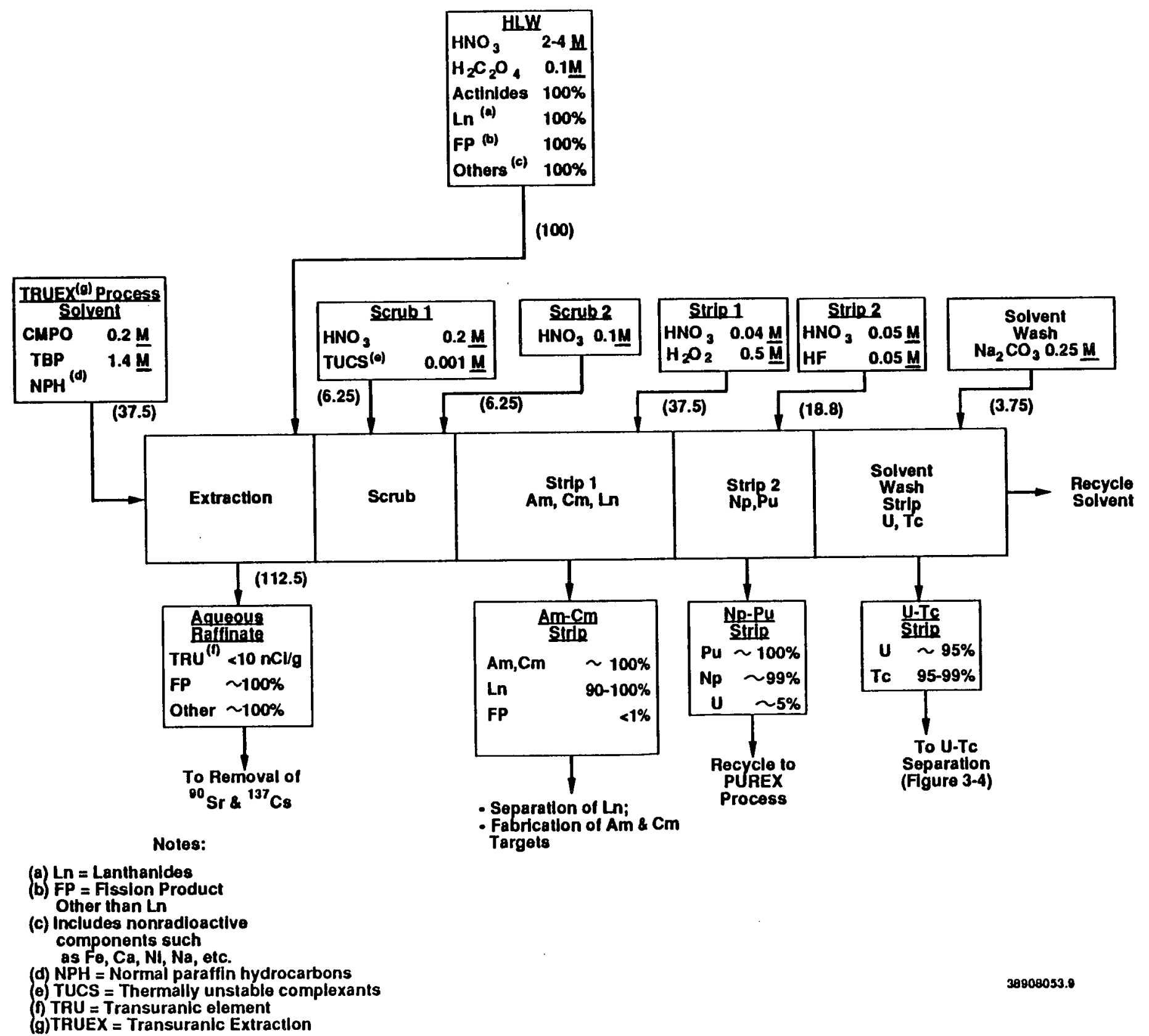

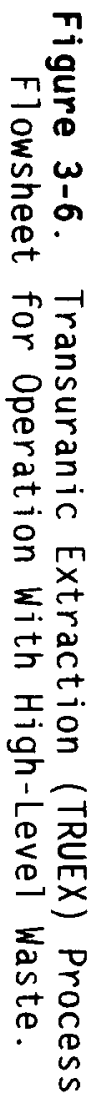

Ln = Lanthanides

$\mathrm{FP}=$ Fission Product

$\mathrm{NPH}=\mathrm{No}$,

(f) TRU = Transuranic element

30909053.8 
from the TRUEX process extraction operation contains radiocesium and radiostrontium, and various other short- and long-lived fission products.

Subsequently, the CMPO extract containing ${ }^{99} \mathrm{Tc}$, actinides, and 1 anthanides is scrubbed to remove $\mathrm{HNO}_{3}$ and traces of co-extracted radioactive and inert impurities. Americium, curium, and lanthanides are preferentially co-stripped from the organic phase into a small volume of $\mathrm{HNO}_{3}$ solution. $\mathrm{A} \mathrm{HNO}_{3}-\mathrm{HF}$ solution is then used to strip $\mathrm{Pu}(\mathrm{IV}), \mathrm{Np}$ (IV), and any residual americium, curium, and lanthanides. Uranium and ${ }^{99} \mathrm{Tc}$, which are not stripped with the other actinides, are removed by contacting the organic phase with an aqueous alkaline solution. The latter solution also serves as a solvent wash to remove acidic solvent degradation products.

The Pu-Np strip product can be routed to an appropriate place in the PUREX Plant. Two options are available for further treatment of the Am- $\mathrm{Cm}$ lanthanide product depending on the amount of lanthanides which can be tolerated in FR target or fuel assemblies. If the tolerance is high, the entire stream can be calcined to yield a mixture of solid oxides suitable for target assembly fabrication. Alternatively, some ion exchange and solvent extraction technology is available to separate and purify $\mathrm{Am}-\mathrm{Cm}$ and lanthanide fractions.* Solid Am-Cm oxides can then be made for fabrication into target assemblies while the lanthanide stream can be routed to final waste treatment and disposal (see Section 3.2).

${ }^{99} \mathrm{Tc}$ Isolation. To separate ${ }^{99} \mathrm{Tc}$ from uranium in the alkaline strip solution from the TRUEX process, the amine solvent extraction process flowsheet shown in Figure 3-7 will be used. The alkaline strip solution which will contain $\mathrm{Na}_{2} \mathrm{CO}_{3}$ will be acidified to a $\mathrm{pH}$ in the range 1 to 2 to prepare feed to the amine extraction process. Since the aqueous raffinate from the amine extraction process will contain large amounts of sodium as

*The shortcomings of currently available technology for plant-scale separation of lanthanides from americium and curium are we 11 recognized. Development of advanced and improved technology for this purpose is called out in Chapters 6 and 7 as one of the critical CURE system technology needs. 
(b)

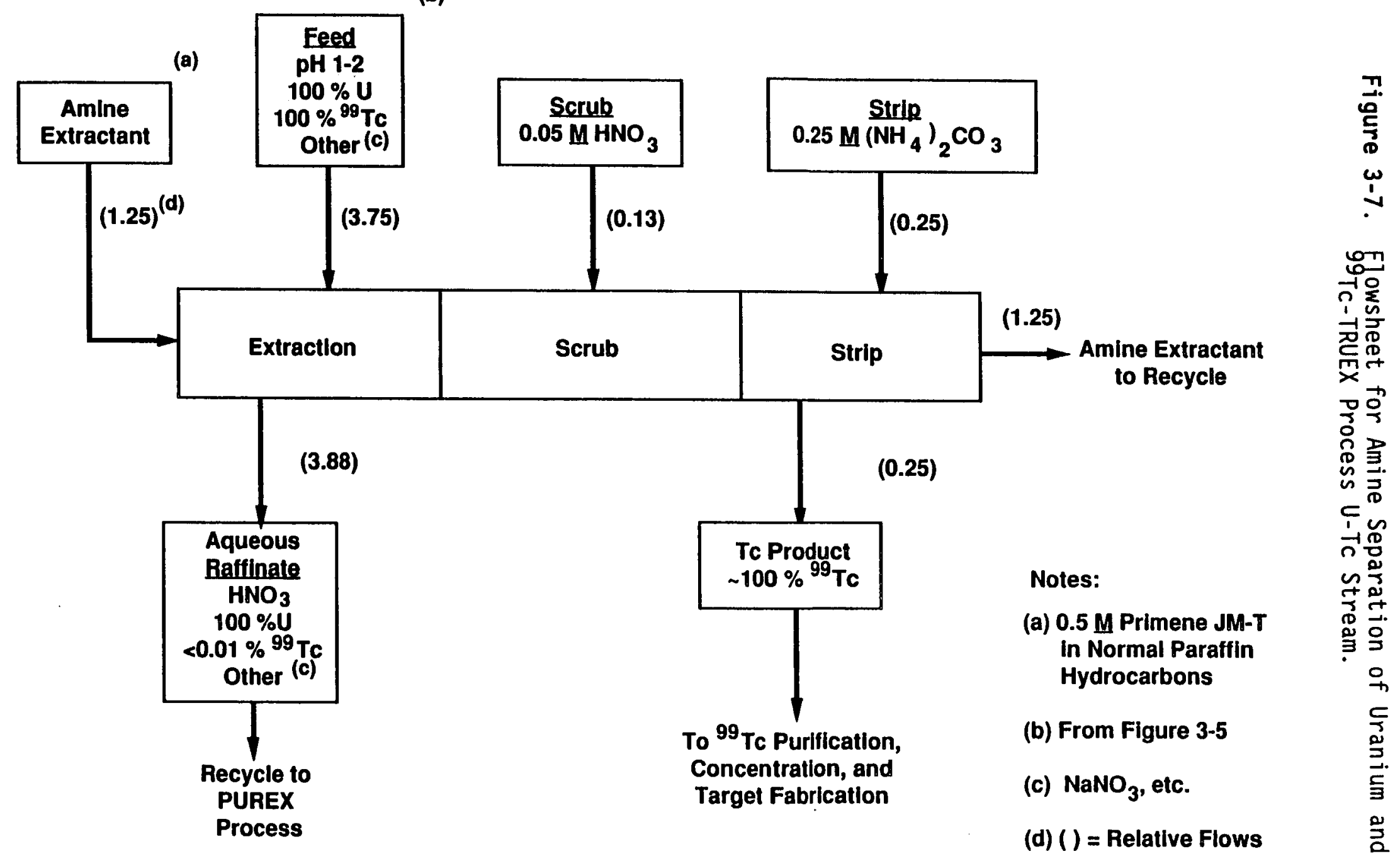


well as uranium, it will be recycled to an appropriate place in the PUREX process for recovery of the uranium. Prior to recycle, the raffinate will be treated as needed to ensure destruction or removal of any traces of CMPO and CMPO degradation products; such treatment may involve acidification and extended boiling or sorption of organic products on a suitable sorbent. The ${ }^{99} \mathrm{Tc}$ will be stripped from the amine solvent and combined with a similar product from the amine extraction process used to separate technetium from uranium in the PUREX process uranium nitrate product (cf. Figure 3-4). The combined ${ }^{99} \mathrm{Tc}$ product will then be converted to a solid technetium material for use in preparing target assemblies for transmutation.

Separation of Cesium. To separate radioactive cesium from the TRUEX process raffinate, phosphotungstic acid (PTA) is added to the aqueous raffinate. The PTA precipitates cesium as insoluble di- and tricesiumphosphotungstates from acidic solutions (Schulz and Bray 1987). By limiting the quantity of PTA added, contamination from rubidium, potassium, ammonium, $\mathrm{Ag}(\mathrm{I})$, and $\mathrm{Hg}(\mathrm{II})$ ions can be controlled. To obtain sufficient removal of cesium from the TRUEX process raffinate, double and even triple PTA precipitation steps may be necessary.

Cesium phosphotungstate precipitates will be combined and washed with water. Subsequently, the phosphotungstate precipitate will be dissolved in $\mathrm{NaOH}$ solution and the cesium concentrated, and purified by a two-stage ion exchange system using a suitable inorganic ion exchange material. After elution with $\left(\mathrm{NH}_{4}\right)_{2} \mathrm{CO}_{3}$ solution, a purified $\mathrm{Cs}_{2} \mathrm{CO}_{3}$ concentrate will be produced.

Finally, the $\mathrm{Cs}_{2} \mathrm{CO}_{3}$ solution will be acidified with $\mathrm{HCl}$ and evaporated to dryness. The resulting $\mathrm{CsCl}$ will be melted and cast into capsules. The inner capsule will be encapsulated in a second capsule suitable for long-term storage or for use as a commercial radiation source.

The baseline PTA precipitation process has been used successfully on a plant-scale at the Hanford Site. A single precipitation of cesium phosphotungstate removed about $96 \%$ of the cesium from actual PUREX process HLW. As 
noted in Section 6.1, there is a need to develop and demonstrate advanced process technology for selectively removing cesium from acidic wastes.

Separation of Strontium. The baseline process for removing strontium from the TRUEX process raffinate (after prior removal of radiocesium) uses bis(2-ethylhexyl)phosphoric acid (HDEHP) as the extractant in a solvent extraction process (Schulz et al. 1963). Typically, the HDEHP is diluted with TBP and a mixture of normal paraffin hydrocarbons. To accomplish extraction of strontium, the cesium-depleted solution from the PTA process is adjusted to $\mathrm{pH} \mathrm{4-5;} \mathrm{organic} \mathrm{complexing} \mathrm{agents} \mathrm{are} \mathrm{added} \mathrm{to} \mathrm{provide} \mathrm{buffering}$ capacity, to prevent precipitation of solids, and to prevent extraction of certain impurities. The HDEHP extract is scrubbed to remove sodium and then is contacted with dilute $\mathrm{HNO}_{3}$ to strip the strontium. Solvent extraction conditions (e.g., extractant concentration, organic-to-aqueous phase flow ratios, number of extraction stages, etc.) that ensure adequate removal of strontium from the feed solution must be specified.

Precipitation processes can be used to remove calcium, magnesium, iron, aluminum, and other metallic impurities from the $\mathrm{Sr}\left(\mathrm{NO}_{3}\right)_{2}$ solvent extraction product. Precipitation of $\mathrm{SrF}_{2}$ from the nitrate solution yields a solid form which can be dried, fired at elevated temperature, and doubly encapsulated for either prolonged storage or use as a radioisotopic power source.

The baseline strontium solvent extraction and precipitation purification processes have been successfully used on a production-scale at the Hanford Site. But, as discussed in Section 6.1, this baseline technology has a number of recognized disadvantages including the need to destroy organic complexants (Figure 3-2). Advanced technology for removing strontium from strongly acidic solutions needs to be developed.*

\footnotetext{
*See footnote page 3-8.
} 
Solidification. Certain radionuclides (e.g., ${ }^{99} \mathrm{Tc},{ }^{237} \mathrm{~Np}$, americium, and curium) are converted to solid oxides by precipitation and/or calcination processes.

Waste Handling. Various solid and liquid wastes will be generated during Waste Separations activities. The most important liquid waste will be the raffinate from the TRUEX process from which cesium and strontium have been removed. It is anticipated that this stream will be concentrated, neutralized, and incorporated in a solid matrix for disposal. Solid waste form options include glass, cement-like grout, and bitumen. Disposal could be in a geologic repository, or possibly in a near-surface repository. Further details of the treatment and disposal of wastes produced in Waste Separation operations are presented in Section 3.2.

\subsubsection{Target Reprocessing}

3.1.4.1 Function. The function of Target Reprocessing activities is to separate and purify ${ }^{99} \mathrm{Tc}$, radioiodine, ${ }^{237} \mathrm{~Np}$, americium, and curium remaining in irradiated target assemblies. Purified radionuclide fractions are converted to solid oxides or other desired compounds and fabricated into target assemblies for additional irradiation and burnup.

3.1.4.2 Key Assumptions. The following list of assumptions was used to establish the baseline Target Reprocessing processes and process flowsheets.

- Process Chemistry: The TRUEX and other chemical separation processes used in the Fuels Reprocessing and Waste Separations activities will be used to reprocess irradiated targets.

- Process Equipment: If practical, irradiated target assemblies will be processed in the same facilities and with the same equipment used to process HLW and other waste streams from PUREX processing of LWR and FR fuels. 
- Process Rate: Processing rates will be set to be consistent with facility and irradiated target receipt requirements.

- Remote Operations: All target material reprocessing and target fabrication processes will be performed remotely in suitably shielded facilities.

3.1.4.3 Process Description. Six principal process tasks make up the overall target reprocessing system:

1. Head-End

2. Solvent extraction

3. Oxide conversion

4. Organic recycle

5. Waste handling

6. Offgas treatment.

Head-End Section. Similar to the Head-End operations in the Fuel Reprocessing PUREX facility, most irradiated target assemblies will be mechanically disassembled and individual cores sheared into small lengths. Exposed core material will be appropriately dissolved in $\mathrm{HNO}_{3}$ media to prepare feed for subsequent PUREX and/or TRUEX process operations. Cladding hulls will be rinsed with water and/or $\mathrm{HNO}_{3}$ solutions and disposed of as described in Section 3.2.3. The $\mathrm{HNO}_{3}$ dissolver solution will be clarified. Any solid material will be treated with appropriate aqueous media to remove actinides and key fission products.

Solvent Extraction. The amine extraction process previously described (Section 3.1.3.4) will be used to recover and separate ${ }^{99} \mathrm{TC}$ from $\mathrm{HNO}_{3}$ solutions of irradiated technetium targets. Selection of amine solvent extraction technology assumes that irradiated ${ }^{99} \mathrm{Tc}$ targets can be satisfactorily dissolved in $\mathrm{HNO}_{3}$ and that the resulting dissolver solution can be satisfactorily adjusted to $\mathrm{pH} 1$ to 2 . Technology development and demonstrations needed to verify this assumption is called out in Chapter 6 of this report. 
Oxide Conversion. The purified Am-Cm nitrate solution produced in TRUEX process operation with irradiated target dissolver solutions may be directly calcined to produce a mixture of oxides suitable for target fabrication. Alternately, addition of oxalate to the Am-Cm nitrate solution will precipitate a mixed $\mathrm{Am}-\mathrm{Cm}$ oxalate which can be separated and calcined to yield mixed Am-Cm oxides. Precipitation of Am-Cm oxalates may be desirable or necessary to obtain purer $\mathrm{Am}$ and $\mathrm{Cm}$ oxides.

Similarly, the alkaline ${ }^{99} \mathrm{Tc}-\left(\mathrm{NH}_{4}\right)_{2} \mathrm{CO}_{3}$ strip solution obtained in the amine extraction process may be calcined to yield a technetium oxide suitable for fabrication of target assemblies. The reference design for technetium targets is the metal or an alloy material. As noted in Section 6, anion exchange procedures can also be used to concentrate and purify the ${ }^{99} \mathrm{Tc}$ in the $\left(\mathrm{NH}_{4}\right)_{2} \mathrm{CO}_{3}$ strip solution before preparation of oxide or metal.

Organic Recycle. Both the amine solvent used in ${ }^{99} \mathrm{Tc}$ recovery operation and the CMPO solvent used in the TRUEX process will be recycled to extraction contactors. As needed or desired, these solvents will be washed with appropriate alkaline media to remove hydrolytic and radiolytic degradation products.

Waste Handling. Several solid (e.g., cladding hardware) and liquid wastes will result from reprocessing of irradiated target assemblies. The various 1 iquid wastes will be concentrated, classified as to type, e.g., HLW or $L L W$, and routed to either disposal (LLW) or recycle and further separation in the Waste Separations area (HLW). Solid wastes will be disposed of by methodology discussed in Section 3.2 .

Offgas Treatment. Offgases from Target Reprocessing activities will be routed to, and combined with, similar gas streams from Fuels Reprocessing activities for treatment and/or recovery processes. 


\subsubsection{Anticipated CURE System Decontamination Performance}

There is sufficient evidence to believe that the CURE concept partitioning technology applied to either LWR or FR spent fuel can routinely produce, except perhaps at very low (i.e., $0.1 \mathrm{~m}^{3} /$ MTU) waste volumes, a waste whose radionuclide content is below U.S. Nuclear Regulatory Commission (NRC) specifications for Class $C$ waste (Tables 3-1 and 3-2). This judgement is based upon (a) performance of modern-day PUREX process solvent extraction and offgas treatment technology, (b) successful Hanford Site experience in large-scale removal of ${ }^{90} \mathrm{Sr}$ and ${ }^{137} \mathrm{Cs}$ from defense wastes, and (c) highly promising bench- and pilot plant-scale tests of the TRUEX process with actual waste. It is clear from the data in Tables 3-1 and 3-2 that anticipated superior TRUEX process performance must be realized to produce a waste containing $<100 \mathrm{nCi} / \mathrm{g}$ of TRU elements, especially when reprocessing spent FR fuel. To obtain the required removal of TRU elements from the HLW from reprocessing FR fuel, it may be necessary to modify the reference TRUEX process flowsheet (Figure 3-5) by adding more extraction stages or by increasing either the CMPO concentration or the organic-to-aqueous phase ratio, or both. Consideration also needs to be given to providing a suitable tailend treatment (e.g., extraction chromatography) for further removal of TRU elements from CURE system liquid waste prior to final disposal in grout form. In any case, experimental verification of the ability of the TRUEX process to provide the needed removal of TRU elements is identified (Chapter 7) as the highest priority CURE system technological need.

If outstanding TRUEX process performance can be realized, the CURE system partitioning processes described in this report may well be capable, when applied to LWR spent fuel, of producing a waste whose radionuclide content is below NRC specifications for Class B waste. However, even with outstanding TRUEX process performance, present partitioning technology likely will not allow production of Class B waste from HLW produced from reprocessing FR fuel.

Generation of wastes meeting or surpassing Incidental Waste specifications (Table $3-1$ ) is a long-term goal of CURE system partitioning technology. To achieve this, it will be necessary to develop and demonstrate 
new and advanced ${ }^{90} \mathrm{Sr}$ and ${ }^{137} \mathrm{Cs}$ removal processes similar to those now being investigated by scientists at the Argonne National Laboratory.

In order for the CURE system partitioning processes to produce waste meeting $C l a s s ~ C$ specifications, it is necessary that efficient dissolution and/or leach techniques and reagents be available and employed to remove TRU elements from various solid residues [e.g., HEPA filters, dissolver solution solids, etc.] produced during fuel and target fabrication and reprocessing.

\subsubsection{Applicability of CURE Concepts to Integral Fast Reactor Fuel Pyrochemical Processing Wastes}

Pyrochemical processing of chopped IFR fuel (a $\mathrm{Zr}$-U-Pu metal alloy) involves placing fuel-bearing segments in anode baskets which are then lowered into an electrorefining cell. The cell consists of an anode of liquid cadmium, an electrolyte mixture of stable chloride salts, and several cathodes of liquid cadmium contained in ceramic crucibles immersed in the electrolyte. The bulk of the uranium, plutonium, and other actinides are deposited on the cathodes from which they are recovered by distilling out the cadmium.

The proposed fuel electrorefining process will generate two principal types of process wastes: (1) anode baskets and (2) spent chloride electrolytes. The former will contain fuel cladding, zirconium metal from the $\mathrm{Zr}-\mathrm{U}-\mathrm{Pu}$ metal fuel, ${ }^{99} \mathrm{Tc}$, noble metal fission products, and a small amount of cadmium. The form of the ${ }^{99} \mathrm{Tc}$ in the anode basket material is not precisely known; it may be associated with the noble metals most of which will be present as small, undissolved particles. The spent chloride electrolyte will contain small amounts of actinides; radiocesium, radiostrontium, and other electropositive fission products; and radioiodine and bromine. Argonne National Laboratory scientists have developed a pyrochemical scheme to remove actinides from the spent chloride electrolyte but are not addressing removal of other radionuclides from either the chloride electrolyte or from the anode basket material. 
Although much technology development would be required, aqueous CURE system technology described previously in this chapter could be used to remove actinides, radiocesium, and radiostrontium from a water solution of the spent chloride electrolyte produced in pyrochemical IFR fuel reprocessing. ${ }^{*}$ Horwitz and other scientists at the Argonne National Laboratory have shown that the TRUEX process can be used to extract actinide elements from aqueous chloride media (Schulz and Horwitz 1988). There is also no known technical reason why the PTA radiocesium precipitation process or the HDEHP radiostrontium extraction process will not work with aqueous chloride solutions. But, if necessary or desirable, known processes could be used to convert from chloride to nitrate solutions. Technology for removing radioiodine from an aqueous solution of the spent chloride electrolyte would have to be devised and demonstrated.

Since the exact form of ${ }^{99} \mathrm{TC}$ in the anode basket material is not known, it is only possible to speculate on the applicability of aqueous technology to separate preferentially ${ }^{99} \mathrm{Tc}$ from other anode basket components. Leaching of the anode basket materials with $\mathrm{HNO}_{3}$ or $\mathrm{HCl}$ solutions, containing an oxidizing agent (e.g., $\mathrm{H}_{2} \mathrm{O}_{2}$ ), may be able to dissolve ${ }^{99} \mathrm{Tc}$ as the ${ }^{99} \mathrm{TCO}_{4}{ }^{-i o n}$. As noted previously, the TRUEX process will also recover $\mathrm{H}^{99} \mathrm{TcO}_{4}$ and partition it from actinide ions.

\subsection{MANAGEMENT/DISPOSAL OF CURE WASTES}

\subsubsection{Introduction}

Various waste streams will be generated in CURE concept chemical processing, separation/purification, and fuel and target fabrication operations. Proper collection and treatment of all these various wastes is

*It is recognized that these may be serious concerns and objections to operating a combined pyrochemical-aqueous process. 
a prime part of the CURE concept. In particular, the objective is to collect and treat all wastes such that they can be either released directly to the environment (gases), or safely deposited in near-surface and deep geologic facilities.

\subsubsection{Gaseous Effluents}

The major gaseous effluents of concern will arise during chemical reprocessing of $L W R$ and $F R$ fuels. Aqueous $\mathrm{HNO}_{3}$ dissolution of such fuels will evolve a gas containing, $\mathrm{NO}_{\mathrm{X}}$, radioiodine, ${ }^{14} \mathrm{C},{ }^{85} \mathrm{Kr}$, and ${ }^{3} \mathrm{H}$. The CURE concept offgas management/treatment processes will be designed and operated to provide for adequate removal of radioactive and chemical constituents from these offgases.

Silver mordenite will effectively and selectively remove radioiodine from the dissolver offgas. Passage of hydrogen gas through the spent silver mordenite bed will release radioiodine. The concentrated iodine fraction can then be converted to a yet-to-be-determined solid suitable for fabrication of irradiation targets. Experimental work to optimize technology for removal of radioiodine from dissolver offgas and its subsequent conversion to a transmutation target is described in Section 6 .

Cryogenic and/or sorption techniques will be used, to the extent necessary, to remove ${ }^{85} \mathrm{Kr},{ }^{14} \mathrm{C}$, and ${ }^{3} \mathrm{H}$ from the dissolver offgas before release to the environment. Nitric oxide is to be recycled to nitric acid or be chemically destroyed as determined by economic conditions.

\subsubsection{Solid Wastes}

The principal solid wastes resulting from CURE concept Chemical Processing and Target Fabrication operations include fuel assembly hardware, cladding hulls, wastes generated in fabricating irradiation targets, solids 
produced during fuel and target dissolution, failed equipment, gloveboxes, HEPA filters, and miscellaneous paper and combustible material. All these various classes of waste will be treated, as necessary, to obtain solids that can qualify for near-surface disposal to the maximum extent possible. Treatment procedures will vary with the type of solid waste, but will be geared to removal of TRU and fission products and to reduction of volume to the extent possible. As discussed more fully in Chapter 6, development and demonstration of technology for collecting and treating, for disposal purposes, all the various CURE system solid wastes is a very high priority CURE system technology item.

Combustible wastes will be treated to destroy cellulosic material. The resulting ash, if qualified, will be disposed of in near-surface facilities, perhaps after incorporation into a grout matrix. If not qualified for immediate disposal, the ash will be leached or dissolved by Catalyzed Electrolytic Plutonium Oxide Dissolution (CEPOD) technology and fed to the PUREX or TRUEX processes.

Solids produced during fuel and target assembly dissolution will be collected and then electrolytically treated with an $\mathrm{HNO}_{3}-\mathrm{Ag}^{2+}$ solution in a CEPOD-type dissolver to solubilize any actinides which are present. The resulting acid solution will be part of the feed to the PUREX or TRUEX processes.

Technology developed at Oak Ridge National Laboratory (ORNL) (Scheitlin and Bond 1980) can be used to remove actinides from HEPA filters. The CEPOD dissolution equipment and procedures may also be useful in removing actinides from HEPA filters.

Fuel assembly hardware, cladding hulls, and failed equipment will be decontaminated from TRU elements and fission products to the desired level by appropriate washing with aqueous solutions containing, if necessary, various strong complexing agents. Also, as needed, failed stainless steel equipment will be electropolished to remove surface contamination. All of 
the metallic wastes will be compacted prior to their disposal. Because they will contain appreciable amounts of activation products such as ${ }^{93} \mathrm{Zr},{ }^{94} \mathrm{Nb}$, etc., cladding hulls and fuel assembly hardware may require repository disposal as GTCC waste (NRC 1982 and 1989).

\subsubsection{Liquid Waste}

The liquid waste of greatest importance in the CURE concept is the aqueous raffinate from the PUREX-TRUEX processes from which radiostrontium and radiocesium have been removed. The radionuclide content of this waste will be low enough for it to be classified as LLW. The liquid waste can be incorporated into a suitable matrix (e.g., grout or bitumen) for disposal in near-surface facilities, or it can be vitrified for near-surface or geologic disposal.

Other liquid wastes generated in chemical processing and target fabrication operations include solvent washes, miscellaneous liquid wastes, and process condensates. As required, each of these waste streams will be treated to remove TRU elements and fission products which might prevent qualification of these various liquid solutions for eventual near-surface disposal. After treatment, each of the treated liquids will be combined with the liquid waste from the mainline PUREX-TRUEX processes prior to solidification. One goal of enhanced CURE concept technology development is to ensure that none of the solvent washes or other miscellaneous wastes contains hazardous chemicals or salts which would interfere with its direct solidification.

\subsubsection{Radiostrontium and Radiocesium Waste}

Part of the waste management activity of the CURE concept is to properly manage and dispose of the radiostrontium and radiocesium recovered from irradiated LWR and FR fuels. It is anticipated that these elements will be 
in demand for beneficial applications. However, safe final disposal of these radioisotopes will need to be provided. For example, these materials could be $p l a c e d$ in interim storage for several half-lives, followed by geologic disposal. 
WHC-EP-0268

\subsection{TRANSHUTATION}

\subsection{NUCLEAR TRANSMUTATION OF KEY RADIONUCLIDES}

\subsubsection{Transmutation Concepts}

Many different types of nuclear particles are available to transmute waste isotopes. In practice, only relatively low energy ( $<1 \mathrm{keV}$ ) neutrons interact with most isotopes with a high enough probability to warrant serious consideration for transmutation. Actinides are an exception; a fast neutron spectrum can efficiently transmute actinides by neutron-induced fission.

Spent fuel radioisotopes that require suitable final disposition (transmutation or storage) include certain fission products $\left({ }^{90} \mathrm{Sr},{ }^{99} \mathrm{Tc}\right.$, ${ }^{129} \mathrm{I}$, and ${ }^{137} \mathrm{Cs}$ ) and all the TRU actinides. Table 4-1, generated from the ORIGEN2 code, lists the estimated quantity of these isotopes in the approximately 130,000 MTU of LWR-spent fuel anticipated in the United States by the year 2030. Table 4-1 also lists stable fission product isotopes of strontium, iodine, and cesium. Any discussion of transmutation of ${ }^{129} \mathrm{I}$, ${ }^{135} \mathrm{Cs},{ }^{137} \mathrm{Cs}$, or ${ }^{90} \mathrm{Sr}$ or beneficial use of ${ }^{90} \mathrm{Sr}$ and ${ }^{137} \mathrm{Cs}$ must also address effects of stable fission product isotopes of iodine, cesium and strontium.

In general, the neutron transmutation cross section of an isotope is a strong function of incident neutron energy. For the longer-lived fission products ${ }^{99} \mathrm{Tc}$ and ${ }^{129} \mathrm{I}$, the most efficient transmutation process is through the capture of neutrons with energies below about $1 \mathrm{keV}$. Such a capture results in a stable nuclide or a shorter-lived nuclide that decays quickly to a stable nuclide. 
Table 4-1. Approximate Remaining Inventory of Key Radionuclides in U.S. Light-Water Reactor Spent Fuel by Year 2030. (a,b)

\begin{tabular}{llll}
\hline Nuclide & Quantity & $\begin{array}{c}\text { Half-Life } \\
(y r)\end{array}$ & Disposition(c) \\
\hline${ }^{90} \mathrm{Sr}$ & $30 \mathrm{MT}(\mathrm{d})$ & 29 & ES(e) \\
${ }^{99} \mathrm{Tc}$ & $99 \mathrm{MT}$ & $2.1 \times 10^{5}$ & TS(f) \\
${ }^{129} \mathrm{I}$ & $23 \mathrm{MT}$ & $1.6 \times 10^{7}$ & TS(g) \\
${ }^{137} \mathrm{Cs}$ & $70 \mathrm{MT}$ & 30.2 & ES(e) \\
$237 \mathrm{~Np}$ & $57 \mathrm{MT}$ & $2.1 \times 10^{6}$ & TF; TB \\
$238 \mathrm{Pu}$ & $12 \mathrm{MT}$ & 87.7 & TF; TS \\
$239 \mathrm{Pu}$ & $656 \mathrm{MT}$ & $2.4 \times 10^{4}$ & TF; TS \\
$240 \mathrm{Pu}$ & $303 \mathrm{MT}$ & 6,560 & TF; TS \\
$241 \mathrm{Pu}$ & $25 \mathrm{MT}$ & 14.4 & TF; TS \\
$242 \mathrm{Pu}$ & $61 \mathrm{MT}$ & $3.8 \times 10^{5}$ & TF; TS \\
$241 \mathrm{Am}$ & $140 \mathrm{MT}$ & 432 & TF; TB \\
$242 \mathrm{~m} \mathrm{Am}$ & $75 \mathrm{~kg}$ & 141 & TF; TB \\
$243 \mathrm{Am}$ & $12 \mathrm{MT}$ & 7,370 & TF; TB \\
$243 \mathrm{Cm}$ & $30 \mathrm{~kg}$ & 28.5 & TF; TB \\
$244 \mathrm{Cm}$ & $1,200 \mathrm{~kg}$ & 18.1 & TF; TB \\
$245 \mathrm{Cm}$ & $120 \mathrm{~kg}$ & 8,530 & TF; TB \\
\hline
\end{tabular}

(a) Based on 33,000 MWd/MT burnup of pressurized water reactor fuel, decay corrected to year 2030. Quantities are normalized to 130,000 MTU (initial inventory).

(b) Tables 1-1, 1-2, and 2-2 1 ist some additional long-1ived $\left(t_{1 / 2}>30 \mathrm{yr}\right)$ radionuclides present in spent fuel; disposition of these ofher radionuclides is discussed in Chapters 2 and 6 .

(c) $\mathrm{ES}=$ Engineered near-surface storage for -300 to $500 \mathrm{yr}$.

TS = Transmutation by thermal or epithermal neutron capture or fission to a short-lived and/or stable nuclide.

$T B=$ Transmutation by thermal or epithermal neutron capture to a beneficial actinide nuclide, e.g., $238 \mathrm{Pu},{ }^{244} \mathrm{Cm}$, $232 \mathrm{Cf}$.

$T F=$ Transmutation by fast-neutron fission to short-lived and/or stable nuclide.

(d) $M T=$ Metric ton

(e) Both ${ }^{90} \mathrm{Sr}$ and ${ }^{137} \mathrm{Cs}$ may have some beneficial uses before or during the engineered storage period.

(f) 99 Tc will be transmuted to stable Ru.

(g) 129 will be transmuted to stable $\mathrm{Xe}$. 
Two options for dealing with the actinides listed in Table 4-1 are

1. Emphasis on fission to produce generally short-lived fission products, or

2. Emphasis on neutron capture to produce heavier actinides for beneficial use.

The optimal method of exercising Option 1 for ${ }^{237} \mathrm{~Np}$ and ${ }^{241} \mathrm{Am}$ is with a fast neutron spectrum with an average neutron energy above a few hundred $\mathrm{keV}$. Use of neutrons in the epithermal ( $1 \mathrm{eV}$ to $1 \mathrm{keV}$ ) or thermal range results in the second option. Option 2 yields large quantities of ${ }^{238} \mathrm{Pu}$, which is an excellent radioisotope heat source. Option 2 can also generate useful quantities of higher mass elements, including curium, berkelium, californium, einsteinium, and fermium. These higher mass elements are useful in heavy element physics and chemistry research, and ${ }^{252} \mathrm{Cf}$ is an important neutron source for a variety of applications. Either fast reactors or thermal reactors can use plutonium as fuel.

The results of the appropriate irradiation of the nuclides listed in Table 4-1 and an associated partitioning step include beneficial radionuclides ( ${ }^{90} \mathrm{Sr},{ }^{137} \mathrm{Cs},{ }^{238} \mathrm{Pu}$, fuel-grade plutonium, ${ }^{244} \mathrm{Cm}$, and $\left.{ }^{252} \mathrm{Cf}\right)$ and shorter-lived fission products and actinides (half-lives $<30 \mathrm{yr}$ ).

\subsubsection{Nuclear Data and Transmutation Possibilities}

For neutron transmutation calculations it is important to have reliable neutron capture cross-section data in the energy range from thermal to about $1 \mathrm{keV}$, and reliable neutron fission cross-section data from thermal to a few MeV. Reasonably reliable nuclear data exist for the following isotopes and elements: ${ }^{99} \mathrm{Tc},{ }^{127} \mathrm{I},{ }^{129} \mathrm{I}$, neptunium, plutonium, americium, curium, and berkel ium. 
Estimates for transmutation of ${ }^{127} \mathrm{I},{ }^{129} \mathrm{I}$, and ${ }^{99} \mathrm{TC}$ are straightforward. All these isotopes can be irradiated without prior isotope separation because a11 neutron capture products are short-lived radioisotopes that decay to stable isotopes (Table 4-1 and Figures 4-1 and 4-2).

Figure 4-1. Iodine Isotope Transmutation Chain.

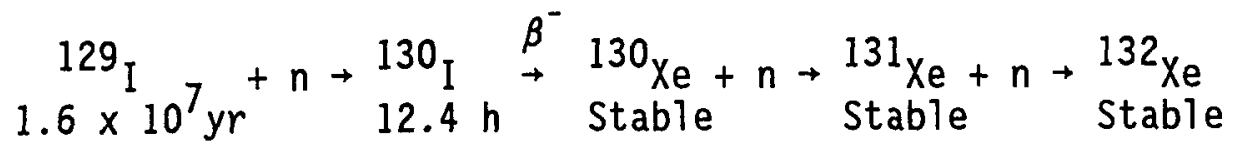

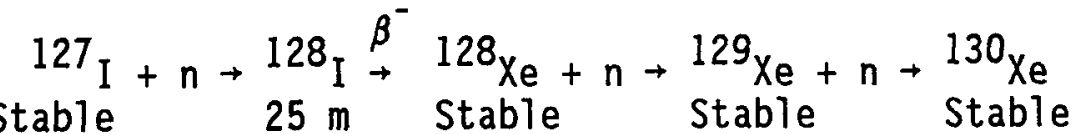

Figure 4-2. ${ }^{99} \mathrm{Tc}$ Transmutation Chain.

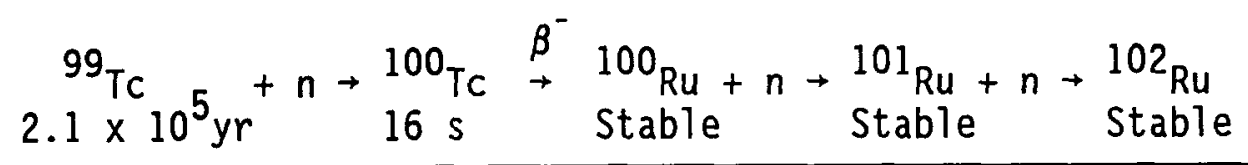

The situations for ${ }^{90} \mathrm{Sr}$ and ${ }^{137} \mathrm{Cs}$ are more complicated. Figures $4-3$ and 4-4 show the transmutation and decay chains for ${ }^{90} \mathrm{Sr}$ and ${ }^{137} \mathrm{Cs}$, respectively. Although there are potentially large-scale beneficial uses for ${ }^{90} \mathrm{Sr}$ and ${ }^{137} \mathrm{Cs}$, these uses are complicated by the existence of other stable or long-lived isotopes of the same element that effectively dilute the beneficial isotopes. It may be desirable to have isotopic separation capability for both strontium and cesium to separate out the ${ }^{90} \mathrm{Sr}$ and ${ }^{137} \mathrm{Cs}$ from the other strontium and cesium nuclides, respectively. Following beneficial use for a long period of time, chemical processing could be used to extract the unused ${ }^{90} \mathrm{Sr}$ and ${ }^{137} \mathrm{Cs}$ to be combined with additional ${ }^{90} \mathrm{Sr}$ or ${ }^{137} \mathrm{Cs}$ in other sources. The amounts of ${ }^{90} \mathrm{Sr}$ and ${ }^{137} \mathrm{Cs}$ that exceeded that employed for beneficial use might be destroyed by irradiation in an optimally chosen particle spectrum. Lack of neutron capture data prevents prediction of the optimal neutron spectrum 
Figure 4-3. Strontium Isotope Transmutation Chain.

\begin{tabular}{|c|c|}
\hline 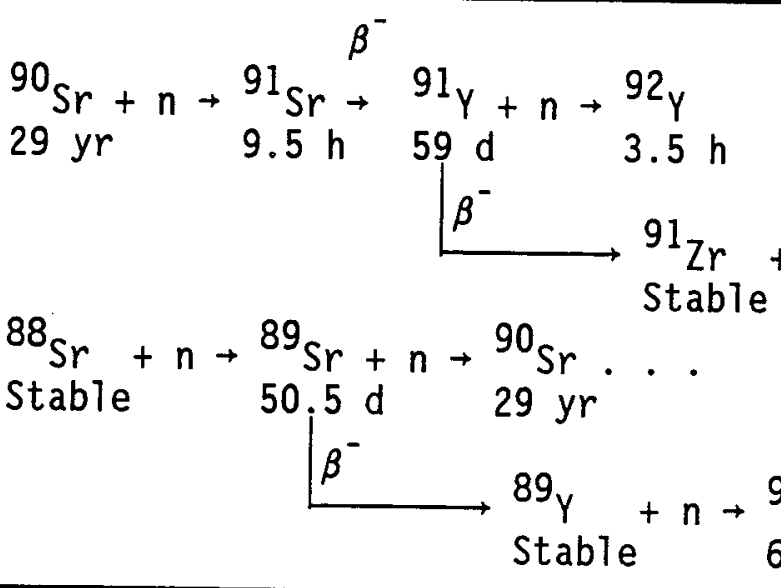 & 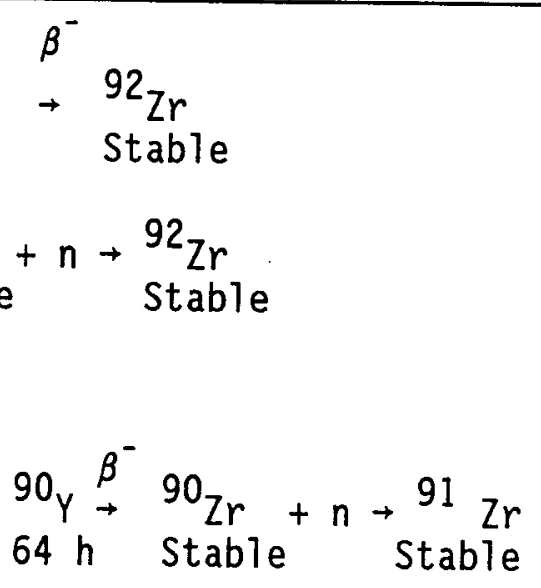 \\
\hline
\end{tabular}

Figure 4-4. Cesium Isotope Transmutation Chain.

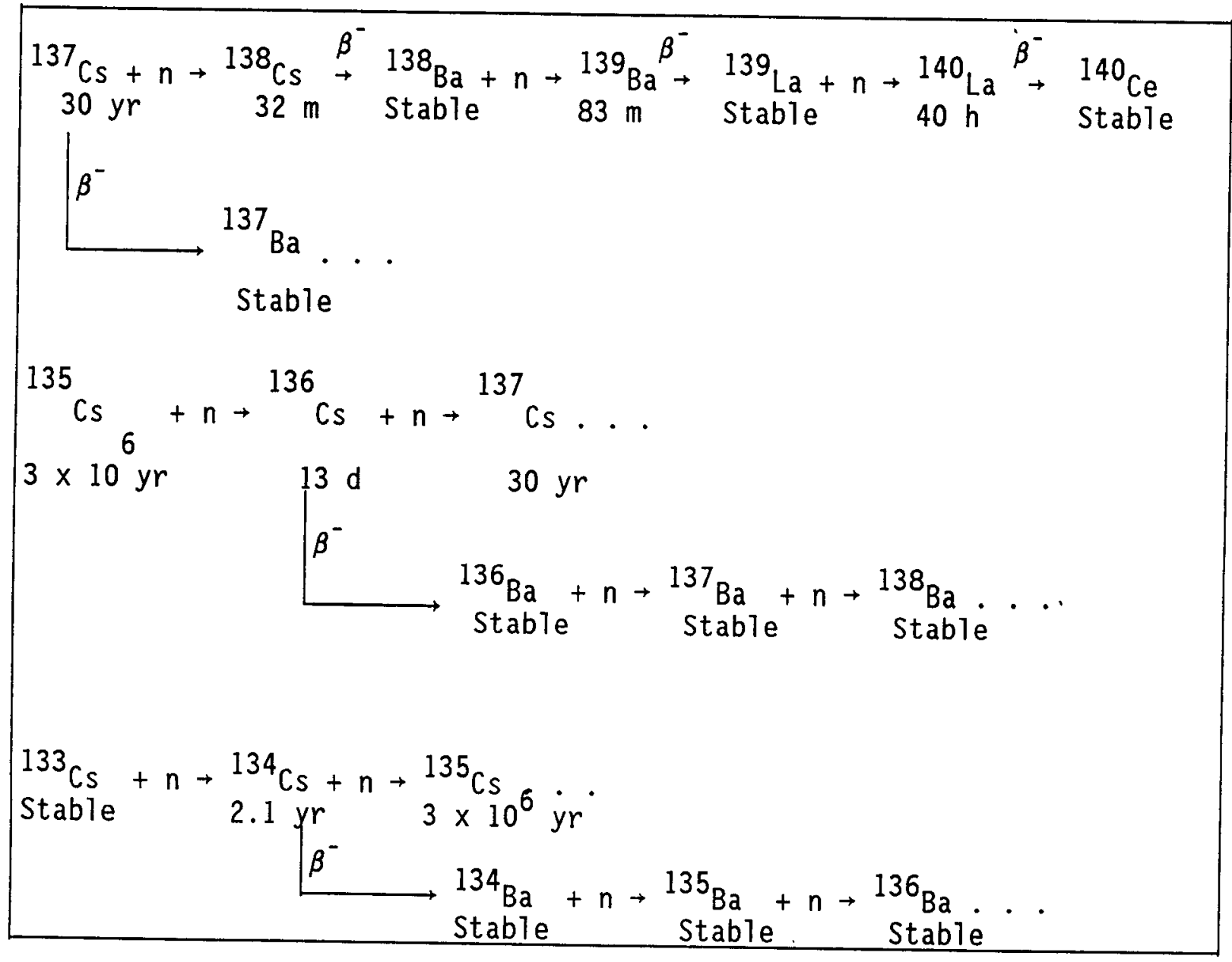


for destruction of ${ }^{90} \mathrm{Sr}$ and ${ }^{137} \mathrm{Cs}$. The natural decay rate of both ${ }^{90} \mathrm{Sr}$ and ${ }^{137} \mathrm{Cs}$ is about $2 \% / \mathrm{yr}$, and this may exceed attainable transmutation rates. High-flux reactor or accelerator targets may provide a long-range means of transmuting ${ }^{137} \mathrm{Cs}$ and ${ }^{90} \mathrm{Sr}$.

Neptunium-237 will make a good fast spectrum reactor fuel (destruction by fission), or it can be irradiated in a thermal or epithermal spectrum to produce ${ }^{238} \mathrm{Pu}$ for beneficial use. Conversion of the $57 \mathrm{MT}$ of ${ }^{237} \mathrm{~Np}$ to ${ }^{238} \mathrm{Pu}$ would result in the equivalent of about 25 megawatt thermal (MWt) heat energy, or enough thermal energy to power many thousands of radioisotope-powered thermoelectric generators for remote space or terrestrial uses. Figure 4-5 shows the neptunium transmutation and decay chain. With proper care in target and reactor design, the undesirable $236 \mathrm{pu}$ product impurity can be held to acceptable concentrations.

Figure 4-5. ${ }^{237} \mathrm{~Np}$ Transmutation Chain.

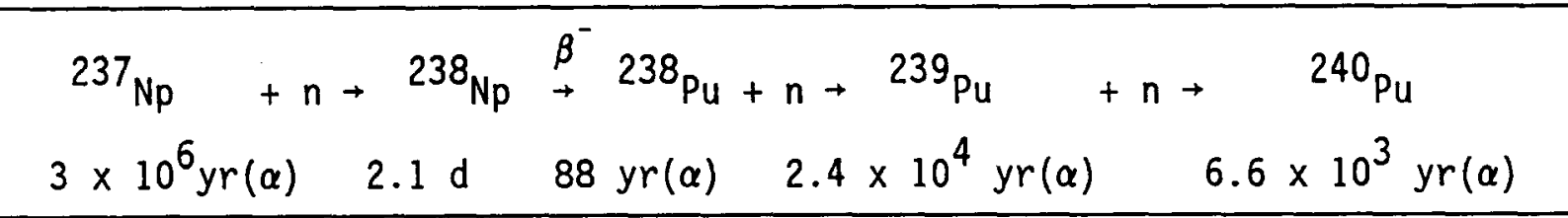

Americium is similar to neptunium, in that it is a good fast-spectrum reactor fuel, and beneficial isotopes are created by neutron capture. Figure 1-1 shows the simplified transmutation and decay scheme for plutonium, americium, and some of the curium isotopes. Neutron capture by $241_{\text {Am }}$ results in the production of ${ }^{242} \mathrm{Am}$ which decays primarily to ${ }^{238} \mathrm{Pu}$. Plutonium produced by americium irradiation (assuming 2 to 3 years of decay) is approximately $80 \% 238 \mathrm{Pu}$ and $20 \% 242 \mathrm{Pu}$, with negligible $236 \mathrm{Pu}$ content. Neutron capture by ${ }^{243} \mathrm{Am}$ produces ${ }^{244} \mathrm{Cm}$, which is a potential high quality heat source isotope. Another option is to allow buildup of the higher curium isotopes into the higher mass elements as shown in Figure 1-1, especially ${ }^{252} \mathrm{Cf}$. The production of ${ }^{252} \mathrm{Cf}$ may require the use of a specially designed high-flux irradiation facility to meet product quality requirements. 
Table 4-1 shows that about 1,000 metric ton plutónium (MTPu) will exist in the U.S. inventory of LWR spent fuel by the year 2030. This amount of plutonium is almost sufficient to fuel enough fast spectrum fission reactors to replace the existing LWR nuclear fission reactor electrical capability. An obvious potential future energy/waste management strategy would be to use plutonium to fuel reactors, some of which could also be used to destroy other hazardous by-products of spent fuel reprocessing. The mix of energygenerating fast breeder and fast burner reactors could be adjusted to any desired energy policy from closing out the use of fission reactors and eliminating the generation of nuclear waste to continuing the use of fission reactors while maintaining a constant or slowly increasing inventory of nuclear waste. To demonstrate the feasibility of such a scenario, adequate nuclear transmutation rates for the longer-1ived fission products and actinides must be demonstrated.

\subsubsection{Potential Neutron Transmutation Devices}

Several devices could be used to generate high-intensity neutron sources to be used for nuclear waste transmutation: fission reactors, fusion reactors, and spallation neutron sources. Fission reactors of various types exist today, as do low-intensity spallation neutron sources.

A few studies of isotope transmutation using fusion reactors exist. Because of the need to produce tritium to sustain the fusion reaction, deuterium-tritium (D-T) fusion reactors may have limited potential for use of leakage neutrons to transmute waste. The feasibility of fusion reactors is not demonstrated.

The high-intensity spallation source envisioned for transmutation purposes might be a 1-2 GeV proton or deuteron linear accelerator with a continuous wave average current of 20 to $300 \mathrm{~mA}$, and a beam power of 20 to $600 \mathrm{MW}$. The charged particle beam would impinge on a heavy element target, generating on the order of 50 to 100 neutrons per proton by a nuclear spallation process (Schneider and Platt 1974). Each proton or deuteron 
interacts directly with several target nuclei to knock out one or more neutrons and leave the target nuclei in excited states which decay by subsequent neutron emission. The resulting neutron spectrum resembles a fission neutron spectrum, with a high-energy tail that extends up to the incident beam energy. Only limited estimates exist for the viability of such devices for nuclear waste transmutation. Because of the flexibility to optimize the neutron spectrum for various waste isotopes and the potential for use in case of phaseout of fission reactors, spallation devices may be a very attractive long-range choice for waste transmutation. Although highintensity spallation sources for waste transmutation appear to be technically feasible, the integrated technology remains to be demonstrated. Such a demonstration may be worthwhile in the near future if preliminary target concepts indicate overall advantages in cost and waste transmutation capability relative to LMRs.

Excess neutrons in fission reactors can be divided into two categories:

1. Neutrons leaking out of the fuel region of the core

2. Neutrons in the fuel region that are not required to sustain the fission reaction.

Neutrons in the first category are typically reflected to the core to the extent possible in order to maximize power generation and to prevent neutron damage and activation of out-of-core components. Neutrons in the second category are mostly captured by the coolant, structural materials, fertile heavy metal, i.e., $238 \mathrm{U}$, control material, and fissile heavy metal, i.e., $235 \mathrm{U}$. Both categories of excess neutrons may be used to transmute waste isotopes. The final choice of the source of transmutation neutrons may differ for different reactor types, and, in general, depends upon many factors.

Table 4-2 lists estimated LWR thermal spectrum destruction rates for some of the longer-1ived waste products. The ${ }^{99} \mathrm{Tc}$ transmutation rate appears 
Table 4-2. LWR Nuclide Destruction Rates.

\begin{tabular}{lc}
\hline Isotope & Rate $(\% / \mathrm{yr})$ \\
\hline${ }^{99} \mathrm{TC}$ & 11 \\
${ }^{129} \mathrm{I}$ & 3 \\
Actinides & $5-7$ \\
\hline
\end{tabular}

NOTE: These rates do not include reprocessing cycle time, and are in units of percent/effective full power year.

attractive in that present LWRs could begin destruction of ${ }^{99} \mathrm{Tc}$. By the middle of the twenty-first century, most energy experts expect a phaseout of uraniumfueled LWRs and an introduction of higher efficiency plutonium burning reactors. This may result in plutonium-fueled advanced light-water reactors (ALWR) and/or plutonium-fueled FRs. No estimates are available for the potential of ALWRs to transmute waste products. However, the ALWR neutron spectrum will be harder than that of today's LWR; hence, ALWR nuclear transmutation rates may be more attractive than those in LWRs for some isotopes.

To achieve high neutron capture rates in a FR, special hydride assemblies would surround the fueled region and moderate the leakage neutrons from the fast region into the epithermal neutron energy range. The epithermal neutron capture cross section is high for both ${ }^{99} \mathrm{Tc}$ and ${ }^{129} \mathrm{I}$, and attractive neutron capture transmutation rates are possible under favorable conditions.

Very limited calculations of the potential for transmutation of selected nuclides in a FR were made as part of this study. The hard neutron spectrum in the fueled region of a FR, because of small neutron capture cross sections, would yield very low waste neutron capture transmutation rates, although this region may be used to fission actinides because of the relatively high fission/capture ratio for this neutron spectrum. 


\subsubsection{Preliminary Estimates of Fast Reactor Transmutation Feasibility}

United States reactor designers have recently studied modular sodiumcooled FR concepts. The emphasis of these studies has been to develop designs that have enough passive safety margin to withstand the most severe postulated accidents without fuel damage.

For purposes of this report, the Rockwell International Corporation's Sodium Advanced Fast Reactor (SAFR) core design was arbitrarily selected for assessment of transmutation feasibility in FRs. The SAFR reference design for 900 MWT ( 400 MWe) utilizes a heterogeneous core design, with both internal and radial uranium blanket assemblies. Several variations of the basic SAFR core layout, with substitution of target assemblies for blanket assemblies, resulted in a decision to limit studies to core designs that retain the internal blanket assemblies and replace only radial blanket assemblies with target assemblies.

The acronym CLFR (Cleanup Fast Reactor) is used in the following discussion to denote a transmutation FR. To compensate partially for the reactivity penalty associated with radial target assemblies, the CLFR also has fuel in the former inner radial blanket row. The resulting core contains only target and fuel assemblies in the row of assemblies adjacent to the core region. For the calculational studies, the fuel consisted of $\mathrm{Pu}-\mathrm{U}-\mathrm{Zr}$ metal fuel. Plutonium isotopic compositions used are typical of those in LWR spent fuel (Table 4-1). Ternary Pu-U-Zr fuel is in the early developmental stage and is used in these calculations mainly for comparisons. Mixed $\mathrm{PuO}_{2}-\mathrm{UO}_{2}$ fuel is the existing proven FR fue1, and burnup extension to 15 atom \% (150,000 MWd/THM) appears feasible using advanced structural materials.

The target assemblies consist of hydride assemblies similar to that demonstrated in the Fast Flux Test Facility (FFTF) in 1987. The FFTF test contained a 19-pin array of yttrium hydride pins with an approximate diameter of $2 \mathrm{~cm}$, with thirty-six $0.6-\mathrm{cm}-$ diameter target pins interspersed among the hydride pins. The FFTF test and supporting analyses demonstrated the ability 
to calculate reaction rates accurately with the Monte Carlo Neutron Photon (MCNP) transport code, provided the basic transmutation nuclear cross sections are well known. If neutron capture cross sections derived from MCNP calculations are used in the two dimensional diffusion theory code (2DB), approximately correct reactivity and transmutation rate data can be obtained.

Table 4-3 summarizes the results of a 2DB calculation for a nonoptimized CLFR core configuration. Target elements were radioiodine (in the form of sodium iodide) and ${ }^{99} T c$ (in metal form). Epithermal and thermal neutron crosssection data are relatively well known for both ${ }^{99}$ Tc and radioiodine. A 100-d burnup calculation provided estimates of the annual reactivity swing, as well as the target isotope fractions transmuted annually, assuming a capacity factor of 70 percent.* The assumed CLFR configuration results in annual destruction rates of about 5 percent/yr and 10 percent/yr for ${ }^{99} \mathrm{Tc}$ and ${ }^{129} \mathrm{I}$, respectively. Because of the much higher macroscopic absorption cross section in the ${ }^{99} \mathrm{Tc}$ target than in the radioiodine target, there is a larger neutron self-shielding and flux depression associated with ${ }^{99} \mathrm{TC}$, resulting in the lower transmutation fraction. The core conversion ratio for this CLFR configuration is about 0.8, which compares with 1.1 for the SAFR design. The CLFR will, therefore, be a net burner of plutonium. A mixture of SAFR and CLFR modules could provide electricity production options ranging from a gradual shutdown of fission reactor capability using only CLFR reactors to an increasing fission reactor capability with more SAFR modules than CLFR modules. In order to estimate recycle target element throughput rates, reactor residence times of $6 \mathrm{yr}$ and $3 \mathrm{yr}$ were assumed for ${ }^{99} \mathrm{Tc}$ and radioiodine targets, respectively, to produce about 30 percent target depletion of each element before recycle.

At the same time the CLFR reactor is transmuting various elements in target assemblies, it is also producing higher mass actinides and fission products in its fuel and internal blanket assemblies. Table 4-4 summarizes the estimated annual production of these elements in the CLFR fuel, based on an ORIGEN2 calculation for the CLFR fuel. The in-reactor fuel inventory, as penalty.

${ }^{\star} 0$ nly technetium and iodine target assemblies present a reactivity 
Table 4-3. Cleanup Fast Reactor Fission Product and Actinide Destruction Rates.

\begin{tabular}{|c|c|c|c|c|c|}
\hline \multicolumn{3}{|l|}{ Parameter } & \multicolumn{3}{|c|}{ Value } \\
\hline \multicolumn{4}{|c|}{$\begin{array}{l}\text { Number of fuel assemblies in radial blanket } \\
\text { Number of Tc assemblies in radial blanket } \\
\text { Number of NaI assemblies in radial blanket } \\
\text { BOL } * \text { eigenvalue } \\
\text { Eigenvalue after } 100-d \text { burnup } \\
\text { Reactivity swing in } 250-d \\
\text { Core conversion ratio at BOL } \\
\text { Burnup in fuel after } 100-d \text { burn } \\
\text { Goal average fuel burnup } \\
\text { Core residence time to achieve goal burnup }\end{array}$} & \multicolumn{2}{|c|}{$\begin{array}{l}12 \\
12 \\
12 \\
1.028 \\
1.019 \\
0.0225 \\
0.82 \\
0.95 \text { wt\% } \\
15 \text { atom\% } \\
6.5 \text { yr }\end{array}$} \\
\hline & ${ }^{99} T \mathrm{C}$ & $\underline{127} \underline{I}$ & $\underline{129}$ I & U & $\mathrm{Pu}$ \\
\hline $\mathrm{BOL}$ target mass, $\mathrm{kg}$ & 327 & 21.9 & 66.6 & - & -- \\
\hline BOL fuel mass, $\mathrm{kg}$ & -- & -- & -- & 7,349 & 2,467 \\
\hline $\mathrm{BOL}$ blanket mass, $\mathrm{kg}$ & - & -- & -- & 3,745 & 0 \\
\hline Fuel mass after 100-d burn, $\mathrm{kg}$ & -- & -- & - & 7,304 & 2,419 \\
\hline Blanket mass after $100-\mathrm{d}$ burn, $\mathrm{kg}$ & - & -- & -- & 3,719 & 22.6 \\
\hline $\begin{array}{l}\text { Rate of target mass burned in } \\
250-\mathrm{d}, \mathrm{kg} / \mathrm{yr}\end{array}$ & 16.3 & 2.3 & 6.5 & - & -- \\
\hline $\begin{array}{l}\text { Rate of target mass burned in } \\
250-d, \% / y r\end{array}$ & 5.1 & 10.5 & 10.0 & - & -- \\
\hline
\end{tabular}

$(*)$ Beginning of life. 
Table 4-4. Approximate Cleanup Fast Reactor Waste Isotope Annual Generation Rates.

\begin{tabular}{lc}
\hline Isotope & Production rate (per 900 MWT module) $(\mathrm{kg} / \mathrm{yr})$ \\
\hline${ }^{88} \mathrm{Sr}$ & 1.3 \\
${ }^{90} \mathrm{Sr}$ & 1.8 \\
${ }^{133} \mathrm{Cs}$ & 7.9 \\
${ }^{135} \mathrm{Cs}$ & 9.4 \\
${ }^{137} \mathrm{Cs}$ & 7.8 \\
${ }^{99} \mathrm{TC}$ & 5.4 \\
${ }^{127} \mathrm{I}$ & 0.6 \\
${ }^{129} \mathrm{I}$ & 1.7 \\
${ }^{237} \mathrm{~Np}$ & 0.1 \\
$241_{\mathrm{Am}}$ & 8.6 \\
$243 \mathrm{Am}$ & 1.0 \\
P1utonium & $-64(*)$ \\
Curium & 0.056 (most ty $244 \mathrm{Cm})$ \\
\hline
\end{tabular}

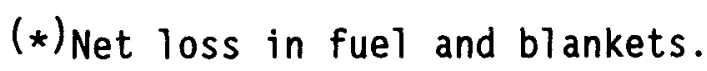


well as that in the CLFR fuel reprocessing stream, must be accounted for in calculations of total isotope inventory calculations. The assumed CLFR driver fuel goal average burnup is 150,000 MWd/MTHM. In the CLFR, the corresponding average core residence time for fuel is about $6.5 \mathrm{yr}$.

Figures 4-6 and 4-7, along with the fuel and target residence times previously defined, provide the relevant inventory and throughput information required for strategy evaluations, facility requirements, and cost estimates for transmutation of only ${ }^{99} \mathrm{TC}$ and ${ }^{129} \mathrm{I}$. [Data in these figures indicate a net destruction of ${ }^{99} \mathrm{TC}$ and ${ }^{129}$ I in the CLFR (see Section 4.2.1).]

Transmutation of either ${ }^{90} \mathrm{Sr}$ or ${ }^{137} \mathrm{Cs}$ is more complicated than transmutation of neptunium, americium, and curium in either a fast neutron core spectrum or an epithermal neutron hydride spectrum. To transmute ${ }^{90} \mathrm{Sr}$ and ${ }^{137} \mathrm{Cs}$, a prior isotopic separation step may be required to isolate these two nuclides from other isotopes of cesium and strontium.

\subsection{TRANSMUTATION OF TECHNETIUM AND IODINE}

\subsubsection{Scenarios That Illustrate CURE Impact}

Two CURE concept scenarios are presented to illustrate the use of CURE concept technology to 1 imit ${ }^{99} T_{c}$ and ${ }^{129}$ I inventory accumulation during the power production phase of the fission reactor life cycle and to effectively eliminate ${ }^{99}$ TC and ${ }^{129}$ I inventory during fission reactor phaseout. Scenario 1 , a reference LWR scenario, is presented for comparison. The case for elimination of the minor actinides $\mathrm{Np}$ and $\mathrm{Am}$ is qualitatively similar.

Because the CURE concept is flexible and can be used to pursue many different goals, a large number of scenarios are needed to adequately characterize its potential. In fact, one goal of follow-on studies of the CURE concept should be to identify opportunities, desirable tradeoffs, and criteria which are most important in shaping CURE scenarios. 


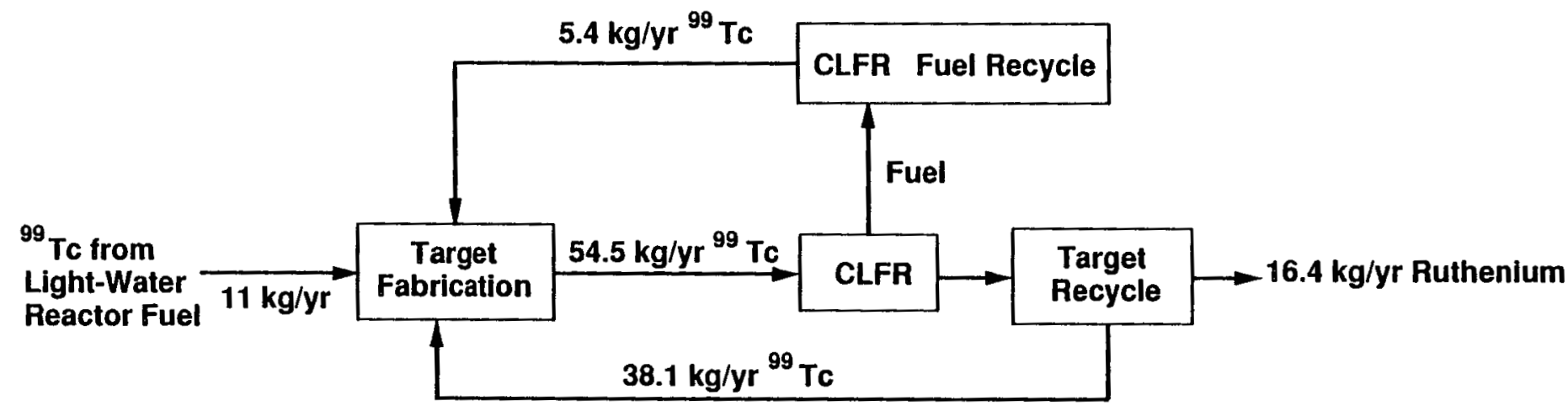

Notes: - Equilibrium CLFR Inventory: $\sim 278 \mathrm{~kg}^{99} \mathrm{Tc}, \sim 49 \mathrm{~kg} \mathrm{Ru}$

- Six-Year Residence Time for Technetium Targets

- Assumes one CLFR Reactor Operating at 900 megawatt thermal (MWt)

- $\mathrm{CLFR}=$ Cleanup Fast Reactor

38909034.2 


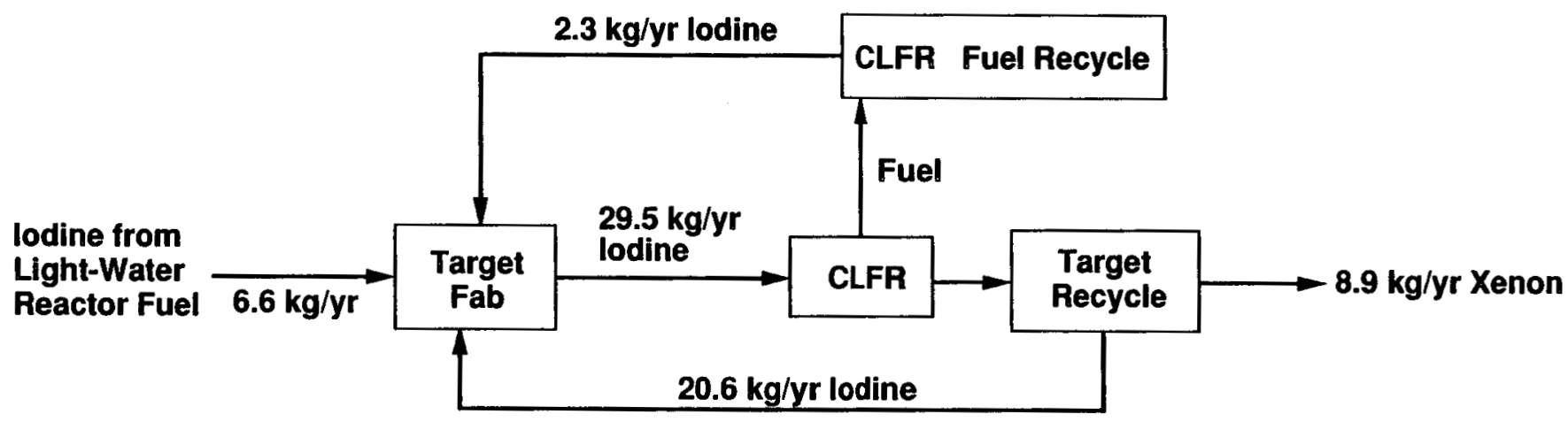

Notes: - Equilibrium CLFR Inventory: $\sim 14 \mathrm{~kg}^{127} \mathrm{l}, \sim 42.6 \mathrm{~kg}^{129} \mathrm{l}, \sim 10 \mathrm{~kg} \mathrm{Xe}$

- Three - Year Residence Time for lodine Targets

- CLFR = Cleanup Fast Reactor

38909034.3 
WHC-EP-0268

The following examples of CURE scenarios are presented with the following caveats:

- Scenarios and the CURE concept are not optimized.

- Subsystem performance is preliminary and not fully developed.

- The tradeoff between early power generation growth by the breeder/burner mix and rapid elimination of ${ }^{99} \mathrm{TC}$ and ${ }^{129} \mathrm{I}$ is a compromise case. Additional scenarios are needed to show either rapid power production growth or increased ${ }^{99}$ TC and ${ }^{129}$ I burning rate.

- The LWR phaseout is arbitrary and flexible. It can be adjusted based on electric power generation needs. The use of LWR to burn ${ }^{99} T C$ was not included.

\section{Scenario 1: Produce Electric Power with LWRs (Reference Scenario).}

In Scenario 1, the following assumptions are made:

- All fission reactor electricity demands are satisfied by LWRs.

- The CURE concept is not employed.

- Electricity demand from power reactors is assumed to be about $100 \mathrm{GW}$ until the year 2030, then grows at a rate of 0.8 percent/yr (Figure 4-8).

Scenario 1 is presented as a baseline case for comparison purposes. The consequence of continued total dependence on LWRs is the inventory accumulation of ${ }^{99} \mathrm{Tc}$ and ${ }^{129}$ I (Figure 4-9). For example, the power production assumed in Scenario 1 results in 95 MT of ${ }^{99} \mathrm{Tc}$ and 21 MT of ${ }^{129}$ I being accumulated by the year 2030. By the year 2150, 470 MT of ${ }^{99}$ TC and 293 MT ${ }^{129}$ I will accumulate. If U.S. reactor fuel is not reprocessed and, consequently, spent 
Figure 4-8. U.S. Nuclear Electricity Production Over Time.

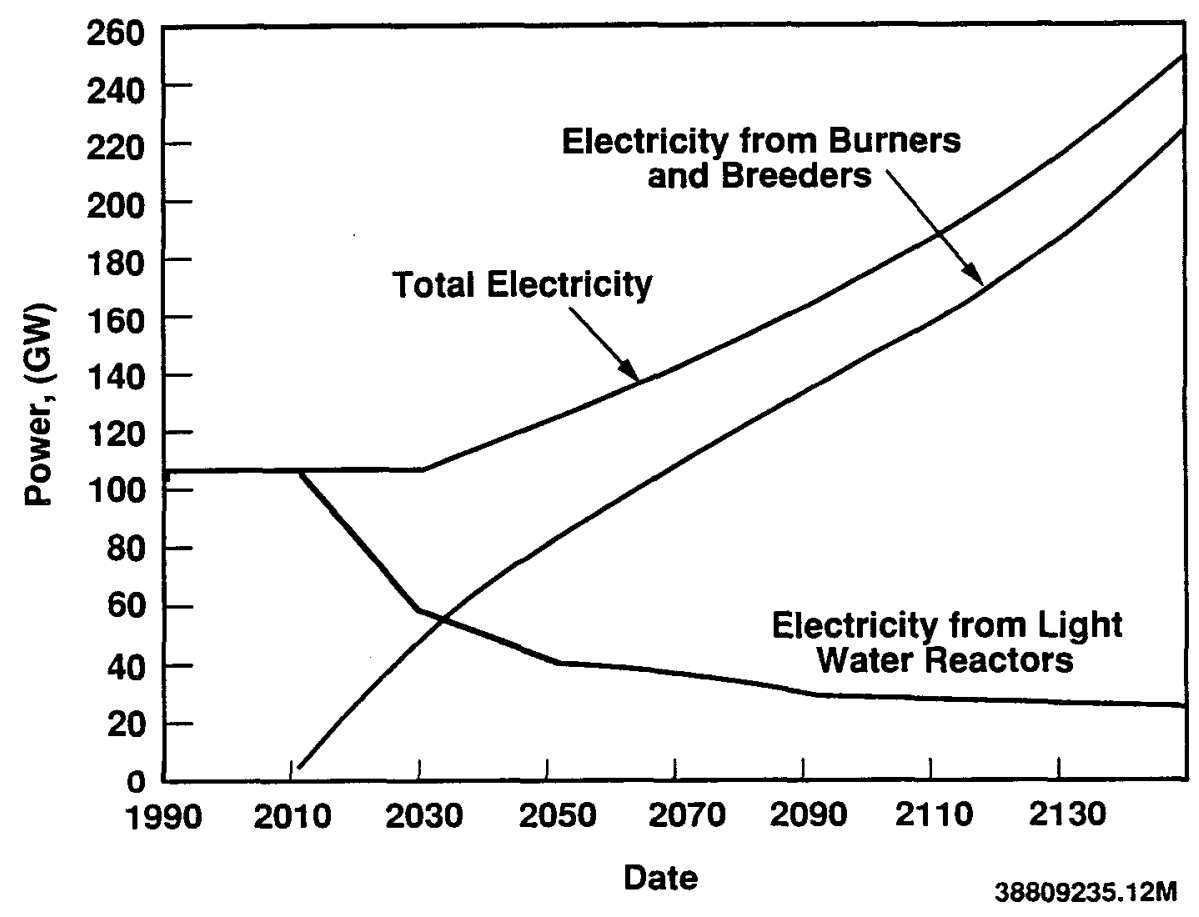


Figure 4-9. Inventory of ${ }^{99} \mathrm{TC}$ and ${ }^{129} \mathrm{I}$ in Light-Water Reactor Fuel as a Function of Time (Scenario 1).

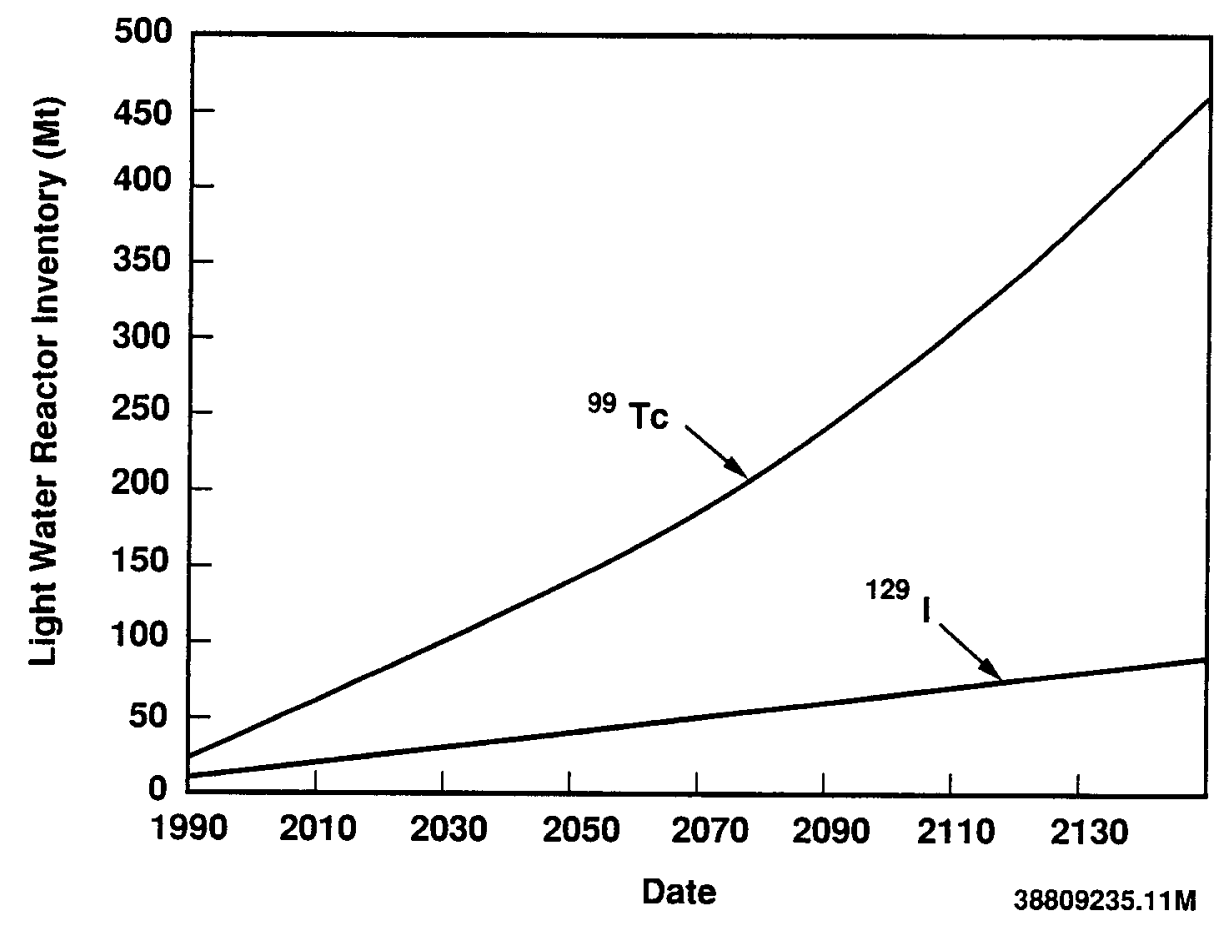


fuel is emplaced in a geologic repository, this entire ${ }^{99} \mathrm{Tc}$ and ${ }^{129} \mathrm{I}$ inventory is also eventually emplaced. These two nuclides extend the hazard period for emplaced HLW to more than 100,000 yr.

\section{Scenario 2: Substitute Breeder and Burner Reactors for LWRS}

This scenario describes a complete fission reactor life cycle which reduces dependence on LWRs. It is divided into three phases:

Phase 1. Phase-in of burners and breeders. During this period the ${ }^{99} \mathrm{TC}$ and ${ }^{129}$ I inventories approach an equilibrium level. Equilibrium is an unchanging ${ }^{99} \mathrm{TC}$ and ${ }^{129}$ I inventory that depends on the ratio of breeders to burners and total power output. The number of breeders and burners that can be built is initially limited by availability of plutonium fuel.

Phase 2. The power generation complex runs at ${ }^{99} \mathrm{Tc}$ and ${ }^{129} \mathrm{I}$ equilibrium.

Phase 3. Fission power is phased out to complete the fission reactor life cycle.

During Phase 2, availability of plutonium is a constraint; a plutonium inventory must be built up to support transmutation of key fission products. Technetium-99 and ${ }^{129}$ I are then burned down to an equilibrium inventory. During Phase 2, the ${ }^{99} T c$ and ${ }^{129}$ I production rate is balanced by the ${ }^{99} T c$ and ${ }^{129}$ I burning rate, so that there is no net increase or reduction in ${ }^{99} \mathrm{Tc}$ and ${ }^{129}$ I inventory.

The SAFR or CLFR modules produce 400 MWe and 900 MWt of power. The total number of modules grows rapidly until all available plutonium has been used (Figure 4-10). It then grows more slowly, as additional plutonium from reprocessing of current LWR fuel and breeder-generated material become available. 
Figure 4-10. Number of Breeder and Burner Modules As a Function of Time (Scenario 2).

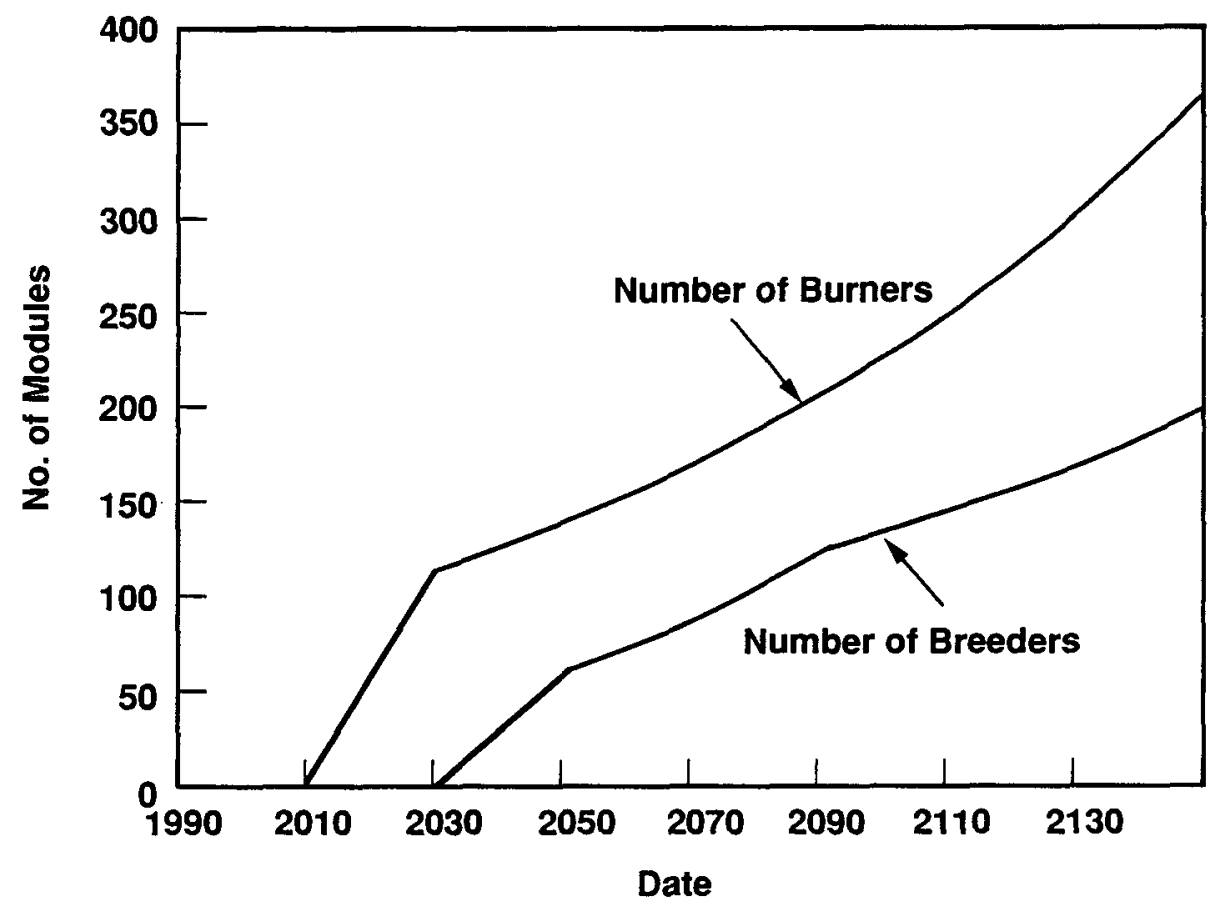

$38809235.10 \mathrm{M}$ 
Figure 4-8 illustrates the phase-in of breeder and burner electric power while phasing out of LWRs. An LWR phaseout period of at least $50 \mathrm{yr}$ is required. At some time when appropriate replacement technology is available, phaseout (Phase 3 ) of fission reactors will be called for. During this phase, when power output is no longer a constraint, burner reactors can eliminate most of the ${ }^{99}$ Tc and ${ }^{129}$ I.

\section{Scenario 3: Phaseout of Fission Reactors}

Scenario 3 describes a situation that demonstrates the ability of CURE concept technology to el iminate most ${ }^{99}$ Tc and ${ }^{129} \mathrm{I}$. The goal is to minimize the ${ }^{99} \mathrm{TC}$ and ${ }^{129} \mathrm{I}$ inventory remaining when the last CLFR type reactor is shut down. Scenario 3 involves all burners and no breeders (Figure 4-11). More burners could be built, if desired. Initially, excess ${ }^{99} \mathrm{Tc}$ and ${ }^{129} \mathrm{I}$ are burned off. Phaseout of burner reactors starts in -2076 to maximize ${ }^{99} \mathrm{Tc}$ and ${ }^{129_{\mathrm{I}}}$ burnout as their availability for in-core inventory becomes limiting.

\subsubsection{Analysis of Scenarios}

\section{Scenario 1:}

In Scenario 1, only LWRs supply electricity through the study period, and the spent fuel is not reprocessed. Figure 4-9 shows the ${ }^{99} \mathrm{Tc}$ and ${ }^{129} \mathrm{I}$ inventory which increases steadily with time. The ${ }^{99} \mathrm{Tc}$ inventory, by 2150 , will have increased to about 470 MT.

\section{Scenario 2:}

Spent fuel reprocessing at a rate of $3000 \mathrm{MT} / \mathrm{yr}$ will begin in the year 2010. The LWR phasedown starts in the year 2012. Thus, reprocessed ${ }^{99} \mathrm{Tc}$ is zero in 2010 (Figure 4-12). The total nuclide inventory is divided between spent LWR fuel, inventory in CURE processing facilities or reactors, and emplaced inventory. The aboveground inventory includes spent fuel inventory, materials in process, stocks for beneficial applications, and in-core reactor 
Figure 4-11. Number of Burner Reactor Modules as a Function of Time (Scenario 3 ).

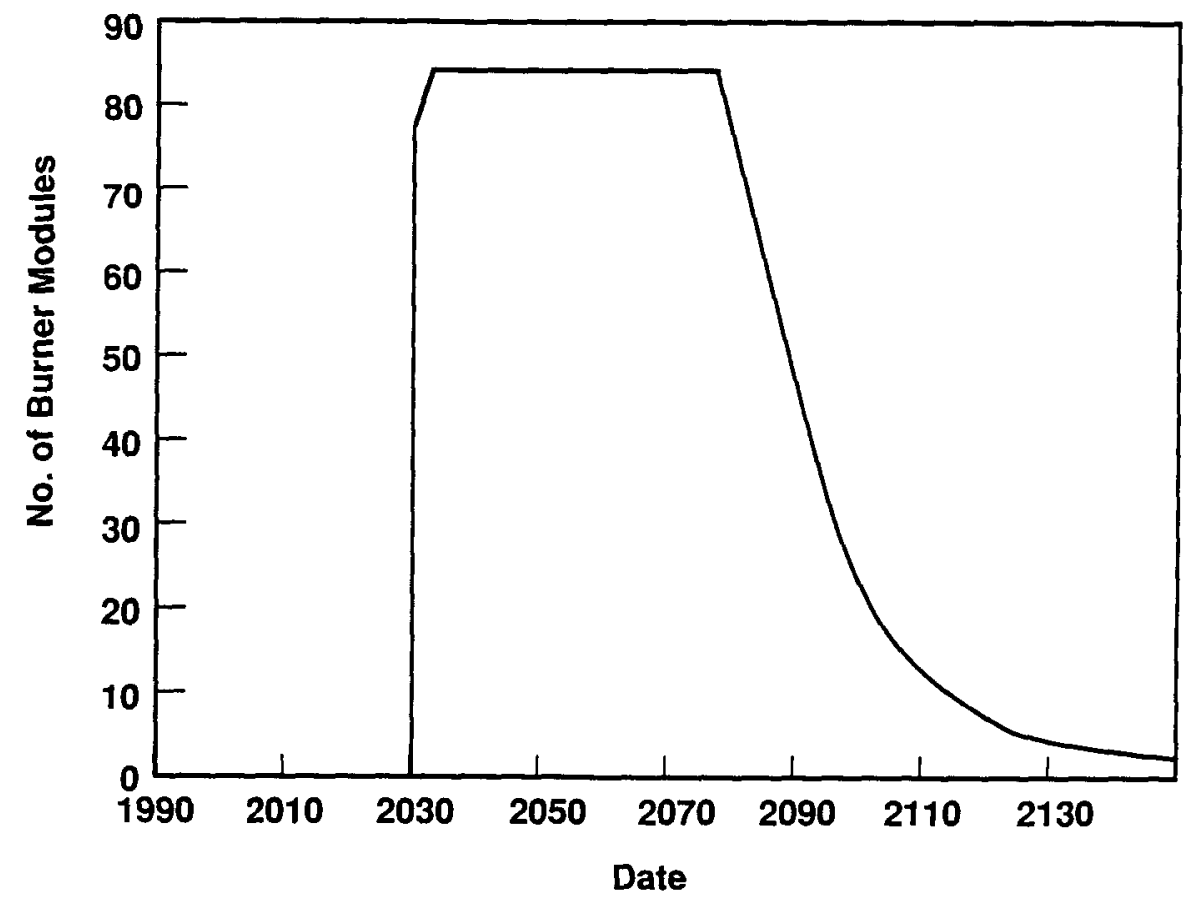

$38809235.13 M$ 
Figure 4-12. Inventory of ${ }^{99} \mathrm{Tc}$ As a Function of Time (Scenario 2).

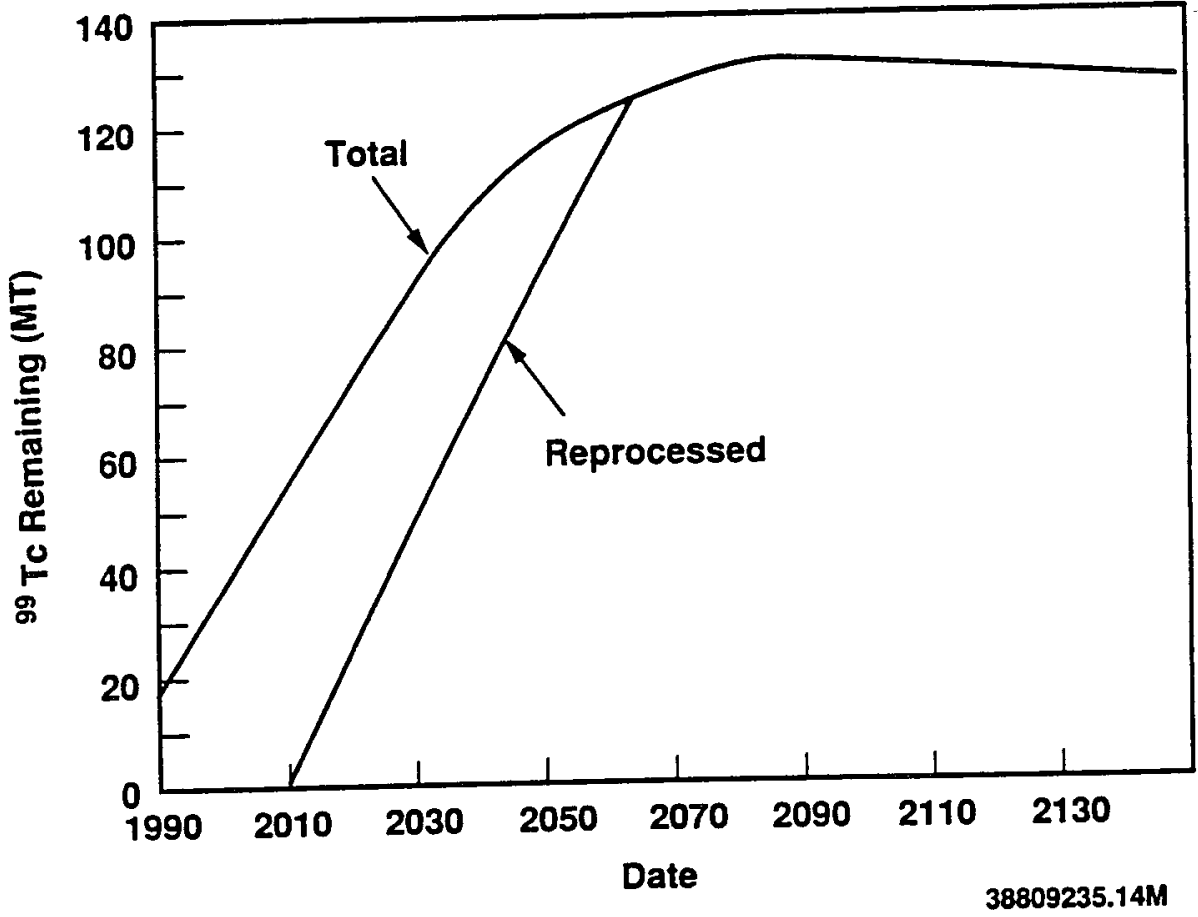


inventories. In Scenario 2, power is produced while containing ${ }^{99} \mathrm{Tc}$ and ${ }^{129} \mathrm{I}$ inventories. At the end of Scenario $2,{ }^{99} \mathrm{Tc}$ and ${ }^{129} \mathrm{I}$ are eliminated, while phasing out fission reactors.

During Phase 1 the large ${ }^{99}$ Tc inventory from LWRs becomes available between the years 2010 and 2055 . Burners el iminate 70 percent of the ${ }^{99} \mathrm{Tc}$, approaching an equilibrium inventory of about 130 MT (Figure 4-12). This shortens the phaseout time at the end of the life cycle and reduces surfacestored ${ }^{99} \mathrm{Tc}$ and radioiodine. The situation is similar for ${ }^{129} \mathrm{I}$ or, for that matter, other nuclides (Figure 4-13).

During Phase 2 the minimum ${ }^{99} \mathrm{Tc}$ and ${ }^{129}$ I inventory at equilibrium is that required in burners (Table 4-5). The equilibrium CURE ${ }^{99} \mathrm{TC}$ and ${ }^{129} \mathrm{I}$ inventories are much lower than the corresponding LWR waste inventories produced by the year 2150 (Scenario 1) and are constant, in contrast to the rapidly growing LWR inventories. At equilibrium of ${ }^{99} \mathrm{TC}$ and ${ }^{129} \mathrm{I}$, the plutonium inventory can either grow or shrink, depending on the breeder/burner ratio (Table 4-5).

\section{Scenario 3:}

Scenario 3 illustrates how the CURE concept can be used to eliminate ${ }^{99} \mathrm{TC}$ and ${ }^{129} \mathrm{I}$ during fission reactor phaseout. Figures 4-14 and 4-15 show the amount of ${ }^{99} \mathrm{Tc}$ and ${ }^{129} \mathrm{I}$, respectively, remaining during the phaseout period. Both the ${ }^{99} T c$ and ${ }^{129} \mathrm{I}$ inventories are reduced rapidly (Table 4-6). Aboveground ${ }^{99} \mathrm{TC}$ and ${ }^{129} \mathrm{I}$ inventories are el iminated over a 100 -yr burnout period. A development goal in this regard is the reduction of eventual ${ }^{99} \mathrm{TC}$ and ${ }^{129}$ I inventories by a factor of 1,000 within $80 \mathrm{yr}$ of fission reactor phaseout. Actinide conversion is expected to be comparable with ${ }^{99} \mathrm{Tc}$ and ${ }^{129}$ I conversion.

In conclusion, Figure 4-16 compares the total ${ }^{99} \mathrm{Tc}$ inventory for the three scenarios. The once-through LWR (no reprocessing) reference scenario results in continual increase in total inventory of ${ }^{99} \mathrm{Tc}$. Scenario 2 is a reactor mix designed to achieve an equilibrium ${ }^{99} \mathrm{Tc}$ inventory, and the same 
Figure 4-13. Inventory of ${ }^{129}$ I As a Function of Time (Scenario 2).

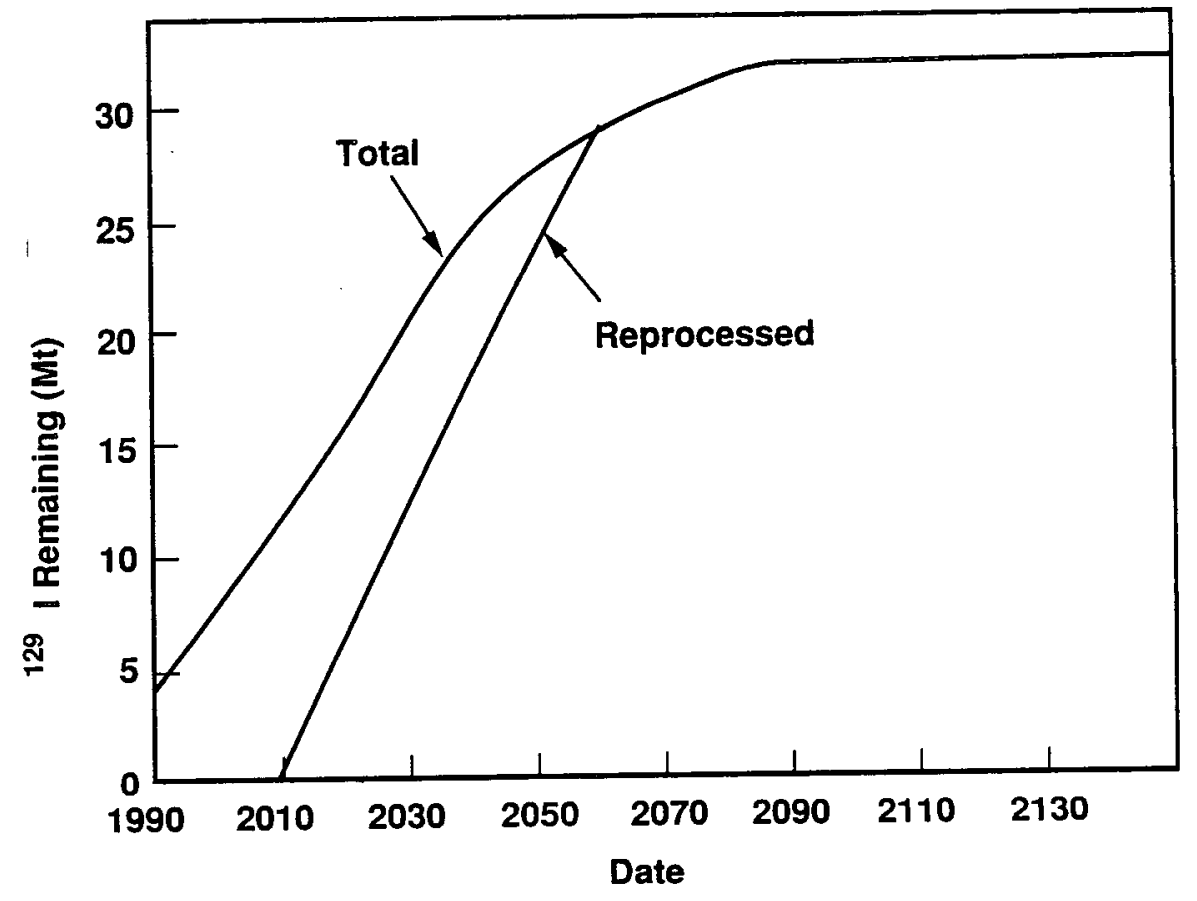

$38809235.15 \mathrm{M}$ 
Table 4-5. Equilibrium ${ }^{99} \mathrm{TC}$ and ${ }^{129} \mathrm{I}$ Inventory versus Breeder/Burner Ratio.

\begin{tabular}{ccc|c}
\hline \multicolumn{3}{c|}{ Equilibrium reactor holdup } & Production rate \\
\hline Breeder/burner ratio & ${ }^{99} \mathrm{TC}_{\mathrm{CMT}}(\mathrm{a})$ & ${ }^{129} \mathrm{I}$ (MT) & $\begin{array}{c}\text { Plutonium } \\
\text { (MT/yr) }\end{array}$ \\
\hline 0 & -- & Basis: $100 \mathrm{GW}$ (b) \\
1.1 & -- & --19 \\
2.1 & $\sim 27$ & $\sim 7.2$ & 0 \\
\hline
\end{tabular}

(a) $M T=$ metric ton.

(b) $\mathrm{GW}=$ gigawatt. 
Figure 4-14. Inventory of ${ }^{99} \mathrm{TC}$ During Phaseout of Fission Reactors.

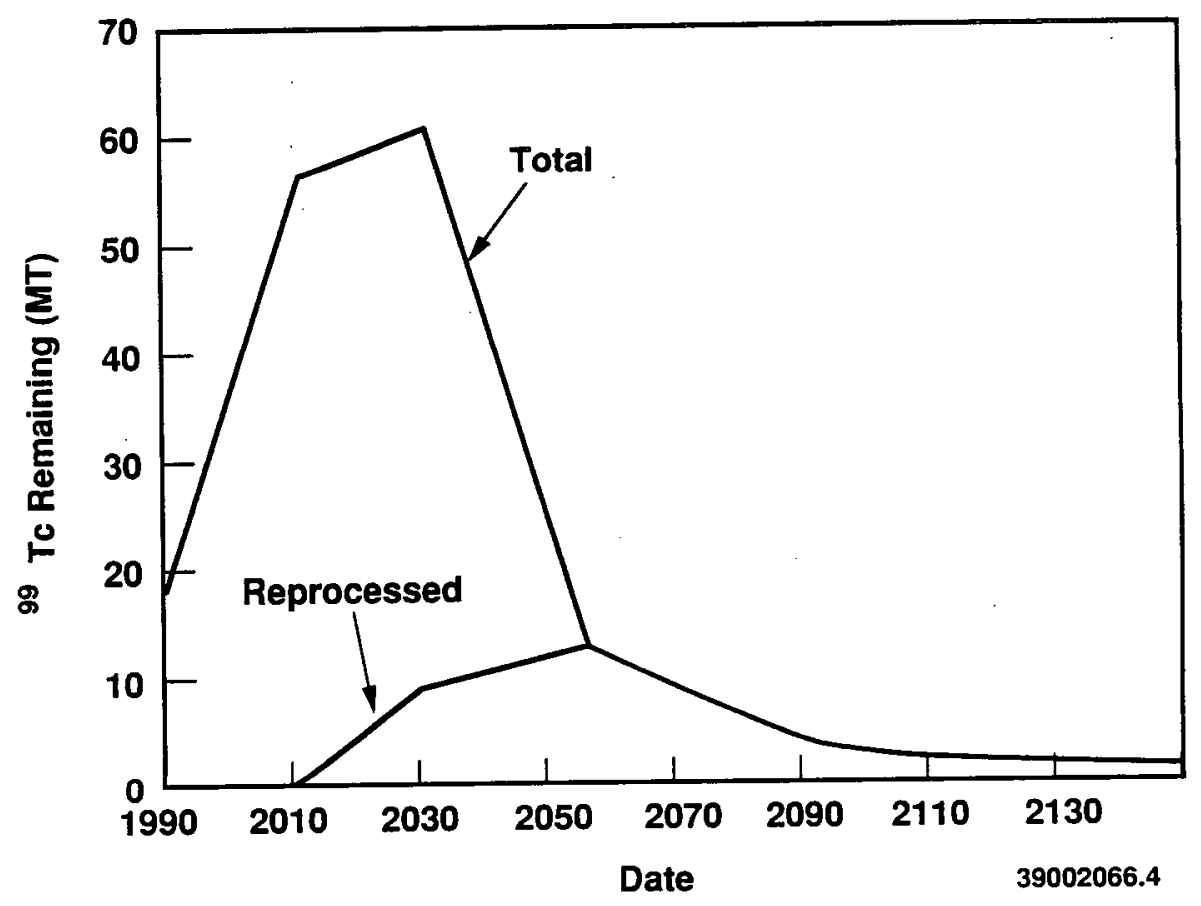


Figure 4-15. Inventory of ${ }^{129}$ I During Phaseout of Fission Reactors.

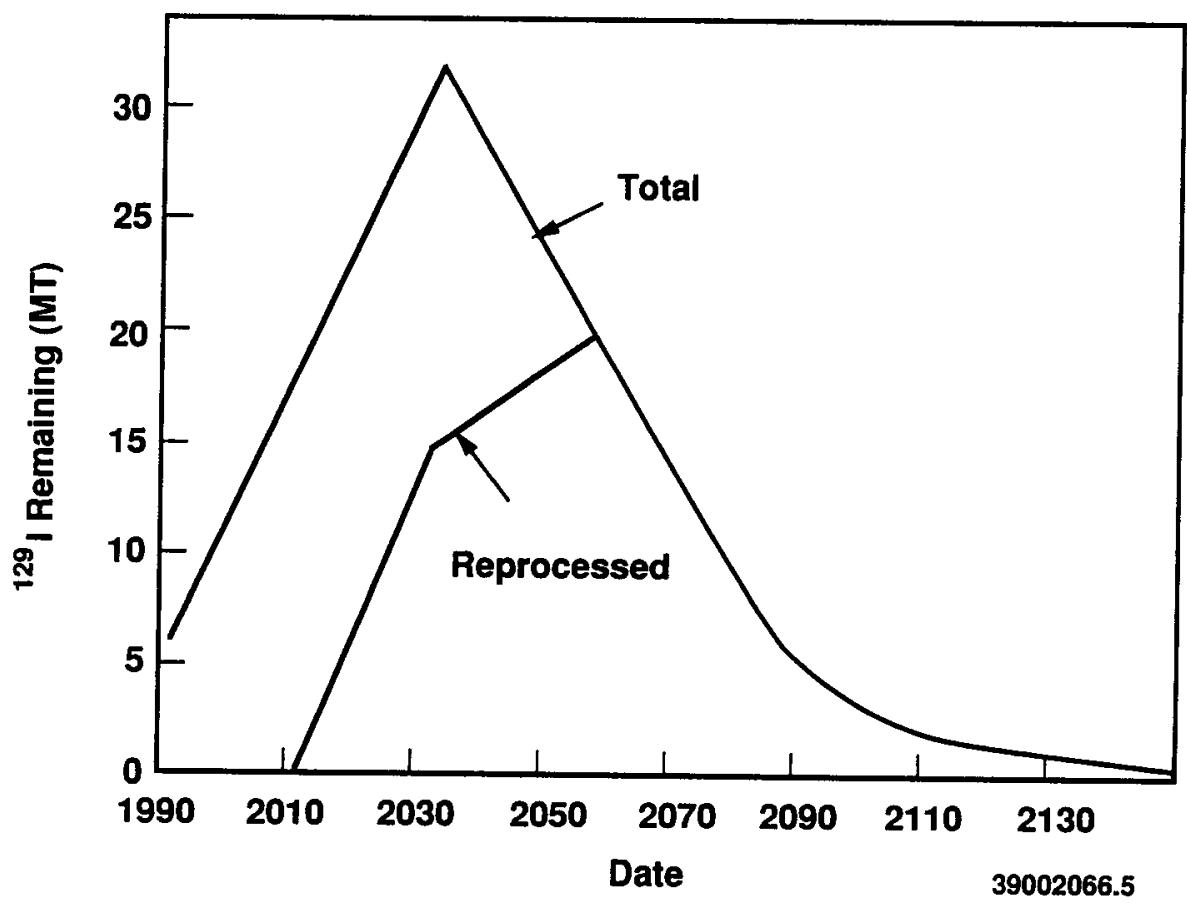


Table 4-6. Burnup of ${ }^{99} T c$ During Reactor Phaseout.

${ }^{99}$ Tc Reduction

\begin{tabular}{cc}
\hline \multirow{2}{*}{ Time $(y r)$} & ${ }^{99}$ Tc burned $(\%)$ \\
\cline { 2 - 2 } 35 & 55 \\
63 & 90 \\
77 & 95 \\
105 & $>99$ \\
\hline
\end{tabular}

power growth as Scenario 1. Finaliy, introduction of fast burner reactors only to replace LWRs (Scenario 3) results in destruction of the inventory of ${ }^{99}$ Tc over a period of about 100 years, as well as a closeout of the nuclear power option. Future studies of Scenario 3 should also focus on elimination of plutonium and other TRU elements.

\subsection{FUEL AND TARGET FABRICATION}

\subsubsection{Fuel Fabrication}

4.3.1.1 Introduction. The fuel fabrication facility for an integrated CURE site is nominally scaled at $300 \mathrm{MTU} / \mathrm{yr}$ and $20 \mathrm{MTPu} / \mathrm{yr}$ input and 1,000 fuel assemblies/yr output (Figure 4-17). Because the national strategy for use of the CURE system may vary with time, the plutonium enrichment and reactor core configuration may also vary appreciably depending on whether the CURE reactor system is used primarily to produce power only or to transmute actinides and other isotopes. In addition, the reprocessing plant produces more plutonium and uranium than used by the 16 CLFRs, and can provide fuel for other reactors including ALWRs (Section 5.1). 
WHC-EP- 0268

Figure 4-16. Comparison of ${ }^{99} \mathrm{TC}$ Inventory for Three Scenarios.

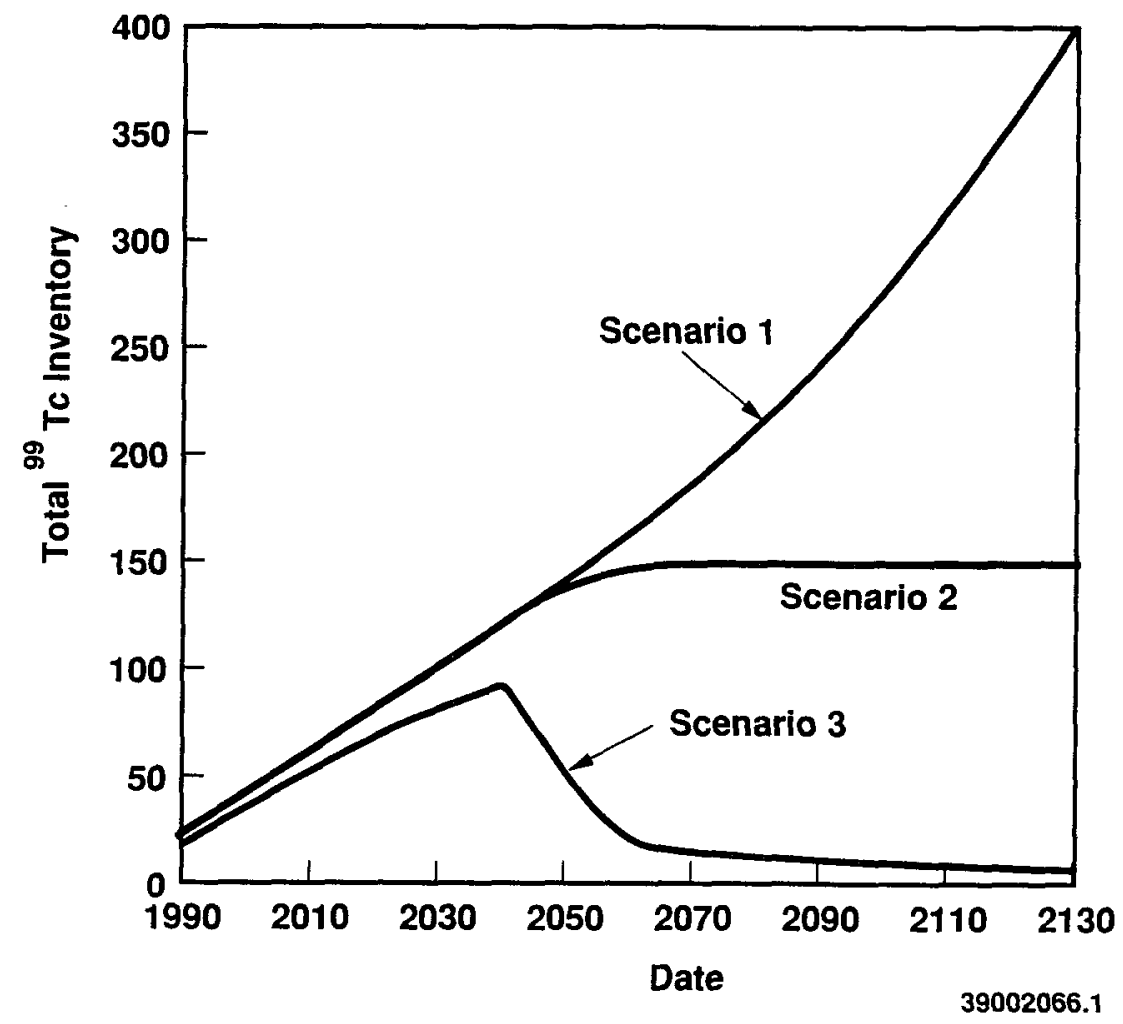




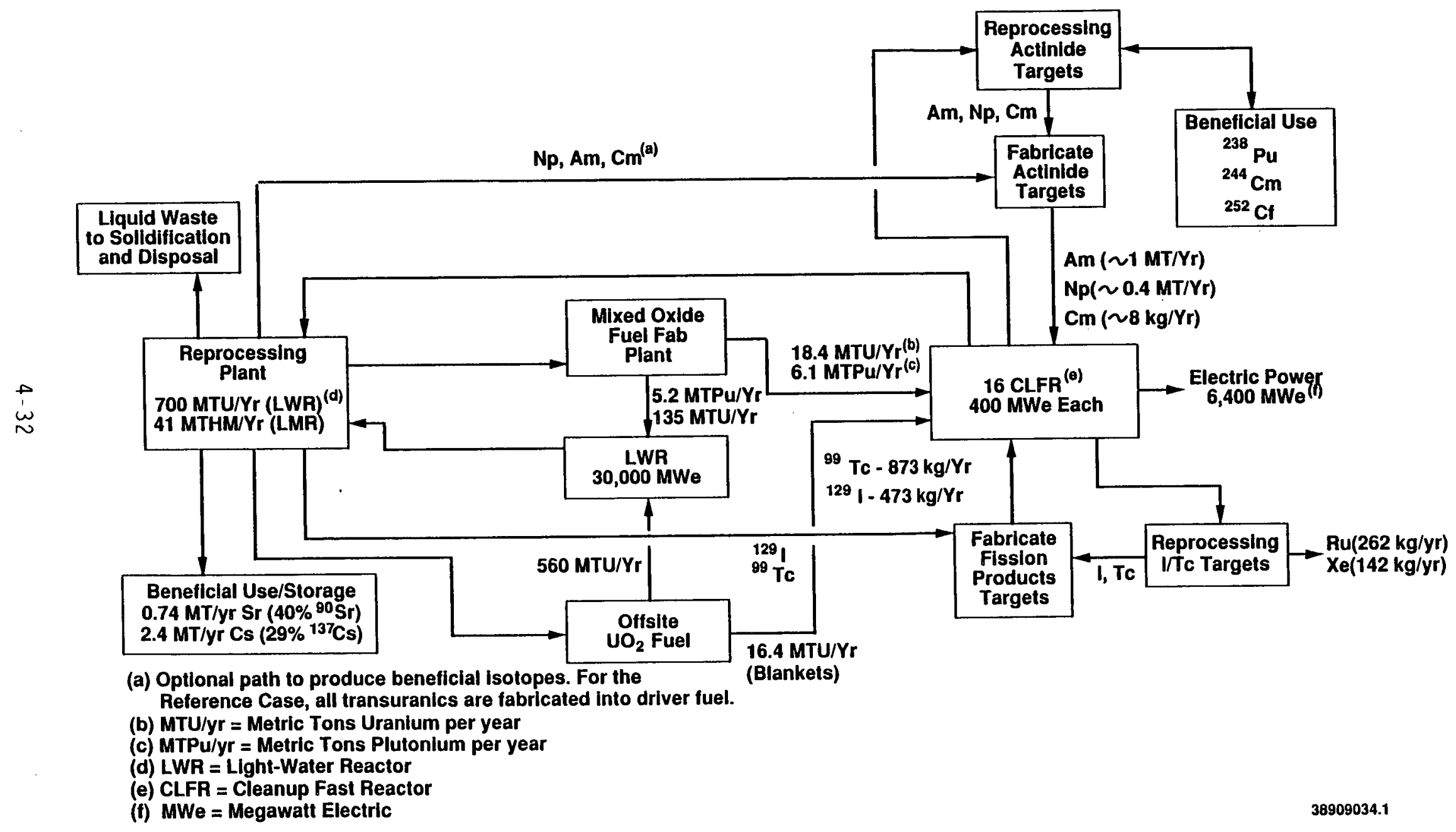


4.3.1.2 Planning Assumptions. The reference fuel design used for the CURE system is $\mathrm{PuO}_{2} / \mathrm{UO}_{2}$ ceramic pellets encapsulated in HT-9 ferritic stainless steel cladding. The oxide regime is selected as the reference case because:

- It is an established, we11-understood process.

- It provides the lowest level of technical uncertainty and programmatic risk.

- It is amenable to operation in large-scale integrated plants.

Fast reactors for a large integrated CURE plant site are assumed to be sized at about $900 \mathrm{MWt}$ ( $400 \mathrm{MWe})$. The integrated plant site is assumed to have 16 reactors. The annual fuel, blanket, and target assembly requirements for a one reactor and for a 16 reactor-site are shown in Table 4-7. While the mass values in Table 4-7 are for a metal fuel design (Section 4.1.4), the corresponding values for oxide fuel will be close for approximate scoping studies.

4.3.1.3 Production Processes. The reference oxide fuel fabrication flowsheet (Figure 4-18) is a flowsheet developed for the Secure Automated Fabrication line at the Hanford Site. The fabrication line will consist of processes to receive, assay, and pelletize fuel materials and to encapsulate the pellets within stainless steel cladding to form fuel pins meeting specifications for FRs. Subsequent processing of sealed fuel pins into finished fuel assemblies will be performed in a series of semiautomated and manual operations to keep operator exposure at minimum levels.

The feed materials for the fuel production process include the following:

- Fuel grade $\mathrm{UO}_{2}$ and $\mathrm{PuO}_{2}$ powders

- Mixed oxide (MOX) fuel returned from either wet or dry scrap recycle operations 
Table 4-7. Approximate Core Material Requirements for CURE System Fast Reactor. (sheet 1 of 2)

\begin{tabular}{|c|c|c|}
\hline Fuel assemblies & One reactor & Sixteen reactors \\
\hline Number of cores & 1 & 16 \\
\hline Fuel life (yr) & 6.5 & 6.5 \\
\hline Number of fuel assemblies in core & 126 & 2016 \\
\hline $\begin{array}{l}\text { Number of fuel assemblies replaced/yr } \\
\text { (average) }\end{array}$ & 19 & 310 \\
\hline Number of fue 1 pins/assembly & 271 & 271 \\
\hline Number of fuel pins in core & $34 K$ & $546 \mathrm{~K}$ \\
\hline Number of fuel pins replaced/yr (average) & $5.3 \mathrm{~K}$ & $84 K$ \\
\hline Enrichment $(\%) \quad(\mathrm{Pu} /(\mathrm{U}+\mathrm{Pu}) \%)$ (LWR recycle) & $25 \%$ & $25 \%$ \\
\hline $\mathrm{Pu}$ mass/assembly $(\mathrm{kg})$ & 19.6 & 19.6 \\
\hline Pu mass in-core (MT) ${ }^{(a)}$ & 2.47 & 39.5 \\
\hline Uranium mass/assembly $(\mathrm{kg})$ & 58.3 & 58.3 \\
\hline Uranium mass in-core (MT) & 7.35 & 118 \\
\hline Uranium mass/assembly in axial blanket (kg) & 23.4 & 23.4 \\
\hline Uranium mass in axial blanket (MT) & 2.95 & 47 \\
\hline Internal blanket assemblies & One reactor & $\underline{\text { Sixteen reactors }}$ \\
\hline Life $(y r)$ & 6.5 & 6.5 \\
\hline Number of blanket assemblies in core & 37 & 592 \\
\hline $\begin{array}{l}\text { Number of blanket assemblies } \\
\text { replaced/yr (average) }\end{array}$ & 5.7 & 91 \\
\hline Number of blanket pins/assembly & 169 & 169 \\
\hline Number of blanket pins in core & $4.8 \mathrm{~K}$ & $77 \mathrm{~K}$ \\
\hline Number of blanket pins replaced/yr (average) & 740 & $11.8 \mathrm{~K}$ \\
\hline
\end{tabular}


Table 4-7. Approximate Core Material Requirements for CURE System Fast Reactor. (sheet 2 of 2)

Internal blanket assemblies

Uranium mass/assembly $(\mathrm{kg})$

Uranium mass in core (MT)

Target (b)

Neptunium

Americium

Curium
Assemblies/yr/reactor

$\operatorname{TBD}(c)$

TBD

TBD
One reactor

100

3.7

Type

oxide

0xide

oxide
Sixteen reactors

100

60

Product

${ }^{238} \mathrm{Pu}$

${ }^{238} \mathrm{Pu} / \mathrm{Cm}$

${ }^{252} \mathrm{Cf}$

NOTE: The potential actinide mass in CLFRs (Np, Am, $\mathrm{Cm}$ ) is 10 to $20 \%$ of the total plutonium from the reprocessing plant, depending mostiy on the age of the discharged-light water reactor fuel.

(a) MT = Metric ton.

(b) Optional path for producing beneficial isotopes. Otherwise, all transuranics are included with $\mathrm{Pu}$ in the driver fuel.

(c) $T B D=$ To be determined. 


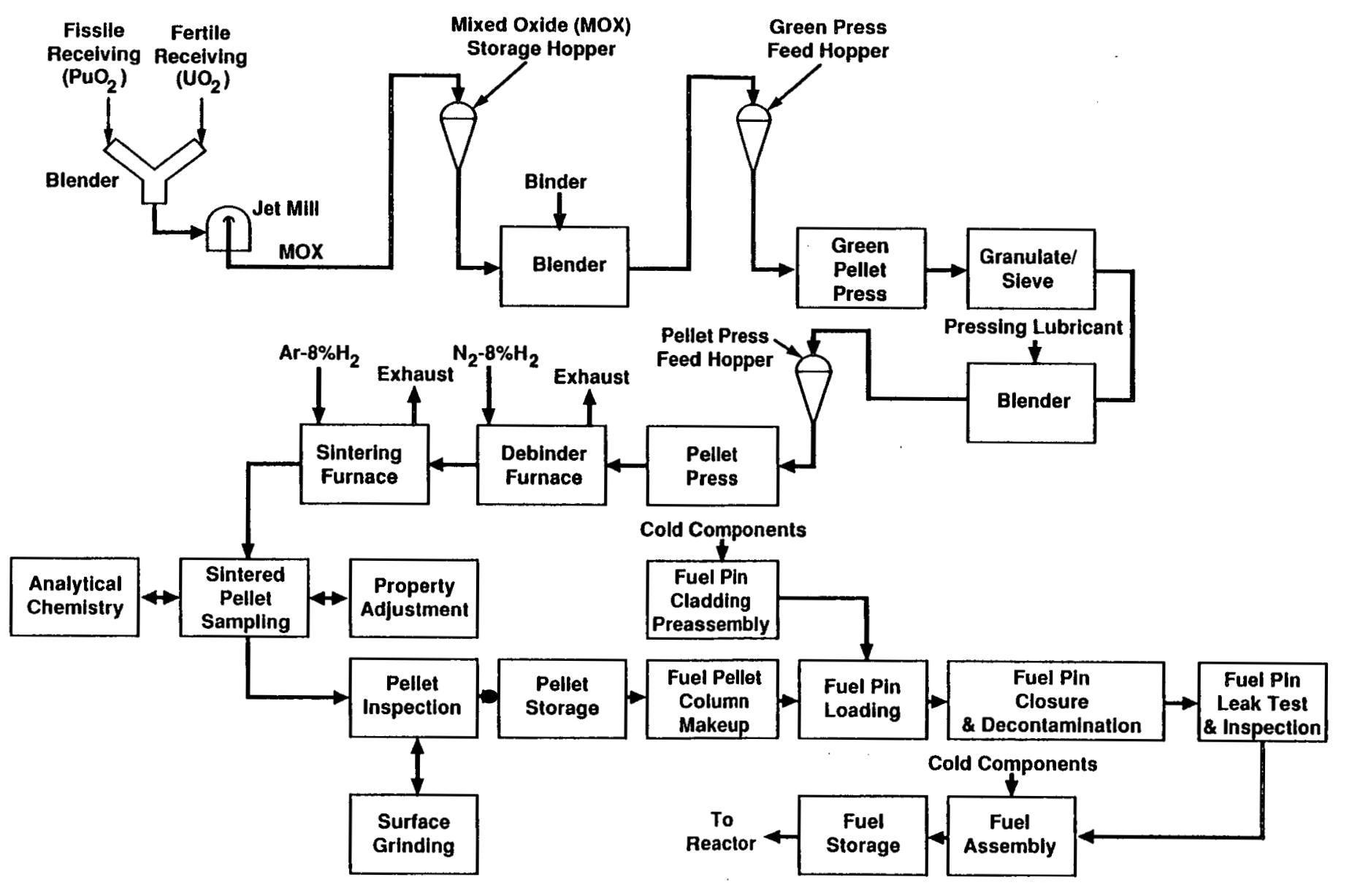

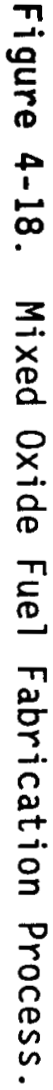


- Depleted $\mathrm{UO}_{2}$ axial blanket pellets

- Non-nuclear material fuel pin components.

The fuel pin fabrication 7 ine will include eight major process systems:

1. Receiving and powder preparation

2. Powder conditioning

3. Pellet pressing and boat loading

4. Debinding, sintering, and property adjustment

5. Boat transport

6. Pellet inspection and finishing

7. Fuel pin loading and closure welding

8. Pin inspection and test operations.

Support systems for the fuel pin line will include the following:

- Feed materials inspection, testing, and certification

- Chemical analysis

- Scrap and waste handling

- Facility and safety

- Maintenance 
- Enclosures

- Line control and data center.

\subsubsection{Target Fabrication}

4.3.2.1 Actinide Targets. The actinides ${ }^{237} \mathrm{~Np}, \mathrm{Am}$ and $\mathrm{Cm}$ would be converted separately to oxide forms from nitrate solutions obtained in the fuel and target reprocessing operations. While laboratory confirmation is needed, it is believed that $\mathrm{Np}, \mathrm{Am}$ and $\mathrm{Cm}$ can be converted to oxide ceramic pellets using similar principles and many of the practices that have been extensively employed to fabricate $\mathrm{UO}_{2}$ and mixed $(\mathrm{U} / \mathrm{Pu})_{2} \mathrm{O}_{2}$ sintered fuel pellets for commercial reactors and for the FFTF at the Hanford Site.

Figure 4-19 shows a $\mathrm{Np}$ target pin process flowsheet developed by Los Alamos Technical Associates in support of the proposed Space Isotope Program (SIP) production of ${ }^{238} \mathrm{Pu}$ from ${ }^{237} \mathrm{~Np}$ at the Hanford Site. The process equipment for fabrication of $\mathrm{NpO}_{2}$ pellets and sealed target pins will need a shielded glovebox or hot cell 1 ine. Conversion of ${ }^{237} \mathrm{~Np}$ to ${ }^{238} \mathrm{Pu}$ requires a moderated neutron environment. The design of the core component carrying the $\mathrm{NpO}_{2}$ target pins will be dictated by the type of reactor providing the neutron flux. For the SIP production of $238 \mathrm{Pu}$ in the FFTF reactor, the target assemblies will include yttrium hydride pins to provide the optimum neutron energy spectrum.

The process equipment for fabricating $\mathrm{Am}$ and $\mathrm{Cm}$ target pins and target assemblies will have to be located in shielded hot cells and be remotely operated and maintained. Adequate provision will have to be made to deal with high thermal loads due to the presence of such isotopes as $238 \mathrm{Pu},{ }^{242} \mathrm{Cm}$, and ${ }^{244} \mathrm{Cm}$. 
Figure 4-19. Neptunium Target Pin Fabrication Process.

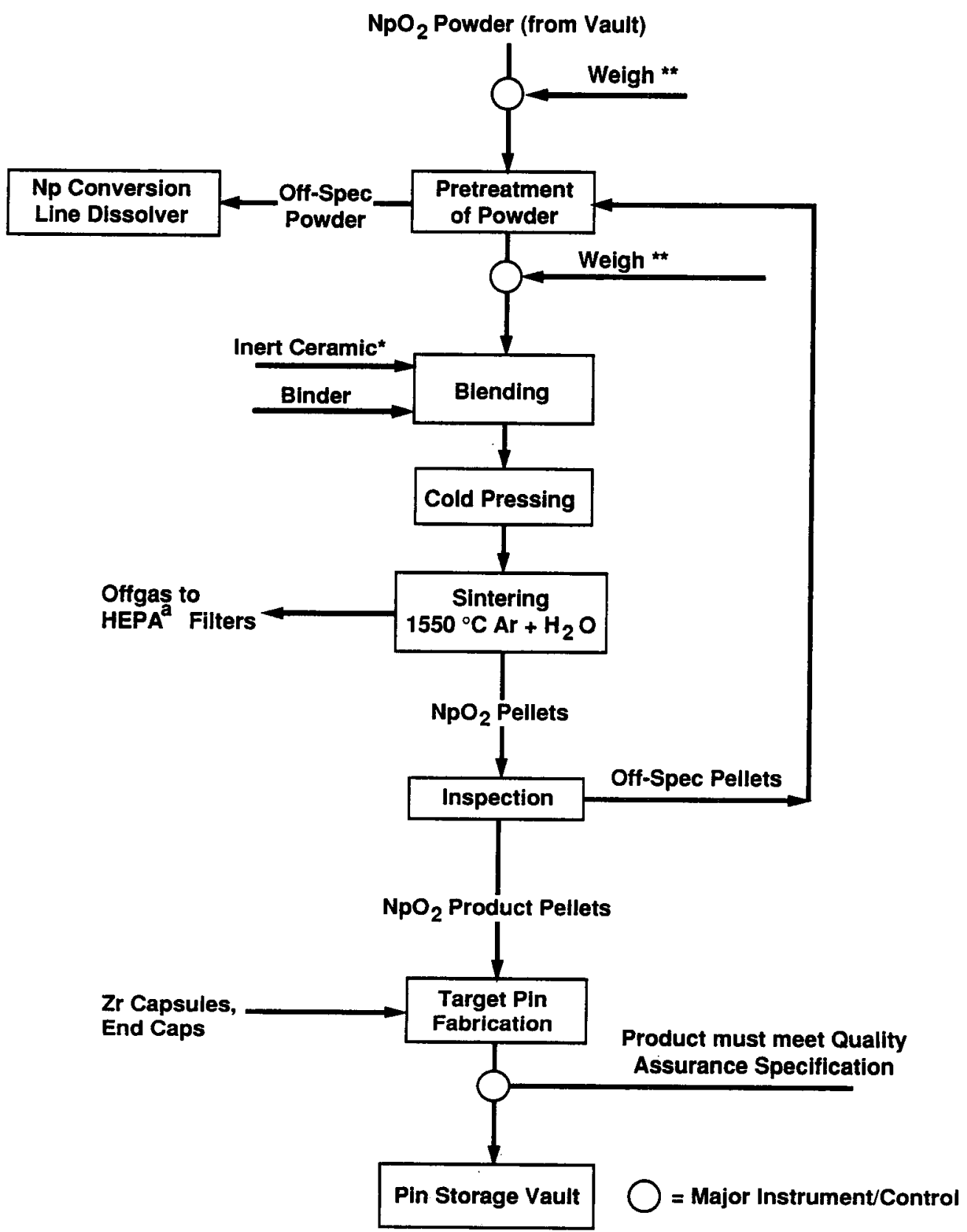

* If needed

** No available NDA ${ }^{b}$ for ${ }^{237} \mathrm{~Np}$ unless ${ }^{233} \mathrm{~Pa}$ and ${ }^{237} \mathrm{~Np}$ are in Equilibrium (180 days are required to establish equilibrium after $\mathrm{Np}-\mathrm{Pa}$ separation).

${ }^{a}$ HEPA = High - Efficiency Particulate Absolute

b NDA $m$ Nondestructive Analysis 
4.3.2.2 Fission Product Targets. Fabrication of ${ }^{99} \mathrm{Tc}$ and radioiodine target pins and in-core target assemblies will require process and materials development, particularly for transmutation of radioiodine. The hightemperature characteristics of iodine compounds and their interaction with encapsulation materials in a FR environment are essentially unknown.

The ${ }^{99} \mathrm{Tc}$ could be alloyed and cast or rolled into metallic target slugs for encapsulation or handled as oxide ceramic pellets. The metal form may be preferred for its high thermal stability. Fabrication of both forms requires the use of unshielded gloveboxes. 


\subsection{COSTS, RISKS, AND OTHER ISSUES}

A preliminary comparison has been made of the annual resource requirements, waste generation costs, and risks for a once-through LWR-only scenario and a CURE-LWR scenario, assuming equal electricity generation in each scenario. In the CURE-LWR scenario, HLW is destroyed at about the same rate that it is generated. The comparisons are based on cost, risk, and system performance estimates available in the literature or developed in previous chapters of this report.

The preliminary comparisons show a cost increase for the CURE-LWR scenario over the once-through LWR-only scenario (U.S. Council for Energy Awareness 1987) of about 7 percent. Risks for the CURE-LWR scenario appear to be slightly lower than for the once-through LWR-only scenario; the increased risks associated with reprocessing and partitioning for the CURELWR concept are more than offset by the decreased risks associated with uranium mining that result from lower $\mathrm{U}_{3} \mathrm{O}_{8}$ requirements caused by plutonium and uranium recycle. Uranium and plutonium are recycled in both LWRs and CLFRs.

The consensus of the CURE concept team is that introduction of breeders and burners (all fast reactors) and phaseout of LWRs in the year 2010 (Figure 4-8) is extremely unikely. A more realistic possibility is the introduction of a new generation of LWRs, combined with enough fast-burner reactors to maintain a constant inventory of long-lived fission products and TRU elements. The LWR/CLFR ratio for such a case is about $5: 1$. This ratio is the basis for the cost/risk assessment for a CURE concept nuclear economy versus the reference case. Plutonium recovered in fuel reprocessing is used to fuel the CLFRs, and any excess plutonium supplies part of the LWR fuel. 


\subsection{COMPARISON OF FUEL CYCLE REQUIREMENTS FOR TWO SCENARIOS}

The annual resource requirements for the once-through LWR-only and the CURE-LWR scenarios are presented in Figures 5-1 and 5-2. Both scenarios assume 36,400 MWe capacity and a 70\% capacity factor. The resource requirements for both scenarios and the incremental savings and increases attributed to the CURE-LWR scenario are shown in Table 5-1. Note that the 16 CLFRs could consume more ${ }^{129} \mathrm{I}$ and ${ }^{99} \mathrm{Tc}$ than produced in the entire complex. In addition, the LWRs could also be used for transmuting ${ }^{99} \mathrm{Tc}$.

\subsection{COST COMPARISONS}

Annual cost savings and increases for the CURE-LWR scenario compared to the once-through LWR-only scenario are summarized in Table 5-2. The net cost increase for the CURE-LWR scenario is $\$ 954 \mathrm{million} / \mathrm{yr}$ or $4.3 \mathrm{mils} / \mathrm{kWh}$. Most of the increased cost occurs in two areas: (1) LWR fuel reprocessing and partitioning ( $\$ 670$ million), and (2) increased capital costs for the CLFRs ( $\$ 590$ million).* These increased costs are partially offset by reduced costs in the LWR-enriched uranium fuel cycle and in spent fuel disposal (\$463 million). Potential revenues from by-products are estimated at $\$ 38$ million. ${ }^{137} \mathrm{Cs}$ accounts for nearly all of the by-product revenues. Future increases in the demand for radioisotopes could increase the value of by-products.

The uncertainties in the scenarios are largely in the unit cost estimates. The process flow requirements are known with reasonable accuracy (DOE/EIA 1987, DOE/RW 1988) The largest uncertainty is in the capital cost

*The CLFR is assumed to cost 30 percent to 40 percent more per $\mathrm{kW}$ than the LWR. Currently, liquid-metal reactors are estimated to cost about twice as much per kW as LWRs. However, projected costs for second generation LMRs are expected to be substantially lower (Hudson and Fuller 1987; Berglund et al. 1988). 
Figure 5-1. Light-Water Reactor Once-Through Scenario: Annual Material Flows and Resource Requirements.

36,400 MWea @ 70\% Capacity Factor
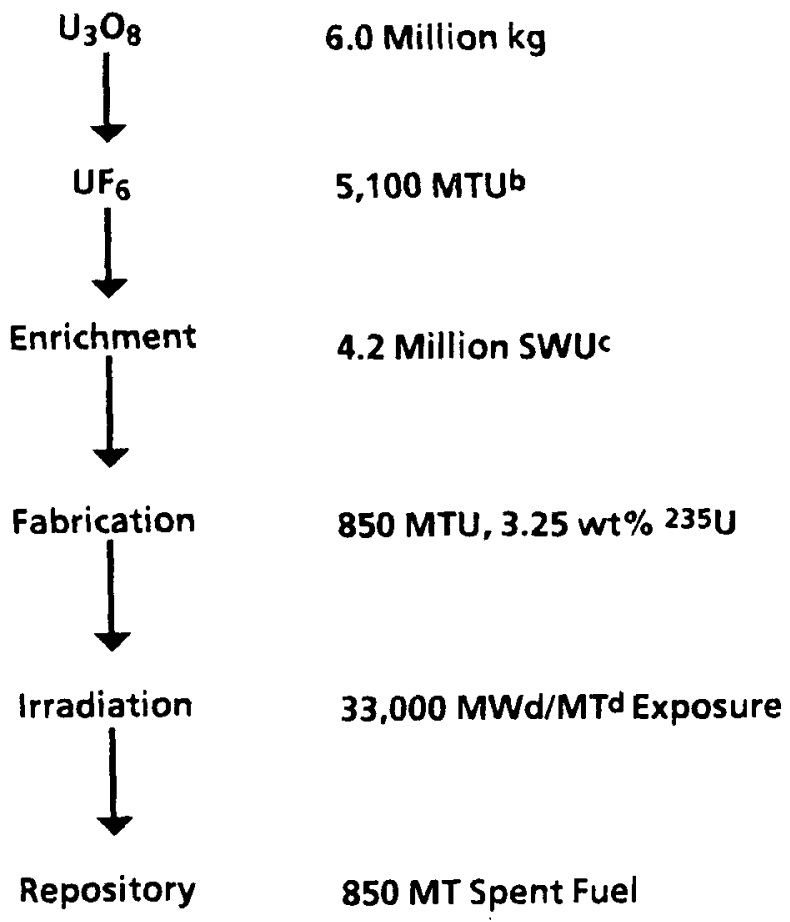

aMWe = Megawatt electric.

bMTU = Metric ton uranium .

cSWU = Separative work unit.

$\mathrm{dMWd} / \mathrm{MT}$ = Megawatt days per metric ton. 
Figure 5-2. CURE Light-water Reactor Scenario:

Material Flows and Resource Requirements.

30,000 MWea LWRb \& 6,400 MWe CLFRc @ 70\% Capacity Factor

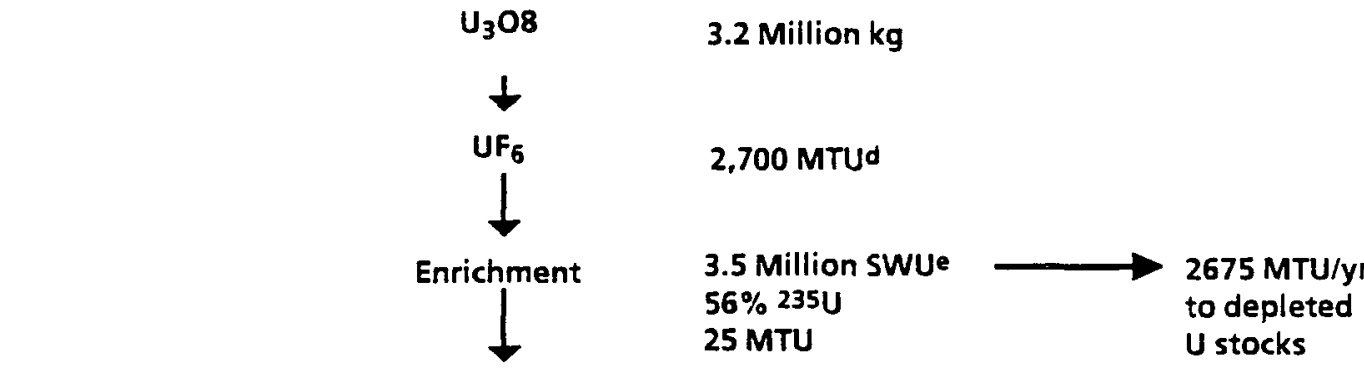

Fabrication $\quad 560$ MTU, $3.25 w t \% 235 U$

$535 \mathrm{MTU}$

$0.78 w t \%$

$235 \mathrm{U}$

Irradiation

LWR

33,000 MWd/MTf

700 MTHMg

$\downarrow$

Reprocessing

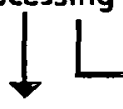

700 MTHM 670 MTU

(Initial) $\quad 6.2 \mathrm{MTPu}$

MOXi Fabrication

LWR

5.2 MTPuh, 135 MTU, $0.78 w t \% 235 U$

140 MTHM

$1.0 \mathrm{MTPu}$

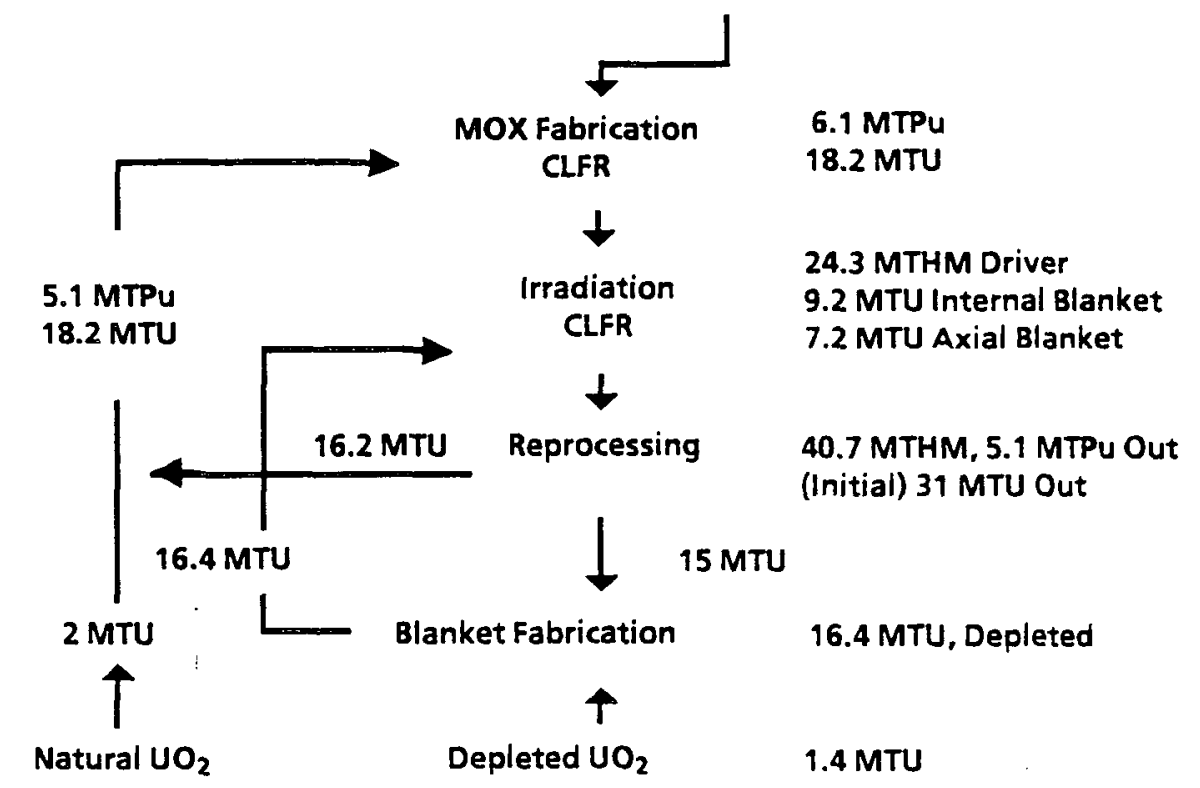

aMWe = Megawatt electric

bLWR = Light Water reactor

$C C L F R=$ Cleanup fast reactor

dMTU = metric ton uranium

esWU = Separative work unit

$f M W d / M T=$ megawatt days per metric ton

gMTHM = metric ton of heavy metals

hMTPu = metric ton plutonium

iMOX $=$ mixed oxide 
Table 5-1. Annual Resource Requirements for Light-Water Reactor Only and CURE Light-Water Reactor Scenarios.

(sheet 1 of 2)

\begin{tabular}{|c|c|c|c|}
\hline & $\begin{array}{l}\operatorname{LWR}(a) \text {-onty } \\
\text { scenario }\end{array}$ & $\begin{array}{l}\text { CURE-LWR } \\
\text { scenario }\end{array}$ & $\begin{array}{l}\text { CURE } \\
\text { savings }\end{array}$ \\
\hline \multicolumn{4}{|c|}{ LWR processes } \\
\hline $\mathrm{U}_{3} \mathrm{O}_{8}\left(10^{6} \mathrm{lb}\right)$ & 13.2 & 7.1 & 6.1 \\
\hline$U F_{6}$ conversion $(M T U)(b)$ & 5,100 & 2,700 & 2,400 \\
\hline Enrichment $\left(10^{6} \mathrm{SWU}\right)(\mathrm{c})$ & 4.2 & 3.5 & 0.7 \\
\hline LWR fuel fabrication (MTU) & 850 & 560 & 290 \\
\hline LWR reactor $\left(10^{9} \mathrm{kWh}\right)$ & 223 & 184 & 39 \\
\hline LWR spent fuel (MTU) & 850 & 700 & 150 \\
\hline Spent fuel repository (MTU) & 850 & 10 & 840 \\
\hline
\end{tabular}

CURE processes

Increased CURE

requirements

Fuel reprocessing and partitioning (MTHM) (d)

LWR-enriched uranium fuel

MOX (e) LWR fue 1

MOX CLFR fuel

Blankets

99 Tc partitioning

129 I partitioning

Target separations

$$
\begin{array}{ll}
99 \\
129
\end{array}
$$

Fuel fabrication (MTHM)

LWR MOX

MOX-driver including other actinides

Blanket fuel fabrication (MTU)

Target fabrication

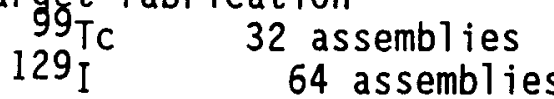

560

140

24

16

$262 \mathrm{~kg}$

$142 \mathrm{~kg}$

$611 \mathrm{~kg}{ }^{99} \mathrm{Tc}, 262 \mathrm{~kg} \mathrm{Ru}$ $330 \mathrm{~kg} \mathrm{I}, 142 \mathrm{~kg} \mathrm{Xe}$

140

24

16

$873 \mathrm{~kg}{ }^{99} \mathrm{TC}$

$472 \mathrm{~kg} \mathrm{I}$ 
Table 5-1. Annual Resource Requirements for Light-Water Reactor Only and CURE Light-Water Reactor Scenarios.

(sheet 2 of 2)

By-products $(\mathrm{kg})$

137 Cs

$90 \mathrm{Sr}$

NOTE: Assumptions

- Total system capacity in each scenario is 36,400 MWe.

- The 36,400 MWe system capacity is about one-third of the current U.S. nuclear capacity.

- About three of these CURE-LWR systems would be required to handle the waste from the existing U.S. LWR capacity.

- The LWR-only scenario assumes all PWRs (f) and a typical PWR fuel cycle with a fuel exposure of $33,000 \mathrm{MWd} / \mathrm{MT}$. (g)

- The CURE-LWR scenario assumes sixteen 400-MWe $(h)$ CLFR $(i)$ reactors and thirty 1,000 MWe PWRs.

- Al1 reactors operate at a $70 \%$ average capacity factor (223 billion $\mathrm{kWh} / \mathrm{yr}$ total).

- About 11.3 MT of plutonium is recycled annualiy, 6.1 MT to CLFRs and 5,2 MT to $W$ WRs.

- $129 \mathrm{I}$ and 99 Tc targets are assumed to require separation and refabrication after $30 \%$ of the atoms have been transmuted.

(a) $L$ LR $=$ Light-Water Reactor.

(b) MTU = Metric ton uranium.

(c) SWU = Separative Work Units.

(d) MTHM $=$ Metric ton of heavy metals.

(e) MOX = Mixed Oxide.

(f) PWR = Pressurized Water Reactor.

(g) MWd/MT = Megawatt days per metric ton.

(h) MWe $^{2}$ Megawatt electric.

(i) $\mathrm{CLFR}=$ Cleanup Fast Reactor. 
Table 5-2. Net Annual Cost Impacts of CURE Light-Water

Reactor Scenario versus Once-Through Light-Water Reactor Only Scenario.

(sheet 1 of 2)

\section{FUEL CYCLE COSTS}

Savings

$\mathrm{U}_{3} \mathrm{O}_{8}$

$\mathrm{UF}_{6}$ conversion

Uranium enrichment

LWR $(c)$ enriched uranium

fuel fabrication

Spent fuel repository

Total savings
Quantity

6.1 million 1 bs

2400 MTU

0.7 million

290 MTU

840 MTU
Unit cost \$(million) Mils/kWh(a)

$\$ 20 / 1 \mathrm{~b}$

$\$ 2.5 / \mathrm{kg}$

$\$ 80 /$ SWU (b) $\quad 56$

$\$ 200 / \mathrm{kg} \quad 58$

$\$ 260 / \mathrm{kg} \quad \underline{218}$

Increases

Fuel and target fabrication(d)

$\begin{array}{lllr}\text { MOX (e) LMR (f) driver } & 24 \text { MTHM } & \$ 1,300 / \mathrm{kg} & 31 \\ \text { MOX LWR driver fuel } & 140 \mathrm{MTHM} & \$ 780 / \mathrm{kg} & 109 \\ \text { LMR Blanket } & 16 \mathrm{MTU} & \$ 200 / \mathrm{kg} & 3 \\ 99 \mathrm{I} \text { c targets } & 873 \mathrm{~kg} 99 \mathrm{Ic} & \$ 1,000 / \mathrm{kg}(\mathrm{g}) & 1 \\ 129 \mathrm{I} \text { targets } & 470 \mathrm{~kg}{ }^{129} \mathrm{I} & \$ 1,000 / \mathrm{kg}(\mathrm{g}) & 1\end{array}$

Depleted uranium

1 MTU

$\$ 3 / \mathrm{kg}$

0.003

Reprocessing and partitioning(d)

LWR-U+Pu
LMR core
LMR blanket
99 Tc targets
129 I targets

700 MTU

24 MTHM

16 MTU

$611 \mathrm{~kg}{ }^{99} \mathrm{Jc}$

Total Increases

NET FUEL CYCLE INCREASE

\section{BY-PRODUCT REVENUES $(h)$}

$\$ 960 / \mathrm{kg} \quad 670$

$\$ 1,200 / \mathrm{kg} \quad 29$

$\$ 1,200 / \mathrm{kg}$ (g) 19

$\$ 1,000 / \mathrm{kg}(\mathrm{g})$

$\$ 2,000 / \mathrm{kg}(\mathrm{g})$

$\underline{865}$

405

3.9

1.8

$\begin{array}{lclr}{ }^{137} \mathrm{Cs} & 77 \mathrm{MCj} & \$ 0.48 / \mathrm{Ci} & 37 \\ { }^{90} \mathrm{Sr} & 114 \text { Pins (3 kW) } & \$ 12,000 / \mathrm{pin} & \frac{1}{(38)} \\ & & & \end{array}$ 
Table 5-2. Net Annual Cost Impacts of CURE Light-Water Reactor Scenario versus Once-Through Light-Water Reactor Only Scenario. (sheet 2 of 2)

CAPITAL COST INCREASE $(i)$

$\operatorname{CLFR}(j)$ reactors
QUANTITY

39 billion kWh
UNIT COST \$(MILLION) MILS/KWH(a)

$\$ 0.015 / \mathrm{kWh} \quad \underline{590}$
2.6

SUMMARY

NET INCREASE

(a) The annual electricity production is 223 billion $\mathrm{kWh}(25.5$ GW-years) in both scenarios.

(b) SWU = Separative work units.

(c) $L W R=$ Light-Water Reactor.

(d) Source of fabrication and reprocessing cost estimates is IAEA 1982. All costs were updated to 1988 constant dollars. The LMR blanket fabrication costs were increased to equal LWR U fabrication costs. The LMR blanket reprocessing costs were increased to equal LMR core reprocessing costs.

(e) MOX = Mixed oxide.

(f) LMR $=$ Liquid Metal Reactor.

(g) Costs are best estimate.

(h) Source: Bloomster et al. 1985; Ross et a1. 1989; Sonde et al. 1977.

(i) Source: Hudson and Fuller 1987; Berglund et al. 1988.

(j) CLFR = Cleanup fast reactor.

(k) Totals do not add due to rounding. 
differential between the CLFRs and the LWRs. As noted, this differential is currently about 100 percent, but a target differential of 30 percent is considered reasonable and is needed to achieve competitiveness. Recent estimates for the modular advanced liquid metal reactor (ALMR) project the costs of the factory-built ALMR to be about equal to the LWR. The $\mathrm{U}_{3} \mathrm{O}_{8}$ costs should increase with time as higher-grade ores are exhausted (DOE/EIA 1987); this should increase both the value of plutonium recycle and the savings from reduced $\mathrm{U}_{3} \mathrm{O}_{8}$ consumption.

The unit cost of reprocessing and partitioning is based on 1980 International Atomic Energy Agency (IAEA) estimates updated to 1988 constant dollars (IAEA 1982). These costs are uncertain but are considered to have an equal probability of being higher or lower over the long-term. Because of their similarity, the IAEA cost estimate for reprocessing LMR blanket material was increased to equal that of the LMR core reprocessing costs. The reprocessing and partitioning costs are also assumed to include the partitioning cost for all isotopes that are processed into fuel or targets and all subsequent waste management costs.

The CLFR driver fuel is expected to recycle plutonium and the other actinides. The fabrication cost estimates are based on 1980 IAEA values updated to 1988 constant dollars (IAEA 1982). Other estimates of fabrication costs (Croff et a1. 1980) are about 30\% lower. This uncertainty is relatively minor $(-1 \%)$ in comparison with the total estimated cost difference between the two scenarios.

The estimated by-product revenues are small by comparison; therefore, the sale of by-products is not essential to the success of the CURE concept. The by-products are not assumed to be recycled; after initial use they are assumed to be placed in intermediate-term storage until decayed sufficiently for surface disposal. The cost of the intermediate term storage is assumed to be included in the reprocessing and partitioning costs. Since recycling would probably require isotopic separation, this would be undertaken only if market demand and economics warranted. The costs of intermediate term storage 
and ultimate disposal are assumed to be included in the reprocessing and partitioning costs. The price of $137 \mathrm{Cs}, \$ 0.48 / \mathrm{Ci}$, is based on its indifference value (Bloomster 1985 ) compared to ${ }^{60} \mathrm{Co}$, recently priced at $\$ 1.25 / \mathrm{Ci}$. The indifference value yields identical costs for irradiation applications for each isotope. Of course, if the incremental costs of preparing Cs capsules for irradiation applications exceeds $\$ 0.48 / C i$, this would not be undertaken. This analysis assumes that the cost of $C s$ encapsulation, whether for storage or use, is included in the reprocessing and partitioning cost.

The target and fuel fabrication costs are assumed to include further conversion, if required, of the fuel and target materials received from the reprocessing plant into the proper compounds.

Transportation costs were assumed to be approximately equal in the two scenarios and were not included in the analysis. The CLFRs were assumed to be collocated with the reprocessing and plutonium processing plants.

Because the addition of CLFRs to the LWR-only system results in higher system costs, increasing the proportion of CLFRs would result in still higher system costs. On the other hand, decreasing the proportion of CLFRs is not feasible since the HLW disposal objectives would not be met. Thus, the ratio appears to be near optimum for these assumptions. When fast reactors become competitive with LWRs, then the proportion of CLFRs would increase and fast reactor breeders would replace LWRs, assuming the cost of CLFRs and breeders are about equal.

\subsection{RISKS}

This section compares the short-and long-term health risks for a oncethrough LWR scenario and a CURE-LWR scenario. Both radiological and non-radiological risks to the public and workers are examined. Qualitative 
and quantitative comparisons are made using best available data (IAEA 1982; Cloniger 1982; DOE 1980).

As noted in Section 5.1, a total system capacity of 36,400 MWe is assumed for each scenario. The LWR scenario assumes all PWR reactors and a typical PWR once-through fuel cycle. The CURE-LWR scenario assumes sixteen 400-MWe CLFR and thirty 1,000-MWe PWRs. The 30 PWRs are supported by an enriched $\mathrm{UO}_{2}$ and MOX fuel cycle. The 16 CLFR are supported by a reprocessing plant and a fuel and target fabrication plant. The CURE processes (reprocessing, fabrication, irradiation, and waste disposal) are assumed to take place in a remote and controlled access enclave.

\subsubsection{Short-Term Risks}

Short-term risks typically include the various combinations of routine and accidental, occupational and public, and radiological and nonradiological risks. A brief literature review was conducted to obtain available short-term risk information for once-through LWR operations and the CURE-LWR scenario operations. The important risk categories, for which information is available, include radiological routine risk to the public, radiological routine risk to the workers, radiological accident risk to the public, and nonradiological accident risk to the workers. Table 5-3 provides short-term risk estimates for the once-through LWR scenario and the CURE-LWR scenario (Schneider et al. 1986). The risk values are reported in terms of health effects per GWe-year. Health effects consist of latent cancers for radiological risk and deaths for nonradiological risks.

The short-term risks are very low for both scenarios considered. Although the CURE processes involve additional processing steps which add to the short-term risk, recycling reduces the LWR fuel requirements which in turn reduces the risks from mining and fuel processing operations. Given the large uncertainties and simplifying assumptions, the net result is no 
Table 5-3. Short-Term Risk Comparisons (Health Effects/GWe-Year).

\begin{tabular}{cccc}
\hline $\begin{array}{c}\text { Radiological } \\
\text { Routine } \\
\text { public }\end{array}$ & $\begin{array}{c}\text { Radiological } \\
\text { Routine } \\
\text { worker }\end{array}$ & $\begin{array}{c}\text { Radiological Nonradiological } \\
\text { public }\end{array}$ & $\begin{array}{c}\text { Accident } \\
\text { worker }\end{array}$ \\
\hline
\end{tabular}

Once-through light-water reactor-only scenarios

\begin{tabular}{lllll} 
Mining & .12 & .05 & - & .09 \\
Mi11ing & .024 & .016 & $2.0 \times 10^{-7}$ & .003 \\
Conversion & .002 & .0002 & $1.1 \times 10^{-6}$ & .0003 \\
Enrichment & $4.0 \times 10^{-6}$ & .00014 & $7.4 \times 10^{-7}$ & .001 \\
Fabrication & .00012 & .002 & $2.0 \times 10^{-6}$ & .0004 \\
Reactor & .015 & .07 & .10 & .01 \\
Transportation & .001 & .002 & $1.0 \times 10^{-5}$ & .008 \\
\multicolumn{1}{r}{ Total } & .16 & .14 & .10 & .10
\end{tabular}

\section{CURE light-water reactor scenario}

\begin{tabular}{|c|c|c|c|c|}
\hline $\begin{array}{l}\text { Mining } \\
\text { Milling } \\
\text { Conversion } \\
\text { Enrichment } \\
\text { Fabrication }(*) \\
\text { Reactor } \\
\text { Transportation } \\
\text { Chemical processing } \\
\text { Mixed oxide/target } \\
\text { fabrication }(*)\end{array}$ & $\begin{array}{l}.065 \\
.013 \\
.001 \\
3.2 \times 10^{-6} \\
.00012 \\
.015 \\
.001 \\
.004\end{array}$ & $\begin{array}{l}.027 \\
.009 \\
.0001 \\
.0001 \\
.002 \\
.07 \\
.002 \\
.002\end{array}$ & $\begin{array}{l}-- \\
1.2 \times 10^{-7} \\
5.9 \times 10^{-7} \\
6.1 \times 10^{-7} \\
2.0 \times 10^{-6} \\
.10 \\
1.0 \times 10^{-5} \\
7.0 \times 10^{-7}\end{array}$ & $\begin{array}{l}.048 \\
.002 \\
.0002 \\
.0008 \\
.0004 \\
.01 \\
.008 \\
.0011\end{array}$ \\
\hline Total & .10 & .11 & .10 & .062 \\
\hline
\end{tabular}

(*) The risks from mixed oxide and Target Fabrication operations are sma11. The risks from mixed oxide, blankets, and Target Fabrication operations in the CURE scenario are assumed identical to the Fabrication risk in the once-through light water reactor scenario. 
significant differences in short-term risks. Short-term risks in both scenarios are low and potentially controllable to lower levels through improved safety systems that would tend to increase cost.

Transportation risks are based on the once-through LWR scenario. It is assumed that since the CURE processes are concentrated at a single site, there are negligible transportation differences between the two scenarios. In addition to the transportation risks listed, transportation has a nonradiological accident risk to the public of .003 deaths per GWe-year.

It is assumed that there are no important reactor risk differences between PWRs and CLFRs. The transmutation of the fission products reduces the neutron efficiency by about 1 percent which in turn could affect the thermal power and hence the electrical output, other things being equal. However, the loss of neutrons can be partially compensated for by the core design. The higher thermal-to-electric conversion efficiency in the fast reactors should, on balance, lead to a more thermally efficient system per unit of electrical output.

The reduction in routine radiological risks is due primarily to reduced mining caused by $U$ and $P u$ recycle; partitioning by itself causes only a small reduction in uranium mining requirements through the fissioning of the higher actinides. Comparing the risks of reprocessing including partitioning and transmutation with the risks of reprocessing with only $\mathrm{Pu}$ and $\mathrm{U}$ recycle, the risks of reprocessing with P-T would probably be slightly higher because of the greater handling requirements for radioactive materials. However, the more relevant comparison is with the once-through cycle since this is the industry standard at present. 


\subsubsection{Long-Term Risks}

Spent fuel and low-level waste disposal are the two operations of interest in examining long-term risks. Radiological risk to the public is the primary risk category of interest. Table 5-4 provides 1 ong-term risk estimates for the once-through LWR scenario and the CURE-LWR scenario.

The long-term risk from geologic disposal of spent fuel is eliminated in the CURE-LWR scenario; this amounts to an estimated 5.2 health effects per GWe-yr in the once-through LWR scenario (Croff et al. 1980). The long-term risk is a statistical risk integrated over $10^{6} \mathrm{yr}$ which is derived primarily from the release of ${ }^{99} \mathrm{Tc}$, and, to a lesser extent, ${ }^{129} \mathrm{I}$ from the repository. The statistical risk derives from low probability natural occurrences, e.g. earthquakes and volcanoes, breaching the repository. ${ }^{99} \mathrm{Tc}$ and ${ }^{129} \mathrm{I}$, which are much more mobile than the actinides if the repository is breached, constitute the greatest risk, whereas actinides are much less mobile under these circumstances.

The long-term risks from near-surface disposal of LLW for the oncethrough LWR scenario are estimated to be less than one health effect per GWe-year, again integrated over $10^{6} \mathrm{yr}$. The long-term risk from LLW disposal for the CURE-LWR scenario is estimated to be 15 percent greater in proportion to the estimated increase in the volume of LLW. The intermediate term risk associated with radiostrontium and radiocesium storage is estimated to be small (less than 0.05 health effects/GWe-yr); provision for this risk is included in the LLW disposal. 
Table 5-4. Long-Term Risk Comparisons

(Health Effects/GWe-Year).

\begin{tabular}{|c|c|c|}
\hline \multicolumn{2}{|c|}{ Once-through light-water reactor } & CURE \\
\hline Low-level waste disposal & $<1$ & $<1.2$ \\
\hline Repository & 5.2 & \\
\hline
\end{tabular}

NOTE: Statistical risk integrated over one million years.

\subsection{TRANSPORTATION ISSUES}

\subsubsection{Introduction}

Transportation of radioactive materials among CURE system facilities will be required to support the activities and equipment which will be integrated to meet CURE system functional requirements. The CURE transportation network will consist of onsite systems for each site that requires movement of radioactive materials among several site-local facilities.

Transportation streams among CURE system functions present a wide range of hazard categories, quantities, and physical forms. Packaging and transportation of radioactive materials are addressed in Federal Codes (NRC 1987b; DOT 1988; DOE 1985). These codes provide criteria for shipping container design and construction, classification of contents, and package certification procedures. Shipping containers to meet CURE system transportation needs can be provided by application of existing technology to design new, or assess existing, shipping containers, perform and document analyses and tests to demonstrate compliance to Federal Codes, and obtain Certificates of Compliance for radioactive materials transportation packages. 


\subsubsection{Planning Assumptions}

Commercial waste in the form of spent fuel assemblies from LWRs and/or monitored retrievable storage (MRS) facilities is a major source of feed material for the proposed CURE chemical processing facility. To diagram potential transportation streams among CURE program functions, chemical processing is treated as a single activity; however, it is comprised of several operations. It is assumed that all chemical processing functions will be under one roof, or in facilities in close proximity to one another. This arrangement eliminates costly packaging and transportation systems for handling liquid and gaseous radioactive materials which must be transferred.

Figure 5-3 identifies potential major transportation streams which will/may use public transportation routes to transfer reactor fuel, spent fuel, target materials, isotopes, and other radioactive materials among CURE facilities/functions.

\subsubsection{Potential Transportation Streams}

Transportation streams among CURE system facilities fall into several categories, each presenting different packaging and transportation requirements.

Products of Chemical Processing. Each of the elements recovered from chemical processing is segregated and constitutes an individual transportation stream. The products of chemical processing fall into two categories:

(1) isotopes that will be irradiated further as fuel or target materials; and (2) isotopes that will be packaged for storage for 300 to $500 \mathrm{yr}$ and which may be used as beneficial radionuclide sources. Isotopes in the first category will be in bulk form and will undergo additional processing to be made into fuel or target materials suitable for further irradiation. Isotopes 


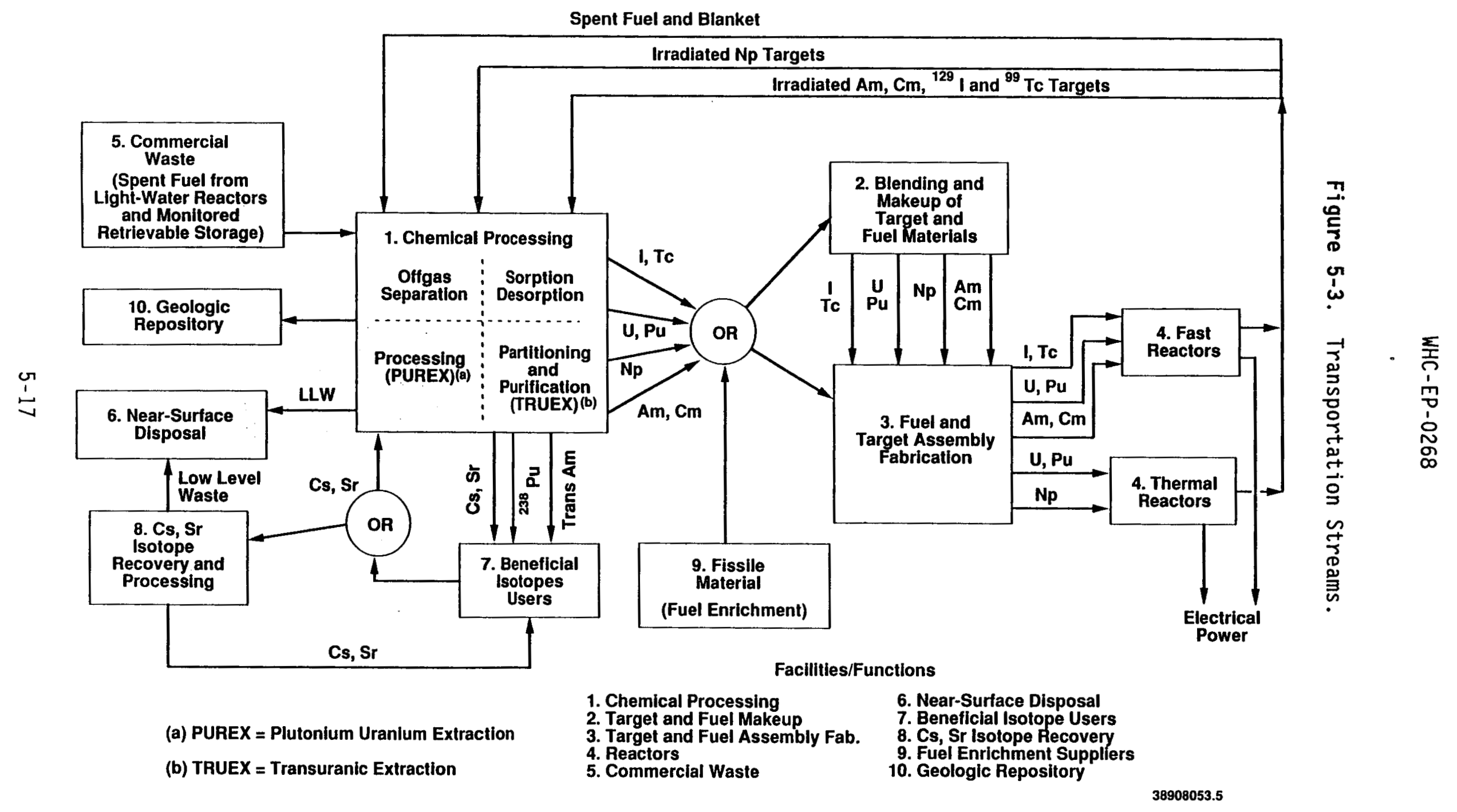


in the second category will be encapsulated in a package which is designed to provide containment in fixed geometry for safe interim storage for 300 to $500 \mathrm{yr}$.

Fuel and Target Feed Material Processing. It is anticipated that several of the products from chemical processing will require additional processing before they can be fabricated into irradiation assemblies. Additional processing may include items such as blending fissile material(s) into fuel isotopes to balance enrichment, combining target isotopes with filler or moderating materials, and preforming and densification in preparation for assembly. Some of these processes may be incorporated into chemical processing and/or fuel target assembly fabrication facilities. Additional studies will determine optimal process parameters and clearly define the transportation streams among chemical processing, makeup of fuel and target materials, and irradiation assembly fabrication functions.

Fabrication of Fuel and Target Assemblies. The assembly fabrication function produces five types of target and fuel assemblies for thermal and fast reactors. Each of these five types of assemblies is considered a separate transportation stream. However, additional studies are expected to show that two or more of these transportation streams can be combined.

Irradiated Fuel and Target Assemblies. Three transportation streams are anticipated for irradiated fuel and target assemblies because the source terms for the three types shown in Figure 5-3 are quite different. Americium and curium target assemblies will have very high neutron and heat production sources, higher than spent fuel or neptunium target assemblies. Shielding and heat dissipation requirements for transportation packages for these three types are sufficiently diverse that at least three shipping container designs will probably be required for transportation of irradiated assemblies from reactors to the chemical processing facility. 
Spent Fuel Assemblies from.LWRs and Monitored Retrievable Storage (MRS) Facilities. Spent fuel assemblies from commercial LWRs and MRS facilities represent another transportation stream. Transportation technology for this stream is well developed, and several shipping containers are currently licensed for this purpose.

Isotope Recovery. ${ }^{137} \mathrm{Cs}$ and ${ }^{90} \mathrm{Sr}$ have half-lives of approximately 30 yrs each, and users will require periodic replacement to maintain stable source levels. Spent sources will be shipped from users to chemical processing or another specialized facility for recovery and reencapsulation of cesium and strontium isotopes which in turn will be returned to users.

Fissile Material. Enriched uranium for fissile enrichment of some reactor fuels will be needed in the initial phase of the CURE system until sufficient plutonium has been recovered to meet enrichment requirements. Shipments of enriched uranium have been made for several decades in support. of commercial power reactors. Packaging requirements are well known and licensed shipping containers are available for this purpose.

Low-Level Waste. Waste in these streams meets criteria for land disposal criteria (NRC 1982; NRC 1987a; NRC 1989) and is suitable for disposal in nearsurface sites. Disposal of Class C LLW in support of nuclear facilities has been ongoing for several years. Transportation systems and certified packages for this activity are well defined and available for use to dispose of CURE system LLW.

\subsubsection{Transportation System Requirements}

Definition of the transportation system requires an initial evaluation of the radioactive materials source terms, the quantity of material, and the package requirements for each transportation stream shown in Figure 5-3. Data from the initial evaluation applied to requirements in the Federal Transportation Codes will provide the basis to determine the number of types 
and optimal size of the shipping container that will be required to support each CURE system transportation stream. With packaging requirements established, the number of shipping containers required and optimal transport modes can be defined for each transportation stream. Compilation of data from all transportation streams will provide the basis to determine costs for the total system.

\subsection{INSTITUTIONAL ISSUES}

The CURE concept includes two phases: (1) a research and development (R\&D) phase, in which the technology is refined and developed to the point where it would be ready for deployment, if needed; and (2) an implementation phase, in which the full CURE concept is placed in operation. The issues are quite different for these phases. The institutional issues can be considered in two categories: concerns (including political and public), and regulatory (including laws and regulations, whether Federal, State, or local).

\subsubsection{Concerns}

The primary concern relates to the existing national commitment to deep geologic disposal. The CURE concept is intended to offer spent fuel pretreatment, recycle, and disposal technologies that could simplify the licensing of a geologic repository. Thus, the need is to demonstrate that the CURE concept is viable and useful. In addition, if the CURE concept is to be implemented, the separation of long-lived nuclides needs to be efficient enough to allow near-surface disposal of the solidified process waste stream. Addition of the TRUEX process (for near-quantitative separation of TRU elements and $\left.{ }^{99} \mathrm{Tc}\right)$ and separation of other long-1ived nuclides ( $\left.{ }^{129} \mathrm{I}\right)$ to the traditional P-T processes are intended to address this issue. 
Another issue is the knowledge that P-T has been studied in the past and not found to be worthwhile. However, this conclusion was based on the assumption that a deep geologic repository is already available, so that P-T beyond recovery of uranium and plutonium is not worth the added cost. These conclusions could change dramatically if the repository program as currently envisioned could benefit from spent fuel pretreatment.

For full implementation of the CURE concept, it would be necessary for public and political perception to change substantially. As discussed above, the change could be initiated by the need to assist long-range issues of the repository or to remove major obstacles. If such a change were to occur, the institutional climate might shift dramatically, and a spent fuel pretreatment a)ternative could become attractive. A sense of urgency might develop, which could be alleviated to some degree by the availability of an option ready for deployment. Thus, it would appear to be highly desirable to develop the CURE concept as fully as possible, to provide credibility as a viable pretreatment option, as well as to permit rapid deployment at a time when aboveground storage capacity for HLW might be severely limited.

\subsubsection{Regulatory}

There are many laws and regulations which might influence full deployment of the CURE concept at the present time. In particular, the Nuclear Waste Policy Act of 1982 (NWPA) authorizes the geologic repository program as the direction of national policy. In Section 222 of the NWPA, DOE is required to continue and accelerate a program of research, development, and investigation of alternative means and technologies for the permanent disposal of high-level radioactive waste. Thus, the R\&D phase is allowed and even encouraged by the NWPA. The act directs the DOE to exclude disposal options for HLW other than deep geologic burial in the Environmental Impact Statement (EIS) that the DOE will issue in support of its NRC license application. Consideration of volume reduction of $\mathrm{HLW}$ by a combination of partitioning, transmutation, and interim storage is clearly not excluded. 
Regulatory requirements are minimal for the R\&D phase because most of the work would be carried out in existing facilities. Necessary permits are already in place, unless major facility changes are needed. Changes could trigger the need for some of the documents or permits required for new facilities, since some of the requirements apply to new or significantly modified facilities.

Full implementation of the CURE concept will require licenses and permits, including those specified by the National Environmental Policy Act of 1969 (NEPA), 42 CFR 4321 documentation, NRC licenses, various permits under the Resource Conservation and Recovery Act of 1976 (RCRA) 42 USC 6901 et req., Clean Air Act of 1977, 41 USC 7401, Clean Water Act of 1977, 33 USC 1251, and various state requirements which will depend on facility location. There is little point in detailing the requirements, because some are site-specific and several are subject to change. For example, the U.S. Environmental Protection Agency (EPA) is developing disposal rules for radioactive waste, the U.S. Congress is considering changes to NRC Iicensing procedures, and RCRA rules change frequently. In addition, the rules under the Atomic Energy Act of 1954, 42 USC 2011, and Energy Reorganization Act of 1974, 5 CFR 5313-5316, are different for DOE and commercial facilities (although some of the other laws are the same for both). It is useful, however, to mention the long lead-time items which could become schedule drivers.

Major facilities will require an Environmental Assessment or an EIS, which could take several years to prepare and review. Major programs with multiple facilities could require a programmatic document as well as individual or combined documents for the facilities. If the facility is considered to be a treatment, storage, or disposal facility under RCRA, a RCRA permit is required before start of construction. Commercial nuclear facilities require an NRC license, a multiyear process. These efforts need to be started in parallel and early in (or even before) the conceptual design stage. 


\subsection{KEY CURE TECHNOLOGY DEVELOPMENT ISSUES}

\subsection{INTRODUCTION}

The basic features of the baseline P-T technology described in Chapters 3 and 4 have been identified; nevertheless, there are numerous opportunities and incentives to develop, prove, and implement enhanced and new P-T technology.

Chapter 6 is devoted to a presentation and discussion of various technical issues which relate to development and implementation of the CURE concept. The CURE concept includes partitioning of radiostrontium and radiocesium as well as actinide elements, ${ }^{99} \mathrm{Tc}$, and radioiodine. The preferred option for disposal of partitioned ${ }^{99} \mathrm{Tc}$ and radioiodine is to transmute them to stable nuclides.

\subsection{CHEMICAL PROCESSING ISSUES}

\subsubsection{Applicability of TRUEX Process to HLW Solutions}

A vital chemical processing part of the CURE program involves use of the recently-developed (Schulz and Horwitz 1987; Schulz and Horwitz 1988) TRUEX process for removing actinide elements $(U, \mathrm{~Np}, \mathrm{Pu}, \mathrm{Am}, \mathrm{Cm})$ from the HLW generated during aqueous (PUREX process) reprocessing of LWR and FR fuel. The fundamental chemistry of the TRUEX process and of CMPO, the TRUEX process solvent, has been thoroughly investigated by Horwitz (1983) and colleagues at Argonne National Laboratory. Recent countercurrent tests and demonstrations of the TRUEX process at the Hanford Site and the LOS Alamos Site, with actual acidic wastes not containing fission products, have been uniformly very successful. Complementary radiolysis and chemical degradation tests with various CMPO-diluent solutions demonstrate that CMPO is very 
resistant to degradation in a highly radioactive environment. Furthermore, conventional alkaline washing treatments effectively remove the primary degradation product.

There is confidence that the TRUEX process can be routinely and successfuily used to remove actinides from HLW. * However, a need exists to set up bench-scale and pilot-plant centrifugal extraction equipment to conduct an extensive series of countercurrent tests of the TRUEX process with actual HLW. An important focal point of these tests should be to ensure that the TRUEX process will adequately remove ${ }^{237} \mathrm{~Np}$ as well as other actinides from the HLW. Countercurrent tests to demonstrate proposed flowsheet conditions for adequate and selective costripping of $\mathrm{Np}$ (IV) and $\mathrm{Pu}$ (IV) are al so needed.

\subsection{2 ${ }^{99} \mathrm{TC}$ Recovery and Separation}

Several technology issues exist relating to recovery, separation, and purification of ${ }^{99} \mathrm{Tc}$ during reprocessing of reactor fuels:

1. Removal and concentration of ${ }^{99} \mathrm{Tc}$ from the mainline PUREX uranium product

2. Separation of ${ }^{99} \mathrm{TC}$ from uranium in the $\mathrm{TC}-\mathrm{U}$ product resulting from TRUEX process operation with PUREX process HLW

3. Concentration and purification of the combined ${ }^{99} \mathrm{Tc}$ fractions.

* Such confidence is greatly enhanced by highly favorable results recently obtained by J. L. Swanson of Pacific Northwest Laboratory in batch extraction tests with actual HLW. Swanson dissolved sheared pieces of spent PWR fuel $\left(-7\right.$ yr 01d, 33,000 MWd/MT) in $\mathrm{HNO}_{3}$ and performed three PUREX-type batch extraction (organic/aqueous $=3$ ) contacts of the resulting dissolver solution with 30\% TBP-NPH solvent. The resulting aqueous solution (HLW) was contacted six times with fresh 1.2 to 1.5 volume portions, and then once with a 3.0 volume portion, of TRUEX process solvent. The total TRU content of the final aqueous raffinate was about $2 \mathrm{nCi} / \mathrm{g}$, corresponding to an overall TRU DF (TRUEX feed to raffinate) of $4.5 \times 10^{5}$. 
From $30 \%$ to $50 \%$ of the fission product ${ }^{99} \mathrm{TC}_{\mathrm{T}}$ in $\mathrm{HNO}_{3}$ dissolver solutions prepared from LWR and FR fuels will coextract with uranium and follow it during PUREX processing operations. The remaining technetium will report to the HLW, from which it will be extracted along with actinides and lanthanides into the TRUEX CMPO solvent. In TRUEX process operations, ${ }^{99} \mathrm{TC}$ will follow uranium to the spent $\mathrm{Na}_{2} \mathrm{CO}_{3}$ solvent wash solution.

An important part of the baseline CURE program chemical processing technology involves separation, by primary amine solvent extraction, of ${ }^{99} \mathrm{Tc}$ from uranium both in the PUREX process uranium nitrate product and in the TRUEX process $\mathrm{Na}_{2} \mathrm{CO}_{3}$ solvent wash solution. Selection of amine extraction technology is warranted on the basis of the known affinity (Shmidt 1971) of amines for $\mathrm{TcO}_{4}$ in weakly acidic aqueous solutions. However, bench-scale and pilot plant-scale countercurrent extraction tests with simulated and actual U-TC feed solutions need to be performed to establish optimum process flowsheet conditions (e.g., amine concentration, aqueous feed pH, strip composition, phase flow ratios, etc).

Amine extraction of ${ }^{99} \mathrm{Tc}$ from the PUREX process uranium nitrate product stream must be accomplished without, in any way, contaminating the uranium with metal ions. * Thus, any reagents which may be used to adjust the acidity of the uranium nitrate stream to $\mathrm{pH} 1$ to 2 , the range needed for efficient primary amine extraction of technetium, must volatilize or decompose when uranium in the raffinate from the ${ }^{99} \mathrm{Tc}$ extraction process is calcined to $\mathrm{UO}_{3}$. Possible reagents for adjusting the $\mathrm{pH}$ of the uranium nitrate stream include hydrazine carbonate, paraformaldehyde, and formic acid. Experimental work needs to be performed to determine whether the acidity of the uranium nitrate product needs to be adjusted, and to select and test various candidate reagents for making the necessary $\mathrm{pH}$ adjustment.

${ }^{*}$ This restriction does not, of course, apply to amine extraction of ${ }^{99} \mathrm{TC}$ from the spent $\mathrm{Na}_{2} \mathrm{CO}_{3}-\mathrm{U}-\mathrm{Tc}$ solvent wash stream from the TRUEX process. This stream already contains large amounts of sodium, and uranium in the aqueous $\mathrm{NaNO}_{3}-\mathrm{UO}_{2}\left(\mathrm{NO}_{3}\right)_{2}$ raffinate from the amine extraction process will be returned to an appropriate place in the mainline PUREX process. 
Bench-scale and pilot plant-scale tests are also needed to investigate alternative methods for removing ${ }^{99} \mathrm{Tc}$ from the PUREX process uranium product. One such method may be to reduce the ${ }^{99} \mathrm{TcO}_{4}$ to insoluble $\mathrm{TcO}_{2}$ as suggested by the results of Pruett and McTaggart (1984). Experimental work in this area should also focus on possible modifications to the PUREX process which would force all the ${ }^{99} \mathrm{Tc}$ to the HLW.

Experimental attention must also be given to the chemical form, concentration, and purity of ${ }^{99} \mathrm{Tc}$ in the product resulting from application of the primary amine extraction process to both the PUREX uranium nitrate stream and to the PUREX process HLW. The reference amine extraction process flowsheet specifies use of $\left(\mathrm{NH}_{4}\right)_{2} \mathrm{CO}_{3}$ solution to strip the ${ }^{99} \mathrm{TCO}_{4}$. This procedure may yield an $\mathrm{NH}_{4} \mathrm{TCO}_{4}$ solution suitable for direct conversion to $\mathrm{TCO}_{2}$ or Tc metal. It may be desirable, however, to concentrate and purify the ${ }^{99} \mathrm{Tc}$ further by means of well known strong base anion exchange sorptionelution techniques (Kraus and Nelson 1956; Hoffman et al. 1956). Experiments should also be conducted to determine if a potentially more decomposable reagent, e.g., hydrazine carbonate, can be used in place of $\left(\mathrm{NH}_{4}\right)_{2} \mathrm{CO}_{3}$ to strip technetium from the amine solvent.

\subsubsection{Separation of Actinides and Lanthanides}

When applied to HLW, the TRUEX process will coextract both radioactive and nonradioactive lanthanides, as well as actinides and ${ }^{99} \mathrm{Tc}$. The trivalent rare earths will co-strip with americium and curium. The extent to which the lanthanides must be separated from americium and curium before transmutation of the latter depends on the irradiation conditions. However, some decontamination of the americium-curium fraction from 1 anthanides will be desired.

Various solvent extraction processes, e.g., Talspeak (Weaver and Kappelman 1968) and Tramex (Leuze and Lloyd 1970), have been developed and, in some cases, actually used. The Talspeak process involves HDEHP extraction 
of the lanthanides from aqueous carboxylic acid solutions containing aminopolycarboxylic acid chelating agents. Haug (1974) has developed a cationexchange cycle for the concentration and decontamination of americium and curium remaining in the aqueous raffinate from the Talspeak process. The Tramex process involves preferential tertiary amine extraction of +3 actinides over +3 lanthanides from $10-11 \mathrm{M} \mathrm{LiCl}-0.02$ to $0.25 \mathrm{M} \mathrm{HCl}$.

In previous times, much use was made of a thiocyanate anion-exchange process to separate americium from rare earths and other impurities (Schulz 1976). Wheelwright (1969) and others have developed and applied chromatographic elution cation exchange schemes employing aminopolycarboxylic acids to separate and purify americium and curium from lanthanides.

All of the available processes for separating americium and curium in the TRUEX process product from associated rare earths have a number of serious drawbacks. First, they are all complicated processes that are difficult to operate and control. Also, they all generate an aqueous waste stream whose disposal is complicated by the presence of objectionable chemical species, i.e., thiocyanate ion, chloride ion, organic carboxylic and/or aminopolycarboxylic compounds. To overcome these disadvantages, it is necessary to develop a straightforward solvent extraction process which can be applied directly to an $\mathrm{HNO}_{3}$ solution of +3 lanthanides and actinides without any need for strict pH control, or for addition of organic complexing and/or buffering agents. Some recent work by Musikas et al. (1986) in France with nitrogen- and sulfur-based extractants offers promise that the requisite solvent extraction process can be satisfactorily developed.

\subsubsection{Removal of Radiostrontium from Acidic High-Level Waste}

The reference ${ }^{90} \mathrm{Sr}$ removal extraction process described in Section 3.1 involves HDEHP extraction of ${ }^{90} \mathrm{Sr}$ from an aqueous feed. This solution is adjusted to $\mathrm{pH} 5$ (by addition of $\mathrm{NaOH}$ ) and contains large concentrations of 
organic compounds such as citric acid as a buffering agent and a complexing agent to prevent precipitation of iron and other nonradioactive feed constituents. Complicated feed preparation procedures generate a ${ }^{90} \mathrm{Sr}$-free raffinate containing large amounts of $\mathrm{NaNO}_{3}$ and aqueous-soluble organic compounds. Solidification of this raffinate is difficult and expensive and results in a large volume of waste requiring disposal.

As noted previously ( 3 3-8), Horwitz and colleagues at the Argonne National Laboratory have developed a new radiostrontium solvent extraction process which appears to eliminate all the objectionable features of the reference HDEHP process. If further batch and countercurrent tests of this new technology are as promising as the initial work, * the Horwitz process will replace the HDEHP process, and this issue will be satisfactorily closed.

If, however, the Horwitz strontium extraction process does not survive exhaustive testing and demonstration, other sorption and solvent extraction processes will be investigated for their use in large-scale direct removal of radiostrontium from $\mathrm{HLW}$. Candidate processes include (1) use of solid antimonic acid $\left(\mathrm{Sb}_{2} \mathrm{O}_{5} \cdot \mathrm{XH}_{2} \mathrm{O}\right)$ which selectively sorbs radiostrontium from strong $\mathrm{HNO}_{3}$ solutions (Abe 1982), (2) solvent extraction of radiostrontium using a four-component extractant containing 27 vol\% TBP, 5 vol\% [(dinonylnapthalene sulfonic acid) (NNS)], 0.02M Crown XVI, a crown ether, and 68 vol\% kerosene (Shuler et al. 1985), (3) solvent extraction of radiostrontium with an organic extractant containing cobalt dicarbolidenitrobenzene from HLW containing a small concentration of a polyethylene glycol, and (4) solvent extraction of radiostrontium. from $H L W$ adjusted to $\mathrm{pH} 2$, with a commercially available phosphonic acid, and containing a small amount of a recentiy developed thermally unstable complexant. The latter

\footnotetext{
*Initial batch tests, by J. L. Swanson of Pacific Northwest Laboratory, of the Horwitz radiostrontium solvent extraction procedure with actual HLW have been very successful. Swanson contacted the aqueous raffinate from the last batch TRUEX process contact with HLW (cf. p. 6-2) three times with fresh three-fold volumes of the Horwitz strontium extractant. The overall radiostrontium DF (HLW to final aqueous raffinate) was 4600 .
} 
WHC - EP-0268

reagents are specially formulated organophosphorus compounds which are powerful complexing agents and which can be easity decomposed into $\mathrm{CO}_{2}$ and phosphoric acid by simple heating and/or treatment with hydrogen peroxide. The R\&D effort to develop one or more of these processes for plant-scale deployment is a very high CURE chemical technology priority.

\subsubsection{Removal of Radiocesium from Acidic High-Level Waste}

Processes--precipitation, ion exchange, and solvent extraction--for efficient removal of cesium from alkaline aqueous media are well-known (Schulz and Bray 1987). Many of these processes have been extensively and successfully used on a plant-scale. However, the situation is far different for removal of radiocesium from $\mathrm{HNO}_{3}(\geq 0.5 \mathrm{M})$ media.

In strong ( 0.5 to $2.0 \mathrm{M}) \mathrm{HNO}_{3}$ solutions, cesium ions react with phosphotungstate ions to produce an insoluble precipitate. This chemistry forms the basis of the reference process specified in Section 3.1. However, the reference precipitation process suffers from several disadvantages, including providing only incomplete (e.g., 95\%) cesium removal per precipitation cycle and the need to dissolve the cesium-bearing precipitate in $\mathrm{NaOH}$ solution to recover and purify the radiocesium.

Certain inorganic ion exchangers (e.g., titanium phosphate, zirconium phosphate, etc.) will sorb cesium from $\mathrm{HNO}_{3}$ solutions, but these expensive materials are not suitable for plant-scale application (Schulz and Bray 1987). On the other hand, two newly-developed solvent extraction systems may prove suitable, with further development and demonstration, for use in plant-scale continuous countercurrent equipment for efficient and selective removal of cesium from acidic HLW. One of these systems, developed by Shuler et al. (1985), employs a four-component organic solvent containing TBP, NNS, a crown ether, and a hydrocarbon diluent. The second extraction system, pioneered by Selucky et al. (1979) uses the compound "dicarbolyde," 
$\mathrm{H}^{+}\left\{\left[\pi-(3)-1,1-\mathrm{Bg}_{2} \mathrm{C}_{11} \mathrm{Cl}_{2}\right]_{2} \mathrm{CO}^{-}\right.$dissolved in a polar solvent such as nitrobenzene to effectively and preferentially extract $\mathrm{Cs}^{+}$from aqueous $\mathrm{HNO}_{3}$ solutions.

In any event, design, development, and testing of new and advanced processes to replace the reference cesium phosphotungstate precipitation process is another high priority technological need of the CURE program.

\subsection{6 ${ }^{237} \mathrm{~Np}$ Recovery Technology}

The baseline CURE program chemical processing flowsheet presented and described in Section 3.1 assumes: (1) some ${ }^{237} \mathrm{~Np}$ will be routed to the HLW during PUREX processing of LWR and FR fuels; (2) ${ }^{237} \mathrm{~Np}$ will be quantitatively extracted, along with other actinides, from the HLW into the TRUEX process solvent; and (3) TRUEX process conditions can be adjusted to selectively partition neptunium with plutonium from the CMPO extract.

The feasibility of the baseline flowsheet is generally supported by all presently available knowledge of neptunium chemistry. However, there is still a great need to demonstrate, with actual feed solution, optimal neptunium extraction-stripping flowsheets under countercurrent conditions. For example, in PUREX processing of LWR fuel, it is difficult to divert all the ${ }^{237} \mathrm{~Np}$ to the HLW as $\mathrm{Np}(\mathrm{V})$ without excessive loss of plutonium as $\mathrm{PU}$ (III). Indeed, of several reducing agents (e.g., $\mathrm{HNO}_{2}$, hydrazine nitrate, $\mathrm{V}$ (IV), $\mathrm{H}_{2} \mathrm{O}_{2}$, butyraldehyde) tested by German scientists (Kolarik and Schuler 1984) for reducing $\mathrm{Np}(\mathrm{VI})$ to $\mathrm{Np}(\mathrm{V})$ in $3 \mathrm{M} \mathrm{HNO}_{3}$, only butyraldehyde was effective. Experimental work with actual HLW is urgently needed to confirm (or refute) the German observations.

Experimental work to confirm expected and desired ${ }^{237} \mathrm{~Np}$ behavior in the TRUEX process is also mandated. This experimental work needs to focus on reagents and conditions for reducing $\mathrm{Np}(\mathrm{V})$ in the PUREX process $\mathrm{HLW}$ to extractable $\mathrm{Np}$ (IV), and reagents and conditions for co-stripping of ${ }^{237} \mathrm{~Np}$ and plutonium. Because the TRUEX process can accommodate +3 actinide ions, 
it is more forgiving with respect to extraction and separation of ${ }^{237} \mathrm{~Np}$ and plutonium than is the PUREX process.

\subsubsection{Radioiodine Recovery Technology}

Radioiodine in spent reactor fue1, present mainly as CSI, is oxidized to elemental iodine in hot $\mathrm{HNO}_{3}-\mathrm{NO}_{\mathrm{X}}$ fuel dissolver solutions. Sparging such solutions with air causes iodine to transfer to the gas phase, from which it can be removed either by aqueous scrubbing techniques or by trapping on solid sorbents. Aqueous $\mathrm{NaOH}, \mathrm{Hg}\left(\mathrm{NO}_{3}\right)_{2}$, and hyperazeotropic $\mathrm{HNO}_{3}$ solutions have all been proposed for scrubbing iodine from gas streams while solid materials such as charcoal, molecular seives, or silver-containing materials all have a great affinity for molecular iodine (Mailen and Toth 1981; Roger et al. 1961; Jubin 1979; Holladay 1978).

The reference CURE concept partitioning system involves selective sorption of iodine from offgas streams on beds of silver mordenite. Subsequently, the iodine is desorbed by passage of hydrogen gas through the mordenite bed. There is no reason to doubt that these procedures will not deliver a purified radioiodine fraction in the required yield. Still, additional bench-scale and pilot plant-scale tests need to be performed with simulated and actual PUREX process offgas to finalize flowsheet sorptiondesorption conditions.

\subsubsection{Head-End Treatment of Irradiated Target Assemblies}

It is not possible at this early stage of CURE program technology to provide exact details for the preparation, irradiation, and chemical processing of ${ }^{99} \mathrm{Tc}$ and individual or mixed actinide target assemblies. For the latter, it is assumed that such assemblies will consist of purified oxides clad in a suitably resistant material, e.g., stainless steel. That ${ }^{99}$ Tc target material will be technetium metal, or an alloy thereof or 
possibly an oxide, is also believed to be a reasonable assumption. Suitable target compounds or cladding materials for radioiodine target assemblies have not yet been identified.

When fuel and target hardware and cladding have been specified and chosen, it will be necessary to ensure that technology is available for head-end treatment of irradiated assemblies. Such head-end treatment will typically involve mechanical removal of cladding and preparation of an aqueous ( $\mathrm{HNO}_{3}$-based) feed solution for subsequent chemical processing.

Based on known chemical properties and experience, no difficulties are foreseen in dissolving actinide oxide targets in $\mathrm{HNO}_{3}$ media. But there is no comparable experience to guide selection of conditions for satisfactory dissolution of technetium fuel forms, let alone for dissolution of presentlyunspecified radioiodine targets. Therefore, comprehensive batch aqueous dissolution tests with both irradiated and unirradiated radioiodine, ${ }^{99} \mathrm{Tc}$, and actinide oxide targets need to be scheduled and completed. Attention should also be paid to the potential applicability of nonaqueous processes (e.g., simple volatilization of Tc and/or I compounds, etc.) for clean and easy separation of ${ }^{99} \mathrm{Tc}$ and radioiodine from irradiated targets.

\subsubsection{Purification of Radiostrontium}

The reference HDEHP radiostrontium extraction process will likely yield a product containing various metallic impurities, e.g., $\mathrm{Na}, \mathrm{Ca}, \mathrm{Fe}, \mathrm{Cr}, \mathrm{Ni}$, etc. Removal of these impurities is necessary to obtain a suitably pure radiostrontium concentrate suitable for conversion to a solid storage form. Various precipitation (e.g., sulfate, hydroxide, etc.) processes have been employed previously at the Hanford Site to purify radiostrontium recovered from wastes generated in processing of defense reactor fuels. A cation exchange process for the latter purpose has also been developed and used at the Hanford Site. 
All the presently available radiostrontium purification processes suffer from a major disadvantage. ${ }^{*}$ They will all contribute large amounts of undesirable chemicals (e.g., sodium, sulfate, organic complexing agents, etc.) to the liquid waste produced by CURE program chemical processing activities. The presence of these added chemicals will contribute to the cost and difficulty of solidification and subsequent disposal of the waste.

New and improved technology for purification of radiostrontium recovered from HLW, which overcomes the difficulties of present purification processes, must be identified and developed. One potentially attractive possibility is to selectively sorb radiostrontium from the impure crude concentrate onto $\mathrm{Sb}_{2} \mathrm{O}_{5} \cdot \mathrm{XH}_{2} \mathrm{O}$ and then elute it with a $\mathrm{HNO}_{3}$ solution containing newly-developed thermally-unstable organic complexants.

\subsection{MANAGEMENT/DISPOSAL OF CURE SYSTEM WASTES}

Baseline CURE concept waste management and disposal technology is described in Section 3.2. The following technical issues represent areas where improvements and enhancements can be made to the baseline practices.

\subsubsection{Adequate Decontamination of CURE System Solid Wastes}

To offer the greatest waste management flexibility, all wastes generated in P-T operations must be decontaminated to levels which permit their disposal in near surface facilities. Technology for partitioning of key long-lived

\footnotetext{
*The new radiostrontium solvent extraction process developed by
} Horwitz et al. (cf., footnote page 3-8) appears to be very selective and to yield a radiostrontium product much purer than that obtained from the reference HDEHP process. Further development and testing of the new Horwitz radiostrontium extraction process may demonstrate the need to develop new technology for purification of the recovered radiostrontium. 
radionuclides from CURE system offgases and 1iquid wastes is much more advanced than that for treating and decontaminating CURE concept solid wastes.

Solid wastes are produced in many parts of the CURE partitioning system. For example, solid wastes are produced in disassembly and decladding of spent fuels and targets; ${ }^{*}$ in dissolution of declad fuel; in fabrication of actinide and fission product targets; in removal of alpha emitters from process offgases; etc. The wide disparity in source, composition, and characteristics (e.g., types and amounts of radioactive contaminants, solubility in $\mathrm{HNO}_{3}$, combustibility, etc.) greatly complicate collection and decontamination of CURE system solid wastes.

In many cases the solids decontamination problem involves reduction of the TRU content of such solids to $<100 \mathrm{nCi} / \mathrm{gram}$. To accomplish this goal, it is desirable to devise treatment procedures that generate an aqueous $\mathrm{HNO}_{3}$ solution suitable as feed to a PUREX or TRUEX process. Leaching reagents/procedures which may be useful in removing actinides from solid wastes include $\mathrm{HNO}_{3}, \mathrm{HNO}_{3}$-TUCS (thermally unstable complexants) solutions, CEPOD solutions, and, less desirably, $\mathrm{HNO}_{3}-\mathrm{HF}$ solutions. Combustible materials (e.g., paper, rags, etc.) would be converted to oxides prior to leaching.

A multistep approach is needed to acquire suitable technology for decontaminating all the various types of solid wastes produced in CURE system operation. Initially, a detailed catalog of all the CURE system solid wastes that require treatment before disposal needs to be prepared. The list of solid wastes should provide, to the extent possible, quantitative information concerning the amount (volume and mass), composition, radionuclide content,

\footnotetext{
${ }^{*}$ Disposal of fuel assembly hardware and cladding hulls in considered in a separate Technology Issue, 6.3.4.
} 
and other relevant properties of each solid waste. Subsequently, comprehensive experimental work with both simulated and actual solid wastes needs to be performed to develop procedures for solubilizing actinides and, if needed, other key radionuclides. These experiments need to demonstrate that the treated solids qualify to the extent possible for near-surface disposal and that the leachate is, or can be converted to, a satisfactory PUREX or TRUEX process feed.

\subsubsection{Disposal of CURE System Low-Level Liquid Wastes}

The reference plan (Section 3.2) for disposal of the primary CURE system liquid waste, after prior removal of TRU elements, radiostrontium, ${ }^{99} \mathrm{Tc}$, radiocesium, and radioiodine involves incorporation in a suitable matrix (e.g., grout, bitumen, glass, etc.), and disposal of the resulting solid product in a suitably engineered, sited, and licensed facility. In some circumstances, near-surface disposal may be practical if the residual radionuclide content is low enough. The reference plan shall include recycling where applicable.

To this end, comprehensive and detailed engineering studies need to be performed to devise candidate solidification and disposal systems and facilities and to evaluate costs and risks of such systems and facilities. Among other important considerations, these engineering studies need to focus on suitable solid matrices, immobilization methods, and disposal facilities to safely contain those long-lived radioisotopes $\left({ }^{14} \mathrm{C},{ }^{79} \mathrm{Se}\right.$, ${ }^{93} \mathrm{Zr},{ }^{107} \mathrm{Pd},{ }^{126} \mathrm{Sn}$, and ${ }^{15} \mathrm{l} \mathrm{Sm}$ ) and any hazardous stable metals (e.g., cadmium) not removed by CURE system partitioning processes. In support of the engineering analyses, bench-scale studies need to be completed to determine leachability of various radionuclides from candidate waste forms as well as uptake of the leached radionuclides by disposal site geologic strata.

Engineering analyses also need to be conducted to specify the treatment and disposal of each of the ancillary CURE system liquid waste streams. 
This latter category of wastes includes spent solvent washes, process condensates, equipment decontamination flushes, solutions obtained by treatment/dissolution of various process solids and residues, spent solvents, etc. In most cases it is expected that treatment processes will produce a concentrated TRU liquid solution which can be routed as feed to the TRUEX process and a liquid waste fraction which can be combined with the primary CURE system waste for solidification and disposal.

\subsubsection{Disposal of Radiocesium and Radiostrontium}

Removal of the heat-producing elements radiocesium and radiostrontium from HLW offers an important degree of waste management flexibility. Elimination of ${ }^{90} \mathrm{Sr}$ and ${ }^{137} \mathrm{Cs}$ greatly simplifies and facilitates disposal of the liquid waste from CURE concept partitioning processes. However, the issue of how to safely contain the separated radiocesium and radiostrontium for at least $300 \mathrm{yr}(-10$ half-lives) in full compliance with all statutory requirements remains. It is anticipated, as pointed out earlier, that purified and doubly-encapsulated radiocesium and radiostrontium may likely find extensive beneficial application. Even after such beneficial use, however, remaining radiocesium and radiostrontium will still need to be properly and permanently disposed of.

If a repository site cannot tolerate a high heat load, the most reasonable and direct way ${ }^{*}$ of disposing of doubly-encapsulated radiocesium and radiostrontium compounds is to contain such capsules for several half-lives in a suitably-designed and constructed near-surface facility. Among other features, an engineered storage structure must provide for (a) redundant barriers to prevent release of radiocesium and/or radiostrontium

*Although it may eyentually be technically feasible, transmutation of separated and purified ${ }^{137} \mathrm{Cs}$ and ${ }^{90} \mathrm{Sr}$ nuclides is not presently considered a viable disposal option. 
under all credible accident conditions; (b) adequate radioactive decay heat removal; (c) systems to remotely inspect and monitor the inventory and condition of capsules; and (d) systems to remotely retrieve and remove individual capsules for whatever reason. Comprehensive engineering studies need to be performed to design, locate, and evaluate the expected performance of hardened engineered-storage facilities.

\subsubsection{Disposal of Cladding Hulls and Fuel Assembly Hardware}

A metric ton of irradiated PWR fuel (cf., Table 1-1) contains about $300 \mathrm{~kg}$ of cladding (Zircaloy 2) and fuel assembly hardware (e.g., Inconel, etc.) (Roddy 1955). * Neutron irradiation of the cladding and assembly hardware under light-water reactor conditions produces several activation products (cf. Table 1-1). Activation products with half-lives greater than

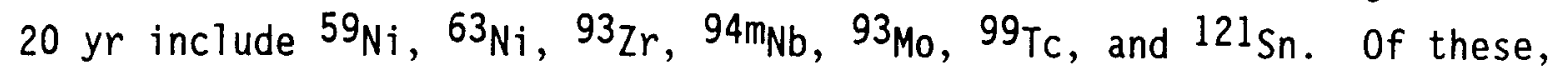
${ }^{63} \mathrm{Ni}\left(t_{1 / 2}=100 \mathrm{yr}\right)$ is especially significant because it is responsible for almost 99 percent of the near-term radioactivity of the combined cladding and assembly hardware. This issue is more pronounced for LMR assembly hardware and cladding, both of which contain nickel.

Unti1 a geologic repository is available, interim storage of the fuel assembly hardware and cladding hulls remaining after fuel reprocessing is an issue. The radionuclide content of some of this solid waste may be too high, according to current regulations, to permit classification as a $\mathrm{Class} \mathrm{C}$ low-level waste. The combined hardware and hulls would then be considered a Greater-Than-Class-C (GTCC) waste. To implement the CURE concept it may be necessary to determine and validate a licensable GTCC interim storage concept. An alternative and potentially licensable method of handling cladding hulls

${ }^{\star}$ For comparison purposes, a metric ton of irradiated boiling water reactor fuel contains about $600 \mathrm{~kg}$ of cladding and fuel assembly hardware. 
and fuel assembly hardware involves retrievable storage in specially designed engineered packages and facilities located either near-surface or, perhaps, in already existing deep mines.

Engineering studies, including associated performance assessments, must be performed to devise and evaluate candidate GTCC storage concepts. These engineering studies also need to address what technology, other than rinsing with $\mathrm{HNO}_{3}$ and water, needs to be developed to ensure than the TRU content of cladding hulls is $<100 \mathrm{nCi} / \mathrm{g}$. Bench-scale and pilot plant-scale tests of the application of CEPOD electrolytic dissolution technology to dissolution of any residual fuel may be necessary. In the engineering studies, consideration should also be given to the technical pros and cons of segregating fuel hardware from cladding hulls for disposal purposes, and of compacting cladding hulls and/or fuel hardware prior to packaging for disposal.

Development of low-activation cladding and hardware for fast reactors is also important. Solute elements to avoid include nickel, niobium, molybdenum, tin, and others that produce long-lived activation products.

\subsubsection{Final Disposal of ${ }^{135} \mathrm{Cs}$}

After storage for 300 years, capsules initially containing both ${ }^{135} \mathrm{Cs}$ and ${ }^{137} \mathrm{Cs}$ will not contain a significant amount of ${ }^{137} \mathrm{Cs}\left(t_{1 / 2}=30 \mathrm{yr}\right)$. Essentially all the initial ${ }^{135} \mathrm{Cs}\left(\mathrm{t}_{1 / 2}=3 \times 10^{6} \mathrm{yr}\right)$ will remain, however. Appropriate studies need to be performed to ascertain a safe, cost-effective, and licensable method for disposal of the inventory of ${ }^{135} \mathrm{Cs}$. Potential options include transfer to a repository or transmutation of ${ }^{135} \mathrm{Cs}$ following isotope separation from stable ${ }^{133} \mathrm{Cs}$. 


\subsubsection{Disposal of ${ }^{14} \mathrm{C}$}

As noted in Table 4-1, U.S. 1ight-water reactor fuel in the year 2030 will contain a total of approximately $16 \mathrm{~kg}$ of ${ }^{14} \mathrm{C}$. Essentially all this radionuclide $\left({ }_{1 / 2}=5070 \mathrm{yr}\right)$ will be evolved as $\mathrm{CO}_{2}$ when the spent fuel is dissolved in $\mathrm{HNO}_{3}$. The concern is how to dispose of the inventory of ${ }^{14} \mathrm{C}$, which is currently a repository technical issue.

One possible disposal scheme is to disperse the ${ }^{14} \mathrm{C}$ into the atmosphere; whether or not future regulations will permit such disposal is not certain. Alternatively, ${ }^{14} \mathrm{CO}_{2}$ can be removed from the process offgas either by scrubbing with an aqueous alkaline solution or, preferably, by sorption on a suitable sorbent. Eventually, the ${ }^{14} \mathrm{C}$ may be converted to $\mathrm{Na}_{2}{ }^{14} \mathrm{CO}_{3}$ which can be incorporated in the same solid form used to dispose of residual CURE concept liquid wastes. Engineering studies and associated bench-scale and pilot plant-scale tests need to be performed to (1) assess the present state of technology for removing ${ }^{14} \mathrm{CO}_{2}$ from PUREX process offgas, (2) fill in missing technology gaps, (3) demonstrate ${ }^{14} \mathrm{CO}_{2}$ removal and concentration on a suitable scale, and (4) assess the performance of solids and disposal sites containing $\mathrm{Na}_{2}{ }^{14} \mathrm{CO}_{3}$.

\subsubsection{Encapsulation Forms for Radiocesium and Radiostrontium}

The baseline chemical processing technology described in Section 3.1 assumes conversion of purified radiocesium to a solid compound, possibly $\mathrm{CsCl}$, and of purified radiostrontium to a solid compound, possibly $\mathrm{SrF}_{2}$, for subsequent double encapsulation and storage. Tentative selection of $\mathrm{CsCl}$ and $\mathrm{SrF}_{2}$ is based on previous Hanford Site experience in preparing and encapsulating these compounds. The choice of $\mathrm{CsCl}$ and $\mathrm{SrF}_{2}$ solid forms for safe extended storage of radiocesium and radiostrontium, respectively, at the Hanford Site was initially made upon the basis of costs, prior experience, ability to achieve high radioactive isotope density, and other 
factors. The cesium chloride and $\mathrm{SrF}_{2}$ have proven to be suitable forms for storing recovered and purified radiocesium and radiostrontium.

Solid forms other than $\mathrm{CsCl}$ and $\mathrm{SrF}_{2}$ may be necessary and/or desirable for interim storage and commercial utilization of radiocesium and radiostrontium recovered from LWR and FR fuels. Many factors, e.g., solubility in water, capsule corrosion, radiolytic products (thermodynamic stability), amenability to upgrading by isotope separation techniques (Section 6.3.9), economics, etc., could lead to a choice of other solid encapsulation forms. There is no lack of potential substitutes for $\mathrm{CsCl}$ and $\mathrm{SrF}_{2}$; candidates for replacing $\mathrm{CsCl}$ include pollucite (Strachan and Schulz 1977) and other aluminosilicates (Strachan and Schulz 1976). Much experience was acquired in the early 1960 s in preparing ${ }^{90} \mathrm{SrTiO}_{3}$ irradiation sources. A comprehensive and systematic listing and evaluation of forms for encapsulating radiocesium and radiostrontium recovered from LWR and FR fuels needs to be undertaken and completed.

\subsubsection{Clean Liquid Waste}

In the suite of baseline chemical processes described in Section 3.1, large amounts of sodium salts may be used in $\mathrm{pH}$ adjustments $(\mathrm{NaOH})$, in solvent washing or stripping operation $\left(\mathrm{Na}_{2} \mathrm{CO}_{3}\right)$, in valence adjustments $\left(\mathrm{NaNO}_{2}\right)$, and in complexing nonradioactive constituents in the HLW (Na ${ }_{4} E D T A$, etc.). The latter process operation also involves addition of large quantities of aqueous-soluble organic compounds into the HLW and eventually the final liquid waste. Objectionable (e.g., $\mathrm{SO}_{4}{ }^{2-}$ ) or potentially objectionable (e.g., $\mathrm{F}^{-}$) anions may also be introduced into the liquid waste by following the baseline chemical processing technology described in Section 3.1. The presence of large concentrations of $\mathrm{Na}^{+}$, hard-to-destroy organic compounds, and $\mathrm{SO}_{4}{ }^{2-}$ and $\mathrm{F}^{-}$in the liquid waste will seriously complicate its solidification and likely greatly increase the cost (because of volume considerations), and possibly increase the risk of near-surface disposal of the solidified liquid waste. 
Both engineering and experimental work need to be performed to identify sources of objectionable nonradioactive chemicals in the liquid waste and to develop alternative processes (e.g., radiocesium and radiostrontium recovery and purification) and reagents (e.g., PUREX and TRUEX processes) which reduce as much as possible the concentration of objectionable and potentially hazardous nonradioactive chemicals in the solidified liquid waste.

\subsubsection{Separation of Isotopes of Cesium and Radiostrontium}

In the CURE concept, radiocesium and radiostrontium separated from the HLW will be purified, converted to suitable solid forms, and doubly encapsulated. The resulting capsules will be safely stored for several half-lives to allow ${ }^{137} \mathrm{Cs}$ and ${ }^{90} \mathrm{Sr}$ to decay to innocuous levels.

Experimental work to develop and demonstrate practical procedures and technology to separate ${ }^{135} \mathrm{Cs}$ and ${ }^{137} \mathrm{Cs}$ from ${ }^{133} \mathrm{Cs}$, and ${ }^{90} \mathrm{Sr}$ from ${ }^{88} \mathrm{Sr}$ needs to be conducted. This isotopic separation technology may prove highly desirable to upgrade the quality of ${ }^{137} \mathrm{Cs}$ irradiators and ${ }^{90} \mathrm{Sr}$ power sources which have been in service for some time. Furthermore, separation of ${ }^{135} \mathrm{Cs}$, ${ }^{137} \mathrm{Cs}$, and ${ }^{90} \mathrm{Sr}$ isotopes from other inert and radioactive isotopes may be a necessary precursor to potential transmutation of either isotope. If not removed, undesirable products may be produced by neutron irradiation of stable ${ }^{133} \mathrm{Cs}$ and ${ }^{88} \mathrm{Sr}$. Suchard (1983) has described a generic plasma process potentially suitable for separating cesium and strontium isotopes. Laser isotope separation technology may also be suitable for the same task.

\subsection{FUEL AND TARGET FABRICATION}

No significant fuel fabrication technology development is required to implement a CURE system based on mixed oxide fuel. Section 3.2.1 describes, in detail, the process for fabrication of mixed $\mathrm{UO}_{2}-\mathrm{PuO}_{2}$ fuel for use in FRs 
and CLFRs. The use of alternate fuel types may involve significant development, and may be desirable from a reactor safety viewpoint.

Successful deployment of a CURE system will require development and validation of suitable actinide target elements as well as ${ }^{99} \mathrm{Tc}$ and radioiodine targets. Validated targets are those approved for use in a reactor by the appropriate regulatory and management agencies, i.e., NRC, DOE, etc.

The following technical issues must be resolved to realize satisfactory transmutation targets for routine use in a deployed CURE system. These technical issues are numbered and discussed in their currently perceived priority order. However, most of the issues are "stand-alone" technological areas which can be resolved or developed and demonstrated as soon as required resources are available.

\subsubsection{Radioiodine Target Fabrication and Irradiation}

Preparation of radioiodine targets suitable for in-reactor transmutation may present a difficult technological challenge to successful deployment of a CURE system. Radioiodine targets must be compounds which are noncorrosive to cladding materials, and stable for long irradiation periods. The target pin design must accommodate xenon production, the transmutation product of irradiating both ${ }^{127} \mathrm{I}$ and ${ }^{129} \mathrm{I}$. An experimental program to prepare candidate radioiodine target materials, clad them, and irradiate them is a very high priority need. Such an experimental program would include extensive postirradiation examination and evaluation of radioiodine targets, not only to verify target stability but also to validate calculated transmutation rates. 


\subsection{2 ${ }^{99} \mathrm{Tc}$ Target Fabrication and Irradiation}

Fabrication of suitable ${ }^{99} \mathrm{Tc}$ targets is expected to be much easier than fabrication of acceptable radioiodine targets. Nevertheless, experiments to determine reactor performance of candidate technetium targets are also considered to be a high priority CURE system technology need. There are, for example, currently no hard data for the behavior of technetium targets during long-term irradiation in a FR. Fabrication, irradiation, and postirradiation testing of candidate technetium target materials will fill in the materials data gap and provide confirmation of nuclear cross-section data.

\subsubsection{Actinide Target Fabrication and Irradiation}

Previous calculational and experimental studies have demonstrated (see references in Appendix $A$ ) that actinide elements can be efficiently transmuted in suitably-designed FRs. Even so, a comprehensive experimental program is necessary to develop and validate suitable target assemblies for large-scale irradiation of various actinide isotopes removed in CURE system partitioning activities. For each actinide nuclide or group of nuclides, the experimental program needs to address the issues involved in transmuting the actinides by fissioning or by sequential neutron capture to higher actinides (e.g., $238 \mathrm{pu},{ }^{244} \mathrm{~cm},{ }^{252} \mathrm{cf}$, etc.). In each case, questions related to heat and neutron generation after irradiation and the need for dispersed targets (e.g., actinide oxides in an inert matrix such as $\mathrm{Al}_{2} \mathrm{O}_{3}$ ) need to be answered. For fissioning of actinides, the advantages and disadvantages of incorporating actinide oxides in driver fuel assemblies need to be considered and, possibly, tested. For transmutation of actinides to higher actinide nuclides, targets and reactor cores which limit fissioning must be designed and tested. For a system designed to produce higher actinides, designers must pay careful attention to the large neutron sources associated with some isotopes. 


\subsubsection{Dissolver Solids Target Fabrication and Irradiation}

A small amount of finely-divided solid residue remains when irradiated LWR fuel is dissolved in $\mathrm{HNO}_{3}$. These dissolver solids consist principally of cladding fines and noble metals, but may also contain some actinide elements. The baseline CURE system partitioning scheme involves treatment, if necessary, of the dissolver solids by CEPOD technology to recover plutonium and other actinides. Such aqueous treatment of dissolver solids is timeconsuming, difficult, and expensive. Alternative methods of dealing with actinides in dissolver solids need to be found. One possible alternative is to incorporate water-washed dissolver solids in an actinide target assembly, or, less desirably, in a ${ }^{99} \mathrm{Tc}$ or a radioiodine target. Calculations, supplemented by experimental test target fabrication, irradiation, and postirradiation examination, need to be performed to determine the technical feasibility of an irradiation approach to treating dissolver solids to transmute or fission any actinides which may be present.

\subsection{CURE SYSTEM TRANSMUTATION PROCESSES}

That various actinide elements, ${ }^{99} \mathrm{Tc}$, and radioiodine can be satisfactorily transmuted to stable or short-lived nuclides is a fundamental precept of the CURE concept. Determination of an optimum reactor fuel and target assembly configuration as well as of target irradiation times requires reliable nuclear cross-section data for all the nuclides involved. The first four technical issues listed are concerned with definitions of nuclear cross-section data for special CURE system target irradiation processes. The last issue addresses potential transmutation options not discussed in other parts of this report. As before, the technical issues are numbered and discussed in their currently-perceived priority order. 


\subsubsection{Key Isotope Nuclear Cross-Section Data}

Reliable nuclear cross-section data for ${ }^{99} \mathrm{TC},{ }^{129} \mathrm{I},{ }^{23} \mathrm{~Np},{ }^{24} \mathrm{Am}$, and other actinide elements are essential for design and operation of CURE system transmutation targets and reactor configurations. A detailed review of the cross-section data for key CURE concept target nuclides needs to be performed. This review should provide a set of baseline cross-section data for use in calculation of isotopic burnup as a function of reactor exposure and of the impact on reactor reactivity of various target designs and loadings. Missing and/or questionable cross-section data need to be identified, and appropriate measurements should be performed.

\subsubsection{Lanthanide Nuclear Cross-Section Data}

A major item of concern to CURE system P-T operation is the extent to which the americium and curium products from TRUEX process operation need to be separated from coextracted fission product lanthanides. Because such separation is complex, tedious, and expensive, it is desirable to minimize it. It is essential, therefore, to determine, both by calculation and by reactor testing, the maximum amount of lanthanide elements that can be tolerated in americium and curium targets destined for fission or for transmutation to higher actinides. Existing lanthanide nuclear cross-section data must be critically reviewed to establish their availability and reliability and to identify cross-section data which need to be obtained and/or verified.

\subsubsection{Strontium Nuclear Cross-Section Data}

Definitive evaluation of the feasibility of transmuting ${ }^{90} \mathrm{Sr}$ in FRs is hampered by lack of reliable nuclear cross-section data for ${ }^{88} \mathrm{Sr},{ }^{89} \mathrm{Sr}$, and ${ }^{90} \mathrm{Sr}$. Cross-section data for neutrons in the keV energy range are particularly important. Knowledge of the cross-sections of ${ }^{88} \mathrm{Sr}$ and ${ }^{89} \mathrm{Sr}$ is necessary to determine the need for separating ${ }^{88} \mathrm{Sr}$ from ${ }^{90} \mathrm{Sr}$ before 
transmuting the latter nuclide. An experimental program to determine the necessary cross-section data needs to be designed and executed.

\subsubsection{Cesium Nuclear Cross-Section Data}

Definitive evaluation of the feasibility of transmuting ${ }^{135} \mathrm{Cs}$ and ${ }^{137} \mathrm{Cs}$ cannot be accomplished until reliable cross-section data, particularly in the $\mathrm{keV}$ neutron energy region, are available for isotopes ${ }^{134} \mathrm{Cs},{ }^{135} \mathrm{Cs}$, ${ }^{136} \mathrm{Cs}$, and ${ }^{137} \mathrm{Cs}$. Data for the listed cesium nuclides are essential to determine the need for separating cesium isotopes prior to in-reactor irradiation. Experiments to obtain the required set of data need to be designed and executed.

\subsubsection{Additional Transmutation Studies}

This report describes very limited FR transmutation scoping calculations for radioiodine and ${ }^{99} \mathrm{Tc}$. Many previous studies document transmutation of actinides by fissioning in LWRs and FRs. Additional scoping calculations are warranted for transmutation in ALWRs fueled with MOX fuel. Such ALWRs could be a more practical option than FRs for near-term deployment, and the neutron spectrum may be better for HLW transmutation than in today's LWRs.

High-power accelerators may also represent attractive transmutation devices. Neutrons produced by spallation reactions of protons with high-Z material may have excellent potential for transmuting fission products as well as actinides. Most neutrons from a spallation target have an energy spectrum similar to a fission spectrum. Therefore, a high-power accelerator system may be comparable with or better than an FR for transmutation. The capabilities and economics of accelerator transmutation should be compared with LWRs, ALWRs, and FRs. If warranted, demonstration of such accelerators and targets could be performed. 


\subsection{CURE CONCEPT--TECHNOLOGY DEVELOPMENT PLAN}

\subsection{INTRODUCTION}

Judging from the cost and risk data presented in Chapter 5 , the CURE concept, even in its present early state of development, appears to be a potentially viable HLW and spent fuel pretreatment alternative. However, before the CURE concept can indeed be regarded as a proven and reliable alternative, the system technology items listed in Chapter 6 must be satisfactorily addressed and completed. Further, the entire integrated CURE $P-T$ system must be demonstrated in a suitable fashion on an appropriate, yet-to-be-determined scale.

Table 7-1 lists what are considered presently to be the critical, highpriority CURE concept technology issues. For example, the CURE concept will not be technically feasible if the TRUEX process will not sufficiently remove ${ }^{237} \mathrm{~Np}$ and other actinide elements from PUREX process HLW. Further, if suitable ${ }^{129}$ I targets cannot be fabricated, irradiated to transmute ${ }^{129}$ I to stable xenon, and reprocessed, then an alternative radioiodine disposal method would be needed. The other seven issues listed in Table 7-1 have a similar priority basis.

As indicated in Table 7-1, the estimated cost of resolving the nine critical CURE system technology issues is about $\$ 68$ million. Expenditure of $\$ 68$ million over an approximate 5 - to $10-y r$ period will provide a solid foundation for definitive evaluation of the technical and economic feasibility of the CURE concept and for deciding whether or not to pursue the concept further.

The total estimated cost (FY 1990 dollars) to close all the technical issues listed in Tables 7-2 through 7-5 is about $\$ 146$ million, excluding the cost to develop technology, if needed, for separation of cesium and strontium isotopes. Once the requisite technology is in hand, additional large 
expenditures would be necessary to set up and operate chemical processing and target fabrication and irradiation equipment to demonstrate, on a yetto-be-determined scale, an integrated CURE system.

If overall nuclear power system studies reveal incentives to develop reactors based on non-oxide fuel systems, the development complexity and costs may increase dramatically. For example, the use of sodium-bonded nitride or metal fuel in fast reactors may result in rather substantial reactor safety advantages relative to gas-bonded oxide fuel. Dissolution of such advanced fuels may require significant development efforts to assure compatibility with chemical processing known to be required for existing LWR spent fuet. 
Table 7-1. CURE System-Critical Technology Items.

\begin{tabular}{|c|c|c|c|}
\hline $\begin{array}{l}\text { Priority } \\
\text { order } \\
\text { number }\end{array}$ & & $\begin{array}{l}\text { Estimated } \\
\text { cost to } \\
\text { acquire } \\
\left(10^{6} \$\right)(a)\end{array}$ & $\begin{array}{c}\text { Estimated } \\
\text { time to } \\
\text { acquire } \\
(y r)\end{array}$ \\
\hline 1 & $\begin{array}{l}\text { App }\} \text { icability of TRUEX(b) process to } \\
\text { HLW } c \text { solutions }\end{array}$ & 7.0 & 3 \\
\hline 2 & $\begin{array}{l}\text { Adequate decontamination of CURE } \\
\text { concept solid waste }\end{array}$ & 20.0 & 4 \\
\hline 3 & ${ }^{129}$ I target fabrication/irradiation & 3.0 & 2 \\
\hline 4 & ${ }^{99} \mathrm{Tc}$ target fabrication/irradiation & 3.0 & 2 \\
\hline 5 & ${ }^{99} \mathrm{Tc}$ recovery and separation & 4.0 & 2 \\
\hline 6 & $\begin{array}{l}\text { Separation of actinides and } \\
\text { lanthanides }\end{array}$ & 4.0 & 2.5 \\
\hline 7 & $\begin{array}{l}\text { Disposal of CURE system low-level } \\
\text { liquid waste }\end{array}$ & 15.0 & 3 \\
\hline 8 & $\begin{array}{l}\text { Removal of radiostrontium from } \\
\text { acidic HLW }\end{array}$ & 6.0 & 4 \\
\hline \multirow[t]{2}{*}{9} & $\begin{array}{l}\text { Removal of radiocesium from } \\
\text { acidic HLW }\end{array}$ & 6.0 & 4 \\
\hline & Total & $\$ 68.0$ & 3 to 4 \\
\hline
\end{tabular}

NOTE: See Chapter 6.0 for detailed description of technology issues and work needed to close issues.

(a) In fiscal year 1990 dollars.

(b) TRUEX = Transuranic extraction.

(c) HLW - High-level waste. 
Table 7-2. CURE Program Chemical Processing Technology Needs.

\begin{tabular}{|c|c|c|c|}
\hline $\begin{array}{l}\text { Priority } \\
\text { order } \\
\text { number }\end{array}$ & & $\begin{array}{l}\text { Estimated } \\
\text { cost to } \\
\text { acquire } \\
\left(10^{6} \$\right)(a)\end{array}$ & $\begin{array}{l}\text { Estimated } \\
\text { time to } \\
\text { acquire } \\
(y r)\end{array}$ \\
\hline 1 & $\begin{array}{l}\text { App }\left\{\begin{array}{l}\text { ifability of TRUEX(b) process to } \\
\text { HLW }\end{array} \text { solutions }\right.\end{array}$ & 7.0 & 3 \\
\hline 2 & ${ }^{99} \mathrm{Tc}$ recovery and separation & 4.0 & 2 \\
\hline 3 & $\begin{array}{l}\text { Separation of actinides and } \\
\text { lanthanides }\end{array}$ & 4.0 & 2.5 \\
\hline 4 & $\begin{array}{l}\text { Removal of radiostrontium from } \\
\text { acidic HLW }\end{array}$ & 6.0 & 4 \\
\hline 5 & $\begin{array}{l}\text { Removal of radiocesium from acidic } \\
\text { HLW }\end{array}$ & 6.0 & 4 \\
\hline 6 & $237 \mathrm{~Np}$ recovery technology & 10.0 & 3.5 \\
\hline 7 & Radioiodine recovery technology & 3.0 & 2.5 \\
\hline 8 & $\begin{array}{l}\text { Head-end treatment of irradiated } \\
\text { target assemblies }\end{array}$ & 12.0 & 4 \\
\hline 9 & Purification of radiostrontium & 3.0 & 2.5 \\
\hline
\end{tabular}

NOTE: See Section 6.2 for detailed description of technology issues and work needed to close issues.
(a) In fiscal year 1990 dollars.
(b) TRUEX = Transuranic extraction.
(c) $\mathrm{HLW}=\mathrm{High}-\mathrm{level}$ waste. 
WHC -EP-0268

Table 7-3. CURE Program Waste Management/Disposal Technology Needs.

\begin{tabular}{|c|c|c|c|}
\hline $\begin{array}{l}\text { Priority } \\
\text { order } \\
\text { number }\end{array}$ & & $\begin{array}{l}\text { Estimated } \\
\text { cost to } \\
\text { acquire } \\
\left(10^{6} \$\right)(a)\end{array}$ & $\begin{array}{c}\text { Estimated } \\
\text { time to } \\
\text { acquire } \\
(y r)\end{array}$ \\
\hline 1 & $\begin{array}{l}\text { Adequate decontamination of CURE } \\
\text { concept solid wastes }\end{array}$ & 20.0 & 4 \\
\hline 2 & $\begin{array}{l}\text { Disposal of CURE system low-level } \\
\text { liquid waste }\end{array}$ & 15.0 & 3 \\
\hline 3 & $\begin{array}{l}\text { Interim storage and disposal of } \\
\text { radiocesium and radiostrontium }\end{array}$ & 8.0 & 3 \\
\hline 4 & $\begin{array}{l}\text { Interim storage disposal of } \\
\text { cladding hulls and fuel } \\
\text { assembly hardware }\end{array}$ & 8.0 & 3 \\
\hline 5 & Final disposal of ${ }^{135} \mathrm{Cs}$ & 8.0 & 3 \\
\hline 6 & Disposal of ${ }^{14} \mathrm{C}$ & 6.0 & 2.5 \\
\hline 7 & $\begin{array}{l}\text { Encapsulation forms for } \\
\text { radiocesium and radiostrontium }\end{array}$ & 0.75 & 2 \\
\hline 8 & Clean CURE system liquid waste & 0.5 & 1.5 \\
\hline 9 & $\begin{array}{l}\text { Separation of isotopes of radiocesium } \\
\text { and radiostrontium }\end{array}$ & $\mathrm{TBD}(b)$ & TBD \\
\hline 10 & $\begin{array}{l}\text { Develop low-activation alloy for fast } \\
\text { reactor cladding and hardware }\end{array}$ & TBD & TBD \\
\hline
\end{tabular}

NOTE: See Section 6.3 for detailed description of technology issues and work needed to close issues.

(a) In fiscal year 1990 dollars.

(b) $\mathrm{TBD}_{\mathrm{T}}=$ To be determined. 
Table 7-4. CURE Program Target Fabrication/Irradiation Technology Needs.

\begin{tabular}{|c|c|c|c|}
\hline $\begin{array}{l}\text { Priority } \\
\text { order } \\
\text { number }\end{array}$ & & $\begin{array}{l}\text { Estimated } \\
\text { cost to } \\
\text { acquire } \\
\left.\left(10^{6} \$\right)^{*}\right)\end{array}$ & $\begin{array}{l}\text { Estimated } \\
\text { time to } \\
\text { acquire } \\
(y r)\end{array}$ \\
\hline 1 & $\begin{array}{l}\text { Radioiodine target fabrication/ } \\
\text { irradiation }\end{array}$ & 3.0 & 4 \\
\hline 2 & ${ }^{99} \mathrm{Tc}$ target fabrication/irradiation & 3.0 & 4 \\
\hline 3 & Actinide target fabrication/irradiation & 5.0 & 3 \\
\hline 4 & $\begin{array}{l}\text { Dissolver solids target fabrication/ } \\
\text { irradiation }\end{array}$ & 5.0 & 3 \\
\hline
\end{tabular}

NOTE: See Section 6.4 for detailed description of technology issues and work needed to close issues.

(*) In fiscal year 1990 dollars.

Table 7-5. CURE Program Transmutation Technology Needs.

\begin{tabular}{|c|c|c|c|}
\hline $\begin{array}{l}\text { Priority } \\
\text { order } \\
\text { number }\end{array}$ & & $\begin{array}{l}\text { Estimated } \\
\text { cost to } \\
\text { acquire } \\
\left(10^{6} \$\right)^{(*)}\end{array}$ & $\begin{array}{l}\text { Estimated } \\
\text { time to } \\
\text { acquire } \\
(y r)\end{array}$ \\
\hline 1 & Key isotope nuclear cross-section data & 0.8 & 1. \\
\hline 2 & Lanthanide nuclear cross-section data & 1.25 & 1.5 \\
\hline 3 & Strontium nuclear cross-section data & 1.25 & 3 \\
\hline 4 & Cesium nuclear cross-section data & 1.25 & 3 \\
\hline 5 & Additional transmutation studies & 2.0 & 4 \\
\hline $\begin{array}{l}\text { NOTE: } \\
\text { needed } \\
\text { * In }\end{array}$ & $\begin{array}{l}\text { See Section } 6.5 \text { for detailed description } \\
\text { to close issues. } \\
\text { iscal year } 1990 \text { dollars. }\end{array}$ & f technology & issues and \\
\hline
\end{tabular}




\subsection{REFERENCES}

Abe, M., 1982, Inorganic Ion Exchange Materials, A. Clearfie]d, Ed., CRC Press, Incorporated, Chapter 5, p. 197, Boca Raton, Florida.

AIJ, 1988, "AEC Formulates Long Range Program for R\&D on Partitioning and Transmutation Technologies," Atoms in Japan, 32(\#11), p. 4-12.

Atomic Energy Act of 1954, Public Law 1073, 68 Stat. 919, 42 CFR 2011.

Berglund, R. C., F. E. Tippets, and L. N. Salerno, 1988, "PRISM, A Safe Economic and Testable Liquid Metal Fast Breeder Reactor Plant, " Proceedings of the ANS International Topical Meeting on Safety of Next Generation Power Reactors, pp. 599-605, Seattle, Washington.

Bloomster, C. H., D. R. Brown, G. A. Bruno, R. F. Hazelton, P. L. Hendrickson, A. J. Lezberg, G. L. Tingey, and G. L. Wilfert, 1985, Potential Value of Cs-137 Capsules, PNL-5380, Pacific Northwest Laboratory, Richland, Washington.

Bloomster, C. H., and E. T. Merri11, 1987, Long Term Need for New Generating Capacity, PNL-6193, Pacific Northwest Laboratory, Richland, Washington.

Bray, L. A., and J. S. Ryan, 1982, "Catalyzed Electrolytic Dissolution of Plutonium Dioxide, " in Actinide Recovery from Waste and Low-Grade Sources, J. D. Navratil and W. W. Schulz, Eds., p.129-154, Hardwood Academic Publisher, London.

Bray, L. A., J. L. Ryan, and E. J. Wheelwright, 1985, Development of the CEPOD Process for Dissolving Plutonium Oxide and Leaching Plutonium from Scrap or Wastes, PNL-5657, Pacific Northwest Laboratory, Richl and, Washington.

Burkholder, N. C., M. 0. Cloninger, D. A. Baker, and G. Jansen, 1976, "Incentives for Partitioning High Level Waste, "Nuclear Technology, No. 31, pp. 202-214.

Clean Air Act of 1977, as amended, Public Law 95-95, 91 Stat. 685, 41 USC 7401.

Clean Water Act of 1977, as amended, Publ ic Law 95-217, 92 Stat. 1566, 33 USC 1251.

Cloninger, M. 0., 1982, "Evaluation of Actinide Partitioning and Transmutation," International Atomic Energy Technical Report Series, No. 214, pp. 79-94, International Atomic Energy Agency, Vienna, Austria.

Croff, A. G., 1980, A Revised and Updated Version of the Oak Ridge Isotope Generation and Depletion Code, ORNL-5621, Oak Ridge National Laboratory, Oak Ridge, Tennessee. 
Croff, A. G., J. 0. Blomeke, and B. C. Finney, 1980, Actinide PartitioningIransmutation Program Final Report. I. Overall Assessment, ORNL 5566, Oak Ridge National Laboratory, Oak Ridge, Tennessee.

DOE, 1980, Final Environmental Impact Statement - Management of Commercially Generated Radioactive Waste, DOE/EIS-0046F, pp. 4.84-4.86, U.S. Department of Energy, Washington, D.C.

DOE, 1985, Safety Requirements for the Packaging and Transportation of Hazardous Materials, Hazardous Substances and Hazardous Waste, " DOE Order 5480.3, U.S. Department of Energy, Washington, D.C.

DOE, 1987a, Final Environmental Impact Statement, Disposal of Hanford Defense High-Level, Transuranic and Tank Wastes, Hanford Site, Richland, Washington, DOE/EIS-0113, U.S. Department of Energy, Washington, D.C.

DOE/EIA, 1987, World Nuclear Fuel Cycle Requirements, DOE/EIA-0436, pp. 2027, U.S. Department of Energy, Washington, D.C.

DOE/EIA, 1989, 1981 Annual Report to Congress, DOE/EIA-0173 180, U.S. Department of Energy, Washington, DC.

DOE/RW, 1988, Integrated Data Base for 1988: Spent Fuel and Radioactive Waste Inventories, Projections, and Characteristics, DOE/RW-0006, Rev 4, 0ak Ridge National Laboratory, Oak Ridge, Tennessee.

DOT, 1988, Radioactive Materials, Title 49, Code of Federal Regulations, Part 173, Subpart I, Research and Special Programs Administration, U.S. Department of Transportation, Washington, DC.

Energy Reorganization Act of 1974, Public Law 93-438, 88 Stat. 1233, 42 CFR 4321 , et. seq.

EPA, 1985, Environmental Standards for the Management and Disposal of Spent Nuclear Fuel, High-Level, and Transuranic Radioactive Wastes, 50 Federal Register, No. 182, pp. 38066-38089, U.S. Environmental Protection Agency, Washington, D.C.

Haug, H. 0., 1974, "Final Purification and Concentration of Americium/Curium Separated from High-Level Reprocessing Waste," J. Radioanal. Chem., No. 21, pp. 187-198.

Hoffman, E. H., R. L. Oswalt, and L. A. Williams, 1956, Journal of Inorganic Nuclear Chemistry, 3, p.49.

Holladay, D. W., 1978, A Literature Survey: Methods for Removal of Iodine Species from Nuclear Power Plant and Nuclear Fuel Reprocessing OffGases and Liquid Waste Streams, with Emphas is on Solid Sorbents, ORNL/TM-6350, Oak Ridge National Laboratory, Oak Ridge, Tennessee. 
Horwitz, E. P., C. A. A. Bloomquist, G. W. Mason, R. A. Leonard, and A. A. Ziegler, 1978, The Recovery of Actinides from TBP $-\mathrm{Na}_{2} \mathrm{CO}_{3} \mathrm{Sol}_{\text {Sotions: }}$ The Aralex Process, ANL-79-74, Argonne National Laboratory, Argonne, Illinois.

Horwitz, E. P., H. Diamond, D. G. Kalina, L. Kaplan, and G.W. Mason, 1983, "Octyl (phenyl) - N, N-diisobutylcarbamoylmethylphosphine 0xide as an Extractant for Actinides from Nitric Acid Waste," Proceedings ISEC 83, Denver, Colorado.

Hudson, C. R., II, and L. C. Fuller, 1987, Cost Estimate Guidelines for Advanced Power Technologies, ORNL/TM-10071/R1, 0ak Ridge National Laboratory, Oak Ridge, Tennessee.

IAEA, 1982, International Atomic Energy Agency Technical Series, No. 214, pp. 103-121, Vienna, Austria.

Isaacson, R. E., and B. F. Judson, 1964, "Neptunium Recovery and Purification at Hanford," Industrial and Engineering Chemistry Process Design and Development, No. 3, pp. 296-301.

Johnson T. R., Plans for the Development of the IFR (Integral Fast Reactor) Fuel Cycle, 1986, Conf. 8610 226-2, Argonne National Laboratory, Argonne, I1 inois.

Jubin, R. T., 1979, A Literature Survey of Methods to Remove Iodine from Off-Gas Streams Using Solid Sorbents, ORNL/TM-6607, Oak Ridge National Laboratory, Oak Ridge, Tennessee.

Kolarik, Z., and R. Schuler, 1983, "Separation of Neptunium from Uranium and Plutonium in the PUREX Process," Proc. Extraction '84, Institute Chem. Eng., Symposium Series 88, pp. 88-90, London, England.

Kraus, K. A., and F. Nelson, 1956, Proceedings of the First International Conference on Peaceful Uses of Atomic Energy, Geneva, 7, p. 113, United Nations, New York.

Leuze, R. E., and M. H. Lloyd, 1970, "Processing Methods for the Recovery of Transplutonium Elements," Progress in Nuclear Energy, Process Chemistry, Series III, C. E. Stevenson, E. A. Mason, and A. T. Gresky Eds., Vol. 4, pp. 549-630, Pergamon Press, New York, New York.

Logan, S. E., R. L. Conartz, H. S.Ng, L. J. Rahal, and C. G. Shirley, 1980, Actinide Partitioning - Transmutation Program Final Report. VII LongTerm Risk Analysis of the Geologic Repository, ORNL/TM-6987, 0ak Ridge National Laboratory, Oak Ridge, Tennessee.

Mailen, J. C., and L. M. Toth, 1981, Chemistry of Volatile Fission Product Elements in Light-Water Reactor Nuclear Fuel Cycle, R. G. Wymer and B. L. Vondra, Eds., CRC Press, Inc., Boca Raton, Florida. 
McKay, H. A. C., J. P. Miles, and J. L. Swanson, The PUREX Process in Science and Technology of Tributyl Phosphate, W. W. Schulz and J. D. Navratil, Eds., Vol. 3, CRC Press, Inc., Boca Raton, Florida, 1989.

Musikas, C., 1985, "Actinide-Lanthanide Group Separation Using Sulfer and Nitrogen Donor Extractants," Actinide-Lanthanide Separations, G. R. Choppin, J. D. Navratil, W. W. Schulz, Eds., World Scientific Publishing, Singapore.

National Environmental Policy Act of 1969, Public Law 91-190, 83 Stat. 852, 422 USC 4321 et. seq.

NRC, 1982, Licensing Requirements for Land Disposal of Radioactive Wastes Final Rule, Title 10, Code of Federal Regulations, Part 61, 47 Federal Registrar, p. 57446, U.S. Nuclear Regulatory Commission, Washington D.C.

NRC, 1983, Disposal of High-Level Radioactive Wastes in Geological Repositories, Title 10, Code of Federal Regulations, Part 60, U.S. Nuclear Regulatory Commission, Washington, D.C.

NRC, 1987a, "Licensing Requirements for Land Disposal of Radioactive Waste," Title 10, Code of Federal Regulations, Part 61, U.S. Nuclear Regulatory Commission, Washington, D.C.

NRC, 1987b, Packaging and Transportation of Radioactive Materials, Title 10, Code of Federal Regulations, Part 71, U.S. Nuclear Regulatory Commission, Washington, D.C.

NRC, 1989, Disposal of Radioactive Wastes, Final Rule, Title 10, Code of Federal Regulations, Part 61, 54 Federal Registrar p. 22578. U.S. Nuclear Regulatory Commission, Washington, D.C.

Nuclear News, 1988, "Waste Management: High-Level Waste; Nevada's Bryan Rips DOE over Geologist's Study," p. 111.

Poe, W. L., R. W. Joyce, and R. I. Martens, 1964, "237 Np and 238Pu Separation at the Savannah River Plant," Industrial and Engineering Chemistry Process Design and Development, Vol. 3, No. 4, p. 314.

Pruett, D. J. and D. R. McTaggart, 1989, "Separation of Uranium from Technetium in Recovery of Spent Nuclear Fuel, " U.S. Patent 4, 443, 413.

Resource Conservation and Recovery Act of 1976, Public Law 94-580, 90 Stat. 2795, 42 USC 6901 et. seq.

Roddy, J. W., 1985, Physical and Decay Characteristics of Commercial LWR Spent Fuel, ORNL/TM-9591, Oak Ridge National Laboratory, Oak Ridge, Tennessee.

Roger, W. A., B. S. McCauley, and R. A. Keeler, 1964, "Gaseous Waste" in Reactor Handbook, Vol II, 2nd Ed., S. M. Stoller and R. B. Richards, Eds., Interscience, New York, New York. 
Ross, W. A., G. A. Jensen, L. L. Clark, D. E. Eskin, J. H. Jarrett, Y. B. Katayoma, R. W. McKee, L. G. Morgan, S. M. Nealy, A. M. Platt, and G. L. Tingey, 1989, Projections of Needs for Gamma Radiation Sources and Other Radioisotopes and Assessments of Alternatives for Providing Radiation Sources, PNL-6250, Pacific Northwest Laboratory, Richland, Washington.

Ryan, J. L., L. A. Bray, and A. L. Boldt, 1987 "Dissolution of $\mathrm{PuO}_{2}$ or $\mathrm{NpO}_{2}$ Using Electrolytically Regenerated Reagents", U.S. Patent 4,686,019, Exxon Nuclear Company, August $11,1987$.

Scheitlin, F. M., and W. D. Bond, 1980, Recovery of Plutonium from HEPA Filters By Ce(IV)-Promoted Dissolution of $\mathrm{PuO}_{2}$ and Recycle of the Cesium Promoter, ORNL/TM-6802, Oak Ridge National Laboratory, Oak Ridge, Tennessee.

Schneider, R. J., and A. M. Platt, Eds; "High-Level Radioactive Waste Management Alternative," BNWL-1900, Battelle Pacific Northwest Laboratory, Richland, Washington, 1974.

Schneider, R. J., P. J. Pelto, P. M. Daling, J. C. Lavender, and B. A. Fecht, 1986, Preliminary Assessment of Radiological Doses in Alternative Waste Management Systems Without an MRS Facility, PNL-5872, Pacific Northwest Laboratory, Richland, Washington.

Schulz, W. W., and G. E. Benedict, 1972, Neptunium-237 Production and Recovery, TID-25955, U. S. Atomic Energy Commission, Oak Ridge, Tennessee.

Schulz; W. W., and L. A. Bray, 1987, "Solvent Extraction Recovery of Byproduct ${ }^{137} \mathrm{Cs}$ and ${ }^{90} \mathrm{Sr}$ from $\mathrm{HNO}_{3}$ Solutions - A Technology Review and Assessment," Sep. Sci and Tech., No. 22, pp. 191-214.

Schulz, W. W., and E. P. Horwitz, 1988, "The TRUEX Process and the Management of Liquid TRU Waste," Sep. Sci. and Tech., No. 23, pp. 1191-1210.

Schulz, W. W., and E. P. Horwitz, 1987, "TRUEX Process: Removal/Recovery of TRU Elements from Acidic Waste Solutions, " Extraction '87, pp. 245-262, Institution Chemical Engineering, London, England.

Schulz, W. W., J. E. Mendel, and G. L. Richardson, 1963, "Solvent Extraction Recovery and Purification of Strontium-90," Ind. Eng. Chem. Process Design Develop., No. 2, p. 134.

Schulz, W. W., 1976, The Chemistry of Americium, Energy Research and Development Administration Technical Information Center, Oak Ridge, Tennessee.

Selucky, P., P. Vanura, J. Rais, and M. Kyrs, 1979, Radiochem. Radioanal. Lett., pp. 38, 297. 
Shmidt, V. S., 1971, Amine Extraction, Israel Program for Scientific Translations, Jerusalem, Israel.

Shuler, R. G., L. B. Bowers, Jr., J. E. Smith, Jr., V. Van Brunt, and M. W. Davis, Jr., 1985, "The Extraction of Cesium and Strontium from Acidic High Activity Nuclear Waste Using a PUREX Process Compatible Organic Extractant," Solv. Extr. Ion Exch., No. 3, p. 567.

Sonde, W. E., W. J. Bjorklund, and N. A. Brooks, 1977, Cost Analys is for Application of Solidified Waste Fission Products Canisters in U.S. Army Steam Plants, BNWL-2266, Pacific Northwest Laboratory, Richland, Washington.

Strachan, D. M., and W. W. Schulz, 1976, Glass and Ceramic Materials for the Immobilization of Megacurie Amounts of Pure Cesium-137, ARH-SA-246, Atlantic Richfield Hanford Company, Richland, Washington.

Strachan, D. M., and W. W. Schulz, 1977, Characterization of Pollucite as a Material for Lonq-term Storage of Cesium-137, ARH-SA-294, Atlantic Richfield Hanford Company, Richland, Washington.

Suchard, S. N., 1983, "The Plasma Separation Process for Generic Isotope Separation," Waste Management 83, R. Post and M. Wacks, Eds., Vol. 2, pp. 113-116, American Nuclear Society, La Grange Park, Illinois.

Szymanski, J. S., 1989, Conceptual Considerations of the Yucca Mountain Groundwater Systems with Special Emphasis on the Adequacy of the System to Accommodate High Level Nuclear Waste Repository, U.S. Department of Energy, Nevada Test Site Office.

U.S. Counci1 for Energy Awareness, 1987, A Comparison of Future Costs of Nuclear and Coal-Fired Electricity: An Update, Washington, DC.

Wachter, J. W., and A. G. Croff, 1980, Actinide Partitioning-Transmutation Program Final Report. III Transmutation Studies, ORNL/TM-6983, Oak Ridge National Laboratory, Oak Ridge, Tennessee.

Weaver, B. and F. A. Kappelmann, 1968, "Preferential Extraction of Lanthanides over Trivalent Actinides by Monoacidic Organophosphates from Carboxylic Acids and from Mixtures of Carboxylic and Aminopolyacetic Acids," J. Inorg. Nucl. Chem, No. 30, pp. 263-272.

Wheelwright, E. J., May 1969, "Ion Exchange Process for Recovering Americium and Curium," U.S. Patent $3,445,201$.

Wilhite, E. L., 1987, Concept Development for Saltstone and Low-Level Waste Disposal, DP-MS-86-110, E. I. Dupont De Nemours Co., Aiken, South Carolina. 
WHC-EP-0268

APPENDIX A

\section{BIBLIOGRAPHY OF LITERATURE REFERENCES TO PARTITIONING AND TRANSMUTATION}

The following list of literature citations was originally compiled by Mr. A. G. Croff of the Oak Ridge National Laboratory. It is reproduced here with the kind permission of Mr. Croff. 
WHC -EP-0268

\section{BIBLIOGRAPHY}

1. National Regulatory Commission, Code of Federal Regulations, Standards for Protection against Radiation, 10 CFR 20.

2. A. G. Croff, D. W. Tedder, J. P. Drago, J. 0. Blomeke, and J. J. Perona, A Prel iminary Assessment of Partitioning and Transmutation as a Waste Management Concept, ORNL/TM-5808 (September 1977), Oak Ridge National Laboratory, Oak Ridge, Tennessee.

3. W. D. Bond and R. E. Leuze, Feasibility Studies of the Partitioning of Commercial High-Level Wastes Generated in Spent Nuclear Fuel Reprocessing: Annual Progress Report for FY 1974, ORNL-5012 (January 1975), Oak Ridge National Laboratory, Oak Ridge, Tennessee.

4. J. W. Bartlett, L. A. Bray, L. L. Burger, R. E. Burns, and J. L. Ryan, Feasibility Evaluation and R\&D Program Plan for Transuranic Partitioning of High-Level Fuel Reprocessing Waste, BNWL-1776 (November 1973), Pacific Northwest Laboratory, Richland, Washington.

5. M. Steinberg, G. Wotzak, and B. Manowitz, Neutron Burning of Long-Lived Fission Products for Waste Disposal, BNL-8558 (September 1964), Brookhaven National Laboratory, Upton, New York.

6. M. V. Gregory and M. Steinberg, A Nuclear Transformation System for Disposal of Long-Lived Fission Product Waste in an Expanding Nuclear Power Economy, BNL-11915 (November 1967), Brookhaven National Laboratory, Upton, New York.

7. H. C. Claiborne, Neutron-Induced Transmutation of High-Level Radioactive Waste, ORNL/TM-3964 (December 1972), Oak Ridge National Laboratory, Oak Ridge, Tennessee.

8. W. C. Wolkenhauer, The Controlled Thermonuclear Reactor as a Fission Product Burner, BNWL-SA-4232 (1972), Pacific Northwest Laboratory, Richland, Washington.

9. W. C. Wolkenhauer, B. R. Leonard, Jr., and B. F. Gore, Iransmutation of High Level Radioactive Waste with a Controlled Thermonuclear Reactor, BNWL-1772 (September 1973), Pacific Northwest Laboratory, Richland, Washington.

10. B. F. Gore and B. R. Leonard, Jr., Trans. Am. Nucl. Soc. 17, Transmutation in Quantity of ${ }^{13} \mathrm{CS}$ in a Controlled Thermonuclear Reactor, 52-53 (November 1973).

11. B. F. Gore and B. R. Leonard, Jr., "Transmutation of Massive Loadings of Cesium-137 in the Blanket of a Controlled Thermonuclear Reactor," Nucl. Sci. Eng. 53, 319-23 (1974).

12. J. Henley and H. W. Meldner, "Neutron Capture in Laser-fusion Pellets," Phys. Rev. C 12, 407-412 (1975). 
13. J. W. H. Chi, S. Kellman, D. Klein, and R. P. Rose, "An Analysis of Actinide Depletions and Radiotoxic Hazards following Irradiation in a

Fusion-Fission Hybrid Reaction," Trans. Am. Nucl. Soc. 23, 262-63 (June 1976).

14. J. W. H. Chi and R. R. Holman, "A Comparative Evaluation of FusionFission Actinide Burner Blanket Concepts," Trans. Am. Nucl. Soc. 23, 26 (June 1976).

15. R. P. Rose, Fusion-Driven Actinide Burner Design Study, EPRI-ER-451 (May 1977, Electric Power Research Inst., Palo Alto, California.

16. G. Lang, E. L. Draper, and T. A. Parish, 1980, EPRI-AP-1642, Determination of Procedures for Transmutation of Fission Product Wastes by Fusion Neutrons, Vol. 1-3, Electric Power Research Inst., Palo Alto, California.

17. U. P. Jenquin and B. R. Leonard, Jr., "Actinide Transmutation in Fusion Reactor Blankets," Trans. Am. Nucl. Soc. 23, 549-550 (June 1976).

18. A. S. Kubo, "Technology Assessment of High-Level Nuclear Waste Management," Ph.D. thesis, Massachusetts Institute of Technology, Cambridge, Massachusetts (May 1973).

19. M. Taube, E. H. Ottewitte, and J. Ligou, A High-Flux Fast Molten Salt Reactor for the Transmutation of Cesium-137 and Strontium-90, EIR-259 (September 1975), Eidgenoessisches Inst. Fuer Reaktor-Forschung, Wuerenlingen, Switzerland.

20. M. Taube, "The Transmutation of Strontium-90 and Cesium-137 in a HighFlux Fast Reactor With a Thermalized Central Region," Nucl. Sci. Eng. 61, 212-21 (1976).

21. R. Paternoster, M. J. Ohonian, R. T. Schneider, and K. Thom, "Nuclear Waste Disposal Utilizing A Gaseous Core Reactor," Irans. Am. Nucl. Soc. $19,203-4$ (October 1974).

22. R. Paternoster, Ph.D. thesis, "A Linear Characteristic-Nodal Transport Method for the Two-Dimensional, $(X, Y)$-Geometry, Multigroup Discrete Ordinates Equations Over an Arbitrary Triangle Mesh, "Vol. 45/07-B of Dissertation Abstracts International, p. 2289, University of Florida, Gainsville (1974).

23. S3 Raman, C. W. Nestor, Jr., and J. W. T. Dabbs, "A Study of the $233 U$ 232 Th Reactor as a Burner for Actinide Waste," proceedings of the Conference on Nuclear Cross Sections and Technology, Washington D.C.. March 5-7, 1975, National Bureau of Standards, Washington, D.C., NBS-SP-425, VoT. 1, p. 222-223.

24. R. H. Clarke, H. F. MacDonald, J. Fitzpatrick, and A. J. H. Goodard, "Waste Disposal Aspects of the Long Term Cooling Characteristics of Irradiated Nuclear Fuels," Ann. Nul. Energy 2, 451-66 (1975). 
25. R. J. Breen, "Elimination of Actinides with LMFBR Recycle," Irans. Am. Nucl. Soc. 21, 262 (June 1975).

26. S. L. Beaman, "Actinide Recycle in LMFBRs as a Waste Management Alternative," Irans. Am. Nucl. Soc. 22, 346 (November 1975).

27. Cooperative Nuclear Data and Methods Development Second Quarterly Report October-December 1975, GEAP-14074-2 (January 1976), General Electric Company, Sunnyvale, California.

28. Cooperative Nuclear Data and Methods Development Third Quarterly Report January-March 1976, GEAP-14074-3 (April 1976), General Electric Company, Sunnyvale, Cal ifornia.

29. S. L. Beaman and E. A. Aitken, "Feasibility Studies of Actinide Recycle in LMFBRs as a Waste Management Alternative," Irans. Am. Nucl. Soc. 23, 547-548 (June 1976).

30. S. L. Beaman and H. S. Bailey, "Plutonium Burnout in Fast Reactors as a Waste Management Alternative," Trans. Am. Nucl. Soc. 23, 263-264 (June 1976).

31. J. J. Prabulos, "Actinide Destruction in a 1500-MW(e) Carbide-Fueled LMFBR," Trans. Am. Nucl. Soc. 23, 548-549 (June 1976).

32. J. Bouchard, M. Darrouzet, and M. Fort, "Actinide Transmutation Studies," proceedings of the First Technical Meeting on the Nuclear Transmutation of Actinides, Ispra, Italy, March 16-18, 1977. Commission of the European Communities EUR 5897.

33. W. Bocola, L. Fritelli, F. Gera, G. Crossi, A. Moccia, and L. Tondinelli, "Considerations on Nuclear Transmutation for the Elimination of Actinides," paper IAEA-SM-208186 presented at the International Symposium on the management of Radioactive Waste from the Nuclear Fuel Cycle, Vienna, March 22-26, 1976. International Atomic Energy Agency, Vienna, Austria.

34. A. S. Kubo and D. J. Rose, "Disposal of Nuclear Wastes," Science 182, 1205-1211 (December 21, 1973).

35. Chem. Technol. Div. Annu. Prog. Rep. Mar. 31, 1975, ORNL-5050, p. 11. Oak Ridge National Laboratory, Oak Ridge, Tennessee.

36. A. G. Croff, "Parametric Studies Concerning Actinide Transmutation in Power Reactors," Trans. Am. Nucl. Soc. 22, 345 (November 1975).

37. T. H. Pigford and J. Choi, Effect of Fuel Cycle Alternatives on Nuclear Waste Management, in Waste Management 76, R. G. Post, ed. Arizona Univ., Tucson, Arizona, p. 39-57. 
38. E. Schmidt and J. Cametti, "On the Neutron-Physical Feasibility of Transmutation of Actinides Other Than Fuel in Nuclear Power Reactors," proceedings of First Technical Meeting on the Nuclear Transmutation of Actinides, Ispra, Italy, March 16-18, 1977. Commission of the European Communities EUR5897 p. 177-191.

39. W. Hage and E. Schmidt, "Reactor Physics Aspects of Burning Actinides in a Nuclear Reactor," paper presented at the First Technical Meeting on the Nuclear Transmutation of Actinides, Ispra, Italy, March 16-18, 1977 .

40. G. Harte, "Some Preliminary Investigations of the Incineration of Actinide Waste from the UK and European Nuclear Power Programmes, " paper presented at the First Technical Meeting on the Nuclear Transmutation of Actinides, Ispra, Italy, March 16-18, 1977.

41. L. Koch, R. Ernstberger, and K. L. Kammericks, "Formation of Minor Actinides and Requirements of Nuclear Incineration," paper presented at the First Technical Meeting of the Nuclear Transmutation of Actinides, Ispra, Italy, March 16-18, 1977.

42. F. Duggan, "The Burnup Characteristics of Individual Actinide Isotopes with a View to Nuclear Incineration," paper presented at the First Technical Meeting on the Nuclear Transmutation of Actinides, Ispra, Italy, March 16-18, 1977.

43. A. Sola, "Some Preliminary Results on Actinide Incineration and Transmutation in a Thermal and A Fast Reactor, " paper presented at the First Technical Meeting on the Nuclear Transmutation of Actinides, Ispra, Italy, March 16-18, 1977.

44. K. J. Schneider and A. M. Platt (eds), High-Level Radioactive Waste Management Alternatives, BNWL-1900 (May 1974), Chap. 9.

45. Alternatives for Managing Wastes from Reactors and Post-Fission Operations in the LWR Fuel Cycle, ERDA076-43 (April 1976).

46. A. Sola and K. Caruso, "Sensitivity Studies on Nuclear Data," paper presented at the First Technical Meeting on the Nuclear Transmutation of Actinides, Ispra, Italy, March 16-18, 1977.

47. E. Schmidt, "Influence of Nuclear Data Uncertainties on Results Recycling Actinides Other Than Fuel," paper presented at the First Technical Meeting on the Nuclear Transmutation of Actinides, Ispra, Italy, March 16-18, 1977.

48. A. Gandini, G. 01 iva, and L. Tondinelli, "Correlation between Irradiation Experiments and Nuclear Data for Actinide Production, " paper presented at the First Technical Meeting on the Nuclear Transmutation of Actinides, Ispra, Italy, March 16-18, 1977.

49. P. E. McGrath, Radioactive Waste Management Potentials and Hazards from a Risk Point of View, KRK 1992 (June 1974). 
50. A. G. Croff, "The Technological Impact of Partitioning-Transmutation," Ispra, Ital, March 16-18, 1977.

51. M. G. Sowerby, "Nuclear Incineration Strategies," paper presented at the First Technical Meeting on the Nuclear Transmutation of Actinides, Ispra, Italy, March 16-18, 1977.

52. H. C. Claiborne, Effect of Actinide Removal on the Long-Term Hazard of High-Level Waste, ORNL-TM-4724, (January 1975).

53. W. D. Bond and R. E. Leuze, "Removal of Actinides from High-Level Wastes Generated in the Reprocessing of Commercial Fuels," pp. 423-32 in Transplutonium Elements, 1975, Proceedings of the Symposium at BadenBaden, September 13-17, 1975, North-Holland, Amsterdam, 1976.

54. C. F. Smith, "Risk Assessments for the Disposal of High-Level Radioactive Wastes," Ph.D. dissertation, UCLA, Los Angeles, California, (1975).

55. H. C. Burkholder, M. 0. Cloninger, D. A. Baker, and G. Jansen, Incentives for Partitioning High-Level Waste, BNWL-1927, (November 1975).

56. J. 0. Blomeke and D. W. Tedder, Actinide Partitioning and Transmutation Program Progress Report for Period October 1, 1976 to March 31, 1977, ORNL/RM-5888 (June 1977).

57. D. W. Tedder and J. 0. Blomeke, Actinide Partitioning and Transmutation Program Progress Report for Period April 1 to June 30, 1977, ORNL/TM-6056 (October 1977).

58. D. W. Tedder and J. 0. Blomeke, Actinide Partitioning and Transmutation Program Progress Report for Period July 1 to September 30, 1977, ORNL/TM-6174 (February 1978).

59. G. H. Thompson, et al., Waste Management Analysis for the Nuclear Fuel Cycle - Parts I and II Progress Report for the Period Ending March 31, 1977, RFP-2749 (October 23, 1978).

60. J. D. Navratil et a1., Waste Management Analysis for the Nuclear Fuel Cycle - Parts I and II Progress Report for Period April 1 to September 30, 1977, RFP-2749 (October 23, 1978).

61. G. H. Thompson, C. M. Smith, E. L. Childs, and R. L. Kavhen, Waste Management Analysis for the Nuclear Fuel Cycle - Actinide Recovery from Combustible Waste, October 1977-March 1978, RFP-2798 (September 18, 1979).

62. D. F. Luthy and E. L. Lewis, Decontamination of HEPA Filters: AprilJune 1977, MLM-2445 (September 1977). 
63. M. L. Williams, J. W. McAdoo, and A. F. Flanagan, Prel iminary Neutronic Study of Actinide Transmutation in a Fast Reactor, ORNL/TM-6309 (August 1978).

64. T. C. Gorre11, Transmutation of Waste Actinides in Thermal Reactors: Survey Calculations of Candidate Irradiation Schemes, DP-1496 (November 1978).

65. T. C. Gorre11, Transmutation of Waste Actinides in Light Water Reactors, DP-1518 (Apri1 1979).

66. L. D. McIsaac, et al., Study of Bidentate Compounds for Separation of Actinides from Commercial LWR Reprocessing Wastes, ICP-1180 (May 1979).

67. S. Katz and W. D. Bond, A Method of Estimating Distribution Coefficients of Degradation Products from Organophosphorus Extractions, ORNL/TM-6776 (May 1979).

68. E. P. Horwitz, C. A. A. Bloomquist, G. W. Mason, R. A. Leonard, and A. A. Ziegler, The Recovery of Actinides from TBP-Na $2 \mathrm{CO}_{3}$ Scrub-Waste Solutions: The Aralex Process, ANL-79-74 (August 1979).

69. C. W. Forsberg, Separation of Americium, Curium, and Rare Earths from High-Level Wastes by 0xalate Precipitation: Experiments with Synthetic Waste Solutions, ORNL/TM-6445 (January 1980).

70. F. M. Scheitl in and W. D. Bond, Recovery of Plutonium from HEPA Filters by CE(IV-Promoted Dissolution of Pu0 2 and Recycle of the Cerium Promoter, ORNL/TM-6802 (May 1980).

71. C. W. Forsberg, Computer Simulation of Displacement Cation Exchange Chromatography. Separation of Trivalent Actinides and Lanthanides, ORNL/TM-6738 (May 1980).

72. A. G. Croff, J. 0. Blomeke, and B. C. Finney, Actinide PartitioningTransmutation Program Final Report, I. Overall Assessment, ORNL-5566 (June 1980).

73. J. W. Wachter and A. G. Croff, Actinide Partitioning-Transmutation Program Final Report. IV. Miscellaneous Aspects, ORNL/TM-6983.

74. C. W. Alexander and A. G. Croff, Actinide Partitioning-Transmutation Program Final Report: III. Transmutation Studies, ORNL/TM-6984.

75. A. E. Smith and D. F. Davis (R. M. Parsons Co.), Actinide PartitioningTransmutation Program Final Report. V. Preconceptual Designs and Costs of Partitioning Facilities and Shipping Casks, ORNL/TM-6985 (January 1980).

76. R. R. Fullwood and R. R. Jackson (Science Applications, Inc.), Actinide Partitioning-Transmutation Program Final Report. VI. Short-Term Risk Analysis of Reprocessing, Refabrication, and Transportation, ORNL/TM-6986 (March 1980). 
Appendix, ORNL/Sub-80/31048/1 (January 1980).

77. S. E. Logan, ét a1. (Los Alamos Technical Associates), Actinide Partitioning-Transmutation Program Final Report. VII. Long-Term Risk Analysis of the Geologic Repository, ORNL/TM-6987 (in press).

Appendix, ORNL/Sub-80/31038/1 (January 1980).

78. R. L. Engel and D. E. Deonigi, Evaluations of Fusion-Fission (Hybrid) Concepts: Market Penetration Analysis for Fusion-Fission Hybrids, prepared by Battelle Pacific Northwest Laboratories for Electric Power Research Institute, EPRI ER-469 (1976).

79. G. A. Harte and R. H. Clarke, An Investigation into the Use of a Fast Breeder Reactor to Incinerate Actinide Waste from the U.K. Nuclear Power Programme, CEGB-RD/V/N-3903 (December 1976).

80. J. J. Prabulos, Recycling of Trans-Uranium Actinides in a 1500 MWE Carbide LMFBR, Combustion Engineering, Inc., CE-FBR-76-352 (1976).

81. M. Taube, "The Transmutation of Strontium-90 and Cesium-137 in a HighFlux Fast Reactor with a Thermalized Central Region," Nucl. Sci., Eng. $\underline{61}, 212-21(1976)$.

82. R. Gasteiger, Development of an Irradiation Technology for the Recycling of Am-24l in Nuclear Reactors--A Contribution to the Possibilities for Reducing the Hazard Potential of Alpha-Bearing Wastes, KFK-2431; ORNL-TR-4585 (1977).

83. T. H. Pigford and J. Choi, Irans. Am. Nucl. Soc. 27, 450-451 (November 1977).

84. E. Zamorani, Surface Dose Rate Contribution by Actinides Mixed in Uranium-Plutonium Fuel Elements, EUR 5917 e, JRC, Ispra, Italy (1977).

85. T. C. Gorrel, Iransmutation of Waste Actinides in Light-Water Reactors, DP-1518 (April 1979).

86. T. C. Gorrel1, "Transmutation of Waste Actinides in Thermal Reactors," Trans. Am. Nucl. Soc. 32, 392-93 (June 1979).

87. G. Oliva, G. Palmiotti, M. Salvatores, and L. Tondinelli, "Elimination of Transuranium Elements by Burnup in a Power Fast Breeder Reactor," Nucl. Tech. 37, 340-52 (March 1978).

88. M. L. Williams, J. W. McAdoo, and G. F. Flanagan, Preliminary Neutronic Study of Actinide Transmutation in a Fast Reactor, ORNL/TM-6309 (August 1978).

89. D. H. Berwald and J. J. Duderstadt, "Preliminary Design and Neutronic Analysis of a Laser Fusion Driven Actinide Waste Burning Hybrid Reactor," Nucl. Tech. 42, 34-50 (January 1979). 
90. D. J. Murphy, Jr., W. M. Farr, and B. D. Ganapol, "Power Production and Actinide Elimination by Fast Reactor Recycle," Nucl. Tech. 45(3), 299306 (October 1979).

91. T. A. Parish, "A Neutronic Assessment of Strontium-90 Transmutation in Fusion Reactors," Nucl. Tech. 42(2), 180-94 (February 1979).

92. T. A. Parish and J.W. Davidson, "Reduction in the Toxicity of Fission Product Wastes through Transmutation with Deuterium-Tritium Fission Neutrons," Nucl. Tech. 42(2), 324-42 (February 1980).

93. A. H. Robinson, G. W. Shirley, A. W. Prichard, and T. J. Trapp, "Burning Actinides in Very Hard Spectrum Reactors," Trans. Am. Nucl. Soc. 30 , 289-90 (November 1978). 
WHC-EP-0268

\section{DISTRIBUTION}

Number of copies

OFFSITE

13

U.S. Department of Energy -

Headquarters

D. E. Bailey

J. W. Bartlett

C. B. Bastin

C. Frank

W. Hartman

P. B. Hemmig

R. A. Hunter

J. E. Lytle

W. H. McVey

S. Russo

R. Stein

C. E. Weber

$\mathrm{NE}-471$

$\mathrm{RW}-1$

$\mathrm{NE}-471$

EM-50

$\mathrm{NE}-46$

$\mathrm{NE}-462$

$\mathrm{NE}-47$

DP-10

$\mathrm{NE}-471$

$\mathrm{RW}-10$

$\mathrm{RW}-30$

R. P. Whitfield

$\mathrm{NE}-14$

$D P-12$

4

Argonne National Laboratory - East 9700 S. Cass Avenue

Argonne, I1 inois 60439-4837
P. Horwitz
L. G. LeSage
R. McKnight
D. Wade

1

Argonne National Laboratory - West

P. 0. Box 1625

Idaho Falls, Idaho 83415

Director, EBR-II Project

1

Brigham Young University

Chemistry Department

Provo, Utah 84602

R. Izatt

4

Brookhaven National Laboratory

Upton, New York 11973

W. Kato

J. Powell

M. Steinberg

G. J. Van Tuyle

Distr-1 
WHC-EP-0268

\section{DISTRIBUTION (cont)}

\section{Number of copies}

OFFSITE

3

Electric Power Research Institute

3412 Hillview Avenue

P. 0. Box 10412

Palo Alto, California

F. Culler

E. Rodwel1

R. Williams

4

General Electric Company

6835 Via Del Oro

San Jose, California 95119-1315

E. L. Gleukler

$S-65$

J. E. Quinn

S -65

I. N. Taylor

$S-72$

M. L. Thompson

$S-72$

23

Los Alamos National Laboratory

P. 0. Box 1663

Los Alamos, New Mexico 87545

E. D. Arthur (5)

M. Berger

F6-43

R. J. Burick

W. Davidson

H. Ettinger

W. Hansen

R. W. Hardie

T. Hirons

J. Jackson

$R$. Jensen

G. Lawrence

W. Lisowski

R. C. Little

P. Miller

R. Perkins

S. 0. Schriber

T. J. Trapp

J. Whetten

W. B. Wilson 


\section{DISTRIBUTION (cont)}

\section{Number of copies}

\section{OFFSITE}

9

Oak Ridge National Laboratory P. 0. Box X

Oak Ridge, Tennessee 83731

C. Alexander

J. Bell

R. S. Booth

W. D. Burch

D. Campbe11

A. G. Croff

J. C. Mailen

R. B. Rothrock

C. W. Forsberg

Oregon State University Corvallis, Oregon 97331

S. E. Binney

Savannah River Laboratory

Aiken, South Carolina 29808

R. Benjamin

Westinghouse Electric Coroporation

MMOB

P. 0. Box 3912

Pittsburgh, Pennsylvania 15230

C. R. Bolmgren

Westinghouse Electric Corporation (Waltz Mi11s) P. 0. Box 158

Madison, Pennsylvania 15663

R. A. Doncals

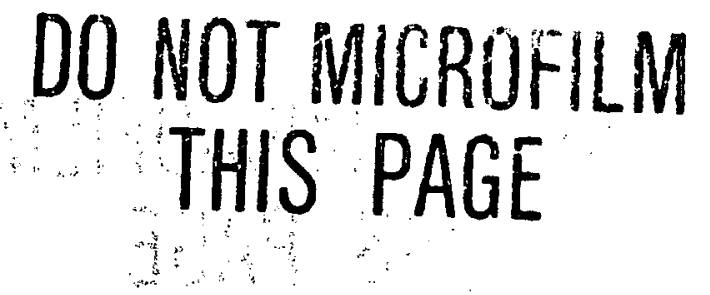

Distr-3 


\section{DISTRIBUTION (cont)}

\section{Number of copies}

\section{OFFSITE}

2

other

W. W. Schulz

307 Pleasant Knoll Ct.

Newark, Delaware 19711

S. Suchard

9912 Star Drive

Huntington Beach, Cal ifornia 92646

\section{ONSITE}

14

U.S. Department of Energy-

Richland Operations office

R. A. Almquist

A6-55

K. W. Bracken

A6- 53

P. K. Clark (3)

A6- 80

R. E. Gerton

A6- -80

W. F. Hendrickson

$A 6-55$

J. M. Hennig

J. R. Hunter

$A 6-55$

J. E. 01 lero

A6 -55

G. W. Rosenwald

Public Reading Room

(2)

Al -55

A6-80

Al -65

43

Pacific Northwest Laboratory

Battelle Blvd.

P. 0. Box 999

Richland, Washington 99352

C. L. Bloomster

K6-47

H. C. Burkholder

P7 -41

R. L. Daubert

P7 -39

R. Einziger

P7 -14

S. W. Heaberl in

$\mathrm{K} 6-42$

C. M. Heeb

$\mathrm{K} 6-42$

B. J. Kaiser

W. Laity

W. W. Little

P8-01

$\mathrm{K} 2-15$

K6-42

K1-77

P2-77 
WHC -EP-0268

DISTRIBUTION (cont)

Number of copies

ONSITE

Pacific Northwest Laboratory

Battelle Blvd.

P. 0. Box 999

Richland, Washington 99352

J. P. NcNeece

J. R. Morrey (25)

K6-42

P7 -14

A. W. Prichard

J. A. Straalsund

K6- 42

J. L. Swanson

E. J. Wheelwright

$\mathrm{K} 1-40$

C. N. Wilson

P7 -25

P7 -25

P7 -14

West inghouse Hanford Company

S. D. Atkin

HO -34

R. B. Baker

S4-08

R. E. Bauer

L6-37

R. A. Bennett

N2-32

C. L. Bennett

N2-32

R. J. Bliss

B3-04

A. L. Boldt

R2- 11

N. C. Boyter

R2-11

H. R. Brager (25)

L5-03

D. J. Brown

B4 -63

C. A. Burgess

L5-32

L. L. Carter

HO-35

T. Chiao

HO-36

C. M. Cox

B3-65

G. E. Culley

L5-32

J. W. Daughtry

HO-35

K. D. Dobbin

N2 -32

D. S. Dutt

L5-60

E. W. Gerber

L5-32

R. L. Gilchrest

H5- 55

H. J. Goldberg

HO- 36

E. A. Gordon

H4 -17

J. M. Grover

L5-55

W. J. Gruber

LO-22

J. W. Hales

L5- 02

R. A. Harris

HO- 35

J. J. Holmes

L5-55 


\section{DISTRIBUTION (cont)}

\section{Number of copies}

ONSITE

West inghouse Hanford Company

J. 0. Honeyman

R3-63

G. F. Howden

J. A. Hunter

$\mathrm{N} 1-34$

G. Jansen

L5-6]

G. D. Johnson

LO-06

D. P. Jordheim

L5- -03

R. L. Knecht

HO-35

B. J. Knutson

$\mathrm{N} 1-47$

M. K. Korenko

$\mathrm{HO}-35$

E. J. Kosiancic

H5- 59

R. D. Leggett

R2 -67

W. D. Leggett

H4 - 16

R. E. Lerch

L5- 04

A. H. Lu

B. J. Makenas

B2 - 35

HO- 36

F. M. Mann

L5- 02

R. S. McBeath

HO-36

A. J. Naser

R2-87

D. J. Newl and

S4-25

L. G. Niccoli

L5-56

R. C. Nichols

L5-3]

R. P. Omberg

B3-02

R. W. Powell

HO- 40

R. J. Puigh

L5 -55

J. A. Rawl ins (60)

L6-39

G. W. Reddick

L5-6]

L. H. Rice

R3-63

W. M. Ritter

B3-03

R. C. Roal

L5- 58

W. G. Ruff

R3 -63

$\times 0-43$

R. E. Schenter

$\mathrm{HO}-36$

F. A. Schmittroth

$\mathrm{HO}-36$

S. E. Seeman

LO- 06

L. K. Severud

H5-60

$P$. K. Shen

$\mathrm{HO}-32$

E. J. Shen

L5- 05

J. P. Sloughter (10)

T6- 18

J. W. Thornton

LO -22

H. Toffer

HO -38

D. J. Watrous

L5-58

A. E. Waltar

$\mathrm{HO}-32$ 
WHC-EP-0268

\section{DISTRIBUTION (cont)}

Number of copies

ONSITE

Westinghouse Hanford Company

D. E. Wood

H4-51

T. W. Woods

LO- 06

D. D. Wodrich

R2-23

D. W. Wootan

$\mathrm{HO}-35$

H. H. Yoshikawa

H5-50

Central Files (2)

L8-04

Publications Services

(11)

L8-07 